\title{
Le statut juridique du Port autonome d'Abidjan
}

Citation for published version (APA):

Sally, A. M. F. J. (2020). Le statut juridique du Port autonome d'Abidjan. [Doctoral Thesis, Maastricht University]. Maastricht University. https://doi.org/10.26481/dis.20200526as

Document status and date:

Published: 01/01/2020

DOI:

10.26481/dis.20200526as

Document Version:

Publisher's PDF, also known as Version of record

\section{Please check the document version of this publication:}

- A submitted manuscript is the version of the article upon submission and before peer-review. There can be important differences between the submitted version and the official published version of record.

People interested in the research are advised to contact the author for the final version of the publication, or visit the DOI to the publisher's website.

- The final author version and the galley proof are versions of the publication after peer review.

- The final published version features the final layout of the paper including the volume, issue and page numbers.

Link to publication

\footnotetext{
General rights rights.

- You may freely distribute the URL identifying the publication in the public portal. please follow below link for the End User Agreement:

www.umlib.nl/taverne-license

Take down policy

If you believe that this document breaches copyright please contact us at:

repository@maastrichtuniversity.nl

providing details and we will investigate your claim.
}

Copyright and moral rights for the publications made accessible in the public portal are retained by the authors and/or other copyright owners and it is a condition of accessing publications that users recognise and abide by the legal requirements associated with these

- Users may download and print one copy of any publication from the public portal for the purpose of private study or research.

- You may not further distribute the material or use it for any profit-making activity or commercial gain

If the publication is distributed under the terms of Article $25 \mathrm{fa}$ of the Dutch Copyright Act, indicated by the "Taverne" license above, 


\section{Le statut juridique du Port autonome d'Abidjan}





\title{
Le statut juridique du Port autonome d'Abidjan
}

\author{
Dissertation \\ to obtain the degree of Doctor at the Maastricht University, \\ on the authority of the Rector Magnificus Prof. dr. Rianne M. Letschert \\ in accordance with the decision of the Board of Deans, \\ to be defended in public on 26 May 2020 at 12.45 p.m.
}

by

Adou Mouah Félix Junior Sally 


\section{Supervisor}

Prof. Michael G. Faure, Maastricht University

\section{Co-supervisor}

Dr. Yves Didier Tiebley, University Félix Houphouët-Boigny of Cocody, Abidjan, Côte d'Ivoire

\section{Assessment Committee}

Prof.mr. C.A. Schwarz, Maastricht University and Erasmus University Rotterdam (Chairman)

Dr. S. Schoenmaekers, Maastricht University

Prof.dr. G. van Calster, KU Leuven, Belgium

Prof.dr. S. van Garsse, University of Antwerp and University of Hasselt, Belgium

L'Université de Maastricht n'entend donner aucune approbation ni improbation aux opinions émises dans la présente thèse.

Ces opinions doivent être considérées comme propres à leur auteur. 


\section{DEDICACE}

\section{"Que ton caeur n'envie point les pécheurs, \\ Mais qu'il ait toujours la crainte de l'Éternel ; \\ Car Il est un avenir \\ Et ton espérance ne sera pas anéantie ».}

Proverbes $23: 17-18$.

À ma famille :

À Clémentine, mon épouse pour ses encouragements et son constant soutien dans la réalisation de cette thèse ;

À mes enfants Joseph, Marie-Sarah, Sylviane, Jérémie et Anne pour l'amour dont ils me comblent jour après jour ;

À mon frère Sally Josué, pour tout le soutien moral et matériel qui m'a permis de réaliser cette thèse ;

À tous mes frères et sœurs de la famille Sally.

À Son Excellence Aimé Henri Konan BÉDIÉ, je vous prie de trouver, en ses lignes, l'expression de ma reconnaissance infinie pour votre bienveillance et votre constant soutien à l'égard de ma modeste personne.

Assurément, la récompense se trouve au bout de l'effort. 



\section{REMERCIEMENTS}

Lors de l'élaboration de la présente thèse, nous avons bénéficié de la direction éclairée, des conseils avisés ainsi que de la précieuse aide de personnes de bonne volonté. Nous les prions de trouver en ces lignes l'expression de notre profonde gratitude. Nous tenons particulièrement à adresser nos vifs remerciements :

- À monsieur Michael G. FAURE, Professeur Docteur en droit, enseignant le droit international et comparé de l'environnement à l'Université de Maastricht, Directeur de l'Institut Metro de l'Université de Maastricht (Royaume des Pays-Bas), Directeur de thèse ;

- À Son Excellence Aimé Henri Konan BÉDIÉ, Président du Parti Démocratique de Côte d'Ivoire Rassemblement démocratique africain (PDCI-RDA), ancien Président de la Côte d'Ivoire (19931999);

- À monsieur René DÉGNI-SÉGUI, Professeur Titulaire de Droit public, Doyen honoraire de la Faculté de Droit de l'Université de Cocody, actuellement Doyen de la Faculté de Droit aux Facultés Universitaires Privées d'Abidjan ;

- À monsieur TIEBLEY Yves Didier, Maître-Assistant à l’UFR des sciences juridiques, administratives et politiques de l'Université Félix Houphouët-Boigny de Cocody ;

- Aux autorités du Port Autonome d'Abidjan pour leur disponibilité à notre égard ;

- Au Dr. SALLY Clémentine, médecin ophtalmologue, ma chère et tendre épouse, pour son précieux et constant soutien dans la réalisation de la présente thèse ;

- À Son Excellence Alain Michel LUVAMBANO, Secrétaire général de l'Organisation Maritime de l'Afrique de l'Ouest et du Centre (OMAOC) pour la communication de précieuses informations nécessaires à la confection de la présente thèse.

Nous ne saurions omettre les honorables membres du Jury de thèse dont les observations et critiques contribueront indéniablement à améliorer la qualité de la présente contribution. 



\section{PRINCIPAUX SIGLES ET ABREVIATIONS}

\begin{tabular}{|c|c|}
\hline ADMA & Annuaire de Droit Maritime et Aérien \\
\hline Aframax & Pétrolier de 50.000 à 99.999 tonneaux de port en lourd (tpl) \\
\hline AGEDI & Agence de gestion et de développement des infrastructures industrielles \\
\hline AJDA & Actualité Juridique (Droit Administratif) \\
\hline AGPAOC & $\begin{array}{l}\text { Association pour la Gestion des Ports de l'Afrique de l'Ouest et du } \\
\text { Centre }\end{array}$ \\
\hline ANAC-CI & Autorité Nationale de l'Aviation Civile de Côte d'Ivoire \\
\hline ANRMP & Autorité Nationale de Régulation des Marchés Publics \\
\hline $\mathrm{AOF}$ & Afrique Occidentale Française \\
\hline AOT & Autorisations d'Occupation Temporaire \\
\hline ASECNA & $\begin{array}{l}\text { Agence pour la sécurité de la navigation aérienne en Afrique et à } \\
\text { Madagascar }\end{array}$ \\
\hline AUDCG & Acte uniforme relatif au droit commercial général \\
\hline AUDCIF & Acte uniforme relatif au droit comptable et à l'information financière \\
\hline AUSCGIE & $\begin{array}{l}\text { Acte uniforme sur les sociétés commerciales et les groupements } \\
\text { d'intérêt public }\end{array}$ \\
\hline AUPSRVE & $\begin{array}{l}\text { Acte uniforme portant organisation des procédures simplifiées de } \\
\text { recouvrement et des voies d'exécution }\end{array}$ \\
\hline BOT & Build-Operate-Transfer \\
\hline Bull. & Bulletin \\
\hline $\mathrm{CA}$ & Cour d'Appel \\
\hline CAA & Cour Administrative d'Appel \\
\hline CAA & Caisse Autonome d'Amortissement \\
\hline Cass. Civ. & Chambre civile de la Cour de Cassation (française) \\
\hline CCJA & Cour commune de justice et d'arbitrage \\
\hline $\mathrm{CE}$ & Conseil d'État \\
\hline $\mathrm{CE}$ & Communauté Européenne \\
\hline CECA & Communauté européenne du charbon et de l'acier \\
\hline CEDEAO & Communauté Économique Des États de l'Afrique de l'Ouest \\
\hline CET & Convention d'exploitation de terminal \\
\hline CFA & Communauté financière africaine \\
\hline CGPPP & Code général de la propriété des personnes publiques \\
\hline $\mathrm{CHEC}$ & China Harbour Engineering Company \\
\hline CIRDI & $\begin{array}{l}\text { Centre international de règlement des différends relatifs aux } \\
\text { investissements }\end{array}$ \\
\hline CIREJ & Centre Ivoirien de Recherches et d'Études Juridiques \\
\hline CNUCED & Conférence des Nations Unies sur le Commerce et le Développement \\
\hline COA & Côte Ouest-Africaine \\
\hline COJO & Commission d'Ouverture des Plis et de Jugement des Offres \\
\hline CPCCA & Code de procédure civile, commerciale et administrative \\
\hline CSCA & Chambre Administrative de la Cour Suprême \\
\hline CSCJ & Chambre Judiciaire de la Cour Suprême \\
\hline DBFO & Design, Build, Finance, Operate \\
\hline $\mathrm{DD}$ & Direction du domaine (du Port autonome d'Abidjan) \\
\hline DCM & Direction commerciale et marketing (du Port autonome d'Abidjan) \\
\hline DEEPDEV & $\begin{array}{l}\text { Direction des Études Économiques et du Développement (du Port } \\
\text { autonome d'Abidjan) }\end{array}$ \\
\hline
\end{tabular}




\begin{tabular}{|c|c|}
\hline DMF & Droit maritime français \\
\hline DPW & Dubai Port World \\
\hline EGS & Entreprises Graviers et Sables \\
\hline EPA & Établissement Public Administratif \\
\hline EPAD & Établissement public pour l'aménagement de la région de la Défense \\
\hline EPIC & Établissement Public Industriel et Commercial \\
\hline EPN & Établissement Public National \\
\hline EVP & Équivalent vingt pieds \\
\hline FCFA & Franc de la Communauté financière africaine \\
\hline FER & Fonds d'entretien routier \\
\hline GA ou GAJA & Grands Arrêts de la Jurisprudence Administrative \\
\hline GATT & $\begin{array}{l}\text { Accord Général sur les Tarifs Douaniers et le Commerce (General } \\
\text { Agreement on Tariff and Trade) }\end{array}$ \\
\hline HGRN & Hôpital Général de Référence Nationale \\
\hline JOCI & Journal Officiel de la Côte d'Ivoire \\
\hline JORCI & Journal Officiel de la République de Côte d'Ivoire \\
\hline JORF & Journal Officiel de la République Française \\
\hline JOUE & Journal officiel de l'Union européenne (JOUE \\
\hline MEVP & Middle East Venture Partners \\
\hline OHADA & Organisation pour l'Harmonisation en Afrique du Droit des Affaires \\
\hline PAA & Port autonome d'Abidjan \\
\hline PAD & Port autonome de Dakar \\
\hline PDG & président directeur général \\
\hline PPP & partenariat public-privé \\
\hline req. & Requête \\
\hline rec. & Recueil des arrêts du Conseil d'État (français) \\
\hline RFDA & Revue française de droit administratif \\
\hline RFI & Radio France Internationale \\
\hline RID & Revue ivoirienne de droit \\
\hline SA & Société Anonyme \\
\hline SETV & Société d'exploitation du Terminal de Vridi \\
\hline SPA & Service public administratif \\
\hline SPFP & Société à Participation Financière Publique \\
\hline SPIC & service public industriel et commercial \\
\hline Suezmax & $\begin{array}{l}\text { Pétrolier de } 100.000 \text { à } 149.999 \text { tpl (Navire capable de passer en charge } \\
\text { par le canal de Suez) }\end{array}$ \\
\hline TA & Tribunal Administratif \\
\hline $\mathrm{TC}$ & Tribunal des conflits \\
\hline TEU & Twenty Empty Unit (conteneur de vingt pieds) \\
\hline TIDM & Tribunal International du Droit de la Mer \\
\hline TPI & Tribunal de Première Instance (en République de Côte d'Ivoire) \\
\hline UEMOA & Union Économique et Monétaire Ouest Africaine \\
\hline ULCC & Ultra Large Crude Carrier (pétrolier de plus de 300.000 tpl) \\
\hline UMOA & Union Monétaire Ouest-Africaine \\
\hline VLCC & Very Large Crude Carrier (pétrolier de 150.000 à 299.999 tpl) \\
\hline ZPM & Zone de Pêche Maritime \\
\hline
\end{tabular}




\section{SOMMAIRE}

Introduction générale

Table des matières

Première partie : Le caractère diversifié et volontariste des normes constitutives du statut juridique du port autonome d'Abidjan

Titre 1 : Un statut juridique relevant initialement de la compétence exclusive du législateur ivoirien Chapitre 1 : Les évolutions successives du statut juridique du port autonome d'Abidjan

Chapitre 2 : La diversité des missions dévolues au port autonome d'Abidjan

Titre 2 : Un statut juridique actuellement investi par le droit communautaire

Chapitre 1 : La soumission du port autonome d'Abidjan au droit de l'UEMOA

Chapitre 2 : Le port autonome d'Abidjan et le droit de l'OHADA

Conclusion de la première partie

Deuxième partie: Un statut juridique perfectible en vue de l'exploitation optimale du port autonome d'Abidjan

Titre $1:$ Les faiblesses du cadre juridique actuel de gestion du domaine public portuaire

Chapitre $1:$ Les pesanteurs de l'occupation privative du domaine public

Chapitre 2 : Les manifestations de l'application rugueuse du droit public au port autonome d'Abidjan

Titre 2: La nécessité de surmonter les faiblesses obérant les performances du port autonome d'Abidjan

Chapitre 1 : Variabilité et évolution des modèles et techniques juridiques de gestion portuaire

Chapitre 2 : Les ajustements statutaires possibles à la nature juridique du port autonome d'Abidjan

Conclusion de la deuxième partie

Conclusion générale

Bibliographie

Résumé

Summary

Valorisation Addendum

Curriculum Vitae

Annexes 
La présente thèse a été élaborée par Monsieur SALLY Adou Mouah Félix $J r$.

Monsieur SALLY exerce actuellement les fonctions de Président de l'USC Worlwide Group. L'U.S.C. est une société de droit privé, précisément une société anonyme, intervenant dans le secteur du transport maritime. L'U.S.C. intervient dans la consignation, la manutention, le fret, le transit maritime et le transport de marchandises.

Le capital de l'U.S.C. est entièrement détenu par des actionnaires privés (ivoiriens). Aucune personne morale de droit public ou personne du secteur parapublic ivoirien n'est actionnaire de l'U.S.C. À ce titre, l'U.S.C. jouit d'une autonomie certaine dans la conduite de ses activités au sein de la plateforme portuaire d'Abidjan et de San Pedro (deuxième port ivoirien situé au sud-ouest de la Côte d'Ivoire). Monsieur SALLY n'est donc pas un fonctionnaire de l'État ivoirien ni un salarié du Port autonome d'Abidjan (PAA). Il est plutôt un homme d'affaires (businessman) dont la nature des activités exercées l'a conduit à faire la connaissance d'autres opérateurs du secteur maritime œuvrant en Afrique, en Asie, en Europe et en Amérique. La présente thèse ne résulte pas non plus d'une "commande" qu'aurait passée le PAA auprès de lui. C'est donc en toute liberté de pensée et d'action que l'auteur de la présente thèse a mené ses recherches. Il espère que cette thèse contribuera à étoffer qualitativement et quantitativement les études juridiques (assez parcellaires d'ailleurs) qui ont été menées à ce jour sur le PAA. 


\section{INTRODUCTION GÉNÉRALE}

«Le Port autonome d'Abidjan est le poumon économique de la Côte d'Ivoire », entend-ton dire souvent.

Cette affirmation est loin d'être anodine. Elle est même en deçà de la réalité : le Port autonome d'Abidjan (PAA) est non seulement le poumon économique de la Côte d'Ivoire mais il est également le principal raccordement des pays de l'hinterland ouest-africain au commerce international par voie maritime.

Une étude judicieuse du PAA nécessite de prime abord que soit effectuée une analyse comparée de l'importance du PAA (I). Ensuite, suivra une présentation succincte du régime juridique applicable au port autonome d'Abidjan (II). La définition des notions fondamentales de l'étude (III) conduira à en poser la problématique (IV). La réponse apportée à la problématique interviendra empruntera la forme d'une hypothèse de travail dont la pertinence sera présentée dans un plan cohérent $(\mathrm{V})$.

\section{ANALYSE COMPARÉE DE L'IMPORTANCE DU PORT AUTONOME D'ABIDJAN}

En comparaison avec d'autres ports notamment ceux d'Asie et d'Europe, le Port autonome d'Abidjan (PAA) est sans doute une infrastructure modeste (A). Il n'empêche que les autorités compétentes ivoiriennes veulent relever le défi de la mutation qui permettrait ainsi au PAA de se hisser au rang de hub régional (B).

\section{A. Le Port autonome d'Abidjan, une infrastructure relativement modeste}

La modestie du PAA, au regard du volume des marchandises ainsi que des activités s'y déroulant, s'apprécie par rapport aux grands ports d'Asie, et d'Europe ou d'Amérique du nord. Le caractère relativement insignifiant du PAA s'apprécie donc à l'échelle mondiale (1). En revanche, le port d'Abidjan occupe une place enviable à l'échelle ouest-africaine (2).

\section{L'insignifiance du PAA à l'échelle mondiale}

Une étude de la société Ocean Shipping Consultants Ltd, publiée en 2008 sous l'égide de la Banque mondiale, révélait que l'Afrique subsaharienne possède un grand nombre de ports dont peu, toutefois, sont de taille importante selon les normes mondiales. Ces ports sont généralement mal équipés, et n'ont qu'un faible niveau de productivité ${ }^{1}$.

Ce constat est corroboré par une autre étude publiée en 2016 sous les auspices de la CNUCED $^{2}$ Au regard, entre autres, du tableau dressé à la page 76 de ladite étude 3 , il apparaît que le niveau d'escales des navires dans les ports d'Afrique est indéniablement faible en comparaison des autres régions du monde.

1 OCEAN SHIPPING CONSULTANTS Ltd, Diagnostics des infrastructures nationales en Afrique. Au-delà des goulots d'étranglement: les ports en Afrique subsaharienne, Banque mondiale, Programme AICD, Document de référence 8 , juin 2008, p. 3.

2 HOFFMANN Jan (dir.), Étude sur les transports maritimes 2016, CNUCED, New York et Genève, Côte UNCTAD/RMT/2016, 2016, p. 76.

3 Voir en annexe de la présente thèse le tableau 1 retraçant les escales de navires, par région et type, 2015. 
On remarquera que l'Afrique figure à la quatrième place (sur sept) en considération du nombre d'escale de navires. Cette position - celle du milieu de tableau - peut paraître flatteuse. Cependant, il convient de tempérer cette appréciation vu que le continent américain, au regard du nombre d'escales, a fait l'objet de scission en trois parties, à savoir l'Amérique du Nord, les Caraïbes et l'Amérique du Sud. En regroupant les escales de ces trois régions, d'ailleurs incluses dans un même continent, il apparaît que le continent américain se hisse à la troisième place après l'Asie et l'Europe ${ }^{4}$. Dans un tel cas de figure, l'Afrique continuera d'occuper la quatrième place, non plus en milieu de classement mais à l'avant-dernière place juste devant l'Océanie.

Concernant particulièrement le PAA, le nombre d'escales de navire a sensiblement varié de l'année 2015 à celle de 2017. Les données annuelles sont respectivement de 2988 (année 2015), 2738 (année 2016) et 2612 (année 2017) ${ }^{5}$.

La baisse enregistrée de l'année 2015 à 2016 est de -250 en valeur absolue; soit un pourcentage de 8,37 de baisse au niveau de la fréquentation du PAA. De l'année 2016 à 2017 la baisse enregistrée est de-126 en valeur absolue ; soit un pourcentage $4,6 \%$ de baisse des escales de navire.

Qu'est-ce qui pourrait expliquer cette baisse graduelle et consécutive des escales de navire au PAA durant ces trois années ?

À défaut de raisons avancées par l'Administration portuaire pour expliquer cette baisse, nous nous risquons à avancer certaines explications plausibles.

Trois raisons, à notre avis, pourraient expliquer cette baisse des escales de navire au PAA sur les trois années précitées. La première raison est celle liée au renchérissement des coûts de passage des navires au PAA. Sur ce point, il est courant de constater que les ports africains, en général, enregistrent des coûts de passage très fortement supérieurs aux coûts de passage connus en Europe (jusqu'à 1500 euros pour la manutention, le stockage et la livraison locale, contre 250 à 300 euros en Europe) ${ }^{6}$.

La deuxième raison pourrait découler des lourdeurs administratives. Il faut garder en tête qu'historiquement, les pays francophones ont été un modèle pour les ports africains, avec un processus administratif souvent lourd et peu adapté. Jusqu'à une période récente, ils ont été opérés de façon fortement étatique ${ }^{7}$.

La troisième raison plausible est la multiplication des contrôles effectués à la sortie des ports par différents organismes étatiques et de sécurité, des infrastructures routières souvent saturées, alourdissent considérablement les délais de traitement et finalement le coût de passage portuaire en Afrique ${ }^{8}$.

En sus de la position au niveau des escales, la modestie du PAA à l'échelle mondiale est décelable également au niveau du volume des marchandises traitées. D'une manière générale, le volume des marchandises traitées par les ports africains, singulièrement les conteneurs, est loin d'égaler ceux des autres continents, notamment ceux traités par l'Asie. Cette dernière

4 Le cumul des escales de l'Amérique du Nord, des Caraïbes et de l'Amérique du Sud s'élève à 185.605.

5 Source : Rapport d'activités 2017 du Port autonome d'Abidjan, p. 19.

6 MEYER Gilbert, «L'insertion des ports africains dans les flux mondiaux : atouts et faiblesses », Secteur privé et Développement, $\mathrm{n}^{\circ} 26$, mars-avril-mai 2017, p. 23.

En ce qui concerne particulièrement le PAA, nous estimons que la raison probable de la hausse des coûts a résulté, à l'époque, de la relative insuffisance des équipements de manutention des navires. Cela a eu pour conséquences des surestaries. En outre, à l'heure actuelle, le monopole conféré à l'exploitant du terminal à conteneurs de Vridi tend à renchérir le coût des prestations de ce dernier.

7 MEYER Gilbert, op. cit., p. 23.

$8 \quad$ Ibidem. 
portion du globe représente, à elle seule, pratiquement les $2 / 3$ du trafic portuaire mondial de conteneurs ${ }^{9}$.

De l'analyse des tableaux 1 et 3 ainsi que du graphique 1 de l'annexe ${ }^{10}$, transparaît la place marginale, à l'échelle mondiale, des ports africains dans le trafic maritime. A fortiori, la place occupée par le Port autonome d'Abidjan dans le trafic mondial est, par euphémisme, très modeste. Cette affirmation s'inscrit dans un constat général tel que dressé par certains experts. En effet, les ports africains sont globalement très petits, aucun ne figurant d'ailleurs dans la liste des plus grands ports de la planète : un grand port à conteneurs comme celui d'Abidjan (en Côte d'Ivoire) a un trafic annuel d'environ 700.000 EVP ; le port de Lagos (au Nigeria), avec ses deux terminaux, a vu transiter près de 1,5 million d'EVP en 2014. Des chiffres remarquables, mais encore très loin des plus de 20 millions de conteneurs qui transitent par le port de Ningbo-Zhoushan (Chine), plus de 12 millions par le port de Rotterdam (Pays-Bas) et près de 10 millions à Anvers (Belgique) ${ }^{11}$.

Si le PAA ne constitue pas une référence mondiale en termes de volume de marchandises traitées, il occupe, en revanche, une place assez enviable au niveau africain, particulièrement sur la façade Atlantique du continent.

\section{La place enviable du PAA à l'échelle ouest-africaine}

On a pu noter une variation des volumes de marchandise traités par le PAA durant la première décennie des années 2000. Avant le déclenchement de la crise militaro-politique, en 2002, le PAA se situait au premier des ports ouest-africains eu égard au tonnes métriques de marchandises qui y ont été traitées. Celles-ci s'élevaient à environ 16.000.000 tonnes au titre de l'année 2002. Le PAA était alors le premier port d'Afrique de l'ouest ${ }^{12}$.

Cependant, cette position enviable sera quelque peu perturbée par la tentative de coup d'État du 19 septembre 2002 qui s'est muée, par la suite, en une rébellion armée. La conséquence immédiate de cette rébellion fut l'érosion quasi complète des transits de marchandises à destination des pays de l'hinterland que sont le Burkina Faso, le Mali et le Niger. En effet, l'instauration, dans la moitié septentrionale de la Côte d'Ivoire, d'une zone sous contrôle rebelle aura pour incidence de dissuader les importateurs du Burkina Faso et du Mali d'emprunter respectivement les corridors Abidjan-Ouagadougou et Abidjan-Bamako.

L'évolution du trafic de transit sur les années 2001, 2002 et 2003 a permis de constater l'ampleur de la désaffection du corridor ivoirien à la suite de la crise. Mais en fait, le trafic de transit ne représentait que $10 \%$ du trafic total du port d'Abidjan, en 2001. La chute de ce trafic, voire son arrêt total n'a donc pas pu peser vraiment sur le volume général du trafic général du port. Seul effet notable, une fonction diminuée en tant que porte océane des pays enclavés ${ }^{13}$.

Dans le même ordre d'idée, on note que le port d'Abidjan, en conditions normales, aurait dû traiter 18 millions de tonnes en 2002. Mais, en raison des tensions politiques locales, le

$9 \quad$ Trafic portuaire de conteneurs en Asie, au titre de l'année 2016, s'élevait à 446813796 EVP contre 27 909132 EVP pour l'Afrique durant la même période de temps. Le graphique 1 est celui des volumes portuaires mondiaux de conteneurs par région, 2016 (Part en pourcentage).

10 Les tableaux 1 et 3 retracent respectivement les escales de navires, par région et type, en 2015, et le trafic portuaire mondial de conteneurs par région, 2014 et 2015 (En EVP et variation annuelle en pourcentage). Le graphique 1 est celui des volumes portuaires mondiaux de conteneurs par région, 2016 (Part en pourcentage).

11 MEYER Gilbert, «L'insertion des ports africains dans les flux mondiaux : atouts et faiblesses », Secteur privé et Développement, $\mathrm{n}^{\circ} 26$, mars-avril-mai 2017, p. 24.

12 Voir la Carte 1 relative au trafic portuaire : Afrique de l'ouest (2002).

13 BIDI Tapé Jean, «Impact de la crise ivoirienne sur les ports ouest-africains, Outre-Terre, 2005/2, n ${ }^{\circ} 11, \mathrm{p}$. 311. 
trafic a péniblement atteint 16,4 millions de tonnes contre 17,2 millions de tonnes en 2001, soit un manque à gagner de plus de 600 millions de francs CFA et une baisse significative des activités connexes (transit, manutention, consignation...) ${ }^{14}$.

En dépit de cette situation insurrectionnelle, le port d'Abidjan a continué d'être fréquenté. En effet, le nombre de navires entrés et sortis a baissé légèrement avec une variation de 6,4\%, passant de 7.197 tonnes en 2002 à 6.736 en 2003. Le trafic maritime total du port s'est élevé à 14.461.239 tonnes contre 14.728.105 tonnes, soit une variation en baisse de $-1,8 \%{ }^{15}$.

Les observations du professeur Tapé Bidi sur la relative insignifiance de l'incidence négative de la fermeture des corridors Abidjan-Ouagadougou et Abidjan-Bamako lors de la crise militaro-politique sont confortées par un autre travail de recherche. Dans sa thèse de doctorat, Messan Lihoussou a élaboré une carte retraçant le trafic portuaire en l'Afrique de l'ouest $^{16}$. On remarquera, dans le cas du PAA, que la part du trafic de transit est assez faible. Cela explique sans doute l'affirmation du professeur Tapé Bidi selon laquelle la fermeture des deux corridors précités n'a pas influé significativement sur le volume du trafic du PAA.

Quoi qu'il en soit, on remarquera que la crise militaro-politique a cependant laissé des traces sur le positionnement du PAA en Afrique de l'ouest. Celui-ci n'est plus le premier port. Il a été relégué au second rang derrière celui de Lagos. Le passage de flambeau entre le port d'Abidjan et celui de Lagos est intervenu durant l'année 2006, durant la période de la longue crise militaro-politique ivoirienne ${ }^{17}$. Depuis lors, la rivalité entre les ports d'Abidjan et de Lagos, en termes de trafic portuaire, tourne à l'avantage de ce dernier ${ }^{18}$. Cette situation ne semble pourtant pas détourner les autorités compétentes ivoiriennes qui envisagent de faire du PAA, un $h u b$ régional.

\section{B. Le défi du Port autonome d'Abidjan à se muer en un hub régional}

Les autorités compétentes ivoiriennes s'assignent, entre autres, pour objectif de transformer le PAA en un hub régional ${ }^{19}$. Cette vocation clairement affichée (2). Pourtant, cette vocation apparaissait compromise au départ, au regard de certains écueils (1).

\section{Une vocation apparemment compromise au départ}

La constitution de hub maritime en Afrique de l'ouest pourrait a priori relever du «mythe». Deux raisons pourraient expliquer cette affirmation. La raison est la vive

14 N'DJAMBOU Léandre Edgard, «Échanges maritimes et enclavements en Afrique de l'ouest : le cas des ports d'Abidjan et de Cotonou », Les Cahiers d'Outre-Mer, n²26-227, septembre 2004, p. 4, note 5.

15 BIDI Tapé Jean, op. cit., p. 311.

16 LIHOUSSOU Messan, Port et désenclavement territorial : cas de l'arrière-pays du port de Cotonou, Thèse de Géographie, Spécialité : Transport et logistique, Université du Havre, 07 juillet 2014, p. 182. Voir Carte 2 reproduite en annexe de la présente thèse; carte intitulée Ports de l'Afrique de l'Ouest étudiés suivant leur trafic total (2010).

17 Voir tableau 4 intitulé Trafics totaux comparés des ports de 2004 à 2010 (en milliers de tonnes).

18 La perte (relative) de compétitivité du Port d'Abidjan pourrait aussi s'apprécier par rapport au port de Téma (Ghana). Même si ce dernier n'a pas ravi la place de second à celui d'Abidjan, il n'empêche qu'il lui a grignoté un volume significatif de trafic. La réduction de l'écart entre le port de Téma et celui d'Abidjan peut s'expliquer par la perte de performance du second, conséquence de la crise sociopolitique passée qui a agité la Côte d'Ivoire (2000-2011). Cf. LIHOUSSOU Messan, Port et désenclavement territorial : cas de l'arrière-pays du port de Cotonou, op. cit., p .182.

19 Plate-forme portuaire de groupage ou dégroupage des marchandises, en général conteneurisées. Le groupage est une notion qui désigne le rassemblement des marchandises en provenance de plusieurs chargeurs. Le dégroupage quant à lui est la dispersion des marchandises à destination des différents destinataires. 
concurrence entre les ports du golfe de Guinée découlant de la grande proximité voire la promiscuité entre les différents ports de la région ouest-africaine.

Relativement aux incidences négatives de cette situation, Yann Alix note que les nombreuses mises en concession (des terminaux des ports ouest-africains) des dernières années ont généré la compétition portuaire sous-régionale. Ainsi, Téma, au Ghana, est devenu plus important qu'Abidjan. Les ports du Nigeria ambitionnent de reprendre le contrôle des captations de trafics par les voisins de Cotonou, Lomé et même Douala. Pointe-Noire s'est imposé comme le vrai hub de l'Afrique centrale tout en observant avec sérénité l'arrivée de Kribi, la modernisation de Walvis Bay ou encore les projets d'extension en Angola. Conakry, San Pedro ou les ports gabonais ne comptent pas non plus rester dans une deuxième ligue, loin des lucratifs mouvements conteneurisés ${ }^{20}$.

Il ajoute que dans un espace géographique équivalent à la rangée Biarritz-Dunkerque, on peut relever : le projet pharaonique de Badagary à proximité d'Apapa au Nigeria (1000 ha et 7 km de linéaire de quais) ; la zone industrialo-portuaire de Lekki au Nigeria (2,5 MEVP); le port en eau profonde d'Ibaka à proximité de la frontière entre le Nigeria et le Cameroun ; le port en eau profonde de Kribi au Cameroun (800.000 EVP); les différents projets équatoguinéens de Luba, Malabo ou Bata ${ }^{21}$. Cette énumération non exhaustive ne prend pas en compte les modernisations annoncées par Bolloré ou APMT sur les terminaux existants de la région de Lagos ${ }^{22}$.

En dépit de la vive concurrence entre les ports de la façade Atlantique du continent africain, les autorités compétentes ivoiriennes s'attellent à concrétiser le projet de transformer le PAA en un hub régional.

\section{Une vocation actuellement en voie de concrétisation}

En dépit de la vive concurrence interportuaire et surtout de l'instabilité politique qui a marqué la première décennie des années 2000, le PAA tire son épingle du jeu. Cela s'explique, entre autres, par des acquis infrastructurels indéniables (a) et la réalisation de travaux de redimensionnement du PAA (b).

\section{a) Des acquis infrastructurels indéniables}

Ce relatif avantage découle des atouts dudit ports. En effet, le port d'Abidjan, qui est d'abord un grand port à conteneurs à l'échelle de la région, disposait, au début des années 2000, d'un terminal comprenant quatre postes à quai d'une longueur de 800 mètres dont l'un, équipé d'une rampe $\mathrm{Ro} / \mathrm{Ro}^{23}$, offre un tirant d'eau de 12,5 mètres pour 200 mètres de long. Il est géré par la Société d'exploitation du Terminal de Vridi (S.E.T.V). Car, dans ce port, la manutention, le stockage, le gardiennage et le transit des marchandises sont assurés par des

20 ALIX Yann, «Afrique de l'ouest: les ports ne seront pas tous des hubs », Journal de la Marine Marchande, $\mathrm{n}^{\circ} 4878$, vendredi 7 juin 2013, p. 12.

Idem, p. 13.

Ibidem.

Un navire Ro/Ro ou navire roulier est un bateau conçu pour transporter des véhicules roulants : camions, remorques, voitures... Ils sont caractérisés par la présence d'une ou plusieurs portes dans la coque et de rampes qui permet l'accès aux ponts, garages de marchandises roulantes (véhicules sur roues ou remorques chargées). On parle aussi de navires à manutention horizontale par opposition aux navires à manutention verticale (dits Lolo, pour load in/load off) qui nécessitent des appareils de levage. Source: https://www.glossaire-international.com/pages/tous-les-termes/roulier-navire.html. Document consulté le 29 juillet 2019. 
entreprises privées possédant en propre le matériel de manutention le plus moderne, adapté à tous les types de trafic ${ }^{24}$.

Par ailleurs, la Côte d'Ivoire s'est engagée en signant, en août 2000, une convention de concession de trente ans avec le consortium anglo-néerlandais P.\&O. Nedlloyd, à ouvrir de nouvelles commodités portuaires à Locodjoro dans le quartier de Yopougon. Le projet, évalué à 71 milliards de francs CFA, devrait inclure une zone franche industrielle, un nouveau terminal conteneurs d'une capacité de 500.000 EVP et une plate-forme de télécommunications. L'objectif est de doubler la capacité du trafic conteneurs d'Abidjan et de renforcer le rôle de transbordement du port, grâce à la construction d'un quai de 600 mètres équipé de trois portiques ${ }^{25}$. Mais ce projet n'avait pas pu être réalisé, vu l'instabilité politique qui prévalait dans le pays.

\section{b) La réalisation de travaux de redimensionnement}

Après son ouverture en 1951, le PAA a été confronté à certains problèmes consécutifs à l'accroissement progressif de son trafic. Ce sont notamment l'étroitesse de l'entrée du canal de Vridi, l'encombrement des quais de débarquement, la vétusté du port de pêche et le déficit d'espaces pour les industriels.

Toutes ces limites ont conduit les autorités compétentes ivoiriennes à entreprendre des travaux d'extension. Ceux-ci ont débuté en 2015 et se sont poursuivis à un rythme effréné. En lieu et place de l'extension initialement prévue sur les réserves foncières de Locodjro et de l'île Boulay (Yopougon), le gouvernement a finalement décidé d'optimiser la plateforme portuaire actuelle qui date de 1951. Les premiers chantiers engagés ont consisté en l'élargissement et l'approfondissement du canal de Vridi ${ }^{26}$.

Exécutés par le groupe chinois China Harbour Engineering Company (CHEC), les travaux devraient s'achever en 2019. Avant l'écoulement de ce délai, on a pu assister à la mise en service, le 15 mars 2018, du nouveau quai roulier, long de 300 mètres, avec un tirant d'eau de 14 mètres, consacrant ainsi l'augmentation de la plateforme logistique du port d'Abidjan' ${ }^{27}$.

Les travaux d'optimisation spatiale se sont poursuivis avec le remblai de plus de 400 hectares destinés à l'implantation des unités industrielles et des entrepôts. Ce remblai est adossé à un projet d'ouverture de voies de desserte comprenant un pont devant relier les quartiers de Vridi et de Zone 4 (Marcory) ${ }^{28}$.

L'inauguration du canal élargi de Vridi s'est déroulée le 21 février 2019 en présence de Monsieur Amadou Gon Coulibaly, Premier ministre de la République de Côte d'Ivoire. Selon ce dernier, "l'élargissement et l'approfondissement $d u$ canal de Vridi permettent de repositionner le Port d'Abidjan comme un hub sous-régional en matière de transport maritime. Ces travaux vont impacter inéluctablement les activités du Port qui pourra accueillir désormais des navires de dernières générations ${ }^{29}$. Le redimensionnement du

24 N'DJAMBOU Léandre Edgard, «Échanges maritimes et enclavements en Afrique de 1'ouest: le cas des ports d'Abidjan et de Cotonou », Les Cahiers d'Outre-Mer, n²26-227, septembre 2004, p. 4

25 Ibidem.

26 Document électronique accessible en ligne sur le site : www.gouv.ci/impactdeveloppement/accueil/terrain_detail/extension-et-modernisation-pour-accompagner-l-emergence775/4. Document consulté le 24 juillet 2019.

27 Ibidem.

28 Ibidem.

29 Anonyme, «Infrastructures : le port d'Abidjan renforce ses capacités », @bidj@n.net, 22 février 2019. Voir aussi EHOUMAN Faustin, «Canal de Vridi élargi et approfondi : le Port autonome d'Abidjan accessible à tous types de navires », Fratmatmat.Info, 22 février 2019. 
canal de Vridi fait passer celui-ci de 200 à 350 mètres de large et de 14 mètres à 22 mètres de profondeur. À travers l'exécution de ces travaux, le Directeur général du PAA affirme: "nous ambitionnons par ces infrastructures d'être le port principal sur la façade atlantique d'Afrique, entre Tanger et le Cap $»^{30}$. Il poursuit en disant : "les navires transportant 10.000 conteneurs au voyage pourront fréquenter notre port contre 3.500 conteneurs au voyage anciennement $\gg$.

Cette déclaration a vu sa première concrétisation avec l'accueil, le 31 mai 2019, du porteconteneur MSC Dymphna, le plus gros navire en termes de capacité que le terminal à conteneurs du PAA ait jamais accueilli ${ }^{31}$.

Toutes ces actions entreprises dans le sens du rehaussement significatif des performances du PAA traduisent l'importance capitale de ce dernier pour l'économie ivoirienne.

\section{Le Port autonome d'Abidjan, une infrastructure d'importance capitale pour l'économie ivoirienne}

Cette importance peut être retracée à travers quelques données quantitatives. La place prépondérante du PAA s'apprécie aussi bien dans l'économie ivoirienne (1) que celle des pays de l'hinterland (2).

\section{Le Port autonome d'Abidjan et l'économie ivoirienne}

Cette importance se perçoit aussi bien dans une perspective historique que sous un angle contemporain.

\section{a) Sous une perspective historique}

La part prépondérante du port d'Abidjan dans l'activité économique de la colonie de Côte d'Ivoire transparait des travaux du professeur Sémi-Bi Zan. Ce dernier écrit: "Après l'ouverture du port d'Abidjan, le pourcentage d'activité des trois ports en question, par rapport à l'activité portuaire globale de la Côte d'Ivoire, baissa considérablement, le wharf de Grand-Bassam ayant été supprimé en 1951. Certes, Tabou et Sassandra se maintinrent et connurent même un trend d'activité ascendant, mais la pente de cette courbe était faible. En 1958, l'ensemble de leur activité (tonnages manipulés) ne représentait que $4,4 \%$ de l'activité portuaire totale de la Côte d'Ivoire même si le port de Sassandra, exutoire maritime de l'ouest ivoirien, était le second port du territoire, son wharf, on le sait, ayant été ouvert au trafic maritime en octobre $1951 »^{32}$ (Souligné par nous).

Les chances de "résurrection" possible des ports de Tabou et Sassandra sont actuellement quasi-inexistantes si l'on tient compte de la création vers la fin de la décennie 60, d'un nouveau port autonome, celui de San Pedro. Ce port autonome, de par sa proximité géographique avec les villes de Tabou et Sassandra empêche la renaissance de ces deux ports en tant que ports de marchandises. Tout au plus, il appartiendra à l'État ivoirien de créer, dans ces deux villes, des ports de pêche.

\footnotetext{
Anonyme, « Côte d'Ivoire : Abidjan inaugure le canal de Vridi élargi et approfondi », RFI, 21 février 2019. Anonyme, «Abidjan Terminal accueil le plus gros navire de son histoire », @bidj@n.net, 7 juin 2019.

SEMI Bi Zan, Équipement public et changements socio-économiques en Côte d'Ivoire (1930-1957), 4ème partie: Conséquences de la mise en place de l'équipement public, Atelier national de reproduction des thèses, Université de Lille, 1986, p .612.
} 


\section{b) Sous un angle contemporain}

Au plan économique, le Port Autonome d'Abidjan (PAA) a commencé ses activités le 05 février 1951 à la suite du percement du Canal de Vridi, mettant en communication directe l'océan Atlantique et la lagune Ébrié. Avec un chiffre d'affaires de 79,926 milliards de FCFA et un résultat d'exploitation de plus de 15 milliards de $\mathrm{FCFA}^{33}$, le PAA gère ses biens (magasins, terre-pleins, et autres dépendances de son domaine public, etc.) de manière autonome, ne recevant aucune subvention de l'État depuis 1973, bien qu'étant, jusqu'à ce jour, une société d'État.

Le PAA représente aujourd'hui 90\% des échanges extérieurs de la Côte d'Ivoire, $70 \%$ des activités industrielles du pays, plus de $85 \%$ des recettes douanières qui constituent plus de $60 \%$ du budget général de l'État ainsi que plus de 40.000 emplois directs et indirects ${ }^{34}$.

Le Port met à la disposition des opérateurs économiques des infrastructures, des équipements, des services afin de permettre le passage de la marchandise et l'escale des navires dans les meilleures conditions. Ce qui a fait de lui, et ce depuis très longtemps d'ailleurs, le leader en Afrique de l'Ouest. Il est également classé parmi les premiers en Afrique.

\section{Le Port autonome d'Abidjan et les pays de l'hinterland}

Relativement à l'interdépendance entre le port d'Abidjan et les pays de l'hinterland, il serait intéressant de se référer à une étude du professeur N'Djambou parue dans la revue scientifique Les Cahiers d'Outre-mer, durant l'année 2004.

Le professeur note qu'Abidjan (sous-entendu le Port d'Abidjan) bénéficie d'un important arrière-pays desservi par la route et la voie ferrée. Vers le Mali, les usagers disposent en effet d'un axe mixte : ferroviaire entre Abidjan et Bouaké, routier entre Bouaké et Mopti ou de Bouaké à Ségou via Bobo-Dioulasso. Vers le Burkina Faso par contre, on a le choix entre un parcours totalement routier d'Abidjan à Ouagadougou via Bouaké et Bobo-Dioulasso de $1.195 \mathrm{~km}$, ou un parcours entièrement ferroviaire d'Abidjan à Ouagadougou de $1.145 \mathrm{~km}^{35}$.

Toutefois, depuis des années, en dépit des efforts de modernisation consentis, ce chemin de fer a vu son trafic décliner en raison du glissement progressif des trafics à l'avantage de la route, du fait aussi de la baisse des transports de clinkers entre Abidjan et Ouagadougou et de la chute du trafic conteneurisé avec le Burkina Faso en raison de la concurrence des autres ports de la région.

SIDIBÉ Sogona, «Côte d'Ivoire : Port Autonome d'Abidjan - Une croissance de 3\% du trafic global enregistrée », article accessible en ligne sur: http://www.fr.africa.com/stories/201601110748.html. Document consulté le 27 mai 2016.

34 Ces chiffres ont été communiqués par le Directeur général du PAA lors de la première journée portuaire organisée par le PAA, le vendredi 21 mars 2014. Document accessible en ligne sur : http://www.news.abidjan.net/h/493328.html. Document consulté le 27 mai 2016. Plus récemment, le bimensuel Jeune Afrique a confirmé, dans l'ensemble, ces chiffres. Selon ce bimensuel, le trafic au port d'Abidjan, qui représente $90 \%$ des échanges extérieurs de la Côte d'Ivoire, a augmenté en 2018 de 6\%, pour atteindre plus de 24 millions de tonnes, a annoncé lundi à Abidjan son directeur, Hien Sié. "Cette croissance s'explique par le dynamisme de l'économie nationale dont le taux de croissance de 7,7\% en 2018 a des répercussions au niveau des activités portuaires» a souligné Hien Sié, annonçant l'inauguration en février d'une importante installation pour doper cette croissance». Cf. https://www.jeuneafrique.com/704754/economie/cote-divoire-trafic-en-hausse-en-2018-pour-le-portdabidjan/. Document consulté le 31 juillet 2019.

35 NDJAMBOU Léandre Edgard, «Échanges maritimes et enclavement en Afrique de l'ouest: le cas des ports d'Abidjan et de Cotonou », Les Cahiers d'Outre-mer, nos 226-227, avril-septembre 2004, p. 5. Article accessible en ligne sur : http://www.com.revues.org/555. Document consulté le 23 février 2016. 
Il importe cependant de tempérer cette note de pessimisme si l'on s'en tient aux résultats des activités du PAA, de l'année 2013. Le Directeur général du PAA souligne qu'un point de satisfaction, à l'issue de l'année 2013, est la forte reprise des trafics avec les pays de l'hinterland. En effet, après le déroutage du trafic en transit vers les ports concurrents de la sous-région en 2011, les années 2012 et 2013 ont été marquées par le retour massif des opérateurs du Burkina Faso et du Mali au Port d'Abidjan.

Selon les mots du Directeur général du PAA, le port a connu un accroissement significatif du trafic global de 3,8\% passant de 21.734.640 tonnes en 2016 à 22.556.809 tonnes en 2017, confirmant ainsi la position de leader du Port d'Abidjan sur la Côte Ouest-Africaine (COA) en termes de volumes de trafics.

Cette progression de 5,5\% (19.332.608 de tonnes) est soutenue, notamment par la croissance de $12,5 \%$ des marchandises générales $(+21,9 \%$ pour les exportations et $+9,1 \%$ pour les importations) et de $13,4 \%$ des produits de pêche. Ce qui confirme le dynamisme de l'économie ivoirienne. À l'instar du trafic national, le trafic en transit, et le trafic conteneurs progressent respectivement de $+3 \%$ (2.026.220 tonnes contre 1.967.115 tonnes en 2016) et 4,4\% (663.601 EVP en 2017 contre 635.647 EVP en 2016) ${ }^{36}$.

\section{APERÇU DU RÉGIME JURIDIQUE DU PORT AUTONOME D'ABIDJAN}

Le PAA relève d'une catégorie juridique de port. Il s'inscrit précisément dans la catégorie des ports propriétaires, ou Landlord Ports (A). Sa préciosité pour l'économie ivoirienne a conduit, à maintes reprises, les autorités compétentes ivoiriennes à procéder à des ajustements statutaires afin de le rendre plus compétitif et plus performant (B).

\section{A. Le Port autonome d'Abidjan, un port propriétaire ${ }^{37}$}

Le PAA, au regard du décret $n^{\circ} 92-940$ du 23 décembre $1992^{38}$ et d'autres textes juridiques pertinents, présente les traits caractéristiques d'un port propriétaire. En effet, le PAA exerce un pouvoir réglementaire qui lui permet d'assurer la police administrative sur le domaine public portuaire. Ầ ce titre, le PAA filtre les entrées et les déplacements des usagers sur la plateforme portuaire. Il veille à l'application, par les industriels et autres opérateurs privés du domaine public portuaire, des normes d'hygiène et de sécurité qui régissent leurs activités. Le PAA bénéficie également du concours de la Gendarmerie nationale qui joue, entre autres, le rôle de police judiciaire dévolue à la recherche des auteurs d'infraction pénale survenue dans le périmètre du port. Enfin, le PAA sanctionne les occupations sans titre (donc illégales) des dépendances du domaine public portuaire.

En sus de ses attributions de police administrative et, accessoirement, de police judiciaire, le PAA assume des missions de service public. Celles-ci se déclinent respectivement en une mission de service public administratif (SPA) et une mission de service public industriel et commercial (SPIC). La mission de SPA consiste pour le Port à veiller la préservation de la

36 Rapport d'activités du Port Autonome d'Abidjan, 2017, p. 5.

37 Une étude de la CNUCED intitulée Étude sur les transports maritimes 2017 permet de relever quatre catégories de ports. Ce sont les ports de services publics, les ports outils, les ports propriétaires et les ports de services privés. $C f$. HOFFMANN Jan (dir.), Étude sur les transports maritimes 2017, New York et Genève, CNUCED, Côte UNCTAD/RMT/2017, p. 77.

38 Décret $n^{\circ} 92-940$ du 23 décembre 1992 portant transformation du Port autonome d'Abidjan en société d'État, JORCI n8, 25 février 1993, p. 159 et ss. En droit ivoirien, une société d'État est une personne juridique de droit privé en vertu de l'article 3 de la loi n97-519 du 4 septembre 1997 portant définition et organisation des sociétés d'État. En vertu de l'article 3 de cette loi, la société d'État jouit de la personnalité morale à dater de son immatriculation au registre du commerce. 
consistance du domaine public portuaire contre tout empiètement ${ }^{39}$. Elle consiste également à veiller à la préservation de la fonctionnalité de l'outillage du port. Quant à la mission de SPIC, elle se perçoit premièrement à travers les prestations fournies aux navires en escale au PAA contre perception de redevances. À cela, s'ajoutent les redevances versées par les occupants privatifs des portions du domaine public portuaire. Ces occupations privatives empruntent la forme soit de permission de voirie, soit de concession de voirie ou encore de bail emphytéotique administratif. À cette panoplie classique, s'ajoute désormais la concession, à des sociétés privées, de l'exploitation des terminaux à conteneurs ${ }^{40}$.

Au regard des missions susmentionnées, le PAA quoique revêtant la nature d'une société d'État - donc une personne morale de droit privé - se présente comme un service public « à double visage ${ }^{41}$.

Le PAA, depuis sa création en 1951 jusqu'à ce jour, a subi des ajustements statutaires successifs aux fins de le rendre capable de remplir les missions que lui confie l'État ivoirien.

\section{B. Les ajustements statutaires du port d'Abidjan}

Ces ajustements comportent trois grandes phases.

La première phase part de l'année 1951 (année d'ouverture du port d'Abidjan) à l'année 1992. Durant cette première phase, le PAA a fonctionné selon un régime juridique de droit public (1).

La seconde phase débute de l'année 1992 et s'étend jusqu'à présent. Elle se caractérise par la transformation du PAA en société d'État. Le corollaire de cette transformation est la soumission partielle du PAA aux normes de droit privé (2). À cette seconde phase d'ajustement statutaire, vient se superposer une troisième. Cette dernière apparaît comme la conséquence logique de la seconde phase. En effet, la transformation du PAA en personne morale de droit privé œuvrant dans le secteur industriel et commercial s'accompagne corrélativement de l'application à celui-ci des normes de droit commercial, et de droit portuaire secrétées par les organes communautaires de l'UEMOA et de l'OHADA. Il s'ensuit une soumission du PAA au droit communautaire de l'UEMOA et de l'OHADA (3).

\section{Le statut initial de personne publique}

Le percement du Canal de Vridi en juillet 1950 a permis de relier la lagune Ébrié à l'Océan Atlantique. Cette ouverture marque la création (physique) du port d'Abidjan. Au plan juridique, le port d'Abidjan a été créé par un arrêté du Gouverneur général de l'Afrique occidentale française (A.O.F.). Il s'agit précisément de l'arrêté GG nº2-86/TP du 10 novembre 1950 portant organisation et fonctionnement des services du port d'Abidjan à partir du $1^{\text {er }}$ janvier 1951.

39 Il est vrai que le domaine public portuaire est inclus dans le patrimoine de la République de Côte d'Ivoire en vertu de l'article $1^{\mathrm{er}} f$ ) du décret (colonial) du 29 septembre 1928 portant réglementation du domaine d'utilité publique et des servitudes publiques (modifié par décrets du 7 septembre 1935 et du 3 juin 1952). Cependant, le Port d'Abidjan en est le gestionnaire en vertu de l'article premier de la loi n ${ }^{\circ} 60-85$ du 10 février 1960, portant création d'un établissement public qui prendra le nom de "Port d'Abidjan », JORCI, $\mathrm{n}^{\circ} 15,20$ février 1960, p. 220.

40 Voir le cas du terminal à conteneurs de Vridi qui a été concédé à la Société d'exploitation du terminal de Vridi (S.E.T.V), à la suite d'une convention signée le 23 octobre 2003 entre le PAA et la S.E.T.V.

41 La théorie du service public «à double visage » a été découverte par le juge administratif français dans l'affaire Abadie. CE 17 avril 1959, Sieur Abadie, Rec. p. 239. 
Initialement, le Port d'Abidjan a fonctionné comme un service spécial maritime dépendant de la Direction générale des Travaux publics. À partir de 1960, il a connu une série de réformes motivées par la recherche constante de compétitivité et d'efficacité.

Ainsi, en 1960, la loi n ${ }^{\circ} 60-85$ du 10 février 1960 érige le Port d'Abidjan en établissement public doté de la personnalité morale ${ }^{42}$. Le $1^{\text {er }}$ janvier 1971, le Port d'Abidjan acquiert son autonomie (par rapport à la Direction générale des Travaux publics dont il dépendait) par la loi des finances $\mathrm{n}^{\circ} 70-726$ du 31 décembre 1970 qui en fait un établissement public à caractère industriel et commercial (EPIC), doté de la personnalité morale et de l'autonomie financière ${ }^{43}$. Ainsi naît le Port Autonome d'Abidjan (PAA) placé sous la tutelle financière du ministère de l'économie et des finances et sous la tutelle administrative du ministère des travaux publics et des transports.

En 1974, le PAA est placé sous la tutelle de trois (03) Ministères :

- Le ministère de l'économie et des finances (tutelle financière);

- Le ministère des travaux publics et des transports (tutelle technique des travaux d'Infrastructures) ;

- Le ministère de la marine (tutelle technique pour la gestion et l'exploitation).

\section{Le statut actuel de personne morale de droit privé}

En 1992, le décret nº2-940 du 23 décembre 1992 transforme le PAA en société d’État ${ }^{44}$, placée sous la tutelle technique et administrative du ministère chargé de la marine marchande et sous la tutelle économique et financière du ministère chargé de l'économie et des finances.

En 2001, suite à l'édiction du décret n²001-143 du 14 mars 2001 portant approbation des statuts du Port autonome d'Abidjan et reclassification des immobilisations concédées ${ }^{45}$, le capital social du PAA est porté à seize milliards (16.000.000.000) de francs CFA entièrement libéré et détenu par l'État de Côte d'Ivoire. Le PAA est placé sous la tutelle technique et administrative du ministère chargé des infrastructures économiques et sous la tutelle économique et financière du ministre de l'économie et des finances.

Force cependant est de relativiser le statut de personne morale de droit privé qui s'applique désormais au Port autonome d'Abidjan. En effet, la détention de l'entièreté du capital du Port par l'État ivoirien se traduit par une marge incompressible de normes de droit

42 Loi n60-85 du 10 février 1960, portant création d'un établissement public qui prendra le nom de « Port d'Abidjan », JORCI, n¹5, 20 février 1960, p. 220. Selon l'article premier de ladite loi, « Il est créé un établissement public investi de la personnalité civile et soumis aux règles générales qui régissent la gestion des deniers publics, notamment à celles de la loi organique du 31 décembre 1959, relative aux lois de finances pour assurer l'administration et l'exploitation du port d'Abidjan et de ses accès et dépendances, $y$ compris la station de pilotage, les feux et balises et le phare de Port-Bouët, ainsi que la gestion de son domaine et les études et les travaux de construction, de réparation et d'entretien des ouvrages ».

43 Loi des finances $\mathrm{n}^{\circ} 70-726$ du 31 décembre 1970 portant loi des finances pour la gestion 1971, JORCI, $\mathrm{n}^{\circ} 15,2$ février 1971, p. 162. En vertu de l'article 8 de la loi des finances précitée, "À compter du $1^{\text {er }}$ janvier 1971, le Port d'Abidjan est érigé en établissement public à caractère industriel et commercial, doté de la personnalité morale et de l'autonomie financière, placé sou la tutelle technique et administrative du ministre des Travaux publics et des Transports et sous la tutelle financière du ministre de l'Économie et des Finances ».

44 Décret n92-940 du 23 décembre 1992 portant transformation du Port autonome d'Abidjan en société d'État, JORCI n ${ }^{\circ}$, 25 février 1993, p. 159 et ss. En droit ivoirien, une société d'État est une personne juridique de droit privé en vertu de l'article 3 de la loi n $97-519$ du 4 septembre 1997 portant définition et organisation des sociétés d'État. En vertu de l'article 3 de cette loi, la société d'État jouit de la personnalité morale à dater de son immatriculation au registre du commerce.

45 Décret $\mathrm{n}^{\circ}$ 2001-143 du 14 mars 2001 portant approbation des Statuts du Port autonome d'Abidjan (PAA) et reclassification des immobilisations concédées, JORCI n ${ }^{\circ}$ 17, 26 avril 2001, p. 313 et ss. 
public s'appliquant à celui-ci. En outre, le PAA, en sa qualité de gestionnaire exclusif du domaine public portuaire, est investi de prérogatives de puissance publique qu'impliquent les missions de police administrative et de service public découlant respectivement de la conservation et de l'exploitation dudit domaine.

\section{La soumission du Port autonome d'Abidjan au droit communautaire de l'UEMOA et de l'OHADA}

L'application du droit communautaire de l'UEMOA ainsi que celui de l'OHADA au PAA est la conséquence de la signature des traités constitutifs de ces deux organisations internationales par la République de Côte d'Ivoire. En effet, la Côte d'Ivoire est partie au Traité constitutif de l'Union Économique et Monétaire Ouest-Africaine (UEMOA), adopté à Dakar le 10 janvier 1994. Elle est également partie au Traité relatif à l'harmonisation du droit des affaires en Afrique (OHADA), adopté à Port-Louis, le 17 octobre 1993 tel que modifié par le Traité de Québec du 17 octobre 2008. Ces deux traités instituent, chacun en ce qui le concerne, un ordre juridique de subordination du droit ivoirien au droit secrété par les organes de l'une ou l'autre de ces deux organisations d'intégration.

Dans le cas de l'UEMOA, le droit communautaire dérivé consiste en des actes juridiques qui se présentent, de manière décroissante, comme suit: les actes additionnels ${ }^{46}$ de la Conférence des chefs d'État et de gouvernement de l'UEMOA, les règlements, les directives et les décisions du Conseil des ministres de ladite organisation d'intégration. À ces actes unilatéraux aux effets contraignants, se greffent les actes unilatéraux non obligatoires que sont les recommandations et les avis, tous deux, émanant du Conseil des ministres de l'UEMOA Il importe d'adjoindre la jurisprudence de la Cour de justice de l'UEMOA ${ }^{47}$ qui, quelle que soit la forme revêtue ${ }^{48}$, s'impose aux organes de l'UEMOA, aux États membres de l'Union ainsi qu'aux autres destinataires. De cette multitude de textes juridiques relevant du droit communautaire, certaines retiendront particulièrement notre attention. Ce sont, entre autres :

- Le Règlement $\mathrm{n}^{\circ} 02 / 2002 / \mathrm{CM} / \mathrm{UEMOA}$ du 23 mai 2002 relatif aux pratiques anticoncurrentielles à l'intérieur de l'UEMOA;

- Le Règlement n02/2008/CM/UEMOA du 28 mars 2008 relatif aux transports maritimes au sein de l'UEMOA ;

- La Directive n04/2008/CM/UEMOA du 28 mars 2008 portant mise en place d'un cadre institutionnel harmonisé du sous-secteur maritime au sein de l'UEMOA ;

- La Directive $\mathrm{n}^{\circ} 03 / 2008 / \mathrm{CM} / \mathrm{UEMOA}$ du 28 mars relative aux fournisseurs de services portuaires au sein de l'UEMOA.

En sus du droit de l'UEMOA, la Côte d'Ivoire et, par voie de conséquence, le PAA sont soumis aux normes constituant le droit de l'OHADA Hormis son traité constitutif, le droit de

46 Couramment désigné sous l'appellation de Protocole ou Protocole additionnel. Le Protocole relève formellement du droit dérivé puisqu'il émane d'un organe institué par le Traité constitutif de l'UEMOA. Du point de vue matériel, c'est-à-dire dans le fond, en revanche, le Protocole relève du droit primaire de l'UEMOA en ce qu'il vient compléter le traité constitutif de ladite organisation sans toutefois le modifier (article 19 du Traité de l'UEMOA).

47 La Cour de justice de l'UEMOA a été instituée par l'article 16 du Traité UEMOA de 1994. Elle a été rendue opérationnelle au moyen, entre autres, du Protocole additionnel $n^{\circ} 1$ relatif aux organes de contrôle de l'UEMOA et l'Acte additionnel n'10/96 du 10 mai 1996 portant statuts de la Cour de Justice de l'UEMOA.

48 Au regard de l'article 27 de l'Acte additionnel $n^{\circ} 10 / 96$ du 10 mai 1996 portant statuts de la Cour de Justice de l'UEMOA, la Cour rend soit des arrêts soit des avis ou encore des recommandations. 
l'OHADA se décline en une multitude d'actes unilatéraux édictés par le Conseil des ministres de ladite organisation : ce sont les Actes uniformes. Il existe une multitude d'Actes uniformes dont ceux en vigueur sont : l'Acte uniforme portant sur le droit commercial général ${ }^{49}$, Acte uniforme portant organisation des procédures collectives d'apurement du passif ${ }^{50}$, Acte uniforme portant organisation des sûretés ${ }^{51}$, Acte uniforme relatif au droit du transport de marchandises par route ${ }^{52}$, Acte uniforme relatif au droit des sociétés commerciales et du groupement d'intérêt économique ${ }^{53}$, Acte uniforme relatif au droit des sociétés coopératives ${ }^{54}$, Acte uniforme portant organisation des procédures simplifiées de recouvrement et des voies d'exécution ${ }^{55}$, Acte uniforme relatif au droit de l'arbitrage ${ }^{56}$, Acte uniforme relatif au droit comptable et à l'information financière (AUDCIF $)^{57}$.

Tous ces Actes uniformes ont vocation à s'appliquer au Port autonome d'Abidjan lorsque celui-ci entreprend une activité ou des activités incluses dans le champ spatial de l'un ou l'autre de ces Actes uniformes.

\section{DÉFINITION DES NOTIONS FONDAMENTALES DE L'ÉTUDE}

Le libellé de notre thème de recherche comporte deux notions majeures qu'il importe de définir afin d'en saisir la problématique sous-jacente. Ce sont respectivement la notion de statut juridique (A) et celle de port autonome (B).

\section{A. La notion de statut juridique}

Comprendre la notion de statut juridique requiert, au préalable, que l'on la définisse (1) avant d'analyser certains actes juridiques qui constituent le statut juridique du Port autonome d'Abidjan (2).

\section{Définition de la notion de statut juridique}

Le Vocabulaire juridique définit le statut juridique comme un ensemble cohérent de règles applicables à une catégorie de personnes (ex. statut des gens mariés) ou d'agents (ex. statut des fonctionnaires) ou à une institution (ex. statut des collectivités locales) et qui en déterminent, pour l'essentiel, la condition et le régime juridiques ${ }^{58}$.

49 Adopté le 15 décembre 2010 à Lomé (Togo), publié au Journal Officiel de l'OHADA le 15 février 2011, il est entré en vigueur le 15 mai 2011.

50 Adopté le 10 septembre 2015 à Grand-Bassam (Côte d'Ivoire), publié au Journal Officiel de l'OHADA le 25 septembre 2015, il est entré en vigueur le 24 décembre 2015.

51 Adopté le 15 décembre 2010 à Lomé (Togo), publié au Journal Officiel de l'OHADA le 15 février 2011, il est entré en vigueur le 15 mai 2011.

52 Adopté le 22 mars 2003 à Yaoundé (Cameroun), publié au Journal Officiel de l'OHADA le 31 juillet 2003, il est entré en vigueur le $1^{\text {er }}$ janvier 2004.

53 Adopté le 30 janvier 2014 à Ouagadougou (Burkina Faso), publié au Journal Officiel de l'OHADA le 04 février 2014, il est entré en vigueur le 05 mai 2014.

54 Adopté le 15 décembre 2010 à Lomé (Togo), publié au Journal Officiel de l'OHADA le 15 février 2011, il est entré en vigueur le 15 mai 2011.

55 Adopté le 10 avril 1998 à Libreville (Gabon), publié au Journal Officiel de l'OHADA le $1^{\text {er }}$ juin 1998, il est entré en vigueur le 31 août 1998.

56 Adopté le 23 novembre 2017 à Conakry (Guinée). Il a été publié au Journal Officiel de l'OHADA le15 décembre 2017 et est entré en vigueur le 15 mars 2018.

57 Adopté le 26 janvier 2017 et publié au Journal Officiel de l'OHADA le 15 février 2017.

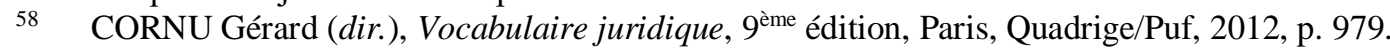


Cette définition est confortée par celle tirée du dictionnaire Larousse selon laquelle le statut juridique est l'ensemble des dispositions législatives ou réglementaires fixant les garanties fondamentales (droits et obligations) accordées à une collectivité publique ou à un corps de fonctionnaires ou d'agents publics (statut général de la fonction publique, statut des magistrats $)^{59}$.

De ces deux définitions, surtout de la seconde, il apparait que le statut juridique se décline aussi bien en textes législatifs ou de valeur égale qu'en textes réglementaires. Il en résulte que, ramené au cas du PAA, le statut juridique de ce dernier se compose des lois et décrets voire arrêtés ministériels par lesquels les autorités compétentes de la Côte d'Ivoire l'ont créé et défini ses missions et attributions.

\section{Aperçu des actes constituant le statut juridique du Port autonome d'Abidjan}

Le premier texte ayant régi le Port d'Abidjan (devenu par la suite Port autonome d'Abidjan) a été un arrêté du Gouverneur général de l'Afrique occidentale française (A.O.F.). Cet arrêté, intitulé arrêté GG n62-86/TP du 10 novembre 1950 portant organisation et

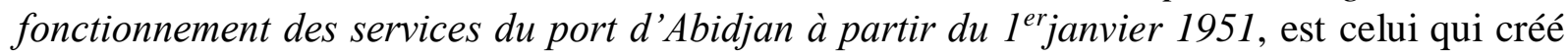
juridiquement le Port d'Abidjan suite à l'ouverture du Canal de Vridi en juillet 1950.

Par la suite, suivront d'autres textes juridiques notamment la loi n $60-85$ du 10 février $1960^{60}$ et la loi $\mathrm{n}^{\circ} 70-726$ du 31 décembre 1970 portant loi de finances pour la gestion 1971. Ces deux textes législatifs transforment le Port d'Abidjan successivement en établissement public $^{61}$ et en établissement public industriel et commercial ${ }^{62}$.

À la catégorie des textes législatifs, se substituera celle des textes réglementaires, particulièrement les décrets, par lesquels l'autorité étatique compétente définit l'organisation, le fonctionnement et les attributions du PAA. Il s'agit, entre autres, du décret n'92-940 du 23 décembre 1992 portant transformation du Port autonome d'Abidjan en société d'État ${ }^{63}$. Ce décret fixe le cadre organique et le régime financier du Port autonome d'Abidjan. À celui-ci, s'ajoute le décret n²001-143 du 14 mars 2001 portant approbation des Statuts du Port autonome d'Abidjan (PAA) et reclassification des immobilisations concédées ${ }^{64}$.

59 http://www.larousse.fr/dictionnaires/français/statut/74543\#vJ11YolBMRHJYYQu.99. Document consulté le 28 septembre 2016.

60 L'intitulé complet de la loi est : Loi n ${ }^{\circ} 60-85$ du 10 février 1960 portant création d'un établissement public qui prendra le nom de «Port d'Abidjan ». Elle a été publiée au JORCI, n 15, 20 février 1960, pp. 220-221.

61 Aux termes de l'article premier de la loi $\mathrm{n}^{\circ} 60-85$ du 10 février 1960, «Il est créé un établissement public investi de la personnalité civile et soumis aux règles générales qui régissent la gestion des deniers publics, notamment à celles de la loi organique du 31 décembre 1959, relative aux lois de finances pour assurer l'administration et l'exploitation du port d'Abidjan et de ses accès et dépendances, y compris la station de pilotage, les feux et balises et le phare de Port-Bouët, ainsi que la gestion de son domaine et les études et les travaux de construction, de réparation et d'entretien des ouvrages ».

62 Aux termes de l'article premier de loi n $70-726$ du 31 décembre 1970 portant loi de finances pour la gestion 1971, «À compter du $1^{\text {er }}$ janvier 1971, le Port d'Abidjan est érigé en établissement public à caractère industriel et commercial, doté de la personnalité morale et de l'autonomie financière, placé sous la tutelle technique et administrative du ministre des travaux publics et des transports et sous la tutelle financière du ministre de l'économie et des finances ».

63 Décret n92-940 du 23 décembre 1992 portant transformation du Port autonome d'Abidjan en société d'État, JORCI n8, 25 février 1993, p. 159 et ss.

64 Décret $\mathrm{n}^{\circ}$ 2001-143 du 14 mars 2001 portant approbation des Statuts du Port autonome d'Abidjan (PAA) et reclassification des immobilisations concédées, JORCI n ${ }^{\circ} 17,26$ avril 2001, p. 313 et ss. Selon l'article premier de ce décret, «le Port autonome d'Abidjan est une société d'État [...] régie par la loi $n^{\circ} 97-519$ du 4 septembre 1997 portant définition et organisation des sociétés d'État et ses décrets d'application, par les dispositions de l'Acte uniforme relatif au Droit des sociétés commerciales et du Groupement d'intérêt économique, ainsi que les présents statuts ». 
En sus des deux décrets précités, figurent d'autres décrets délimitant le périmètre portuaire ainsi que les attributions du PAA en matière de police de la conservation du domaine portuaire. Parmi ces textes réglementaires, on range le décret n ${ }^{\circ}$ - 151 du 25 mars 1998 portant délimitation des zones d'extension du Port autonome d'Abidjan (Locodjro, Île Boulay, Cordon littoral) ${ }^{65}$. Ce décret complète la délimitation du domaine portuaire précédemment effectuée dans le décret $n^{\circ} 60-110$ du 16 mars 1960 au moyen du plan $n^{\circ} 78-2$ 009. Ce dernier plan est modifié et remplacé par le plan n $78-2-009 \mathrm{C}$ en vertu de l'article premier du décret $n^{\circ} 98-151$ du 25 mars 1998 précité. Au titre des décrets, il est également possible de mentionner le décret $\mathrm{n}^{\circ} 99-318$ du 21 avril 1999 portant règlement de police du Port autonome d'Abidjan ${ }^{66}$. Celui-ci définit les compétences du PAA pour prévenir et, le cas échéant, sanctionner les atteintes contre la consistance du domaine portuaire.

Hormis ces textes s'appliquant spécialement au PAA, on note une multitude d'autres textes s'intéressant, de manière incidente il est vrai, au PAA. Certains revêtent, à l'heure actuelle, un intérêt historique, tandis que d'autres sont encore d'actualité. Dans la première catégorie se situent :

- la loi nº0-1071 du 13 septembre 1980 fixant les règles générales relatives aux établissements publics nationaux et portant création de catégories d'établissements publics $^{67}$;

- le décret $n^{\circ} 81-137$ du 18 février 1981 portant régime financier et comptable des établissements publics nationaux ;

- le décret $\mathrm{n}^{\circ} 82-402$ du 21 avril 1982 portant organisation administrative des établissements publics nationaux ${ }^{68}$. Ce dernier, encore en vigueur, a été modifié par le décret n94-396 du 28 juillet 1994. Cependant, il ne s'applique plus au PAA vu que ce dernier n'est plus un établissement public mais a été transformé en une société d'État.

D'autres textes, encore en vigueur, s'intéressent incidemment au PAA. C'est particulièrement le cas de la loi $\mathrm{n}^{\circ} 97-519$ du 4 septembre 1997 portant définition et organisation des sociétés d'État ${ }^{69}$. Celle-ci abroge et remplace la loi n ${ }^{\circ} 80-1071$ du 13 septembre 1980 portant définition et organisation des sociétés d'État. À cette énumération de textes juridiques, se greffe le droit de l'OHADA, singulièrement l'Acte uniforme relatif au Droit des sociétés commerciales et du Groupement d'intérêt économique, conformément au décret $\mathrm{n}^{\circ} 2001-143 \mathrm{du} 14$ mars 2001 portant approbation des Statuts du Port autonome d'Abidjan (PAA) et reclassification des immobilisations concédées. Selon l'article premier de ce décret, "le Port autonome d'Abidjan est une société d'État [...] régie par la loi $n^{\circ} 97-519$ du 4 septembre 1997 portant définition et organisation des sociétés d'État et ses décrets d'application, par les dispositions de l'Acte uniforme relatif au Droit des sociétés commerciales et du Groupement d'intérêt économique, ainsi que les présents statuts ».

65 Décret n98-151 du 25 mars 1998 portant délimitation des zones d'extension du Port autonome d'Abidjan (Locodjro, Île Boulay, Cordon littoral), JORCI, ${ }^{\circ} 18,30$ avril 1998, p. 455.

66 Décret $\mathrm{n}^{\circ}$ 99-318 du 21 avril 1999 portant règlement de police du Port autonome d'Abidjan, $\mathrm{JORCI}, \mathrm{n}^{\circ} 32$, 12 août 1999, p. 661 et ss.

67 Cette loi a été abrogée et remplacée par la loi $\mathrm{n}^{\circ} 98-388$ du 2 juillet 1998 fixant les règles générales relatives aux établissements publics nationaux et portant création de catégories d'établissements publics et abrogeant la loi $n^{\circ} 80-1070$ du 13 septembre 1980.

68 Décret $\mathrm{n}^{\circ} 82-402$ du 21 avril 1982 portant organisation administrative des établissements publics nationaux, JORCI $\mathrm{n}^{\circ} 23,27$ mai 1982 , p. 410 et suivants.

69 Loi ${ }^{\circ} 97-519$ du 4 septembre 1997 portant définition et organisation des sociétés d'État, JORCI 2 octobre 1997, n40, pp. 1060-1066. 
Plus récemment, le législateur ivoirien a adopté un Code maritime qui, à bien d'égards, s'applique aux activités du $\mathrm{PAA}^{70}$. Il en va ainsi du Livre I intitulé Les domaines publics maritime, lagunaire et fluvial et les autres zones maritimes sous juridiction nationale. Relativement au domaine public maritime (abordé au Titre 2 du Livre I précité), le chapitre 3 traite du domaine public portuaire et définit le régime juridique des activités de remorquage et de pilotage.

La notion de statut juridique appréhendée, se pose la nécessité de cerner la notion de port autonome.

\section{B. Notion de port autonome : une approche de droit comparé}

Contrairement à ce que l'on pourrait penser, la notion de port autonome recouvre une définition variable selon que l'on soit en droit ivoirien ou en droit français. Sur ce point, il apparaît que le port autonome n'a pas fait l'objet d'une définition expresse en droit ivoirien (1). En revanche, le droit français s'est attelé, de manière progressive, à lui conférer une définition précise (2).

\section{Une absence de définition explicite en droit ivoirien}

La lecture de la panoplie de textes juridiques s'appliquant au PAA ne permet pas de cerner une définition explicite de la notion de port autonome. Le PAA n'étant plus un établissement public, implique que la définition de l'autonomie telle que cela ressort de la loi de 1998 instituant les catégories d'établissement public en Côte d'Ivoire ne saurait lui être appliquée. En effet, selon l'article premier de la loi n $98-388$ du 2 juillet 1998, un établissement public est une "personne morale de droit public créée par l'État, disposant de l'autonomie financière, dont l'objet exclusif et spécialisé est de remplir une mission de service public, en suivant des règles adaptées à sa mission, et comportant des contraintes et des prérogatives de droit public».

De cette définition, il est évident que certaines caractéristiques ne sont plus applicables au Port autonome d'Abidjan. C'est notamment le cas de la personnalité morale de droit public.

Il en résulte que l'autonomie (textuelle) du PAA se déduirait de sa nature de société commerciale dotée d'une personnalité juridique distincte de celle de l'État. En effet, le PAA, rappelons-le, est désormais une société commerciale par sa forme, au regard de l'article premier du décret n²001-143 du 14 mars 2001 et de l'article 4 de la loi n $97-519$ du 4 septembre 1997.

À ce titre, il jouit de la latitude de recruter (librement) son personnel et de le soumettre au régime défini par le Code du travail, y compris les membres de la direction générale qui sont nommés par le conseil d'administration de la société d'État ${ }^{71}$. En outre, elle dispose d'un budget propre qui n'est plus un budget annexe à la loi des finances, comme c'était le cas lorsqu'il était encore un établissement public national. Il importe cependant de tempérer fortement l' «autonomie » du PAA eu égard au fait que l'État est détenteur de l'entièreté du capital de cette société d'État. Si, textuellement, elle comporte les éléments précités qui militeraient en faveur de son autonomie, celle-ci est manifestement très limitée au regard de la forte emprise de l'État traduite par la détention de l'entièreté du capital du PAA, la

Le nouveau Code maritime ivoirien résulte de l'adoption de la loi n²017-442 du 30 juin 2017 portant Code maritime. Elle a été publiée au JORCI, dans le numéro spécial paru le mardi 13 novembre 2018, pp. 129-208.

71 Article 20 des Statuts du Port autonome d'Abidjan. 
représentation exclusive de l'État au conseil d'administration ${ }^{72}$, le contrôle administratif et le contrôle juridictionnel pesant sur le PAA.

Il en résulte que ni les textes constitutifs du Port autonome d'Abidjan ni ceux s'appliquant au Port autonome de San Pedro ne définissent explicitement la notion de port autonome. Aussi, sommes-nous conduits à essayer d'élaborer une définition de la notion de port autonome.

Selon le Vocabulaire juridique, le port autonome est un établissement public de l'État créé par décret et responsable de la gestion administrative, technique, commerciale et financière d'un ensemble portuaire ${ }^{73}$.

Cette définition ne saurait s'appliquer, en l'état, en droit ivoirien vu que les deux ports autonomes de la Côte d'Ivoire - celui d'Abidjan et celui de San Pedro - sont des sociétés d'État. En tenant également compte de l'état de la législation en vigueur bien avant la transformation du PAA en société d'État, on peut adapter la notion de port autonome comme suit : un port autonome est une personne morale de droit public ou de droit privé, créée par décret, appartenant à l'État, et qui est investie de la mission d'assurer la police de la conservation du domaine portuaire, l'entretien et l'exploitation des installations portuaires.

L'absence de définition explicite de la notion de port autonome en droit ivoirien contraste avec la définition évolutive et précise de ladite notion en droit français.

\section{Une définition évolutive et précise en droit français}

La notion de port autonome a connu une évolution sémantique en droit français. À la définition initiale contenue dans la loi du 29 juin 1965 a succédé celle de la loi du 4 juillet 2008.

Initialement, selon la définition qu'en donne l'article $1^{\text {er }} \S 2$ de la loi du 29 juin $1965^{74}$, reprise à l'article L. 111-1 du Code des ports maritimes, "les ports autonomes sont des établissements publics de l'État, dotés de la personnalité civile et de l'autonomie financière, placés sous la tutelle du ministre chargé des ports maritimes et soumis au contrôle économique et financier de l'État ».

Il apparait de ce qui précède que le port autonome, en France, était d'abord une personne morale de droit public, appartenant à l'État qui en assurait la tutelle à la fois technique et financière.

L'article $2 \S 1$ de la loi précitée du 29 juin 1965, reprise à l'article L. 111-2 du Code des ports maritimes définit les missions du port autonome. Selon cette disposition, "le port autonome est chargé, à l'intérieur des limites de sa circonscription [...], des travaux d'extension, d'amélioration, de renouvellement et de reconstruction ainsi que de l'exploitation, de l'entretien et de la police, au sens des dispositions du Livre III du Code des ports maritimes, du port et de ses dépendances et de la gestion du domaine immobilier qui lui est affecté ».

Les missions précitées peuvent être regroupées en deux catégories: d'une part, les missions relevant du service public administratif et, d'autre part, les missions incluses dans le

72 Au regard de l'article 11 des Statuts du Port autonome d'Abidjan, le conseil d'administration est composé de : un (1) représentant du premier ministre, deux (2) représentants du ministère chargé des infrastructures économiques parmi lesquels est choisi le président du conseil d'administration, un (1) représentant du ministère de l'économie et des finances, un (1) représentant du ministère chargé du commerce, un (1) représentant du ministère chargé des transports, un (1) représentant du ministère chargé de la défense, le directeur général de l'Administration des douanes, le président de la chambre de commerce et d'industrie ou son représentant; soit un total de neuf (9) membres.

73 CORNU Gérard (dir.), Vocabulaire juridique, 9 ème édition, Paris, Quadrige/Puf, 2012, p. 767.

74 Loi n65-491 du 29 juin 1965 sur les ports maritimes autonomes, JORF, 30 juin 1965, pp. 5436-5438. 
service public industriel et commercial. De l'énumération ci-dessus, il apparait que l'exploitation du port et de ses dépendances, ainsi que la gestion du domaine immobilier à lui affecté, relèvent du service public industriel et commercial. En revanche, les autres missions s'inscrivent plutôt dans le cadre du service public administratif ${ }^{75}$.

Actuellement, avec l'adoption de la loi n²008-660 du 4 juillet 2008 portant réforme portuaire, la notion de port autonome a connu une démarcation d'avec une notion connexe, celle de "grand port maritime ». Ainsi que le notent les professeurs Bordereaux et Braud, la loi précitée de 2008 met en place une nouvelle gouvernance portuaire, jugée a priori plus efficiente, et organise le passage de la formule "port autonome » à celui de "grand port maritime ». Cette évolution reflétait l'abandon du modèle "port outil» au bénéfice de l'adoption de celui de "port propriétaire», "caractérisé par une distinction nette entre l'autorité publique, qui gère les infrastructures, l'aménagement et la politique tarifaire, et le secteur privé, chargé des services portuaires ou général ${ }^{76}$.

Au regard de l'article L. 101-2 du Code des ports maritimes, les grands ports maritimes sont des établissements publics de l'État. À ce titre, ils sont soumis, tout comme les ports autonomes, à la double tutelle technique et financière de l'État. Les grands ports maritimes ne sont donc pas des sociétés anonymes à capitaux publics (des sociétés d'État, comme on dirait en Côte d'Ivoire).

Cependant, l'institution de grands ports maritimes comporte des innovations parmi lesquelles une retiendra particulièrement notre attention. Il s'agit de la possibilité de privatiser l'exploitation de l'outillage, à travers la prise de participation minoritaire dans une personne morale de droit privé, chargée d'exploiter les équipements de manutention, auparavant gérés par les ports autonomes (article L. 103-2 Code des ports maritimes).

En somme, il apparaît sur le fondement de l'article L. 100-1 du Code des ports maritimes, qu'en droit français, il existe :

- des grands ports maritimes ;

- des ports autonomes ;

- des ports maritimes relevant des collectivités territoriales et de leurs groupements ;

- dans les départements d'outre-mer et à Saint-Pierre-et-Miquelon, les ports maritimes relevant de l'État;

- le port de Port-Cros, relevant pour son aménagement, son entretien et sa gestion, du parc national de Port-Cros.

La compréhension du libellé de la présente étude commande que l'on cerne la problématique de notre sujet.

\section{PROBLÉMATIQUE DU SUJET}

Le libellé de notre sujet pourrait susciter une multitude d'interrogations. Il pourrait, à la limite, incliner à scruter seulement l'incidence du statut juridique du PAA sur les performances économiques de celui-ci. Ce faisant, une telle analyse revêtirait une orientation prioritairement tournée vers les sciences économiques.

75 Sur la dualité des missions dévolues au port autonome, cela transparaît de la théorie du « service public à double visage » telle que cela a été dégagé de la jurisprudence Abadie du Conseil d'État français. En vertu de cette théorie, une personne morale, notamment le Port autonome de Bordeaux, a pu valablement exploiter, à la fois, un service public industriel et commercial, d'une part, et un service public administratif, d'autre part. Cf. CE 17 avril 1959, Sieur Abadie, Rec. p. 239, concl. Henry.

76 BORDEREAUX Laurent et BRAUD Xavier, Droit du littoral, Paris, Coll. Master Pro, Gualino, 2009, p. 204. 
Toutefois, la nature du diplôme préparé, un doctorat en droit, incline à privilégier l'approche juridique. Cette approche sera l'occasion d'analyser non seulement le corpus juridique applicable au PAA, mais aussi d'apprécier son adaptation à la réalisation des missions dévolues audit port. Il est clair que l'adoption du statut juridique du PAA ne constitue pas une fin en soi. Ce statut est plutôt un levier au service de l'action politique des gouvernants en vue de leur permettre de réaliser l'objectif de développement de la Côte d'Ivoire. Ainsi, se pose, eu égard du libellé du sujet, une multitude de questions parmi lesquelles trois constitueront notre problématique.

Avant de formuler les interrogations constituant notre problématique, il importe avant tout de clarifier un point, celui relatif à la pertinence de l'étude consacrée au statut juridique du PAA. En d'autres termes, pourquoi doit-on analyser le statut juridique du PAA ? Cette question est loin d'être anodine. Elle se justifie, au contraire, si l'on s'en tient à l'absence, jusqu'ici, d'une étude (académique) systématique et actuelle portant exclusivement sur la consistance et la pertinence dudit statut. Il en résulte que la présente étude se présente quelque peu comme une œuvre de pionnier qui, à n'en point douter, pourra être amendée voire améliorée par d'autres travaux plus poussés que les nôtres.

Cette précision étant faite, il importe de recentrer notre problématique en formulant les interrogations qui la constituent :

La première interrogation porte sur l'adaptabilité du statut juridique du PAA à un environnement de vive concurrence interportuaire en Afrique de l'ouest. Autrement dit, le statut juridique actuel du PAA lui permet-il de faire face à la vive concurrence entre les ports de la façade atlantique de l'Afrique?

La deuxième interrogation est relative à la consistance et à l'incidence de la législation communautaire $^{77}$ sur le fonctionnement du PAA. Cette interrogation met en relief, sous certains aspects, le déplacement du centre de décision en matière d'exploitation portuaire. En effet, la législation communautaire - adoptée par des instances autres que les autorités ivoiriennes pour régir le Port - définit, au regard de certains textes juridiques, les règles d'organisation et de fonctionnement des ports autonomes de l'espace inclus respectivement dans l'UEMOA et l'OHADA La législation portuaire édictée par les instances communautaires de l'UEMOA et de l'OHADA n'entre-t-elle pas en conflit avec les règles juridiques adoptées par les autorités ivoiriennes?

Enfin, ce statut juridique est-il adapté à l'heure actuelle eu égard au recours grandissant aux concessions (à objet complexe) ${ }^{78}$ faisant davantage intervenir des sociétés privées dans l'exploitation du Port ? En d'autres termes, les normes statutaires unilatéralement définies par l'État ivoirien n'entrent-elles pas en conflit avec le mode concessif auquel recourt de plus en plus le gestionnaire du port d'Abidjan?

L'ensemble des interrogations ci-dessus posent, en filigrane, la question de l'adéquation des normes juridiques régissant le Port autonome d'Abidjan avec la volonté des autorités étatiques ivoiriennes de hisser le Port autonome d'Abidjan comme un port incontournable de la façade atlantique de l'Afrique et, partant, de le positionner au premier niveau africain.

À la série d'interrogations ci-dessus, il est possible de dégager une hypothèse de travail dont la pertinence sera présentée dans un plan cohérent.

77 Sont ici visées la législation pertinente de l'UEMOA et celle de l'OHADA, les deux organisations supranationales dont est membre la République de Côte d'Ivoire.

78 Une concession à objet multiple peut être définie comme un contrat portant occupation du domaine public portuaire ouvert à toute autre qualification spéciale car combinant plusieurs objets. A priori, ces contrats d'occupation du domaine public sont signés par les autorités portuaires en Côte d'Ivoire avec des partenaires privés pour atteindre trois objectifs majeurs : valoriser le domaine public portuaire, équiper et accroître la performance des installations portuaires et finalement positionner la Côte d'Ivoire comme un hub portuaire en Afrique de l'ouest. Cf. ABA Séka Clément, Contribution à l'étude juridique des concessions portuaires, Paris, L'Harmattan, 2015, p. 419. 


\section{HYPOTHÈSE DE TRAVAIL ET ANNONCE DU PLAN}

L'analyse minutieuse du statut juridique du PAA permet de formuler des réponses aux interrogations ci-dessus. De prime abord, il est clair que la pertinence de la présente étude, ainsi qu'il a été souligné plus haut, ne saurait valablement être contestée : elle vient combler quelque peu la faiblesse des publications scientifiques, en la matière.

Relativement à la première interrogation, celle de l'adaptabilité du statut juridique au contexte de vive concurrence interportuaire, il est indéniable que le recentrage du PAA sur les activités de réglementation et la concession de l'exploitation aux personnes de droit privé a, jusqu'ici, eu un effet bénéfique sur la compétitivité du PAA par rapport aux autres ports de la façade atlantique de l'Afrique. Cependant, nous sommes d'avis qu'il serait possible, pour la Côte d'Ivoire, de tirer davantage de bénéfices si l'on parvenait à impliquer les personnes morales de droit public ivoirien dans la gestion du Port d'Abidjan ${ }^{79}$. Cette implication emprunterait les traits d'une inclusion desdites personnes morales dans le capital du PAA en vue d'étendre considérablement l'assiette de leurs ressources.

En outre, le recours grandissant à la technique moderne des concessions (à objet complexe) se justifie pleinement au regard de la configuration actuelle des contrats administratifs - dans le cadre du partenariat public-privé - par lesquels l'État ivoirien transfère substantiellement la réalisation d'ouvrage public ou l'exécution de missions de service public à des personnes privées qui en supportent totalement ou presque le financement ${ }^{80}$.

L'avantage des concessions à objet complexe réside, en ce qui concerne l'État, dans le fait qu'elles permettent de surmonter l'écueil que constitue l'insuffisance des ressources financières de l'État, personne publique propriétaire du port d'Abidjan. En outre, l'État, le propriétaire du PAA, peut retirer des utilités financières de l'exploitation des ouvrages publics et de l'outillage du port tout en continuant d'assurer - de manière indirecte, il est vrai - sa mission principale qui est celle de satisfaire l'intérêt général. Comme on peut le constater, les concessions à objet complexe permettent à l'État ivoirien à la fois d'accroître la "performance économique du domaine public» et de moderniser les services publics portuaires $^{81}$.

$\mathrm{Au}$ regard de tout ce qui précède, il est possible de soutenir que le statut juridique, d'ailleurs diversifié, du Port autonome d'Abidjan traduit la volonté des autorités ivoiriennes

79 Et même de celui du Port autonome de San Pedro. L'objectif recherché à travers une telle innovation est de transformer particulièrement les collectivités territoriales ivoiriennes en des actionnaires de ces deux entreprises rentables que constituent les Ports autonome d'Abidjan et de San Pedro. Le « retour sur investissement » comme on le pourrait dire prosaïquement ne saurait faire l'ombre d'un doute.

80 Voir, à ce sujet, les modes concessifs de gestion du service public ou des ouvrages publics par les personnes privées tels que cela était prévu par le (défunt) décret n²012-1151 du 19 décembre 2012 relatif aux contrats de partenariats public-privé. Au regard de l'article premier du décret précité, étaient inclus dans les modes concessifs : la concession de service public, le contrat de conception, construction, financement, exploitation; le contrat de construction, exploitation, transfert. Ces deux derniers types de contrat semblent être une nouveauté dans le corpus juridique ivoirien. De manière plus synthétique, le décret $\mathrm{n}^{\circ}$ 2018-358 du 29 mars 2018 définissant les règles relatives aux contrats de partenariats publicprivé définit, en son article 3, les modes concessifs, dans le cadre des contrats de partenariat public-privé. Ce dernier décret, en son article 36, abroge le décret $\mathrm{n}^{\circ}$ 2012-1151 du 19 décembre 2012 relatif aux contrats de partenariats public-privé.

81 «Aujourd'hui, cette assertion traduit avec justesse les préoccupations actuelles des gestionnaires des activités portuaires qui, pour moderniser les services publics et valoriser le domaine public portuaire choisissent de recourir au contrat de concession comme instrument juridique de collaboration avec des investisseurs privés ou publics» (Souligné par nous). Cf. ABA SÉKA Clément, Contribution à l'étude juridique des concessions portuaires, Paris, L'Harmattan, 2015, p. 305. 
d'en faire un outil de développement économique. Cependant, ce statut comporte des limites qui requièrent nécessairement d'être améliorées.

La pertinence de notre hypothèse de travail se vérifiera au moyen de la méthode dialectique. Ainsi, le caractère diversifié et volontariste des normes constitutives du statut juridique du port autonome d'Abidjan ( $1^{\text {ère }}$ partie) ne masque pourtant pas le caractère perfectible dudit statut ( $2^{\text {ème }}$ partie). 



\section{PREMIERE PARTIE : Le caractère diversifié et volontariste des normes constitutives du statut juridique du Port autonome d'Abidjan}

Le statut juridique du PAA, on le rappelle, est constitué d'une diversité et d'une pluralité de normes juridiques. Celles-ci consistent en des normes nationales ivoiriennes puis, en des normes communautaires. Si les premières sont exclusivement le produit de l'activité du législateur ivoirien, les secondes, en revanche, découlent des actes juridiques adoptés par les organes communautaires de l'UEMOA et de l'OHADA. Ainsi, si le statut juridique du PAA relevait initialement de la compétence exclusive du législateur ivoirien (Titre 1), il est actuellement investi par le droit communautaire de l'UEMOA et de l'OHADA (Titre 2). 



\section{TITRE I : UN STATUT JURIDIQUE RELEVANT INITIALEMENT DE LA COMPÉTENCE EXCLUSIVE DU LÉGISLATEUR IVOIRIEN}

La création du PAA résulte d'un acte juridique édicté par les autorités coloniales d'alors en $1950^{82}$. Puis, suivra une multitude de textes juridiques imprimant différentes évolutions statutaires au PAA (Chapitre 1). L'adoption de ces différents textes juridiques s'est accompagnée d'une diversité de missions conférées au PAA (Chapitre 2).

82 La création du Port d'Abidjan s'est effectuée au moyen de l'Arrêté GG nº62-86/TP du 10 novembre 1950 portant organisation et fonctionnement des services du port d'Abidjan à partir du $1^{\text {er }}$ janvier 1951 . 



\section{CHAPITRE 1 : LES ÉVOLUTIONS SUCCESSIVES DU STATUT JURIDIQUE DU PORT AUTONOME D'ABIDJAN}

Le Port autonome d'Abidjan (PAA), dès sa création, est apparu comme une excroissance de l'Administration de la colonie de Côte d'Ivoire. En dépit des ajustements statutaires opérés par la suite, le PAA a été soumis à une gestion centralisée. La nécessité d'accroître les performances du port amène à s'interroger sur une libéralisation progressive de cette gestion. La période de la gestion centralisée du PAA s'est manifestée par la soumission du Port autonome d'Abidjan exclusivement aux règles de droit public (Section 1), même si, par la suite, certains ajustements statutaires sont venus pour en tempérer la rigueur, à travers le recours à un statut juridique mixte (Section 2).

\section{SECTION 1: D'un statut relevant exclusivement du droit public...}

L'acte juridique portant création du Port autonome d'Abidjan (initialement dénommé "Port d'Abidjan ») a fait de cette entité un service spécial maritime dépendant de la Direction générale des Travaux publics. Celui-ci a d'abord fonctionné en régie (paragraphe 1). Par la suite, le législateur ivoirien en fera un établissement public national (paragraphe 2).

\section{Paragraphe 1 : Un service public géré en régie}

Appréhender le fonctionnement du PAA sous la forme de régie nécessite que soit, au préalable, cernée la notion de régie (A). Par la suite, suivra l'application de cette notion au PAA (B).

\section{A. La notion de régie}

Selon le professeur Dégni-Ségui, la régie consiste pour l'Administration à assurer non seulement la direction, mais aussi le fonctionnement du service public ${ }^{83}$. Un service public est géré en régie lorsqu'il est assumé directement par la collectivité publique dont il dépend. Le service n'est de ce fait pas distinct de la collectivité à laquelle il appartient, pour l'État. Celleci assure ainsi intégralement la direction du service et le fait fonctionner avec ses propres moyens budgétaires et humains. Contrairement à l'établissement public, la régie simple ne dispose pas d'une personnalité juridique autonome ${ }^{84}$.

La régie est le mode traditionnel de gestion des services publics et notamment de certains services comme ceux correspondant aux activités régaliennes. Ces services publics ne sont pas dotés de la personnalité juridique. Pourtant, il existe des formes particulières de régies. En

83 DÉGNI-SÉGUI René, Droit administratif général, $3^{\text {ème }}$ édition, Tome $2:$ L'action administrative, CEDA, 2002, p. 394.

84 De VILLIERS Michel et De BERRANGER Thibaut (dir.), Droit public général : Institutions politiques, administratives et européennes, Droit administratif, Finances publiques et droit fiscal, $7^{\mathrm{èm}}$ édition, Paris, LexisNexis, $\mathrm{n}^{\circ} 593$, p. 548 ; CHAPUS René, Droit administratif général, Tome 1, $15^{\text {ème }}$ édition, Paris, Montchrestien, n807, p. 637. 
effet, la gestion d'un service public selon le mode de la régie revêt généralement deux modalités : la régie simple ou directe et la régie intéressée ${ }^{85}$.

La régie directe est un mode de gestion d'un service public assuré directement par la personne publique dont dépend ce service avec son personnel et ses moyens matériels et financiers ${ }^{86}$. Il en résulte que dans le cadre de la régie directe, la gestion du service public est assurée par la collectivité publique elle-même avec ses propres moyens. Le service n'a aucune autonomie financière. Il n'a pas d'organe de gestion, ni de personnalité juridique propre. En cas de litige avec un tiers, c'est la responsabilité de la collectivité publique dont relève le service qui est engagée.

La régie intéressée, malgré le nom de régie, est le mode de gestion d'un service public par une personne privée, qui ne supporte pas les pertes éventuelles du service et qui est rémunérée par la collectivité publique sous la forme d'une participation au chiffre d'affaires ou aux bénéfices, la collectivité bénéficiant du reste des bénéfices ${ }^{87}$.

\section{B. L'application de la notion au Port d'Abidjan}

Suite à l'ouverture du Canal de Vridi en juillet 1950, le Port d'Abidjan a été créé officiellement par l'arrêté $\mathrm{n}^{\circ} 62-86 / \mathrm{TP}$ du 10 novembre 1950 portant organisation et fonctionnement de ses services, à partir du $1^{\mathrm{er}}$ janvier 1951.

Sur le fondement de l'acte juridique l'instituant, le Port d'Abidjan a fonctionné comme un service spécial maritime dépendant de la Direction générale des Travaux publics.

$\mathrm{Au}$ regard des types de régie définies ci-dessus, il apparait que le Port d'Abidjan n'était nullement géré par une personne de droit privé. Il était plutôt un bourgeonnement du ministère des Travaux publics. À ce titre, le Port d'Abidjan revêtait incontestablement la nature juridique d'une régie directe ${ }^{88}$.

À partir de 1960, il a connu une série de réformes motivées par la recherche constante de compétitivité et d'efficacité. Cela s'est traduit par sa transformation en établissement public.

\section{Paragraphe 2 : Une transformation en établissement public}

La loi ${ }^{\circ} 60-85$ du 10 février 1960 se caractérisait par une absence de précision sur la catégorie d'établissement public ${ }^{89}$ dont relevait le port d'Abidjan (A). En revanche, la loi

85 DÉGNI-SÉGUI René, Droit administratif général, 3 ème édition, Tome $2:$ L'action administrative, CEDA,

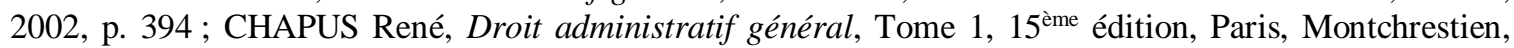
2001, n॰807, p. 637.

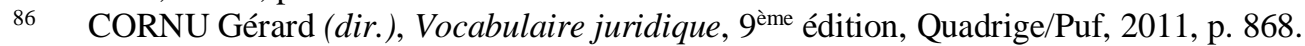

87 GUILLIEN Raymond et VINCENT Jean (dir.), Lexique des termes juridiques, 12 ème édition, Dalloz, 1999, p. 447

88 Ce constat est mutatis mutandis corroboré par le professeur Djé Bi Djè qui soulignait que le Port d'Abidjan, bien qu'ayant été par la suite érigé en EPIC, continuait cependant de fonctionner comme un service en régie: "le Port autonome d'Abidjan, l'Office des postes et télécommunications, la Radio télévision ivoirienne, qualifiés d'établissements publics industriels et commerciaux avaient une autonomie très limitée et fonctionnaient plutôt comme des services en régie ». Cf. DJÈ Bi DJÈ Christiane, « La réorganisation du secteur public en Côte d'Ivoire : La réforme du 13 septembre 1980 », RID 1986, $n^{\text {os }} 1-2$, p. 19.

89 Dans la conception classique, un établissement public est un service public doté de la personnalité morale.

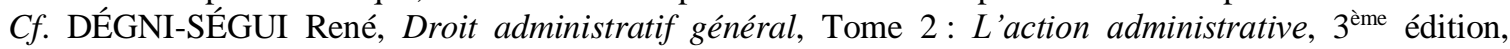
CEDA, 2003, p. 396 ; LOMBARD Martine et DUMONT Gilles, Droit administratif, 9ème édiction, Paris,

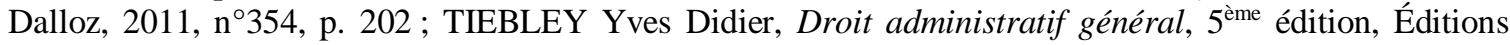
ABC, 2017, pp. 87-88. D'ailleurs, l'article premier de la loi du 2 juillet 1998 définit l'établissement public national comme une "personne morale de droit public créée par l'État, disposant de l'autonomie 
n70-726 du 31 décembre 1970 indique clairement le caractère industriel et commercial de l'établissement public qu'est le Port d'Abidjan (B).

\section{A. Le caractère imprécis de la catégorie d'établissement public}

En dépit du silence de la loi $n^{\circ} 60-85$ du 10 février 1960 sur la catégorie d'établissement public $^{90}$ dont relevait le port d'Abidjan, celui-ci présentait les caractéristiques d'un "service public à double visage ».

En effet, aux termes de l'article premier de la loi nº6-85 du 10 février 1960, «Il est créé un établissement public investi de la personnalité civile et soumis aux règles générales qui régissent la gestion des deniers publics, notamment à celles de la loi organique du 31 décembre 1959, relative aux lois de finances pour assurer l'administration et l'exploitation $d u$ port d'Abidjan et de ses accès et dépendances, y compris la station de pilotage, les feux et balises et le phare de Port-Bouët, ainsi que la gestion de son domaine et les études et les travaux de construction, de réparation et d'entretien des ouvrages ».

Comme soulignée plus haut, la disposition précitée ne précise nullement la catégorie juridique dont relève le nouvel établissement public. Cependant, il est possible d'affirmer, au regard des articles premier et 3 de la loi précitée, que le nouvel établissement créé exploite à la fois un service public administratif et un service public industriel et commercial. Il est, en effet, possible qu'un établissement public gère à la fois un service public administratif et un service public industriel et commercial : on parle alors, d'établissement public à "double visage».

Relativement à sa mission de service public administratif, au regard de l'article premier mentionné ci-dessus, le nouvel établissement public dénommé "Port d'Abidjan » assure la conservation des dépendances du domaine public et privé de l'État qui lui est affecté ${ }^{1}$. Dès lors, le Port d'Abidjan se trouve investi d'une mission de service public administratif ainsi que le précise la jurisprudence du Conseil d'État (français) dans une situation similaire, celle de l'affaire Sieur Abadie ${ }^{92}$.

Concernant l'exploitation d'un service public industriel et commercial, cela découle de la lecture de l'article 3 de la loi précitée du 10 février 1960. En effet, sur le fondement de l'article 3, l'établissement public dénommé Port d'Abidjan est prévu être financé au moyen

financière, dont l'objet exclusif et spécialisé est de remplir une mission de service public, en suivant les règles adaptées à sa mission, et comportant des contraintes et des prérogatives de droit public ».

90 Dans la conception classique, un établissement public est un service public doté de la personnalité morale.

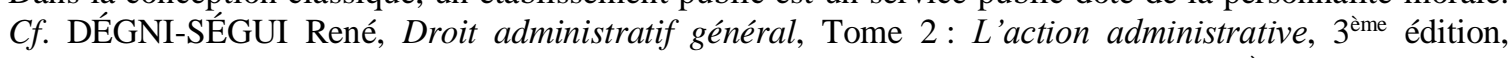
CEDA, 2003, p. 396 ; LOMBARD Martine et DUMONT Gilles, Droit administratif, 9 ème édiction, Paris, Dalloz, 2011, n³54, p. 202 ; TIEBLEY Yves Didier, Droit administratif général, $5^{\text {ème }}$ édition, Éditions ABC, 2017, pp. 87-88. D'ailleurs, l'article premier de la loi du 2 juillet 1998 définit l'établissement public national comme une "personne morale de droit public créée par l'État, disposant de l'autonomie financière, dont l'objet exclusif et spécialisé est de remplir une mission de service public, en suivant les règles adaptées à sa mission, et comportant des contraintes et des prérogatives de droit public ».

91 Il importe de souligner que le Port d'Abidjan, n'était pas le propriétaire des dépendances qui ont été affectées à sa mission, ainsi que l'indique l'article $2 \S 2$ de la loi précitée du 10 février 1960. En effet, en vertu de l'article $2 \S 2$, «Le port et ses dépendances continuent à faire partie du domaine public et du domaine privé de l'État».

92 Dans l'affaire Sieur Abadie, le Conseil d'État a considéré que le Port autonome de Bordeaux assure, d'une part, l'aménagement, l'entretien et la police des accès des ouvrages du Port ; qu'il a la charge de maintenir cette partie du domaine public de l'État à la disposition des usagers dudit domaine conformément à la destination de celui-ci ; qu'il dispose, pour ce faire, de recettes fiscales et éventuellement, de subventions de l'État; que le service ainsi géré présente, tant à raison de son objet que des ressources qui lui sont affectées, le caractère d'un service administratif. Cf. CE Sect. 17 avril 1959, Sieur Abadie, Rec. 239, Concl. Henry. 
« des droits de quai et des taxes de péages qui peuvent être institués par décret et recouvrés dans le port et à son profit $»^{93}$.

Il résulte de tout ce qui précède que la catégorie juridique de l'établissement public dénommé Port d'Abidjan n'était nullement précisée par la loi du 10 février 1960. Il n'empêche que celui-ci a été investi d'une mission de " service public à double visage " ${ }^{94}$.

En revanche, la loi no70-726 du 31 décembre 1970 indique clairement le caractère industriel et commercial de l'établissement public qu'est le Port d'Abidjan.

Avant l'édiction du décret $n^{\circ} 92-940$ du 23 décembre $1992^{95}$, le PAA était un établissement public industriel et commercial (EPIC) institué par la loi nº70-726 du 31 décembre 1970 portant loi de finances pour la gestion 1971 et régi par la loi n80-1070 du 13 septembre $1980^{96}$.

La loi de finances du 13 décembre 1970 ne précisait pas si l'EPIC dénommé Port d'Abidjan était habilité à effectuer des actes de commerce. La clarification sur cette question a été apportée, une décennie plus tard, par la loi précitée du 13 septembre 1980. En effet, cette loi ne prévoyait pratiquement aucun élément de gestion privée en faveur des établissements publics industriels et commerciaux. Au regard de l'article 20 de la loi du 13 septembre 1980, les EPIC n'ont pas la qualité de commerçant, ils sont soumis aux règles de la comptabilité publique. Les quelques assouplissements à ce régime sont très minimes et se présentent comme des exceptions confirmant la règle : par exemple, ils peuvent être soustraits aux règles de la comptabilité publique par décret ${ }^{97}$.

\section{B. La précision sur le caractère industriel et commercial de l'établissement public}

La précision apportée à la catégorie dont relève désormais le Port d'Abidjan découle d'un acte juridique (1). Elle déploie des effets juridiques (2).

\section{Le fondement juridique de l'érection du Port en EPIC}

La catégorie dont relève l'établissement public dénommé Port d'Abidjan a été précisée au moyen de la loi nº70-726 du 31 décembre 1970 portant loi de finances pour la gestion 1971.

93 Ce mode de financement est similaire à celui du Port autonome de Bordeaux tel que l'a relevé le Conseil d'État dans l'affaire Sieur Abadie. Selon la haute juridiction, "Considérant que le Port autonome assure, d'autre part, l'exploitation de l'outillage public du Port; que les prestations ainsi fournies aux usagers sont rémunérées par des redevances dont le montant est fixé par délibération du conseil d'administration du Port; que le service ainsi géré présente, tant à raison de son objet que de ses ressources, le caractère d'un service industriel et commercial... ». Cf. CE Sect. 17 avril 1959, Sieur Abadie, Rec. 239, Concl. Henry.

94 Sur la théorie du service public à double visage, il est possible de se référer, entre autres, à certaines

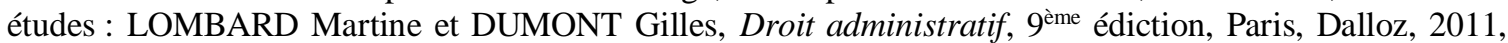
n 358, p. 204 ; LACHAUME Jean-François, « Brèves remarques sur les services publics à double visage », RFDA, 2003, p. 362 et ss.

95 Décret n92-940 du 23 décembre 1992 portant transformation du Port autonome d'Abidjan en société d'État, JORCI n8, 25 février 1993, p. 159 et ss.

96 Loi $\mathrm{n}^{\circ} 80-1070 \mathrm{du} 13$ septembre 1980 fixant les règles générales relatives aux établissements publics nationaux et portant création de catégories d'établissements publics.

97 En vertu de l'article 5 de la loi du 13 septembre 1980 qui dispose : "sauf dérogation accordée par décret, l'établissement public est soumis à l'ensemble des règles de la comptabilité publique ». Il est également possible de se référer, à ce sujet, à l'article de doctrine du professeur Djè Bi Djè. Cf. DJÈ Bi DJÈ Christiane, « La réorganisation du secteur public en Côte d'Ivoire : La réforme du 13 septembre 1980 », RID 1986, $\mathrm{n}^{\text {os }} 1-2$, p. 49. 
Aux termes de l'article premier de ladite loi, « ̀̀ compter du $1^{\text {er }}$ janvier 1971, le Port d'Abidjan est érigé en établissement public à caractère industriel et commercial, doté de la personnalité morale et de l'autonomie financière, placé sous la tutelle technique et administrative du ministre des travaux publics et des transports et sous la tutelle financière du ministre de l'économie et des finances ».

Cette disposition laisse transparaître les éléments caractéristiques de l'établissement public : à savoir la personnalité juridique (distincte de l'État), l'autonomie financière et la mission spéciale à elle confiée.

Contrairement à la loi $\mathrm{n}^{\circ} 60-85$ du 10 février 1960 portant création d'un établissement public qui prendra le nom de "Port d'Abidjan », le caractère industriel et commercial du Port d'Abidjan est nettement précisé dans la loi précitée du 31 décembre 1970. Cependant, le caractère industriel et commercial conféré au Port d'Abidjan ne saurait nullement occulter la gestion par celui-ci, à la fois, d'un service public administratif et d'un service public industriel et commercial.

Cela découle d'un constat :

- D'une part, le Port d'Abidjan exploite l'outillage, les quais et autres dépendances du domaine public étatique qui lui a été concédé, en vue d'en retirer des utilités financières ;

- D'autre part, il est chargé d'exercer la police de la conservation des dépendances domaniales. Ce faisant, le Port d'Abidjan veille non seulement à l'intégrité des dépendances domaniales qui lui ont été affectées par l'État mais s'assure également du maintien de son affectation.

En vue d'accroître les performances du PAA, le législateur ivoirien interviendra pour procéder à un ajustement statutaire par lequel il transformera ledit en une personne morale de droit privé soumise à un statut juridique mixte.

\section{Les implications juridiques de la transformation du Port en EPIC}

En dépit de sa transformation en EPIC, le Port d'Abidjan n'était pas habilité à effectuer des actes de commerce. Cette interdiction formelle connaissait toutefois une atténuation à travers la possibilité reconnue aux EPIC de recourir au crédit et d'accepter des effets de commerce $^{98}$.

Il n'empêche que certaines règles strictes régissant les établissements publics nationaux étaient de nature à amoindrir la compétitivité du PAA. En témoigne la rigidité des normes fiscales, comptables voire budgétaires appliquées aux établissements publics nationaux (EPN) et, singulièrement, aux EPIC. Cela transparait de la lecture des articles 5 à 9 et 12 à 15 de la loi n80-1070 du 13 septembre 1980. De l'analyse des textes précités, il appert que les EPN, y compris les EPIC, sont astreints aux procédures de passation des marchés publics (article 6), à l'obligation de déposer leurs disponibilités auprès du Trésor ou de la Caisse autonome

98 Sur le fondement respectif de l'article 22 f) de la loi n80-1071 du 13 septembre 1980 fixant les règles générales relatives aux établissements publics nationaux et portant création de catégories d'établissements publics; et de l'article 40 du décret n81-137 du 18 février 1981 portant régime financier et comptable des établissements publics nationaux. Selon l'article 22 f) de la loi du 13 septembre 1980, «les ressources des établissements publics à caractère industriel et commercial sont constituées [...] des produits de leurs emprunts dans les conditions fixées par décret ». Au regard de l'article 40 du décret précité du 18 février 1981, "seuls les établissements publics à caractère industriel et commercial peuvent accepter un effet de commerce en règlement d'une créance. Ce mode de règlement doit avoir recueilli l'accord préalable de l'Ordonnateur ». 
d'amortissement (CAA) ${ }^{99}$ (article 10). En outre, les excédents des ressources EPN, y compris les EPIC, sont versés en fin d'exercice, après approbation des comptes, à un compte ouvert dans les écritures du Trésor et dont les modalités de fonctionnement sont fixées par décret (article 11). Enfin, les EPN sont soumis au même régime fiscal et douanier que les services administratifs de l'État (article 12).

Le contrôle minutieux, très minutieux, découlant de la loi du 13 septembre 1980 visait indéniablement à minimiser le plus possible les déprédations et déperditions des deniers publics constatés dans la gestion des sociétés d'État. Aussi, la loi du 13 septembre 1980 procédait-elle de la volonté de l'État de mieux contrôler les entreprises publiques. À ce sujet, le professeur Djé Bi Djè note: "Par cette réforme, l'État ne manifeste pas la volonté de retrait du domaine économique, mais plutôt, la volonté de mieux contrôler le secteur public. En transformant nombre de sociétés d'État en établissements publics industriels et commerciaux, il renforce sa tutelle sur ces établissements ${ }^{100 .}$.

Cependant, le début de la décennie 90, verra le législateur ivoirien emprunter une nouvelle orientation en soumettant le PAA à un régime de droit privé, par sa transformation en une société d'État, une société de forme commerciale. Cette tendance sera confortée en 2001 par l'édiction du décret $n^{\circ} 2001-143$ du 14 mars 2001 portant approbation des Statuts du Port autonome d'Abidjan (PAA) et reclassification des immobilisations concédées.

\section{SECTION 2 : ... À un statut juridique mixte}

Cet ajustement s'est traduit par la soumission (partielle, il est vrai) du Port d'Abidjan à un statut de droit privé à travers sa constitution sous la forme d'une société d'État (paragraphe 1). Cette transformation statutaire emporte des implications juridiques (paragraphe 2).

\section{Paragraphe 1 : La constitution du Port sous la forme d'une société d'État}

En 1992, le législateur ivoirien a procédé à une transformation statutaire du Port d'Abidjan - désormais dénommé Port autonome d'Abidjan. Désormais, le Port autonome d'Abidjan devient une société d'État. La société d'État est une notion spécifique au droit ivoirien (A). Le Port autonome d'Abidjan a été érigé en société d'État sur le fondement du décret du 23 décembre $1992^{101}$ (B).

\section{A. Notion de société d'État en droit ivoirien}

Le législateur ivoirien a créé une catégorie spécifique de société anonyme, la société d'État, au moyen de la loi n97-519 du 4 septembre 1997 portant définition et organisation des sociétés d'État ${ }^{102}$. La société d'État jouit de la personnalité morale à dater de son

99 Organisme financier incontournable dans le développement économique de la Côte d'Ivoire, la Caisse autonome d'amortissement (CAA) est devenue, le 19 février 2004, la Banque nationale d'investissement (BNI). Cette dernière est une société d'État régie par la loi n $97-519$ du 04 septembre 1997 et le décret n98-11 du 14 janvier 1998 tel que modifié par le décret n²004-188 du 19 février 2004. La BNI a depuis 2004 un capital de 20,5 milliards détenu par l'État de Côte d'Ivoire.

100 DJÈ Bi DJÈ Christiane, «La réorganisation du secteur public en Côte d'Ivoire : La réforme du 13 septembre $1980 », R I D 1986, \mathrm{n}^{\text {os }} 1-2$, p. 86.

101 Décret n92-940 du 23 décembre 1992 portant transformation du Port autonome d'Abidjan en société d'État.

102 Loi n97-519 du 4 septembre 1997 portant définition et organisation des sociétés d’État, JORCI n40, 2 octobre 1997, p. 1060 et ss. En vertu de l'article 5 de la loi précitée, la société d'État est créée par décret 
immatriculation au registre du commerce ${ }^{103}$. Toute modification statutaire (fusion, scission, transformation, dissolution) est décidée par décret pris en conseil des ministres ${ }^{104}$. Selon l'article 4 de la loi n ${ }^{\circ}$ 7-519 précitée, la société d'État est une personne morale de droit privé, commerciale par sa forme. À ce titre, elle est régie, à titre principal, par la loi nº97-519 et, à titre subsidiaire, par les dispositions législatives et réglementaires applicables aux sociétés commerciales pourvu que celles-ci ne soient pas contraires aux dispositions de la loi précitée et des décrets pris pour son application ${ }^{105}$.

En tant que société de forme commerciale, la structure de la société d'État devrait se rapprocher de la société anonyme. À ce titre, elle devrait, en principe, revêtir une structure tripartite, à savoir: une Assemblée générale, un Conseil d'administration, une Direction générale $^{106}$. Cependant, le chapitre III de la loi $n^{\circ} 97-519$ du 4 septembre 1997 (particulièrement les articles 14 à 25) ne prévoit que deux organes, à savoir le Conseil d'administration et la Direction générale.

Le Conseil d'administration comprend trois (3) membres, au moins, et douze (12) membres, au plus. Quand plusieurs personnes publiques sont actionnaires, le nombre de représentants au Conseil d'administration est proportionnel à leur participation (article 14). Les membres du Conseil d'administration sont nommés et révoqués par décret pris en conseil des ministres. Leur mandat est de 3 ans renouvelables deux fois, au maximum. Nul ne peut appartenir simultanément au Conseil d'administration de plus de deux sociétés d'État (article 15). Le Conseil d'administration élit un président. Cette élection est entérinée par décret (article 17). Il dispose des pouvoirs les plus étendus pour agir au nom de l'État dans la limite de l'objet social (article 18).

À la tête de la direction générale se trouve un directeur général. Il est nommé et révoqué par le Conseil d'administration (article 23). Il s'agit d'une grande innovation qui confère un véritable pouvoir au Conseil d'administration. Les fonctions de directeur général peuvent provisoirement être confiées au président du Conseil d'administration. Dans ce cas, il porte le titre de président directeur général (PDG). Les fonctions du PDG prennent fin à compter de la nomination d'un nouveau directeur général (article 23).

Le directeur général représente la société d’État dans ses rapports avec les tiers. Ses pouvoirs sont fixés et délégués par le Conseil d'administration (article 25). Toute convention passée entre la société d'État et le directeur général ou tout autre administrateur doit recueillir l'autorisation préalable du Conseil d'administration (article 26).

\section{B. Le fondement juridique de la transformation du Port en société d'État}

La transformation du PAA en société d'État a résulté, dans un premier temps, du décret $\mathrm{n}^{\circ} 92-940$ du 23 décembre 1992 portant transformation du Port autonome d'Abidjan en société d'État, puis du décret n²001-143 du 14 mars 2001 portant approbation des Statuts du Port autonome d'Abidjan (PAA) et reclassification des immobilisations concédées ${ }^{107}$.

pris en conseil des ministres. Le décret approuve les statuts de la société qui énoncent la durée de la société, l'objet, la raison sociale, le siège, etc.

103 Article 3 de la loi n $97-519$ du 4 septembre 1997 portant définition et organisation des sociétés d'État.

104 Article 51.

105 Article 3 de la loi n97-519 du 4 septembre 1997 portant définition et organisation des sociétés d'État.

106 C'était le cas des sociétés d'État avant l'adoption de la loi n97-519 du 4 septembre 1997 portant définition et organisation des sociétés d'État. Le conseil de surveillance tenait lieu d'assemblée générale. Mais, il n'en existait pas dans toutes les sociétés d'État; cette pratique avait été légalisée par une loi du 28 juillet 1987. Par ailleurs, une assemblée générale n'a guère de signification quand le seul actionnaire de la société d'État est l'État.

107 Ces deux décrets ont été publiés respectivement au JORCI n8, 25 février 1993, p. 159 et $s s$ (en ce qui concerne le décret du 23 décembre 1992) et JORCI $n^{\circ} 17,26$ avril 2001, p. 313 et ss (en ce qui concerne le décret du 14 mars 2001). 
Au regard de l'article premier de ses statuts tels qu'approuvés par le décret du 14 mars 2001 précité, le PAA est une société commerciale par sa forme. Au regard de cette disposition, "le Port autonome d'Abidjan est une société d'État [...] régie par la loi $n^{\circ} 97-$ 519 du 4 septembre 1997 portant définition et organisation des sociétés d'État et ses décrets d'application, par les dispositions de l'Acte uniforme relatif au Droit des sociétés commerciales et du Groupement d'intérêt économique, ainsi que les présents statuts».

Cette disposition, on le voit, soumet le PAA au droit commercial, en général, précisément au droit de l'OHADA Cela emporte des implications juridiques.

\section{Paragraphe 2: Les implications juridiques de la nouvelle nature juridique du Port}

Désormais, le PAA est soumis aux normes du droit commercial (A). On note cependant la persistance d'une marge incompressible du droit administratif applicable au PAA (B).

\section{A. La soumission aux normes du droit commercial}

La soumission de la société d'État au droit commercial résulte de la combinaison de trois dispositions de la loi du 04 septembre 1997 sur les sociétés d'État.

Selon l'article 3 § 2 de ladite loi : «À titre subsidiaire, la société d'État est régie par les dispositions législatives et réglementaires applicables aux sociétés commerciales en ce que ces dispositions ne sont pas contraires aux dispositions de la présente loi et les décrets pris pour son application ».

Il importe ici de relever la restriction apportée à la soumission de la société d'État au droit commercial. En effet, son capital étant détenu exclusivement par une personne morale de droit public, le régime juridique de cette catégorie de société comporte inévitablement une dose incompressible de prérogatives de puissance publique qui, nécessairement, la soustrait aux voies d'exécution et autres procédures contraignantes applicables aux sociétés commerciales.

À l'article $3 \S 2$ précitée, s'ajoute une autre plus précise qui fait de la société d'État une entité juridique de forme commerciale. Ainsi, en vertu de l'article $4 \S 1$ de la loi précitée de 1997, "la société d'État est une personne morale de droit privé, commerciale par sa forme».

Tirant la conclusion de cette disposition, l'article $6 \S 1$ de ladite loi exige de procéder à l'immatriculation au registre du commerce de la société d'État. L'accomplissement de cette formalité conditionne l'obtention de la personnalité juridique par la société d'État ${ }^{108}$. Ainsi, l'absence d'immatriculation au registre du commerce de l'entité concernée entraine son inexistence juridique.

À ces trois dispositions soumettant le PAA au droit commercial s'ajoute l'Acte uniforme révisé relatif au droit des sociétés commerciales et du groupement d'intérêt économique (ciaprès AUSCGIE). Selon l'article premier dudit Acte, "toute société commerciale, y compris celle dans laquelle un État ou une personne morale de droit public est associé, dont le siège social est situé sur le territoire de l'un des États parties au Traité relatif à l'harmonisation du droit des affaires en Afrique [...] est soumise aux dispositions du présent Acte uniforme ».

108 «La société d'État jouit de la personnalité morale à dater de son immatriculation au registre du commerce » (Article $6 \S 1)$. 
Cette disposition prévoit, en son alinéa 3, la possibilité de son application combinée avec le droit commercial généré par le législateur de chaque État membre dès lors que ce droit national n'est pas incompatible avec les dispositions de l'AUSCGIE ${ }^{109}$.

\section{B. La persistance d'une marge incompressible de droit public}

La soumission du PAA aux normes du droit privé, particulièrement aux règles du droit commercial, ne signifie nullement que celui-ci soit totalement soustrait aux règles de la domanialité publique. En effet, le contentieux des contrats comportant occupation privative du domaine public portuaire établit la soumission de tels contrats aux règles du droit administratif. Ainsi, dans l'affaire Port autonome d'Abidjan c/ Entreprise Graviers et Sables (EGS), la Chambre administrative de la Cour suprême a considéré que de tels contrats, selon le décret-loi du 17 juin 1938 sont des contrats administratifs ${ }^{110}$. Il s'ensuit, selon la Chambre administrative, que le contentieux découlant de ces contrats doit être soumis aux normes de droit administratif en dépit de la nature juridique du PAA, une personne morale de droit privé $^{111}$. Dans ce cas, l'application du droit administratif se fera, en cassation, par la Chambre judiciaire de la Cour suprême ${ }^{112}$. La compétence de la Chambre judiciaire, en lieu et place de la Chambre administrative se fonde sur une disposition du Code de procédure civile, commerciale et administrative (CPCCA). Selon l'article 54 de la loi nº4-440 du 16 août 1994 relative à la Cour suprême, la Chambre administrative est compétente pour connaître en cassation des décisions rendues en dernier ressort dans les procédures où une personne morale de droit public est partie ${ }^{113}$. Il s'ensuit que si le litige oppose uniquement des personnes de droit privé, seule la Chambre judiciaire de la Cour suprême sera compétente pour statuer en cassation. Il convient cependant de relativiser la portée de l'article 54 du CPCCA qui attribue compétence à la Chambre judiciaire de la Cour suprême pour connaître du contentieux relatif à l'occupation privative du domaine public lorsque le litige oppose deux personnes juridiques de droit privé. En effet, l'article 55 de l'Ordonnance du 03 août 2016 investit la Chambre administrative de la Cour suprême de la compétence exclusive pour connaître du contentieux de l'occupation privative du domaine public quand bien même qu'une personne morale de droit public ne serait pas partie au procès ${ }^{114}$. Il est fait ici application du principe lex posterior derogat priori.

109 Selon l'article $1^{\mathrm{er}}$ alinéa 3 de l'AUSCGIE, «... les sociétés commerciales et les groupements d'intérêt économique demeurent soumis aux lois non contraires au présent Acte uniforme qui sont applicables dans l'État partie où se situe leur siège social ».

110 «Considérant qu'en statuant comme elle l'a fait, alors que selon le décret-loi du 17 juin 1938 tous les contrats touchant au domaine public sont des contrats administratifs par détermination de la loi... ». CSCA 23 mars 2005, Arrêt n¹4, Port Autonome d'Abidjan c/ Entreprises Graviers et Sables (EGS), req. 2003-453 CASS/AD. De même, dans une autre affaire, la Cour suprême a statué dans le même sens : «Considérant que selon le décret-loi du 17 juillet 1938, tous les contrats portant sur le domaine public portuaire sont administratifs par détermination de la loi ». Cf. CSCA 30 mai 2012, Arrêt n 94 , Port autonome d'Abidjan c/ Sicpro \& autres, req. n²008-347 CIV.

111 "Qu'en vertu des principes généraux de la domanialité publique, le domaine public ne peut faire l'objet de contrats d'occupation relevant du droit privé ». Cf. CSCA 30 mai 2012, Arrêt n94, Port autonome d'Abidjan c/ Sicpro \& autres, req. n²008-347 CIV.

112 «Qu'il s'ensuit qu'au regard du caractère administratif du contrat d'occupation du domaine public à l'origine du litige, le Port Autonome d'Abidjan n'est pas fondé à soutenir que la Cour Commune de Justice et d'Arbitrage (CCJA) est compétente ; Que seule la Chambre Judiciaire doit connaître de ce pourvoi ». Cf. CSCA 30 mai 2012, Arrêt n94, Port autonome d'Abidjan c/ Sicpro \& autres, req. n²008-347 CIV.

113 Loi $\mathrm{n}^{\circ}$ 94-440 du 16 août 1994 relative à la Cour suprême telle que modifiée par la loi $\mathrm{n}^{\circ} 97-243$ du 25 avril 1997.

114 L'article 55 de l'ordonnance $n^{\circ} 2016-588$ du 03 novembre 2016 portant titres d'occupation du domaine public dispose en effet: "Sous réserve de l'épuisement des voies de recours non juridictionnelles, sont portés devant la Chambre administrative de la Cour suprême les litiges relatifs [...] aux autorisations ou 
En outre, le PAA se distingue par le fait qu'en dépit de sa qualité de personne morale de droit privé, il est investi de la compétence pour exploiter et entretenir les installations portuaires, conserver le domaine portuaire contre tout empiètement ou démembrement ${ }^{115}$ ainsi que pour gérer les mouvements des navires qui entrent dans le port ${ }^{116}$.

Ce faisant, il apparaît que le PAA jouit d'une nature juridique hybride : formellement, il est une personne de droit privé mais, matériellement, il fonctionne, au regard de ses attributions, comme une personne morale de droit public.

Il n'empêche que la transformation statutaire du PAA débouche sur une diversité de missions dévolues à celui-ci.

contrats comportant occupation du domaine public, quelle que soit leur forme ou leur dénomination, accordés ou conclus par les personnes morales de droit public ou privé mentionné à l'article 1 ».

115 Article 4 \$ 2 des Statuts du Port autonome d'Abidjan.

116 En vertu du Chapitre III (articles 16 à 50) du décret $n^{\circ} 99-400$ du 21 avril 1999 portant règlement de police du Port autonome d'Abidjan. 


\section{CHAPITRE 2: LA DIVERSITÉ DES MISSIONS DÉVOLUES AU PORT AUTONOME D'ABIDJAN}

À la lecture des statuts du PAA approuvés par le décret n²001-143 du 14 mars 2001, les missions dévolues audit port revêtent deux grandes formes. La première forme d'intervention consiste en une activité de prestation relevant du service public administratif tandis que la seconde forme de prestation s'inscrit dans le cadre d'un service public industriel et commercial. Aussi, note-t-on, d'une part, des attributions relevant d'un service public administratif et qui sont relatives à l'entretien du domaine portuaire et de l'outillage (Section 1) et, d'autre part, des attributions s'inscrivant dans le cadre d'un service public industriel et commercial et qui sont relatives à l'exploitation économique dudit domaine (Section 2).

\section{SECTION 1: L'entretien du domaine portuaire et de l'outillage}

L'analyse de la présente rubrique nécessite que soit, au préalable, cerné la notion de "domaine portuaire» (paragraphe 1). Sur ce domaine et sur l'outillage, le PAA exerce des activités de police (paragraphe 2).

\section{Paragraphe 1 : La notion de domaine portuaire}

Le domaine portuaire n'a pas été défini - du moins selon la méthode conceptuelle - en droit ivoirien (A). Toutefois, cette absence de définition conceptuelle n'empêche qu'il ait une consistance $(\mathrm{B})$.

\section{A. $\quad$ Absence de définition (conceptuelle) du domaine portuaire}

Pour définir le domaine des personnes publiques - singulièrement le domaine public - le législateur ivoirien privilégie la méthode énumérative (1) et opte pour une définition négative ou résiduelle de leur domaine privé (2).

\section{Définition du domaine public au moyen de la méthode énumérative}

Le droit applicable aux dépendances domaniales en République de Côte d'Ivoire se distingue, entre autres, par le fait que le domaine - singulièrement le domaine public - n'ait pas fait l'objet d'une définition conceptuelle. En lieu et place de la définition conceptuelle - le législateur a opté pour une définition par énumération. Ce choix a été amorcé par le décret (colonial) du 29 septembre 1928 portant réglementation du domaine public et des servitudes d'utilité publique en Afrique Occidentale Française, et a été reconduit par plusieurs autres textes juridiques ${ }^{117}$.

117 La méthode énumérative est également décelable, entre autres, à l'article premier de la loi n83-788 du 2 août 1983 déterminant les règles d'emprise et de classement des voies de communication et des réseaux divers de l'État et des collectivités territoriales, à l'article 37 de la loi n96-766 du 3 octobre 1996 portant Code de l'environnement, à l'article 11 de la loi n98-755 du 23 décembre 1998 portant Code de l'eau, à l'article 91 de la loi $\mathrm{n}^{\circ}$ 2012-1128 portant organisation des collectivités territoriales, à l'article 50 de 
Cette lacune est quelque peu décelable en droit français. En effet, la notion de port ellemême est absente de la loi française, tout autant que celle de domaine public portuaire. Seule la délimitation des ports est évoquée à l'article R 151-1 du Code des ports maritimes : "Il est procédé à une délimitation des ports maritimes relevant de la compétence de l'État, du côté de la mer et du côté des terres, par le préfet sous réserve du droit des tiers ${ }^{118}$.

En droit comparé, on note que la législation espagnole, au contraire de celle de la Côte d'Ivoire définit la notion de domaine public portuaire. Cette définition résulte de deux textes juridiques de 1992 et 2003. La loi de 1992 définit très précisément la notion de port maritime, comme un "ensemble maritime comprenant des espaces terrestres, des eaux maritimes et des installations qui, situé sur le littoral maritime ou fluvial, réunit les conditions physiques, naturelles ou artificielles et d'aménagement de nature à permettre la réalisation d'opérations de trafic portuaire, et a été affecté au développement de ces activités par l'administration compétente ${ }^{119}$. "Un port maritime ne peut être qualifié de port de commerce que s'il réunit les conditions techniques, de sécurité et de contrôle administratif indispensables à la réalisation des activités commerciales portuaires ». Les ports maritimes d'intérêt général relèvent tous de l'État, et le territoire affecté aux ports d'intérêt général est intégré au domaine public portuaire de l'État (articles 10 et 14 de la loi de 1992). Enfin, la nature et la composition du domaine public portuaire sont évoquées à l'article 94 de la loi de $2003^{120}$.

Au-delà de l'allusion au droit espagnol, en la matière, l'idée qui prévaut est que la définition énumérative, en droit ivoirien, du domaine public privilégie une approche empirique qui permette de cerner sans aucun doute les composantes dudit domaine. Ce faisant, elle prévient toute polémique éventuelle ou controverse doctrinale relative à la composition de ce domaine. En témoigne l'arrêt de la Chambre administrative de la Cour suprême (CSCA) rendu dans l'affaire Agence de gestion et de développement des infrastructures industrielles dite AGEDI c/ Conservateur de la propriété foncière et des hypothèques de Yopougon 1. Dans cette affaire, l'AGEDI a assimilé la Zone industrielle de Yopougon à une dépendance du domaine en se référant à la définition synthétique du domaine public telle que cela se rencontre en droit français ${ }^{121}$. La Cour suprême a invalidé cette interprétation en soulignant le fait que seule la définition énumérative du domaine public prévaut en droit ivoirien. Aussi, a-t-elle refusé de faire droit aux prétentions de l'AGEDI ${ }^{122}$.

l'ordonnance n²012-293 du 21 mars 2012 relative aux télécommunications et aux technologies de l'information et de la communication.

118 Voir à ce sujet, le mémoire de Julien Rosgovas. $C f$. ROSGOVAS Julien, L'utilisation du domaine public portuaire, Mémoire, Master 2 Droit maritime et des transports, Université Paul Cézanne, Aix Marseille 3, 2005, p. 8

119 Article premier de la Ley 27/1992, du 24 novembre 1992, de Puertos del Estado y de la Marina Mercante.

120 ROSGOVAS Julien, L'utilisation du domaine public portuaire, Mémoire, Master 2 Droit maritime et des transports, Université Paul Cézanne, Aix Marseille 3, 2005, p. 9

121 L'AGEDI prétend que la Zone industrielle est une dépendance du domaine public de l'État ivoirien au regard des conditions suivantes : 1) affectation à l'usage direct du public ou à son service public ; 2) exercice d'un droit de propriété sur le bien par une personne publique ; 3) exigence d'un aménagement indispensable. En filigrane, l'AGEDI reprend à son compte les critères de qualification du domaine public en droit français.

122 Selon la Cour, «Considérant que, contrairement aux moyens invoqués par l'A.G.E.D.I., l'affectation à l'utilité publique ne peut, seule, suffire pour déterminer l'appartenance au domaine public d'un bien domanial de l'État; Qu'en Côte d'Ivoire, le domaine public de l'État est défini par le décret du 29 septembre 1928 susvisé et par des textes législatifs; que les Zones Industrielles ne figurent pas dans l'énumération résultant de ce décret; qu'aucun texte législatif n'a classé les Zones Industrielles dans le domaine public ». Cf. CSCA 27 décembre 2017, AGEDI c/ Conservateur de la propriété foncière et des hypothèques de Yopougon 1. 


\section{La définition négative ou résiduelle du domaine privé}

Au regard de cette méthode de définition, le domaine privé apparait comme une catégorie résiduelle comprenant les biens des personnes publiques non incluses dans leur domaine public. À ce sujet, le professeur Kobo note : "Il n'existe pas de définition légale du domaine privé. Le domaine privé est défini en réalité par opposition au domaine public. Les biens des personnes publiques qui n'appartiennent pas au domaine public font nécessairement partie du domaine privé ${ }^{123}$.

Le recours à la définition résiduelle du domaine privé en droit ivoirien est également relevé par le professeur Mambo dans son Cours de droit administratif général. Il écrit, en effet, "une fois le domaine public défini, le domaine privé ne pose pas de problème quant à sa définition et sa composition. Les biens des personnes publiques qui n'appartiennent pas au domaine public constituent le domaine privé. Il n'existe pas de définition légale du domaine privé, défini en réalité par opposition au domaine public $»^{124}$.

La définition négative du domaine public n'est pas le propre du droit ivoirien. Elle se perçoit également en droit français ${ }^{125}$. Ainsi, le professeur Morand-Deviller écrit : «La définition du domaine privé se présente presque toujours de manière négative et résiduelle : il s'agit de l'ensemble des biens publics qui ne remplissent pas les conditions d'affectation nécessaires à l'appartenance au domaine public. L'article 2 du Code du domaine de l'État, après avoir donné la définition du domaine public, ajoute péremptoire : "les autres biens constituent le domaine privé » ${ }^{126}$.

L'absence de définition conceptuelle du domaine portuaire en droit ivoirien requiert que l'on se penche sur certains textes juridiques particuliers afin de cerner la consistance les dépendances domaniales du PAA.

\section{B. La consistance du domaine portuaire}

Le PAA - initialement dénommé Port d'Abidjan - et ses dépendances font partie intégrante $\mathrm{du}$ domaine public et du domaine privé de l'État ivoirien ${ }^{127}$. Toutefois, ces dépendances domaniales sont concédées au Port d'Abidjan afin de lui permettre d'exercer ses activités relevant de sa mission de service public ${ }^{128}$. Tous les biens et autres éléments d'actif initialement concédés (par l'État au PAA) sont désormais classés comme éléments du patrimoine de la société d'État Port autonome d'Abidjan ${ }^{129}$. Le domaine portuaire se répartit entre le domaine immobilier, inclus dans le domaine public (1) et un ensemble de biens meubles qui, bien que non inclus dans le domaine public, sont nécessaires à l'exploitation dudit domaine. Ces biens meubles sont désignés sous le vocable d'outillage (2).

123 KOBO Pierre-Claver, Droit administratif des biens : Le domaine des personnes publiques, l'expropriation, Abidjan, Éditions ABC, 2004, p. 100.

124 MAMBO Paterne, Cours de droit administratif des biens, inédit, Abidjan, 2018-2019, p. 57.

125 De VILLIERS Michel et De BERRANGER Thibaut (dir.), Droit public général (Institutions politiques,

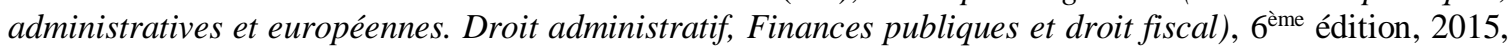

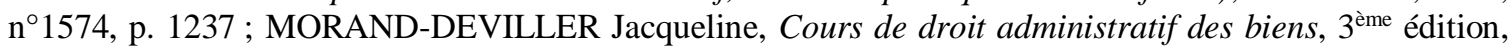
Paris, Montchrestien, 2003, p .324.

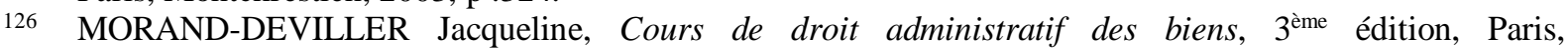
Montchrestien, 2003, p. 324.

127 «Le Port et ses dépendances continuent à faire partie du domaine public et du domaine privé de l'État ». En vertu de l'article $2 \S 2$ de la loi n60-85 du 10 février 1960 portant création d'un établissement public qui prendra le nom de "Port d'Abidjan », JORCI n 15, 20 février 1960, p. 221. Cette disposition est reconduite par l'article $5 \S 2$ des statuts du PAA approuvés par le décret n ${ }^{\circ} 2001-143$ du 14 mars 2001.

128 Sont placés sous le régime de la concession, les terrains du domaine public de l'État et le canal de Vridi (Article $2 \S 1$ du décret $n^{\circ} 2001-143$ du 14 mars 2001).

129 Article $2 \S 2$ du décret $\mathrm{n}^{\circ} 2001-143$ du 14 mars 2001 portant approbation des statuts du Port autonome d'Abidjan (PAA) et reclassification des immobilisations concédées, JORCI n 17,26 avril 2001, p. 313. 


\section{Le domaine immobilier}

Le domaine immobilier se compose de trois zones, à savoir la zone sous douane (a), la zone hors douane (b) et les réserves foncières (c).

\section{a) La zone sous douane}

Cette zone est la frontière maritime du PAA. Elle se trouve dans la barrière douanière et se compose de magasins cales, de terre-pleins, d'espaces banalisés et de terminaux spécialisés (roulier, minéralier, engrais, céréalier ...). Les installations sous douane sont réparties comme suit :

- dix-neuf (19) magasins-cales d'une capacité d'accueil de 106.200 mètres carrés ;

- dix-neuf (19) terre-pleins de première zone d'une superficie totale de 53.792 mètres carrés ;

- $75632 \mathrm{~m}^{2} \mathrm{~d}$ 'espaces non couverts (terre-pleins, terminaux, garage et autres) dont 24.781 mètres carrés ont été réquisitionnés aux fins de construction de cinq (05) nouveaux magasins-cales ;

- le parc UNICAO d'une superficie de 70.032 mètres carrés ;

- 279.934 mètres carrés de terre-pleins pavés au Terminal à conteneurs de Vridi dont 16.143 mètres carrés en graveleux ;

- 65.315 mètres carrés d'un parc à bois débité ;

- un terminal fruitier ce qui a permis au PAA de disposer d'une infrastructure moderne pour le traitement des fruits avec notamment :

- un espace de stockage plus grand ;

- un plus grand tirant d'eau admissible ;

- un mur de quai prolongé permettant d'accueillir simultanément deux (02) navires à quai.

Il est à noter que le PAA traite annuellement près de cinq cent mille (500.000) tonnes de bananes et d'ananas. Au total, la zone sous douane s'étend sur superficie globale de 651.000 mètres carrés d'espace exploitable.

\section{b) La zone hors douane}

Elle est la zone se trouvant en dehors de la barrière douanière se compose de terrains, d'installations et d'infrastructures socio-économiques (parkings pour camions, espaces de restauration communautaire, gargotes...). Quatre cent quatorze (414) permissionnaires de voirie occupent 562 lots d'une superficie de 4.349.467 mètres carrés du domaine portuaire hors douane. 
La consistance du domaine portuaire, singulièrement des réserves foncières, ressort des textes juridiques que sont, respectivement :

- Le décret n60-110 du 16 mars 1960 portant organisation administrative du Port d'Abidjan ${ }^{130}$;

- Le décret n98-151 du 25 mars 1998 portant délimitation des zones d'extension du Port autonome d'Abidjan (Locodjro, Île Boulay, Cordon littoral) ${ }^{131}$.

L'article 2 du décret $n^{\circ} 60-11016$ mars 1960 définit le domaine immobilier du port d'Abidjan comme celui dont le port de commerce d'Abidjan avait antérieurement la gestion. Il en est de même de son domaine mobilier. L'alinéa 3 de l'article 2 avait prévu l'établissement d'un inventaire descriptif des terrains, ouvrages et bâtiments ainsi que du matériel pris en charge. Cet inventaire devrait être divisé en deux parties relatives, la première, au domaine public, la seconde, au domaine privé. En vertu de cette disposition, le gouvernement ivoirien a adopté le plan n ${ }^{\circ} 78-2-009$.

Le décret précité du 25 mars 1998 institue le plan n78-2-009 C. En vertu de l'article premier du décret du 25 mars 1998, le plan $n^{\circ} 78-2-009$ C modifie et remplace le plan $n^{\circ} 78-2$ 009. Sur le fondement de l'article 2 du décret du 25 mars 1998, le nouveau domaine portuaire délimité par le plan n78-2-009 C comprend désormais :

- Le site tel que défini dans le décret nº0-110 du 16 mars 1960 et délimité par le plan $\mathrm{n}^{\circ} 78-2-009$;

- Le site de Locodjro délimité par le plan n91-2-032;

- Le site mis en réserve sur l'Île Boulay, d'une superficie 679 ha 48 a $91 \mathrm{ca}$, compris entre les abscisses 380500 et 389000 d'une part, et les ordonnées 579000 et 582500 d'autre part dans le système de coordonnées du cadastre.

Hormis les sites précités, le patrimoine du PAA comprend des biens meubles que constitue l'outillage.

\section{L'outillage}

Selon le Conseil national de Ressources Textuelles et Lexicales (CNRTL), l'outillage se définit comme «l'ensemble des outils nécessaires à l'exercice d'un métier, d'un travail, à la pratique d'une activité manuelle; ensemble des outils et des machines nécessaires à la marche d'une entreprise, d'une exploitation ${ }^{132}$.

Dans le cas particulier du PAA, l'outillage comprend les engins de manutention et les hangars publics destinés au stockage des marchandises. L'outillage mis à la disposition du PAA par l'État ivoirien peut faire l'objet d'une concession d'outillage public ou d'une autorisation d'outillage privé avec obligation de service public. Ces concessions et

JORCI, n²0, pp. 343 à 348.

JORCI, $n^{\circ} 18$, p. 455.

www.cnrtl.fr>definition>outillage. Définition consultée le 12 décembre 2018. 
autorisations peuvent être accordées tant à des collectivités publiques qu'à des établissements publics et à des entreprises privées ${ }^{133}$.

Hormis les modes traditionnels de concession de l'outillage du PAA, on note de plus en plus la conclusion d'une nouvelle forme de contrat dénommée convention d'exploitation de terminal (CET). Concrètement, il s'agit par ce contrat de confier la gestion d'un terminal spécialisé (comme un terminal à conteneurs) à un opérateur unique : un groupe d'armateurs ou un grand manutentionnaire. Avec ce contrat, l'opérateur unique bénéficie d'une priorité d'utilisation de l'outillage qui lui a été confié, ainsi que des infrastructures correspondantes (tels que les quais afférents). Sur la base de cette nouvelle forme de contrat, l'État ivoirien a confié l'exploitation d'un terminal spécifique à une entreprise privée au moyen d'une CET. En vertu de cette CET, une société privée, la Société d'exploitation du terminal de Vridi (S.E.T.V), s'est vu confier le monopole de la gestion du terminal à conteneurs du PAA.

En vue d'assurer l'intégrité du domaine portuaire, le PAA exerce des activités de police sur ledit domaine.

\section{Paragraphe 2 : Les activités de police sur le domaine portuaire}

La police est une notion polysémique qu'il convient de définir afin de comprendre le contenu des rubriques ci-dessus.

La police se définit comme l'ensemble des règles imposées par l'autorité publique aux citoyens en vue de faire régner l'ordre, la tranquillité et la sécurité dans l'État ${ }^{134}$. Elle se compose de la police administrative ${ }^{135}$ (ou police préventive) et la police judiciaire ${ }^{136}$ (ou police répressive). Les activités de police exercées par le PAA ou au sein dudit port relèvent à la fois de la police administrative et de la police judiciaire. Toutes deux se retrouvent dans la police de la conservation du domaine public portuaire (A) et dans la police de la sécurité et de l'ordre public (B).

\section{A. La police de conservation du domaine public portuaire}

L'option faite, sous cette rubrique, de n'aborder que la conservation du domaine public s'explique par le fait qu'il n'existe pas de police administrative spéciale destinée à protéger le domaine privé de l'Administration. En revanche, l'intégrité matérielle et le respect de l'affectation des dépendances du domaine public font l'objet d'une protection spécifique, qui se veut sévère, reposant sur une police particulière, assortie de sanctions répressives : la police de la conservation du domaine public ${ }^{137}$.

La police de la conservation du domaine public affecté au PAA est régie par les articles 89 à 91 du décret n'99-318 du 21 avril 1999 portant règlement de police du Port autonome d'Abidjan ${ }^{138}$.Au regard de l'article 89, "nul ne doit porter atteinte au bon état du Port

133 Article 15 du décret $\mathrm{n}^{\circ}$ 60-110 du 16 mars 1960 portant organisation administrative du Port d'Abidjan.

134 CORNU Gérard (dir.), Vocabulaire juridique, $9^{\mathrm{ème}}$ édition, Quadrige/Puf, 2012, p. 765.

135 Ensemble des moyens juridiques et matériels - réglementations, autorisations, défenses, injonctions, coercitions - mis en œuvre par les autorités administratives compétentes en vue d'assurer, de maintenir ou de rétablir l'ordre public ; on distingue la police administrative générale chargée du maintien de la sécurité, de la tranquillité et de la salubrité publiques, des polices administratives spéciales applicables à telle ou telle activité, ex. chemin de fer... Cf. CORNU Gérard (dir.), Vocabulaire juridique, op. cit., p. 765.

136 Activité des autorités ayant la qualité d'officier de police judiciaire qui consiste à constater les infractions, à en rechercher les auteurs et à rassembler les preuves permettant l'inculpation de ces derniers. $C f$. CORNU Gérard (dir.), Vocabulaire juridique, op. ci.t, p. 765.

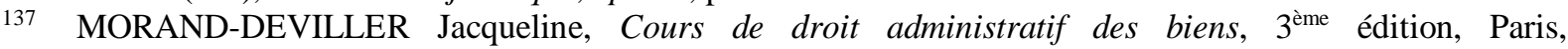
Montchrestien, 2003, p. 183.

138 JORCI n³2, 12 août 1999, p. 661 et ss. 
d'Abidjan ni de ses accès tant dans leur profondeur et dans leur netteté que dans leurs installations. Toute personne qui porte atteinte au bon état du Port d'Abidjan, au bon état de ses ouvrages et au bon état de ses installations doit en rendre compte immédiatement au commandant du Port d'Abidjan ».

Mais, s'il arrivait qu'un navire, lors d'un abordage, d'un amarrage ou de toute autre cause accidentelle coulait, déplaçait ou détériorait un feu flottant, une bouée ou une balise, le capitaine ou le patron dudit navire devrait le signaler par les moyens les plus rapides dont il dispose et dans un délai maximum de vingt-quatre heures suivant son arrivée au premier port où il aborde (article 90). En tout état de cause, la réparation d'un ouvrage ou d'une installation portuaire endommagé(e) par un usager ou son préposé incombe audit usager conformément aux normes définies dans le règlement d'exploitation (article 91).

\section{B. Les autres polices exercées sur le Port autonome d'Abidjan}

La police de la conservation du domaine public portuaire n'est la pas seule forme de police à s'exercer sur le PAA. D'autres polices s'y exercent également par l'intermédiaire d'autorités différentes et selon des règles différentes. Il s'agit notamment de la police de la sécurité et de la salubrité publiques (articles 84 à 88 et, singulièrement les articles 99 à 127 en ce qui concerne la lutte contre les incendies), la police de l'ordre public (articles 57 à 83) ${ }^{139}$, la police des eaux, notamment la prévention contre la pollution des eaux portuaires par les navires qui accostent au PAA (articles 92 à 98), la police des pêches maritimes (articles 128 à 133), la police aux frontières, la surveillance du territoire et la police des douanes même si ces deux dernières polices ne sont pas explicitement prises en compte dans le règlement de police du Port d'Abidjan.

L'exercice de la police n'implique pas automatiquement la répression d'infractions. Dans le PAA, les agents chargés de cette mission ont surtout pour rôle de régler le mouvement des navires et de désigner les postes d'amarrage. Ils désignent les emplacements pour le stockage des marchandises sur les quais et terre-pleins. Mais, lorsqu'il est porté atteinte au bon fonctionnement du service public ou à l'intégrité des ouvrages portuaires, les agents chargés de la police portuaire constatent les infractions ${ }^{140}$, en vertu de l'article 138 du décret du 21 avril 1999.

En sus de la conservation de la consistance du domaine portuaire, le PAA est investi d'autres missions. Celles-ci revêtent un caractère économique.

\section{SECTION 2: Les missions de nature économique exercée par le Port autonome d'Abidjan}

Ces missions sont diverses. Aussi, importe-t-il de les scinder en deux groupes : d'une part, la prestation de services (paragraphe 1) et, d'autre part, l'exploitation économique du domaine public portuaire (paragraphe 2).

139 La police de l'ordre public est régie par le Chapitre $V$ du décret du 21 avril 1999. Il est intitulé «Accès au Port, accès au navire, circulation ».

140 Les agents concernés, sur le fondement de l'article 138 du décret du 21 avril 1999, sont le Commandant du Port ainsi que les autres officiers du port auxquels s'ajoutent les pilotes assermentés, les ingénieurs et les agents assermentés faisant partie des services du PAA. Ils sont investis des attributions dévolues aux officiers de police judiciaire pour la constatation des infractions prévues par le règlement du Port d'Abidjan. 


\section{Paragraphe 1 : Les prestations de services aux usagers du PAA}

Les services fournis par le PAA à ses usagers sont multiples et divers. Ils sont énumérés par un document dénommé Barème des redevances portuaires. Ce dernier, entré en vigueur depuis le $1^{\text {er }}$ juillet 2010, distingue plusieurs prestations de service qui entrainent corrélativement la perception de redevances.

Ce sont, entre autres, les redevances sur le navire, les redevances sur conteneurs, les redevances sur les marchandises.

Les redevances sur navire. En vertu de l'article $1^{\mathrm{er}} \mathrm{du}$ Barème des redevances portuaires, les tarifs sur les navires sont fixés en Euros $(€)$ ou autres devises (Dollars étasuniens US\$; Livre sterling £...). Les redevances rémunèrent les services rendus par le PAA à ses usagers sur la base de tarifs hors taxes (TVA ou TPS). Ces redevances ne sauraient, en aucun cas, être assimilées à des taxes à caractère fiscal. Le non-paiement des redevances dans les délais prescrits entraine une pénalité de retard au taux de $2 \%$ par mois sur le montant de la facture. Cette pénalité est mentionnée sur la facture et est exigible dès le premier jour de retard de paiement (article 2 du Barème sur les redevances portuaires).

En vertu de l'article 4 du Barème précité, il est perçu une taxe d'environnement en Euro sur tous les navires en escale au Port autonome d'Abidjan à l'exclusion des navires de pêche et de servitude. Ainsi, tous les navires, à l'exclusion des pétroliers, sont soumis à une taxe environnementale de 19,82 €. En revanche, les navires pétroliers seront taxés au prorata de leur volume. Ainsi :

- De 0 à $5.000 \mathrm{~m}^{3}$ :

- De 5.001 à $20.000 \mathrm{~m}^{3}$ :

- De 20.001 à $150.000 \mathrm{~m}^{3}$ :

- Supérieur à $150.000 \mathrm{~m}^{3}$ :
$15,24 €$

$76,22 €$

$152,45 €$

$228,67 €$

Hormis les redevances ci-dessus, les navires sont soumis à d'autres redevances que sont la redevance de droit d'entrée au port, la redevance de pilotage et la redevance de séjour. Chacune est fixée en fonction du volume du navire concerné (voir en annexe le Barème de redevances portuaires).

Les redevances sur conteneurs. Elles diffèrent selon qu'il s'agit de conteneurs hors transbordement et transit, de conteneurs en transbordement, de conteneurs en transit.

Dans le premier cas, celui des conteneurs hors transbordement et transit, il est perçu une redevance en sus de celle appliquée sur la marchandise conteneurisée par application des tarifs ci-après en Euros par TEU. Les tarifs sont hors taxe (TVA ou TPS). Il est perçu sur les conteneurs hors transbordement et transit, une redevance au titre du Code ISPS dénommé redevance de sûreté ISPS égale à $10 \%$ du montant total de la facture sur les conteneurs.

Ensemble du PAA, hors TCV et hors terminal RO/RO

\begin{tabular}{|l|c|}
\hline & Tarif en Euro \\
\hline Conteneurs pleins $: 20^{\prime} /$ TEU & 11,33 \\
\hline Conteneurs vides $: 20^{\prime} /$ TEU & 5,57 \\
\hline
\end{tabular}




\section{Conteneurs au TCV et au terminal RO/RO}

\begin{tabular}{|l|c|}
\hline & Tarif en Euro \\
\hline Conteneurs pleins : $20^{\prime} /$ TEU & 7,44 \\
\hline Conteneurs vides $: 20^{\prime} /$ TEU & 3,66 \\
\hline
\end{tabular}

Dans les cas de conteneurs en transbordement, le conteneur plein en transbordement quels que soient le tonnage et la nature des marchandises est facturée à 12,96€.

Dans les cas de conteneurs en transit pour les pays sans littoral, le conteneur en transit quel que soit le tonnage est facturé comme suit :

- Un conteneur disant contenir des produits alimentaires ou agricoles est facturé à 100.000 F CFA par TEU ;

- Un conteneur disant contenir des matériaux de construction est facturé à $25.000 \mathrm{~F}$ CFA par TEU ;

- Un conteneur disant contenir tous les autres produits est facturé à $75.000 \mathrm{~F}$ CFA par TEU.

Les redevances sur les marchandises. Au regard de l'article premier du Chapitre $3 \mathrm{du}$ Barème des redevances portuaires, elles comprennent les redevances sur la marchandise, les pénalités de stockage prolongé et de dépôt tardif de manifestes et de fiches conteneurs, ainsi que les redevances sur les passagers.

Les redevances sur les marchandises sont déterminées par application des tarifs indiqués dans des tableaux figurant dans le Barème des redevances portuaires. Les tarifs sont hors taxe (TVA ou TPS).

\section{Paragraphe 2 : L'exploitation économique du domaine public portuaire}

Le PAA, à l'image d'autres acteurs économiques, s'attelle à retirer des utilités financières de l'exploitation de son domaine. Pour ce faire, il permet certaines occupations privatives (A) dudit domaine moyennant paiement de redevances par les usagers (B).

\section{A. Les occupations privatives du domaine public portuaire}

En disséquant plusieurs formes d'occupation privative sur le domaine public. Certaines d'entre elles confèrent aux occupants privatifs des droits réels sur la dépendance domaniale tandis que d'autres ne leur confèrent pas de droits réels. Dans le cadre de la présente rubrique, seules les occupations privatives non constitutives de droits réels retiendront notre attention vu que celles conférant des droits réels seront développées dans la suite des présents travaux. Ainsi, dans la catégorie des occupations privatives non constitutives de droits réels, on note que l'une procède d'un acte unilatéral de l'Administration tandis que l'autre résulte d'un acte conventionnel entre l'Administration propriétaire ou gestionnaire du domaine public et l'usager. Dans le premier cas, on est en présence d'une permission de voirie (1) tandis que dans le second cas, il est question d'une concession de voirie (2). 


\section{La permission de voirie}

La permission de voirie est un acte unilatéral autorisant un particulier à occuper privativement une parcelle du domaine public. En République de Côte d'Ivoire, la permission de voirie, tout comme la concession de voirie, dans le cadre du domaine public portuaire, se fonde sur l'article $24 \S 2$ des statuts du PAA approuvés par le décret du 14 mars 2001. En vertu de cette disposition, le directeur général du PAA est compétent pour attribuer les titres d'occupations du domaine portuaire.

La permission de voirie accordée par le directeur général du PAA constitue un acte administratif. Aussi, la décision du directeur général de retirer une permission de voirie peutelle être attaquée par le moyen du recours pour excès de pouvoir intenté auprès de la Chambre administrative de la Cour suprême (CSCA). Un tel recours doit être nécessairement précédé d'un recours administratif qui peut être gracieux ou hiérarchique ${ }^{141}$. Toutefois, la Cour suprême rejette le recours juridictionnel précédé d'un recours hiérarchique intenté devant une autorité administrative incompétente. Ainsi, dans l'affaire Sivcoge Industrie contre Port autonome d'Abidjan, la Chambre administrative de la Cour suprême a rejeté le recours juridictionnel de la société Sivcoge Industrie au motif que celle-ci avait intenté un recours hiérarchique auprès du ministre des infrastructures économiques en vue d'obtenir l'annulation de la décision du directeur général du PAA. La raison en est que le ministre chargé des infrastructures économiques n'est pas le supérieur hiérarchique du directeur général du Port autonome d'Abidjan ${ }^{142}$.

Il importe de souligner qu'en République de Côte d'Ivoire, en raison de l'unité juridictionnelle ou monisme juridictionnel, la juridiction exclusivement compétente pour connaître du contentieux de l'annulation de l'acte administratif est la chambre administrative de la Cour suprême ${ }^{143}$.

141 «Considérant qu'il résulte des pièces du dossier que pour solliciter l'annulation de la décision $n^{\circ} 00229$ du 30 janvier 2007 du Directeur du Port d'Autonome d'Abidjan qui lui retire l'autorisation d'occupation à lui octroyée en mars et mai 2005, la SIVCOGE, pour satisfaire à l'exigence du recours administratif préalable, s'est adressé au ministre des infrastructures économiques pour un recours hiérarchique en date du 28 mars 2007 ». Cf. CSCA 21 janvier 2009, Sivcoge Industrie c/ Port Autonome d'Abidjan, Arrêt n ${ }^{\circ} 05$.

142 «Mais, considérant que le recours hiérarchique pour être valable doit être adressé à une autorité administrative supérieure à celle qui a pris l'acte et qui a, conséquemment, compétence pour annuler éventuellement, la décision contestée; qu'au regard des textes susvisés, le ministre des infrastructures économiques n'est pas dans un rapport hiérarchique, mais de tutelle avec le Port Autonome d'Abidjan qui est une société d'État, dotée de personnalité juridique propre; qu'il s'ensuit que la SIVCOGEIndustrie en s'adressant au ministre des infrastructures économiques a formulé un recours administratif préalable devant une autorité incompétente; que dès lors, la requête n'est pas recevable pour $n$ 'avoir pas respecté les dispositions des articles 57 et 58 de la loi sur la Cour Suprême ». Cf. CSCA 21 janvier 2009, Sivcoge Industrie c/ Port Autonome d'Abidjan, Arrêt $n^{\circ} 05$.

143 La Compétence exclusive de la Chambre administrative de la Cour suprême (CSCA) découle de l'article 54 de la loi $\mathrm{n}^{\circ}$ 94-440 du 16 août 1994 relative à la Cour suprême qui dispose que la CSCA «connaît des pourvois en cassation dirigés contre les décisions rendues en dernier ressort dans les procédures où une personne morale de droit public est partie. Toutefois, les décisions rendues par les juridictions répressives sont, dans tous les cas, dévolues à la Chambre judiciaire; En premier et dernier ressort, des recours en annulation pour excès de pouvoir formés contre les décisions émanant des autorités administratives ». L'unité juridictionnelle ou le monisme juridictionnel de la République de Côte d'Ivoire a d'abord découlé de la Constitution du 3 novembre 1960 qui, en son titre VI, particulièrement à l'article $57 \S 1$, instituait une Cour suprême comprenant une Chambre constitutionnelle, une Chambre judiciaire, une Chambre administrative et une Chambre des comptes. Il est à remarquer qu'il n'y a qu'une seule juridiction suprême, à savoir la Cour suprême avec, en son sein, des formations spécialisées que constituent les chambres précitées. Par la suite, la loi $n^{\circ} 61-155$ du 18 mai 1961 portant organisation judiciaire reconduira l'option prise dans la Constitution du 3 novembre 1960. L'article premier de la loi précitée du 18 mai 1968 dispose : "Dans la République de Côte d'Ivoire, la justice est rendue en matière civile, commerciale, pénale et administrative par la Cour suprême, la Cour d'appel, des tribunaux de première instance et des justices de paix ». Les justices de paix disparaîtront peu après. Elles ont été remplacées par les sections 


\section{La concession de voirie}

La concession de voirie est un contrat conclu entre l'Administration et un particulier en vue de l'occupation privative d'une dépendance domaniale ${ }^{144}$.

La nature juridique de la concession de voirie avait donné lieu, au début du XXe siècle, à une controverse doctrinale en République Française. Toutefois, la nature contractuelle de la concession de voirie a été close avec l'adoption du décret-loi du 17 juin 1938 instituant un Code du domaine de l'État. En vertu de l'article premier dudit Code, ces contrats relèvent tous de la compétence du juge administratif, ce qui implique leur caractère de contrat administratif et leur soumission au droit public ${ }^{145}$. Les règles de droit privé ne sont pas applicables à la concession de voirie telles celles concernant le versement des loyers, les baux commerciaux ou le maintien dans les lieux. Ainsi, en concluant sur son domaine public un bail commercial qu'elle savait illicite, une ville engage sa responsabilité délictuelle ${ }^{146}$.

En République de Côte d'Ivoire, la Chambre administrative de la Cour suprême a réitéré la nature administrative de la concession de voirie dans plusieurs affaires. Selon la haute juridiction, les contrats comportant occupation du domaine public sont des contrats administratifs par qualification de la loi (en l'occurrence le décret-loi du 17 juin 1938) ${ }^{147}$.

détachées des tribunaux de première instance. Il en va autrement au sein de la République Française. Cette dernière $\mathrm{a}$, en effet, opté pour la dualité juridictionnelle. Cela implique un juge spécial qualifié pour connaître du contentieux administratif. Il en résulte deux ordres de juridictions coiffés respectivement par la Cour de cassation (ordre judiciaire, appliquant quasi-exclusivement le droit privé) et le Conseil d'État (ordre administratif, donc juge de l'Administration, appliquant le droit administratif). Dans l'ordre administratif, on note l'existence de: Tribunaux administratifs (en première instance), des Cours administratives d'appel (en appel), et du Conseil d'État (en cassation). Il existe, en outre, des juridictions administratives spécialisées dans divers domaines de l'Administration française. Le lecteur pourra davantage s'imprégner de l'organisation juridictionnelle administrative de la République française en consultant, entre autres : CHAPUS René, Droit administratif, $15^{\text {ème }}$ édition, Tome 1, Montchrestien, 2001 ; BRAIBANT Guy et STIRN Bernard, Le droit administratif français, $6^{\text {ème }}$ édition, Paris, Presses de Sciences po et Dalloz, 2002 ; LOMBARD Martine et DUMONT Gilles, Droit administratif, $9^{\mathrm{ème}}$ édition, Paris, Dalloz, 2011.

144 MORAND-DEVILLER Jacqueline, Cours de droit administratif des biens, $3^{\text {zeme }}$ édition, Monchrestien, 2003, p. 275.

145 L'article premier du décret-loi du 17 juin 1938 instituant un Code du domaine de l'État dispose : « Sont portés en premier ressort, devant le Conseil de préfecture, sauf recours au Conseil d'État, les litiges relatifs aux contrats comportant occupation du domaine public, quelle que soit leur forme ou dénomination, passés par l'État, les départements, les communes, les établissements publics ou leurs concessionnaires $»$.

146 CE 6 décembre 1985, Mademoiselle Boin-Favre, req. n44716 ; Rec. CE p. 353 ; RFDA 1986, p. 382, note Terneyre.

147 «Considérant qu'en statuant comme elle l'a fait, alors que selon le décret-loi du 17 juin 1938 tous les contrats touchant au domaine public sont des contrats administratifs par détermination de la loi... ». CSCA 23 mars 2005, Arrêt n ${ }^{\circ}$, Port Autonome d'Abidjan c/ Entreprises Graviers et Sables (EGS), req. 2003-453 CASS/AD. « Considérant que selon le décret-loi du 17 juillet 1938, tous les contrats portant sur le domaine public portuaire sont administratifs par détermination de la loi; Qu'en vertu des principes généraux de la domanialité publique, le domaine public ne peut faire l'objet de contrats d'occupation relevant du droit privé ; Qu'il s'ensuit qu'au regard du caractère administratif du contrat d'occupation du domaine public à l'origine du litige, le Port Autonome d'Abidjan n'est pas fondé à soutenir que la Cour Commune de Justice et d'Arbitrage (CCJA) est compétente; Que seule la Chambre Judiciaire doit connaître de ce pourvoi ». CSCA 30 mai 2012, Arrêt n 94 , Port autonome d'Abidjan c/ Sicpro \& autres, req. ${ }^{\circ}$ 2008-347 CIV. "Considérant au fond, que les actes par lesquels le Port Autonome d'Abidjan a donné, puis retiré l'autorisation d'occuper un bien immobilier dépendant du domaine public portuaire sont des actes administratifs dont le contentieux relève de la juridiction administrative suivant la procédure du recours en annulation pour excès de pouvoir ». CSCA 28 juillet 2010, Arrêt n ${ }^{\circ} 81$, Port autonome d'Abidjan (dite PAA) c. Société Pexagri, req. n²009-008 CASS/ADM. 
Cette jurisprudence est d'ailleurs confirmée par le Tribunal de commerce d'Abidjan qui, dans l'affaire Société El Nasr Export-Import c. Port autonome d'Abidjan, a reconnu la nature administrative des autorisations d'occupation du domaine public portuaire délivrées par le Port autonome d'Abidjan ${ }^{148}$. En outre, le juge des référés ne peut valablement ordonner au PAA de procéder à la réintégration de l'occupant dans ses locaux situés sur le domaine public portuaire. Enfin, le juge d'appel ne saurait assimiler la concession de voirie à des baux commerciaux et les soumettre, par conséquent, aux règles de privé, notamment le droit commercial de l'OHADA ${ }^{149}$.

La concession de voirie est la forme la plus usitée pour les occupations du domaine public avec des investissements d'une certaine importance (cas des stations d'essence, des entreprises maritimes, de transit, des hôtels, etc.). Ces concessions interviennent le plus souvent sous la forme de bail emphytéotique conformément au décret du 29 septembre $1928^{150}$ et surtout de son arrêté d'application du 24 novembre $1928^{151}$.

\section{B. Les obligations et garanties du permissionnaire et du concessionnaire de voirie}

L'étude du régime juridique de la permission de voirie et de la concession de voirie permet de saisir les droits et devoirs respectifs du permissionnaire de voirie (a) et du concessionnaire de voirie (b).

\section{Les droits et obligations du permissionnaire de voirie}

Le permissionnaire de voirie est soumis à l'obligation de verser une redevance à l'Administration concédante, quelle qu'elle soit (a). Il bénéficie, en contrepartie, de certains droits personnels (b).

148 «Or, en la matière, conformément à la jurisprudence constante de la chambre administrative de la Cour Suprême, il résulte des dispositions légales, notamment du décret-loi du 17 juin 1938 et du décret $n^{\circ} 2001$ 143 du 14 mars 2001 portant approbation des statuts du Port autonome d'Abidjan et reclassification des immobilisations concédées, que le Port autonome d'Abidjan, bien qu'étant une société de droit privé par sa forme, est chargé de la gestion du domaine public portuaire; À ce titre, les actes par lesquels il a donné puis retiré à la Société EL NASR Export-Import, l'autorisation d'occuper le lot litigieux, qui est un bien immobilier dépendant du domaine public portuaire, sont des actes administratifs dont le contentieux relève de la juridiction administrative ». Tribunal de commerce d'Abidjan, Ordonnance de référé, 11 octobre 2013, Société El Nasr Export-Import c. Port autonome d’Abidjan, RG n 1456/13.

149 CSCA 23 mars 2005, Port autonome d'Abidjan c/ Entreprises Graviers et Sables (EGS), Arrêt n¹4, req. $\mathrm{n}^{\circ} 2003-453$ CASS/AD.

150 Décret du 29 septembre 1928, portant réglementation du Domaine public et des servitudes d'utilité publiques en Côte d'Ivoire modifié par D. du 7 sept 1935 et D. n52-679 du 3 juin 1952.

151 L'intitulé intégral de l'arrêté est: Arrêté GG n²895 A.E. du 24 novembre 1928, réglementant les conditions d'application du décret du 29 septembre 1928 sur le Domaine et les servitudes d'utilité publique. Le Titre IV de cet arrêté se rapporte à la forme d'occupation par bail emphytéotique renouvelable. Voir également KOBO Pierre-Claver, Droit administratif des biens, Éditions ABC, 2012, pp. 91-92. 
L'utilisation collective du domaine public, en général, est gratuite. Toutefois, le Conseil constitutionnel français considère que la gratuité n'est pas un principe à valeur constitutionnelle ${ }^{152}$.

L'utilisation privative du domaine public, en revanche, n'est nullement gratuite. Aussi, le permissionnaire de voirie est-il tenu de verser une redevance à l'Administration concédante. Ce caractère onéreux se justifie non seulement par un souci de bonne gestion du patrimoine communal, mais également par une atteinte "tolérée » aux droits d'accès de tous les usagers au domaine public. La redevance s'affiche comme une sorte de compensation, de contrepartie des avantages procurés au bénéficiaire d'un titre d'occupation. Le conseil d'État français a réaffirmé le caractère obligatoire de la redevance dans l'affaire Société des autoroutes Estérel-Côte d'Azur-Provence-Alpes ${ }^{153}$.

L'exigence de la redevance est si ancrée que même si une collectivité publique s'engage au moyen d'une convention à ne pas percevoir de redevance et, corrélativement, admet la gratuité de l'occupation du domaine public, cette collectivité publique est juridiquement en droit, ultérieurement, d'assujettir l'occupation de son domaine public au paiement de redevances. L'occupant ne peut pas refuser de payer. À défaut, le gestionnaire du domaine public peut résilier la convention par laquelle il avait antérieurement opté pour la gratuité de l'occupation privative du domaine public. Le Conseil d'État français a, en effet, considéré que l'instauration d'une redevance tenant compte des avantages de toute nature qu'un permissionnaire est susceptible de retirer de l'occupation de ce domaine, fait partie des motifs d'intérêt général pouvant justifier qu'il soit mis prématurément fin à un contrat d'occupation du domaine public ${ }^{154}$.

Le titre d'occupation du domaine public (en l'occurrence la permission de voirie) est personnel. Le permissionnaire de voirie ne saurait donc les céder à titre gratuit (succession) ou onéreux sans l'accord de l'Administration. Un changement d'occupant impose la délivrance d'un nouveau titre d'occupation ${ }^{155}$.

Selon le Conseil constitutionnel français, «si la liberté d'aller et venir est un principe de valeur constitutionnelle, celui-ci ne saurait faire obstacle à ce que l'utilisation de certains ouvrages donne lieu au versement d'une redevance; que, si la loi du 30 juillet 1880 dispose : Il ne sera plus construit à l'avenir de ponts à péage sur les routes nationales ou départementales, il ne saurait en résulter que le principe de la gratuité de la circulation sur ces voies publiques doivent être regardé, au sens du préambule de la Constitution de 1946, repris par celui de la Constitution de 1958, comme un principe fondamental reconnu par les lois de la République ». CC, Décision n79-107 DC du 12 juillet 1979, Loi relative à certains ouvrages reliant les voies nationales ou départementales, Rec., p. 31.

153 Dans cette affaire, le Conseil d'État a considéré : «il appartient à l'autorité chargée de la gestion du domaine public, en l'absence de dispositions contraires, de fixer les conditions de délivrance des permissions d'occupation et, à ce titre, de déterminer le tarif des redevances en tenant compte des avantages de toute nature que le permissionnaire est susceptible de retirer de l'occupation du domaine public ; que ces règles trouvent à s'appliquer, même en l'absence de toute réglementation particulière, au concessionnaire autorisé à délivrer des permissions d'occupation sur le domaine public dont l'exploitation lui est concédée... ». Cf. CE 10 juin 2010, Société des autoroutes Estérel-Côte d'AzurProvence-Alpes (ESCOTA), n³05136.

154 «Considérant, d'autre part, que la volonté d'assurer une meilleure exploitation du domaine public, notamment par l'instauration d'une redevance tenant compte des avantages de toute nature qu'un permissionnaire est susceptible de retirer de l'occupation de ce domaine, fait partie des motifs d'intérêt général pouvant justifier qu'il soit mis fin à un contrat d'occupation du domaine public avant son terme ». Cf. CE 23 mai 2011, Établissement public pour l'aménagement de la région de la Défense (EPAD), $\mathrm{n}^{\circ} 328525$.

155 MORAND-DEVILLER Jacqueline, Cours de droit administratif des biens, op. cit., p. 263. Voir également KOBO Pierre-Claver, Droit administratif des biens, Éditions ABC, 2012, p. 91. 
La rigueur des obligations pesant sur le permissionnaire de voirie est quelque peu atténuée par les droits qui lui sont reconnus.

\section{b) Les droits personnels du permissionnaire de voirie.}

Le permissionnaire dispose du pouvoir d'utiliser provisoirement la dépendance domaniale, ce qui ne s'apprécie cependant pas comme un véritable droit de jouissance : il ne peut percevoir un loyer en sous-louant sa parcelle à une personne tierce. Il peut, en revanche, effectuer tous les travaux prévus par l'autorisation ou impliqués nécessairement par elle. Il ne dispose pas non plus de pouvoirs de police ${ }^{156}$. Dans le cas particulier du Port autonome d'Abidjan, les pouvoirs de police sur le domaine public portuaire relèvent du Commandant du port. En effet, il est responsable de l'ordre public dans les limites de la circonscription du Port d'Abidjan, et est placé sous les ordres immédiats du directeur général du Port autonome d'Abidjan ${ }^{157}$.

À l'égard des tiers, le permissionnaire de voirie dispose d'un minimum de garanties pour faire respecter ses droits. Il peut intenter une action possessoire et une action en responsabilité en cas d'atteinte à ses droits. Ainsi, l'Administration engage sa responsabilité pécuniaire lorsqu'elle permet à un tiers d'occuper indûment une fraction du domaine public comprise dans les limites d'une autorisation délivrée antérieurement ${ }^{158}$.

À l'égard de l'Administration, en l'occurrence le Port autonome d'Abidjan, le permissionnaire de voirie se trouve dans une situation de précarité. En réalité, toutes les occupations du domaine public, qu'elles soient privatives ou collectives, sont soumises au principe de précarité. Nul n'a de droit acquis au maintien sur le domaine public ${ }^{159}$. Une permission de voirie peut être révoquée dans l'intérêt général sans que cette abrogation ouvre droit à indemnité ${ }^{160}$.

Hormis les permissionnaires de voirie, des droits et des obligations seront aussi reconnus aux concessionnaires de voirie.

\section{Les droits et les obligations du concessionnaire de voirie}

Le concessionnaire de voirie est soumis à certaines prérogatives de l'Administration, précisément du Port autonome d'Abidjan. Il jouit, en contrepartie, de certaines garanties.

\section{a) Les prérogatives reconnues au Port autonome d'Abidjan à l'égard du concessionnaire de voirie}

Conformément à la théorie générale du contrat administratif, le Port autonome d'Abidjan dispose du pouvoir de modification unilatérale de la concession de voirie. Cependant, le Port autonome d'Abidjan ne peut procéder à la modification unilatérale des redevances que

156 MORAND-DEVILLER Jacqueline, op. cit., p. 263.

157 Article 6 du décret n99-318 du 21 avril 1999 portant règlement de police du Port autonome d'Abidjan.

158 CE 5 décembre 1962, Ville de Marseille, RDP 63, p. 607.

159 Dans l'affaire Ville de Charleville-Mézières, le Conseil d'État a considéré que «le maire a pu, sans excéder ses pouvoirs, prévoir [...] le renouvellement annuel des autorisations et rappeler [...] le caractère précaire et révocable de ces autorisations, commun à toutes les autorisations d'occupation du domaine public, enfin préciser [...] les conditions et modalités des retraits d'autorisation ». Cf. CE 4 février 1983, Ville de Charleville-Mézières, $n^{\circ} 24912$.

160 CE 6 mai 1932, Demoiselle Taillandier, Sirey, III, p. 65. 
doivent verser le concessionnaire de voirie. Cette limitation de ses compétences, en la matière, s'explique par le fait que le PAA n'a que la gestion du domaine public portuaire, propriété de l'État de Côte d'Ivoire ${ }^{161}$. L'État a ainsi fixé le montant des redevances (annuelles) à verser par l'occupant privatif dudit domaine. Ces redevances étaient initialement contenues dans l'ordonnance $\mathrm{n}^{\circ} 61-183$ du 18 juin 1961 portant fixation des redevances exigibles pour occupation du domaine public et privé de l'État. À l'heure actuelle, les redevances d'occupation du domaine public portuaire sont fixées par le Barème des redevances portuaires entré en vigueur le $1^{\mathrm{er}}$ juillet 2010.

En outre, le PAA bénéficie du pouvoir de résiliation unilatérale de la concession de voirie. Il en résulte qu'il lui est loisible de mettre prématurément fin à la concession de voirie en vertu du principe de la précarité. Ainsi que le soulignait le professeur Kobo, "la précarité constitue une réserve à garantir pour l'Administration, la possibilité d'un changement d'affectation. L'autorité domaniale peut toujours mettre fin à une affectation pour des motifs d'intérêt général " ${ }^{162}$. Et il ajoute, "l'occupant, même contractuel [...] ne peut exiger une durée ferme de jouissance, sauf cas particuliers. Le fait qu'une autorisation a été accordée pour une durée déterminée ne limite pas la liberté de l'Administration : la fixation d'un terme permet de prévoir la durée maximale de l'utilisation, non sa durée minimale ${ }^{163}$. Il résulte de ce qui précède que le refus de l'Administration de renouveler une concession de voirie n'ouvre pas droit à une indemnité au profit du concessionnaire ${ }^{164}$.

Les inconvénients découlant des prérogatives de l'Administration expliquent les garanties reconnues au concessionnaire.

\section{b) Les garanties reconnues au concessionnaire de voirie}

Le concessionnaire, bien que ne bénéficiant pas de droits réels sur le domaine public, a le droit d'utiliser la dépendance domaniale sans être troublé par l'Administration. Sur la portion qui lui est concédée, il peut exécuter des travaux et établir des installations qui devront être démolies en fin d'occupation - sauf si l'Administration en revendique la propriété par voie d'accession.

À la différence du permissionnaire, les droits du concessionnaire sont mieux garantis lorsqu'il est mis fin au contrat unilatéralement et prématurément, il a droit, en principe, à une indemnisation le plus souvent prévue dans la convention ${ }^{165}$.

Le droit de propriété de l'État sur le domaine public portuaire découle de l'analyse de deux dispositions relevant de deux textes juridiques. Ce sont l'article $2 \S 1^{\text {er }}$ du décret n ${ }^{\circ} 2001-143$ du 14 mars 2001 portant approbation des statuts du Port Autonome d'Abidjan; et l'article $5 \S 2$ des Statuts du Port autonome d'Abidjan. Selon l'article $2 \S 1^{\mathrm{er}}$ du décret précité du 14 mars 2001, "sont placés sous le régime de la concession, les terrains du domaine public de l'État et le canal de Vridi». L'article $5 \S 2$ des Statuts du Port autonome d'Abidjan dispose : «le Port et ses dépendances font partie du domaine public et privé de l'État».

162 KOBO Pierre-Claver, Droit administratif des biens, Éditions ABC, 2012, p. 97.

163 Ibidem.

164 CE 8 janvier 1960, Lafon, Rec. p. 15.

165 MORAND-DEVILLER Jacqueline, Cours de droit administratif des biens, $3^{\text {ème }}$ édition, Montchrestien, 2003, p. 277. 
Tableau 1: Comparaison entre la permission de voirie et la concession de voirie

\begin{tabular}{|c|c|}
\hline Permission de voirie & Concession de voirie \\
\hline \multicolumn{2}{|c|}{ Ressemblances } \\
\hline \multicolumn{2}{|c|}{$\begin{array}{l}\text { - Précaires et révocables. Elles peuvent être retirées avant terme. } \\
\text { - Elles doivent respecter l'intérêt du domaine et les autres intérêts généraux. } \\
\text { - Si les travaux publics occasionnent une gêne et sont entrepris dans l'intérêt de la dépendance } \\
\text { occupée : pas de dommages-intérêts. } \\
\text { - Elles donnent lieu à la perception d'une redevance. }\end{array}$} \\
\hline \multicolumn{2}{|c|}{ Différences } \\
\hline $\begin{array}{l}\text { - Situation de l'occupant moins bien protégé : } \\
\text { pas d'indemnité si retrait avant terme. } \\
\text { - Modification unilatérale possible. } \\
\text { - Contentieux de l'excès de pouvoir. }\end{array}$ & $\begin{array}{l}\text { - Situation de l'occupant mieux protégée : } \\
\text { indemnisation en cas de résiliation avant } \\
\text { terme. } \\
\text { - Modification prévue par le contrat. } \\
\text { - Intention des parties recherchée. } \\
\text { - Plein contentieux. }\end{array}$ \\
\hline
\end{tabular}

Source: MORAND-DEVILLER Jacqueline, Cours de droit administratif des biens, $3^{\text {ème }}$ édition, Montchrestien, 2003, p. 275.

Le statut juridique du Port autonome d'Abidjan ne résulte plus seulement des actes juridiques adoptés par l'État ivoirien. Désormais, ce statut comprend des normes juridiques édictées par certaines organisations communautaires. 


\section{TITRE DEUX: UN STATUT JURIDIQUE ACTUELLEMENT INVESTI PAR LE DROIT COMMUNAURAIRE}

L'application des normes communautaires au PAA se traduit respectivement par la soumission dudit port au droit de l'UEMOA (Chapitre 1) et l'application du droit de l'OHADA aux activités menées par le PAA (Chapitre 2). 



\section{CHAPITRE 1 : LA SOUMISSION DU PORT AUTONOME D'ABIDJAN AU DROIT DE L'UEMOA}

Le droit de l'UEMOA applicable au PAA comprend, d'une part, le droit primaire de ladite organisation et, d'autre part, son droit dérivé. Le droit primaire se compose du traité ayant donné naissance à l'organisation communautaire. Ce traité constitutif définit les organes principaux de l'organisation ainsi que leurs compétences et leurs modes de fonctionnement. Le droit dérivé est l'ensemble des décisions prises par les organes de l'organisation communautaire conformément au(x) traité(s) constitutif(s) de l'organisation.

Relativement au droit de l'UEMOA, on note que son droit primaire définit le cadre juridique général applicable au PAA (Section 1) tandis que les normes juridiques spécifiques découlent du droit dérivé de ladite organisation (Section 2).

\section{SECTION 1: Le cadre général découlant du droit primaire de l'UEMOA}

Le droit primaire de l'UEMOA découle, à titre principal, du Traité constitutif de l'organisation éponyme, adopté le 10 janvier 1994, à Dakar au Sénégal (paragraphe 1). De manière accessoire, le droit primaire de l'UEMOA est généré, entre autres, par le Protocole additionnel $\mathrm{n}^{\circ}$ II relatif aux politiques sectorielles de l'UEMOA (paragraphe 2). Relativement au Protocole additionnel $\mathrm{n}^{\circ} \mathrm{II}$, on pourrait a priori refuser de le ranger dans la catégorie des normes relevant du droit primaire de l'UEMOA Cette position s'expliquerait par le fait que le Protocole additionnel est un acte juridique édicté par la Conférence des chefs d'État et de gouvernement de l'UEMOA, un organe de ladite organisation d'intégration. D'un point de vue formel, le Protocole additionnel nII précité relèverait donc du droit dérivé.

D'un point de vue matériel, en revanche, le Protocole additionnel n'II se présente comme une excroissance du Traité du 10 janvier 1994 instituant l'UEMOA En effet, le Protocole additionnel $\mathrm{n}^{\circ}$ II vient non seulement compléter le Traité constitutif de ladite organisation ${ }^{166}$, mais lui est aussi intégré sur le fondement de l'article 102 du Traité du 10 janvier $1994^{167}$.

\section{Paragraphe 1 : Le Traité de l'UEMOA}

Le traité de l'UEMOA institue une politique économique commune à tous les États membres de l'Union (A) ainsi qu'un marché commun (B).

Eertu de l'article 19 du Traité de l'UEMOA «... Les actes additionnels sont annexés au Traité. Ils complètent celui-ci sans toutefois le modifier. Leur respect s'impose aux organes de l'Union ainsi qu'aux autorités des États membres ». De manière plus explicite, l'article 101 dispose : "En vue de compléter les politiques économiques communes menées au niveau de l'Union, il est institué un cadre juridique définissant les politiques sectorielles devant être mises en ouvre dans les États membres. Ces politiques sectorielles sont énoncées et définies dans le Protocole additionnel $n^{\circ} I I »$.

167 En vertu de l'article 102 du Traité de l'UEMOA, «Le Protocole additionnel $n^{\circ} I I$ fait partie intégrante du présent traité ». 


\section{A. La politique économique}

La politique commune mise en place par le Traité de l'UEMOA n'est pas, à proprement parler, circonscrite au PAA. Elle s'applique à toutes les activités économiques des États membres de l'Union. Par conséquent, le PAA outil majeur de développement économique de la Côte d'Ivoire se trouve être un élément inclus dans cette politique communautaire.

En adhérant au Traité UEMOA, les États membres se sont départis, entre autres, d'une partie de leur souveraineté économique au profit de l'organisation communautaire. Il s'ensuit qu'ils ne peuvent plus, chacun en ce qui le concerne, définir unilatéralement leurs politiques économiques. Ils doivent, par conséquent, tenir compte des normes pertinentes de l'Union qui coordonnent les politiques économiques des États membres.

L'économie de l'article 63 du Traité de l'UEMOA constitue quelque peu une entrave au pouvoir des autorités ivoiriennes de légiférer, entre autres, sur le PAA. Ainsi, elles sont dans l'obligation de ne pas adopter de texte contra legem au regard des textes juridiques communautaires relatifs à l'organisation et au fonctionnement des ports des États membres ${ }^{168}$.

La politique économique de l'Union vise certains objectifs. Ceux-ci sont définis à l'article $64 \S 2$ du Traité UEMOA. Il s'agit des objectifs de :

- De croissance soutenue du revenu moyen ;

- De répartition des revenus ;

- De solde soutenable de la balance des paiements courants ;

- D’amélioration de la compétitivité internationale des économies de l'Union.

Le Conseil des ministres est l'organe compétent pour se prononcer sur les grandes orientations des politiques économiques des États membres et de l'Union. Les décisions, en la matière, sont prises par voie de recommandations arrêtées à la majorité des deux tiers $(2 / 3) \mathrm{du}$ Conseil des ministres (articles 64 \$ 1 Traité UEMOA).

\section{B. Le marché commun}

L'article $76 \mathrm{du}$ Traité de l'UEMOA définit les objectifs dont la réalisation progressive conditionne celle du marché commun. Ces objectifs consistent en l'élimination, dans les échanges intracommunautaires, des barrières tarifaires et des barrières non tarifaires sous réserve du respect des règles pertinentes de l'UEMOA édictées par voie de protocole additionnel.

En outre, l'institution du marché commun requiert :

- L'établissement d'un tarif extérieur commun (TEC), l'institution de règles communes de concurrence ;

- La mise en œuvre des principes de liberté de circulation des personnes, d'établissement et de prestations de services ;

- La liberté de mouvements des capitaux requis pour le développement du marché financier régional ;

Selon l'article 63 du Traité de l'UEMOA, «les États membres considèrent leurs politiques économiques comme une question d'intérêt commun et les coordonnent au sein du Conseil en vue de la réalisation des objectifs définis à l'article 4 paragraphe b) du présent Traité. À cette fin, le Conseil met en place un dispositif de surveillance multilatérale des politiques économiques de l'Union dont les modalités sont fixées aux articles 64 à $75 »$. 
- Ainsi que l'harmonisation et la reconnaissance mutuelle des normes techniques ainsi que des procédures d'homologation et de certification du contrôle de leur observation.

\section{La libre circulation des personnes, des services et des capitaux}

La libre circulation des personnes, des services et des capitaux est la règle dans l'espace communautaire. Aussi, l'article 96 du Traité de l'UEMOA prohibe-t-elle les restrictions à l'exercice de ces libertés. Toutefois, l'article 97 dudit traité admet la possibilité pour chaque État membre de restreindre la libre circulation des personnes, des services et des capitaux lorsque cela est justifié par des raisons d'ordre public ou de sécurité publique.

Sous réserve des cas dérogatoires susvisés, le Traité de l'UEMOA distingue, dans l'ensemble, la liberté de circulation et de résidence et la liberté d'établissement.

\section{a) Liberté de circulation et de résidence}

Sur le fondement de l'article 91 du Traité UEMOA, les ressortissants d'un État membre bénéficient sur l'ensemble du territoire de l'Union de la liberté de circulation et de résidence.

L'exercice de cette liberté implique :

- L'abolition entre les ressortissants des États membres de toute discrimination fondée sur la nationalité, en ce qui concerne la recherche et l'exercice d'un emploi, à l'exception des emplois dans la Fonction publique ;

- Le droit de se déplacer et de séjourner sur le territoire de l'ensemble des États membres ;

- Le droit de continuer à résider dans un État membre après y avoir exercé un emploi.

Le droit de résidence sur le territoire d'un État membre de la C.E.D.E.A.O. est reconnu aux citoyens désirant accéder ou non à une activité salariée et à l'exercer, à part les emplois de l'administration publique à moins d'une règlementation nationale contraire. Les citoyens auront les mêmes droits et libertés que les nationaux de l'État membre d'accueil, exception faite des droits politiques.

Toutefois, l'exercice de cette liberté peut être restreint, limité par des motifs justifiés d'ordre public, de sécurité publique et de santé publique.

\section{b) Liberté d'établissement}

Les ressortissants d'un État membre bénéficient du droit d'établissement dans l'ensemble $\mathrm{du}$ territoire de l'Union. Le droit d'établissement est le droit reconnu à un citoyen, ressortissant d'un État membre de l'Union, de s'installer ou de s'établir dans un État membre autre que son État d'origine, d'accéder à des activités économiques, de les exercer ainsi que de constituer et de gérer des entreprises et ou sociétés dans les conditions définies par la législation de l'État membre d'accueil pour ses ressortissants. Selon l'article $92 \S 2$ du Traité de l'UEMOA, "sont assimilées aux ressortissants des États membres, les sociétés et personnes morales constituées conformément à la législation d'un État membre et ayant leur 
siège statutaire, leur administration centrale ou leur principal établissement à l'intérieur de l'Union ».

Le droit d'établissement comporte l'accès aux activités non salariées et leur exercice ainsi que la constitution et la gestion d'entreprises, dans les conditions définies par la législation du pays d'établissement pour ses propres ressortissants, sous réserve des limitations justifiées par des raisons d'ordre public, de sécurité publique et de santé publique (article 92 §3).

Les ressortissants de chaque État membre peuvent fournir des prestations de services dans un autre État membre dans les mêmes conditions que celles que cet État membre impose à ses propres ressortissants, sous réserve des limitations justifiées par des raisons d'ordre public, de sécurité publique et de santé publique et sans préjudice des exceptions prévues par le présent Traité (article 93 Traité UEMOA) ${ }^{169}$.

Par dérogation aux articles 92 et 93 et sous réserve des mesures d'harmonisation des législations nationales mises en œuvre par l'Union, les États membres peuvent maintenir des restrictions à l'exercice, par des ressortissants d'autres États membres ou par des entreprises contrôlées par ceux-ci, de certaines activités lorsque ces restrictions sont justifiées par des raisons d'ordre public, de sécurité publique, de santé publique ou par d'autres raisons d'intérêt général. Les États membres notifient à la Commission toutes restrictions maintenues en vertu des dispositions de l'article $94 \S 1$ du Traité UEMOA. La Commission procède à une revue annuelle de ces restrictions en vue de proposer leur harmonisation ou leur élimination progressive (article 94 \$2 Traité UEMOA).

\section{La libre circulation des marchandises}

Le principe de la libre circulation des marchandises revêt un contenu (a) et est assorti de certaines restrictions (b).

\section{a) Le contenu du principe}

La circulation des marchandises est soumise à des principes s'inspirant de ceux en vigueur dans le cadre l'Accord Général sur les Tarifs Douaniers et le Commerce ${ }^{170}$. Ainsi, les États membres de l'Union s'abstiennent d'introduire entre eux tous nouveaux droits de douane à l'importation et à l'exportation ainsi que toutes taxes d'effet équivalent et d'augmenter ceux qu'ils appliquent dans leurs relations commerciales mutuelles.

169 Dans l'UEMOA et dans le cadre de la facilitation du droit d'établissement, le Conseil des ministres de l'UEMOA a édicté divers textes dont : la Directive n06/2005/CM/UEMOA du 16 décembre 2005 relative à la libre circulation et à l'établissement des médecins ressortissants de l'Union au sein de l'espace UEMOA ; la Directive $\mathrm{n}^{\circ} 07 / 2005 / \mathrm{CM} / \mathrm{UEMOA}$ du 16 décembre 2005 relative à la libre circulation et à l'établissement des architectes ressortissants de l'Union au sein de l'espace UEMOA ; le Règlement $\mathrm{n}^{\circ} 05 / 2006 / \mathrm{CM} / \mathrm{UEMOA}$ du 2 mai 2006 relatif à la libre circulation et à l'établissement des expertscomptables et des comptables agréés ressortissants de l'Union au sein de l'espace UEMOA; le Règlement $\mathrm{n}^{\circ} 10 / 2006 / \mathrm{CM} / \mathrm{UEMOA}$ du 25 juillet 2006 relatif à la libre circulation et à l'établissement des avocats ressortissants de l'Union au sein de l'espace UEMOA; le Règlement nº3/2008/CM/UEMOA du 28 mars 2008 relatif aux conditions d'exercice des professions d'intermédiaires de transport maritime au sein de l'UEMOA ; la Directive $\mathrm{n}^{\circ} 06 / 2008 / \mathrm{CM} / \mathrm{UEMOA}$ du 28 juin 2008 relative à la libre circulation et à l'établissement des pharmaciens ressortissants de l'Union au sein de l'espace UEMOA ; la Directive $\mathrm{n}^{\circ}$ 07/2008/CM/UEMOA du 28 juin 2008 relative à la libre circulation et à l'établissement des chirurgiensdentistes ressortissants de l'Union au sein de l'espace UEMOA.

170 En anglais, General Agreement on Tariff and Trade (GATT). 
En substance, ils s'engagent non seulement à ne pas établir, dans leurs relations mutuelles, de nouvelles barrières tarifaires mais aussi à ne pas augmenter les barrières tarifaires existantes.

En outre, les États membres de l'Union s'engagent à proscrire les barrières non tarifaires,

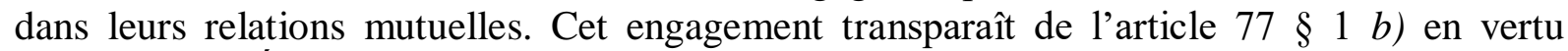
duquel, "les États membres s'abstiennent, dès l'entrée en vigueur du présent Traité [...] d'introduire entre eux de nouvelles restrictions quantitatives à l'exportation ou à l'importation ou des mesures d'effet équivalent, ainsi que de rendre plus restrictifs les contingents, normes et toutes autres dispositions d'effet équivalent ».

Dans leurs relations commerciales avec les États tiers, les États membres de l'Union devraient s'assurer que les tarifs douaniers appliqués aux marchandises en provenance des États tiers ne constituent pas un protectionnisme déguisé ${ }^{171}$.

\section{b) Les restrictions à la libre circulation des marchandises}

La libre circulation des marchandises ne revêt pas une portée absolue. Aussi, peut-elle être restreinte par les États membres de l'Union sur le fondement de l'article 79 du Traité UEMOA.

Ainsi, les États membres conservent la faculté de maintenir et d'édicter des interdictions ou des restrictions d'importation, d'exportation et de transit, justifiées par des raisons de moralité publique, d'ordre public, de sécurité publique, de protection de la santé ou de la vie des personnes et des animaux, de préservation de l'environnement, de protection des trésors nationaux ayant une valeur artistique, historique ou archéologique et de protection de la propriété industrielle et commerciale (article 79 \$ 1 Traité UEMOA).

Cependant, les interdictions ou restrictions appliquées en vertu de l'article $79 \S 1$ précité ne doivent constituer ni un moyen de discrimination arbitraire ni une restriction déguisée dans le commerce entre les États membres. Les États membres notifient à la Commission toutes les restrictions maintenues en vertu de l'article $79 \S 1$ du Traité de l'UEMOA. La Commission procède à une revue annuelle de ces restrictions en vue de proposer leur harmonisation ou leur élimination progressive.

\section{La politique commerciale}

L'analyse du contenu de la politique commerciale communautaire (a) précèdera les dérogations à celle-ci (b).

\section{a) Contenu}

La réalisation de la politique commerciale de l'Union nécessite l'adoption de certaines mesures. Au regard de l'article 82 du Traité de l'UEMOA, le Conseil des ministres de l'UEMOA adopte à la majorité des deux tiers (2/3) de ses membres, sur proposition de la Commission :

Conformément aux dispositions de l'article XXIV (5) (a) de l'Accord Général sur les Tarifs Douaniers et le Commerce (GATT), l'Union s'assure que l'incidence globale des droits de douane et des autres règlements du commerce vis-à-vis des pays tiers n'est pas plus restrictive que celle des dispositions en vigueur avant la création de l'Union. 
a) les mesures relatives à l'harmonisation des dispositions législatives, réglementaires et administratives des États membres nécessaires au fonctionnement de l'union douanière ;

b) les règlements relatifs au tarif extérieur commun (TEC) ;

c) les règlements fixant le régime de la politique commerciale avec les États tiers ;

d) le régime applicable aux produits du cru et de l'artisanat.

Dans la réalisation des objectifs définis à l'article 76 du Traité de l'UEMOA, l'Union respecte les principes de l'Accord Général sur les Tarifs Douaniers et le Commerce (GATT) en matière de régime commercial préférentiel (article 83 Traité de l'UEMOA). Il en résulte que l'Union se doit d'accorder le bénéfice de la libre circulation à tous les produits, quelle que soit leur origine, locale ou extracommunautaire. L'exigence de l'article 83 précité est conforme à l'article XXIV $\S 5 a$ ) et $b$ ) du GATT qui prescrit, en substance, que les participants à une intégration économique régionale doivent s'abstenir "d'opposer des obstacles au commerce avec les pays tiers ».

L'analyse des articles 84 et 85 du Traité de l'UEMOA permet d'affirmer que l'Union peut participer à des négociations commerciales multilatérales soit directement (article 84) soit par l'entremise de ses États membres (article 85).

\section{b) Dérogations}

En vertu de l'article 86 du Traité de l'UEMOA, les États membres sont autorisés à prendre, par dérogation aux règles générales de l'union douanière et de la politique commerciale commune, des mesures de protection destinées à faire face à des difficultés graves dans un ou plusieurs secteurs de leurs économies.

Les mesures de sauvegarde adoptées en vertu des règlements pris en application de l'article $86 \S 1$ précité ne peuvent excéder une durée de six (6) mois, éventuellement renouvelable. Elles doivent être autorisées par la Commission, tant dans leur durée que dans leur contenu, avant leur entrée en vigueur.

\section{Paragraphe 2: Le Protocole additionnel $n^{\circ}$ II relatif aux politiques sectorielles de l'UEMOA}

En vue de compléter les politiques économiques communes menées au niveau de l'Union, l'article $101 \mathrm{du}$ Traité de l'UEMOA institue un cadre juridique définissant les politiques sectorielles devant être mises en œuvre par les États membres. Ces politiques sont énoncées et définies dans le Protocole additionnel $\mathrm{n}^{\circ} 2$ du 29 janvier 2003 relatif aux politiques sectorielles de l'UEMOA.

Les politiques sectorielles visées par le Protocole additionnel $\mathrm{n}^{\circ} 2$ couvre divers domaines :

- Le développement des ressources humaines (article premier à l'article 4);

- L'aménagement du territoire (articles 5 à 6 ) ;

- La politique des transports et des télécommunications (articles 7 à 8);

- L'harmonisation de l'environnement (articles 9 à 12) ;

- La politique agricole (articles 13 à 16) ;

- La politique énergétique (articles 17 à 20); 
- La politique industrielle et minière (articles 21 à 23).

De l'énumération ci-dessus, le domaine de la politique des transports et des télécommunications ainsi que celui la politique industrielle et minière est celui qui entretient un rapport évident avec le PAA. Le premier des deux domaines précités a trait, entre autres, au transport maritime, singulièrement aux navires accostant au PAA tandis que le second domaine intéresse les rapports entre le PAA et les unités industrielles localisées dans le domaine public portuaire.

Quoi qu'il en soit, on remarquera que le cadre juridique découlant du droit primaire de l'UEMOA ne se limite pas aux seules activités du PAA. Celui-ci se révèle comme un élément parmi tant d'autres appréhendés par le droit primaire de l'UEMOA.

Hormis le droit primaire de l'UEMOA définissant le cadre général d'exercice des activités économiques au sein de l'Union, on note l'existence d'un cadre juridique spécifique découlant du droit dérivé de l'UEMOA Ce cadre juridique intéresse singulièrement les activités menées dans le domaine portuaire géré par le PAA.

\section{SECTION 2: Le cadre spécifique découlant du droit dérivé de l'UEMOA}

Le droit secrété par les organes de l'UEMOA relativement aux activités portuaires des États membres de l'Union sont multiples et diverses. En simplifiant quelque peu, on pourrait les énumérer les unes après les autres, de la manière suivante : d'abord, les textes juridiques exigeant une simplification des procédures administratives portuaires (paragraphe 1), ensuite, ceux réglementant l'exercice des activités connexes aux missions du Port (paragraphe 2) et, enfin, la soumission du Port autonome d'Abidjan aux normes prohibant les pratiques anticoncurrentielles (paragraphe 3).

\section{Paragraphe 1: Les exigences relatives à la simplification des procédures administratives portuaires}

L'UEMOA, à travers deux instruments juridiques, exige de ses États membres qu'ils procèdent à la simplification des procédures administratives au niveau de leurs ports respectifs. Ce sont, d'une part, le Code des douanes de l'UEMOA (A) et la recommandation $\mathrm{n}^{\circ} 02 / 2002 / \mathrm{CM} / \mathrm{UEMOA}$, d'autre part (B).

\section{A. Le Code des douanes de l'UEMOA ${ }^{172}$}

Le Code des douanes de l'UEMOA s'intéresse, entre autres, à la célérité des formalités douanières à remplir lors de l'importation (ou de l'exportation) des marchandises par voie de mer. Cela transparaît particulièrement des articles 43 et 138 du Code des douanes de l'UEMOA.

Au regard de l'article 43 précité, obligation est faite au capitaine de navire de déclarer les marchandises à bord de son navire lorsqu'il entre dans le territoire douanier de l'UEMOA ${ }^{173}$.

172 Institué par l'Annexe au Règlement n09/2001/CM/UEMOA du 26 novembre 2001.

173 En vertu de l'article 5 de l'Annexe au Règlement nº9/2001/CM/UEMOA du 26 novembre 2001, le territoire douanier de l'UEMOA comprend : le territoire de la République du Bénin, le territoire du Burkina 
À cet effet, il est tenu de déposer certains documents au bureau de douane, dans un délai de 24 heures maximum. Les documents exigés sont de trois types :

a) à titre de déclaration sommaire, le manifeste de la cargaison, sa traduction authentique dans la langue officielle de l'État membre concerné lorsque cela s'avère nécessaire pour permettre le traitement de la déclaration en détail des marchandises ;

b) Les manifestes spéciaux de provisions de bord et des marchandises de pacotille appartenant aux membres de l'équipage ;

c) Les chartes-parties ou connaissements, acte de nationalité et tous autres documents qui pourront être exigés par l'Administration des douanes en vue de l'application des mesures douanières.

La déclaration doit être faite même si le navire se trouve sur lest (article 43 § 2). Cependant, le délai de 24 heures ne court pas les dimanches et jours fériés (article $43 \S 3$ ).

La volonté de parvenir à une célérité dans le traitement des marchandises importées sur le territoire douanier de l'Union transparaît également de l'article 138 du Code des douanes de l'UEMOA. En vertu de cette disposition, la durée de stockage dans un entrepôt industriel marchandises importées sous ne doit pas excéder un an. Pour comprendre cette exigence, il importe de saisir, au préalable, la notion d'entrepôt de douanes, et celle d'entrepôt industriel.

Relativement à l'entrepôt de douanes. Au regard de l'article $119 \mathrm{du}$ Code des douanes de l'UEMOA, le régime de l'entrepôt de douane est le régime douanier en application duquel les marchandises importées sont stockées sous contrôle de la douane dans un lieu désigné à cet effet (entrepôt de douane) sans paiement des droits et taxes à l'importation. Sauf dispositions spéciales contraires, la mise en entrepôt :

- $\quad$ suspend l'application des prohibitions et autres mesures économiques, fiscales ou douanières dont sont passibles les marchandises admises en entrepôt ;

- entraine tout ou partie des effets attachés à l'exportation des marchandises entreposés.

Il existe trois catégories d'entrepôt de stockage :

- l'entrepôt public ou réel,

- l'entrepôt privé,

- l'entrepôt spécial.

Relativement à l'entrepôt industriel. L'entrepôt industriel est un établissement placé sous le contrôle des autorités douanières où les entreprises qui travaillent pour l'exportation ou, à la fois, pour l'exportation et le marché intérieur peuvent être autorisées à procéder, pour ces deux destinations, à la mise en œuvre des marchandises non communautaires ${ }^{174}$ en suspension des droits et taxes dont elles sont passibles en raison de l'importation (article 135).

Faso, le territoire de la République de Côte d'Ivoire, le territoire de la République de Guinée-Bissau, le territoire de la République du Mali, le territoire de la République du Niger, le territoire de la République du Sénégal, le territoire de la République Togolaise. Sont compris dans le territoire douanier de l'Union, les eaux territoriales et l'espace aérien des États membres visés ci-dessus.

174 Au regard de l'article premier du Code des douanes de l'UEMOA, les marchandises communautaires celles qui satisfont aux règles d'origine fixées par l'Union. En vertu de l'article $15 \mathrm{du}$ Code des douanes de 
L'entreprise bénéficiant du régime de l'entrepôt industriel doit domicilier toutes ses opérations auprès d'un même bureau de douane (article 136).

L'entrepôt industriel est accordé par les autorités nationales compétentes qui déterminent notamment :

- la nature et l'espèce tarifaire des produits dont l'importation est autorisée ;

- les produits compensateurs à représenter ;

- le taux de rendement et le taux de déchets admis ;

- le pourcentage de réexportation obligatoire des produits compensateurs.

Lorsqu'une entreprise possède plusieurs usines, seuls les établissements désignés dans l'autorisation d'exercer bénéficient du régime (article 137).

La durée de séjour des marchandises en entrepôt industriel ne peut excéder un an, au terme duquel les produits compensateurs doivent être mis à la consommation, exportés hors du territoire douanier de l'Union, placés en zone franche ou sous un autre régime douanier, détruits sous le contrôle des autorités douanières, ou abandonnés au profit du Trésor Public (article 138 § 1). Une prorogation de délai peut être accordée dans les cas dûment justifiés, par l'autorité ayant accordé l'entrepôt industriel, et moyennant renouvellement des engagements souscrits (article $138 \S 2$ ).

En sus des dispositions précitées du Code des douanes de l'UEMOA qui visent la célérité des formalités douanières, on note l'existence de la Recommandation $\mathrm{n}^{\circ} 02 / 2002 / \mathrm{CM} / \mathrm{UEMOA}$ relative à la simplification des procédures administratives et de transit portuaire au sein de l'UEMOA.

\section{B. La recommandation $n^{\circ} 02 / 2002 / C M / U E M O A^{175}$}

L'article premier de la recommandation précitée invite les États membres de l'UEMOA à adopter le Programme de simplification et d'harmonisation des procédures administratives et de transit portuaire ainsi que ses annexes.

Les États membres étaient invités à créer, au plus tard le 31 décembre 2002, des Comités nationaux de facilitation des transports, dont les attributions et les modalités de fonctionnement sont précisées à l'annexe I du programme de simplification et d'harmonisation des procédures administratives et de transit portuaire.

En outre, la Recommandation $n^{\circ} 02 / 2002 / C M / U E M O A$ invite les États membres à ratifier deux conventions internationales relatives à la simplification des procédures administratives ou douanières. Ce sont : la Convention visant à faciliter le trafic maritime international, dite Convention FAL, signée le 09 avril 1965, à Londres ; et la Convention internationale pour la simplification et l'harmonisation des régimes douaniers, dite Convention de Kyoto révisée, signée le 18 mai 1973 à Kyoto ${ }^{176}$.

Il est à remarquer que la Recommandation ci-dessus est un acte juridique de portée non obligatoire. À cet égard, la Recommandation du Conseil des ministres de l'UEMOA se rapproche de celle en vigueur dans l'Union Européenne. En effet, en droit communautaire européen, une recommandation est un acte du Conseil (de l'Europe) ou de la Commission (européenne) demandant aux destinataires de suivre un comportement donné sans pour autant

l'UEMOA, les règles applicables pour la détermination de l'origine des marchandises sont fixées par Protocole additionnel de la Conférence des Chefs d'État et de Gouvernement.

175 Recommandation $\mathrm{n}^{\circ}$ 02/2002/CM/UEMOA du 27 juin 2002 relative à la simplification et à l'harmonisation des procédures administratives et de transit portuaire au sein de l'UEMOA.

176 Notamment en ses dispositions pertinentes relatives à la simplification et à l'harmonisation des procédures douanières portuaires. 
les lier (article 189 de l'ancien Traité CEE ; article 161 de l'ancien Traité CEEA ; article 288 du TFUE) $)^{177}$.

Toutefois, il en va autrement dans le cas du Traité instituant la Communauté européenne du charbon et de l'acier (CECA). En effet, la recommandation était l'acte de la Haute Autorité de la CECA comportant obligation dans les buts qu'il assigne, mais laissant aux destinataires le choix des moyens propres à atteindre ces buts (article 14 Traité CECA) ${ }^{178}$. Il est vrai que la CECA a disparu. Cependant, la texture du droit qu'elle avait généré continue d'inspirer d'autres organisations d'intégration communautaire. Ainsi, la recommandation, dans le cadre de la (défunte) CECA, présentait des similitudes avec la directive telle qu'elle a cours actuellement aussi bien dans l'Union européenne que dans l'UEMOA.

Sur la base de la Recommandation n02/2002/CM/UEMOA, l'accomplissement des obligations incombant aux États membres de l'Union dépendra de leur bon vouloir à moins qu'ils ne soient juridiquement liés par suite de la ratification des deux conventions précitées de Londres et de Kyoto.

Hormis les procédures administratives, le droit de l'UEMOA s'attelle à réglementer l'exercice de certaines activités connexes aux missions du PAA.

\section{Paragraphe 2 : La réglementation d'activités connexes aux missions du Port}

Les textes juridiques communautaires encadrant l'exercice de certaines activités portuaires sont au nombre de quatre (04). Chronologiquement, le premier d'entre eux est la Recommandation $n^{\circ} 03 / 1998 / \mathrm{CM} / \mathrm{UEMOA}$. Elle a été adoptée le 03 juillet 1998. Cependant, elle ne revêtait pas une force juridique obligatoire. Son application dépendait donc de la bonne volonté de chaque État membre. Cette lacune a été comblée par les textes juridiques postérieurs qui, eux, obligent les États membres de l'Union. Ce sont respectivement :

- La Directive n03/2008/CM/UEMOA du 28 mars 2008 relative aux fournisseurs de services portuaires au sein de l'UEMOA ;

- La Directive n ${ }^{\circ}$ 4/2008/CM/UEMOA du 28 mars 2008 portant mise en place d'un cadre institutionnel harmonisé du sous-secteur maritime au sein de l'UEMOA ;

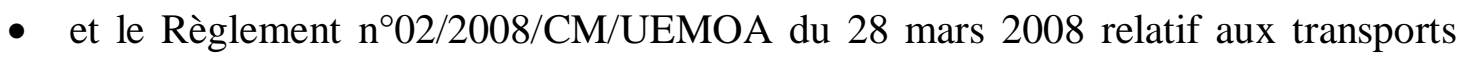
maritimes au sein de l'UEMOA.

177 L'article 189 du Traité instituant la Communauté économique européenne (CEE), l'article 161 de l'ancien traité instituant la Communauté européenne de l'énergie atomique (CEEA ou Euratom) sont rédigés de la même manière. Ainsi, chacun des articles précités dispose : "Pour l'accomplissement de leur mission et dans les conditions prévues au présent Traité, le Conseil et la Commission arrêtent des règlements et des directives, prennent des décisions et formulent des recommandations ou avis [...] Les recommandations et les avis ne lient pas ». L'article 288 de la version consolidée du Traité sur le fonctionnement de 1'Union Européenne (TFUE) présente une légère différence en début de rédaction lorsqu'il dispose : «Pour exercer les compétences de l'Union, les institutions adoptent les règlements, des directives, des décisions, des recommandations et des avis [...] Les recommandations et les avis ne lient pas ».

178 En vertu de l'article 14 du Traité instituant la CECA, «pour l'exécution des missions qui lui sont confiées et dans les conditions prévues au présent Traité, la Haute Autorité prend des décisions, formule des recommandations ou émet des avis [...] Les recommandations comportent obligation dans les buts qu'elles assignent, mais laissent à ceux qui en sont l'objet le choix des moyens propres à atteindre ces buts...». 
Ces trois textes, toutes adoptées à Dakar, revêtent, en revanche, une force juridique obligatoire ${ }^{179}$. Aussi, convient-il de les analyser l'un après l'autre.

\section{A. La Directive $n^{\circ} 03 / 2008 / C M / U E M O A^{180}$}

Cette Directive détermine les règles générales applicables à trois fournisseurs de services portuaires. Ce sont les pilotes (1), les remorqueurs (2), les avitailleurs de navire (3) et les manutentionnaires (4).

\section{Les pilotes}

L'article $3 \S 1$ de la Directive précitée définit le pilote comme un capitaine breveté et expérimenté, commissionné par l'État membre pour assister les capitaines dans la conduite des navires à l'entrée, à la sortie ou lors de leurs déplacements dans les ports, rades, eaux maritimes, fleuves et canaux.

L'alinéa 2 de la Directive fait obligation aux pilotes d'avoir une formation supérieure en navigation maritime et justifier d'une expérience éprouvée en la matière et dans les questions navales.

On remarquera le laconisme quant au nombre d'années à l'issue duquel le pilote sera réputé être expérimenté.

Les alinéas 3 fait obligation aux États membres de l'Union de s'assurer de la formation appropriée du pilote ainsi que de son aptitude physique à l'exercice de sa fonction. En outre, l'alinéa 4 oblige les États membres à s'assurer du maintien des aptitudes techniques et physiques du pilote. Cette dernière exigence traduit l'importance indéniable de l'Académie régionale des sciences et techniques de la mer (A.R.S.T.M.) dans la formation des gens de mer, à travers notamment les formations dispensées dans les filières de navigation, d'une part, et les filières industrielles, d'autre part. Les premières débouchent sur les qualifications d'Officier Pont ${ }^{181}$, d'Officier mécanicien ${ }^{182}$, et de Sous-officier ${ }^{183}$. Les secondes, à savoir les filières industrielles, débouchent sur une multitude et une diversité de qualifications ${ }^{184}$.

\section{Les remorqueurs}

La notion de remorqueur est un dérivé du verbe remorquer. De ce verbe, est issue la notion de remorquage. Celui-ci est défini comme la traction d'un bâtiment de mer ou de

179 Tous ces textes juridiques trouvent leur analogue en droit communautaire européen à travers précisément le Règlement (UE) 2017/352 du Parlement européen et du Conseil du 15 février 2017, établissant un cadre pour la fourniture de services portuaires et des règles communes relatives à la transparence financière des ports. Ce Règlement a été publié le 3 mars 2017, au Journal officiel de l'Union européenne (JOUE), n ${ }^{\circ} \mathrm{L}$ 57, pp. 1-18.

180 Directive $\mathrm{n}^{\circ}$ 03/2008/CM/UEMOA du 28 mars 2008 relative aux fournisseurs de services portuaires au sein de l'UEMOA.

181 Lieutenant de navire de commerce, Second capitaine de navire de commerce, Commandant de navire de commerce.

182 Lieutenant mécanicien de navire de commerce, Second mécanicien de navire de commerce, Chef mécanicien de navire de commerce.

183 Chef de Quart machine, Chef de Quart pont, Maître de Port, Officier de Port.

184 Ces qualifications sont celles de : Thermicien, Maintenancier de tout type d'appareil ; Maintenancier des appareils de communication; Maintenancier en conduite et entretien des groupes électrogènes ; Maintenancier en conduite et entretien de moteurs diesel ; Maintenancier en conduite des installations thermiques ; Responsable technique d'usine ; Maintenancier des machines techniques. 
rivière par un autre bâtiment appelé remorqueur ${ }^{185}$. À ce titre, le remorquage participe de l'assistance maritime. Cette dernière est un secours porté par un navire à un navire en danger. Elle se distingue donc du sauvetage, qui concerne les épaves ${ }^{186}$.

Sur le fondement de l'article $4 \S 1$ de la Directive ${ }^{\circ}$ 03/2008/CM/UEMOA, l'activité de remorquage est un service public que les États membres de l'Union concèdent à des entreprises publiques ou privées spécialisées après appel d'offres. Chaque État membre (le concédant) veille à ce que la société de remorquage (le concessionnaire) s'acquitte de son cahier de charges. La Directive semble reconduire une prérogative de puissance publique - le pouvoir de contrôle - généralement reconnue à l'Administration publique lorsqu'elle conclut un contrat administratif ${ }^{187}$; la concession de service public étant un contrat administratif.

\section{Les avitailleurs de navire}

Ce sont des personnes agrées par l'État qui se livrent à l'avitaillement. Celui-ci peut être soit une activité soit le résultat de cette activité. En tant qu'activité, l'avitaillement se présente comme l'approvisionnement d'un navire ou d'un aéronef prêt à partir en carburant, vivres et produits nécessaires à la vie à bord. En tant que résultat d'une activité, l'avitaillement est l'ensemble des vivres embarqués pour la nourriture de l'équipage et des passagers d'un navire ou d'un aéronef ${ }^{188}$.

En vertu de l'article 5 de la Directive $n^{\circ} 03 / 2008 / \mathrm{CM} /$ UEMOA, les avitailleurs de navires sont des personnes morales de droit privé agréées par l'État membre dans le port duquel ils fournissent leurs services.

En Côte d'Ivoire, la profession d'avitailleur est régie par le décret n97-615 du 16 octobre 1997 portant réglementation de l'exercice de la profession d'avitailleur maritime dans les ports ivoiriens. Est avitailleur maritime, toute personne morale auxiliaire du transport maritime chargée de fournir à un navire son approvisionnement. Selon l'article 3 du décret précité, l'avitaillement maritime s'exécute à quai et au mouillage ainsi que sur les plateformes pétrolières, en présence des agents des douanes. L'accès à bord du navire étant soumis à la présentation par l'avitailleur des propositions du consignataire.

\section{Les manutentionnaires}

L'article premier de la Directive $\mathrm{n}^{\circ} 03 / 2008 / \mathrm{CM} / \mathrm{UEMOA}$ du 28 mars 2008 relative aux fournisseurs de services portuaires au sein de l'UEMOA définit le manutentionnaire comme un auxiliaire de transport maritime faisant profession habituelle de procéder à titre principal aux opérations matérielles de chargement et de déchargement des navires, de manipulation des marchandises sur les quais, terre-pleins et hangars et d'effectuer, s'il y a lieu, des opérations juridiques de réception et de reconnaissance de la cargaison.

La manutention portuaire, en général, comprend les opérations d'embarquement, d'arrimage, de désarrimage et de débarquement des marchandises et les opérations de mise et de reprise des marchandises sur terres pleins ou magasins en vertu d'un contrat qui donne lieu à une rémunération.

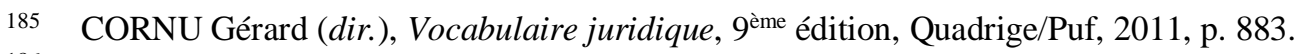

186 Idem, p. 92.

187 L'Administration concédante doit exercer ce pouvoir de contrôle dans le respect strict de la liberté de gestion reconnue au concessionnaire. Cf. CE 18 juillet 1930, Compagnie des chemins de fer PLM et autres, RDP 1931, p. 141.

188

CORNU Gérard (dir.), op. Cit., p. 113.
} 
Elle se distingue de l'acconage en ce sens que ce dernier comprend les opérations tendant à assurer la réception, le pointage et la reconnaissance à terre des marchandises embarquées ou débarquées ainsi que leur gardiennage, jusqu'à leur embarquement ou leur délivrance au destinataire.

Les manutentionnaires assurent les opérations de manutention, portage, déplacement ou chargement de marchandises, de produits ou d'objets. Ils réalisent les opérations manuellement ou à l'aide d'engins spéciaux de manutention.

L'agrément de manutentionnaire portuaire et/ou de consignataire maritime ne peut être accordé qu'aux personnes régulièrement constituées et justifiant d'un capital social minimum $^{189}$. Un dossier de demande d'agrément, adressé au ministre chargé de la Marine Marchande ${ }^{190}$ est à retirer et à retourner à la Direction des Transports Maritimes et Fluviolagunaires, en huit (08) exemplaires reliés ${ }^{191}$.

189 Le capital social est fixé comme suit :

Port de commerce :

- Cent cinquante millions (150.000.000) F CFA pour la manutention portuaire

- Cinquante millions (50.000.000) F CFA pour la consignation maritime

- Deux cent millions (200.000.000) F CFA en cas de cumul des deux activités

Port de pêche :

- Soixante-dix millions (70.000.000) F CFA pour la manutention portuaire

- Trente millions (30.000.000) F CFA pour la consignataire maritime

- Cent millions (100.000.000) F CFA en cas de cumul des deux activités

En Côte d'Ivoire, cette compétence est actuellement exercée par le Ministère des transports vu que le Ministère de la marine marchande n'existe plus depuis 1992.

191 Le dossier de demande d'agrément comprend les pièces suivantes :1- Quelle que soit la forme de la société :

- Une assurance multirisque pour la manutention;

- Une assurance de responsabilité civile pour la consignation;

- Une copie des avis publié au journal d'annonces légales;

- Une copie des statuts de la société;

- Une copie du/des Certificat de dépôts des statuts au greffe du tribunal;

- Un extrait du/des registre de commerce;

- Une déclaration fiscale d'existence;

- Une copie du détail des charges prévisionnelles d'exploitation;

- Une prévision d'investissement en équipements et matériels;

- Une copie du schéma de la situation géographique de la société;

- Une attestation de domiciliation bancaire;

- Une lettre d'intention de collaboration de la part d'un armateur, d'un exploitant de navire, d'un affréteur;

- Un certificat de souscription au capital social délivré par un notaire;

- Une lettre d'engagement au respect de la réglementation en vigueur;

- Cartes grises des véhicules et engins.

2- Sont également exigés :

Pour les sociétés anonymes (S.A)

- Une copie du procès-verbal de l'assemblée générale des actionnaires au cours de laquelle a été désigné le Président Directeur Général et, éventuellement, le Directeur Général ou l'administrateur ayant reçu délégation, conformément aux dispositions prévues dans les statuts de la société et dans la législation relative aux sociétés anonymes.

Pour les autres types de sociétés:

- Une photocopie de la carte nationale d'identité ou de toute autre pièce en tenant lieu, du représentant légal;

- Un extrait du casier judiciaire, datant de moins de trois mois, du représentant légal;

- Une copie du procès-verbal de l'Assemblée Générale des associés au cours de laquelle ont été désignés le ou les gérants s'il n'est pas ou s'ils ne sont pas gérants statuaires ;

- Le curriculum vitae du gérant. 


\section{B. La Directive $n^{\circ} 04 / 2008 / C M /$ UEMOA $^{192}$}

Cette directive pourrait être perçue comme un renforcement de la force juridique du programme commun de développement du sous-secteur tel que contenu dans la Recommandation $n^{\circ}$ 03/1998/CM/UEMOA, du 03 avril 1998.

Cette recommandation, comme l'indique son intitulé, ne revêtait pas une force juridique contraignante. Cette lacune a été comblée par l'adoption de la Directive $n^{\circ}$ 04/2008/CM/UEMOA. Celle-ci se distingue, entre autres, par sa force juridique obligatoire même si elle laisse la latitude à chaque État de déterminer librement les modalités de mise en œuvre des exigences contenues dans la directive précitée.

Dans l'ensemble, la directive précitée vise l'harmonisation des actions des différentes institutions publiques ou privées intervenant dans le sous-secteur maritime au niveau des États membres de l'Union, ainsi que la prise en charge effective et efficace des interventions des États membres en mer. Pour ce faire, la Directive précitée fait obligation auxdits États de procéder à la mise en place d'un cadre institutionnel harmonisé capable de prendre en charge efficacement leurs politiques maritimes respectives.

Enfin, la Directive vise la simplification et l'harmonisation des procédures administratives et de transit dans les ports des États membres de l'Union et le rehaussement de l'efficacité des diverses activités professionnelles qui y sont exercées.

\section{Le Règlement n ${ }^{\circ} 02 / 2008 / C M / U E M O A^{193}$}

Le Règlement $n^{\circ} 02 / 2008 / C M / U E M O A$ énonce, d'une part, des règles communes aux opérateurs maritimes (1) et, d'autre part, des règles spécifiques aux transports maritimes dans l’Union (2).

\section{Règles communes aux opérateurs maritimes}

Ces règles communes énoncent des considérations générales (a) ainsi que des règles d'exploitation des services de transport maritime (b).

\section{a) Considérations générales}

Relativement à son champ d'application, le Règlement vise les transports maritimes intérieurs, les transports maritimes intracommunautaires et les transports maritimes internationaux au départ ou à destination d'un port d'un État membre de l'Union, qu'il s'agisse de transport de passagers ou de marchandises.

Chaque Etat membre détient un droit de trafic maritime sur les cargaisons générées par son commerce extérieur. Il reconnaît le même droit aux autres États membres. En vertu de ce droit de trafic, chaque État membre de l'Union jouit de la prérogative reconnue à un État sur le trafic maritime généré par son commerce extérieur. Concrètement, ce droit de trafic fonde l'État à prélever des taxes sur les marchandises qui viendraient à être embarquées ou débarquées à partir de son ou ses ports.

192 harmonisé du sous-secteur maritime au sein de l'UEMOA.

193 Règlement $\mathrm{n}^{\circ} 02 / 2008 / \mathrm{CM} / \mathrm{UEMOA}$ du 28 mars 2008 relatif aux transports maritimes au sein de l'UEMOA. 


\section{b) Règles d'exploitation des services de transport maritime}

Ces règles s'attellent portent sur la conclusion de contrats de service public, les conférences maritimes, les conditions de sécurité à respecter lors du chargement du navire.

Le contrat de service public est celui conclu entre les autorités compétentes d'un État membre de l'Union et un armateur communautaire dans le but de fournir au public des services de transport pouvant répondre à certaines normes, notamment de continuité, de régularité, de capacité, de qualité, de prix, en particulier pour certaines catégories de voyageurs ou pour certaines liaisons.

La conclusion des contrats de service public avec des armateurs communautaires doit se faire sur une base non discriminatoire à l'égard de tous les armateurs concernés. Ces contrats donnent lieu à rémunération convenue entre parties. Il est évident qu'en vertu du régime juridique de la concession de service public, le concessionnaire, en l'occurrence l'armateur communautaire, se rémunère sur les usagers. En effet, la concession de service est un mode de gestion par lequel la collectivité charge son cocontractant de réaliser des travaux de premier établissement et d'exploiter à ses frais le service pendant une durée déterminée, en prélevant directement auprès des usagers du service public des redevances qui lui restent acquises ${ }^{194}$. Comme le note le professeur Dégni-Ségui, le critère tiré de la réalisation des premiers travaux est celui qui distingue, d'une part, la concession de service public et, d'autre part, le contrat d'affermage. Celui-ci est un mode de gestion du service public dans lequel l'Administration, la collectivité affermente, charge une personne physique ou morale, le fermier ${ }^{195}$, de gérer un service public, en se rémunérant sur les usagers, en agissant à ses risques et périls. La différence se situe au niveau des investissements: le fermier se charge uniquement de l'exploitation du service public, les investissements initiaux ayant été déjà réalisés par la collectivité affermente. Dès lors, le fermier doit verser une redevance à la collectivité affermente ${ }^{196}$.

Dans le cadre spécifique de la concession de service public conclue conformément au Règlement $n^{\circ} 02 / 2008 / \mathrm{CM} / \mathrm{UEMOA}$, le concessionnaire, l'armateur communautaire, versera au concédant, l'État membre de l'Union, une redevance représentant vraisemblablement le prix de l'utilisation privative du domaine public maritime de ce dernier.

Une conférence maritime, sur le fondement de l'article premier du Règlement précité, est le regroupement d'au moins deux transporteurs exploitants de navires qui assurent des services internationaux réguliers pour le transport de marchandises sur une ligne ou des lignes particulières dans des limites géographiques déterminées et qui est régi par un accord ou un arrangement, quelle qu'en soit la nature, dans le cadre duquel ces transporteurs opèrent en appliquant des taux de fret uniformes ou communs et toutes autres conditions de transport concertées pour la fourniture de services réguliers.

194 CE 30 mars 1916, Compagnie générale d'éclairage de Bordeaux, GAJA, n³0, $18^{\mathrm{ème}}$ édition, 2011, p. 179; De VILLIERS Michel et De BERRANGER Thibaut (dir.), Droit public général (Institutions politiques,

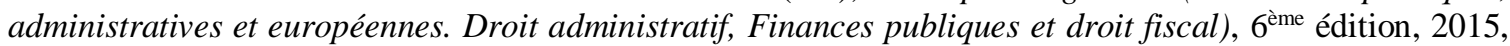
n596, p. 551.

195 La notion de fermier, dans les présents travaux, ne devrait pas être confondue avec celle de fermier agricole. Ce dernier est une personne qui exploite un domaine agricole à ferme, c'est-à-dire qu'il exploite un domaine agricole sous le régime de la location de longue durée avec un loyer annuel fixe (le fermage) qu'il verse au propriétaire du domaine. Dans le cas du contrat d'affermage (qui, on le souligne, est un contrat administratif se rapprochant de la concession vue que tous deux sont des délégations de service public opérées par l'Administration), l'État (ou une autre personne morale de droit public interne) confie la réalisation de la mission de service public à une personne de droit privé. Cette dernière, en sa qualité de cocontractant de l'Administration, est appelée fermier (tout court).

196 DÉGNI-SÉGUI René, Droit administratif général, Tome 2 : L'action administrative, Abidjan, CEDA, 2002, p. 411. 
On remarquera que le champ d'activité de la conférence maritime n'est pas circonscrit aux ports des États membres de l'Union. Le critère pertinent est celui de l'utilisation d'un ou plusieurs ports d'un ou plusieurs États membres de l'Union.

En vertu de l'article 6 du Règlement précité, les Conférences maritimes desservant les côtes des États membres de l'Union, sont soumises à la règle de la déclaration préalable, sous réserve du respect de la réglementation communautaire. Cette déclaration est faite auprès de l'Autorité maritime compétente de l'État membre dont le port est concerné et auprès de la Commission. Toute Conférence maritime desservant les côtes d'un État membre de l'Union, doit s'ouvrir aux compagnies de transport maritime des États membres.

Les conditions de sécurité à respecter lors du chargement du navire sont définies aux articles 7, 8 et 9 du Règlement. En vertu de l'article 7, un navire desservant un port de l'Union, quel que soit son pavillon, ne peut effectuer des services de transport mixte de fret et de passagers que, s'il offre les aménagements adéquats pour ce faire. Toute modification ou adaptation non certifiée par une société de classification agréée dans l'Union est interdite, même dans les cas de dérogations accordées par le certificat de navigabilité.

En outre, tout navire, quel que soit son pavillon, qui embarque du fret ou des passagers au départ d'un port d'un Etat membre de l'Union, quelle qu'en soit la destination, doit se conformer aux conditions de sécurité et de sûreté requises à cet effet. Les prescriptions figurant sur le certificat de navigabilité sont d'ordre public (article 8).

La sanction à la non-conformité aux deux exigences ci-dessus est l'interdiction d'appareiller conformément à l'article 9 qui dispose : "Tout navire qui ne se conforme pas aux dispositions des articles 7 et 8 du présent Règlement, fera l'objet d'une interdiction formelle d'appareiller dans l'Union par décision motivée, ordonnée par l'Autorité maritime compétente. La mainlevée de l'interdiction est donnée, si l'irrégularité est corrigée».

\section{Règles spécifiques s'appliquant au transport maritime dans l'Union}

Ces règles spécifiques sont relatives, d'une part, aux conditions d'accès aux transports maritimes intérieur et intercommunautaire (a) et, d'autre part, aux conditions d'accès au transport international (b).

\section{a) Conditions d'accès aux transports maritimes intérieur et intracommunautaire}

Sur le fondement de l'article premier du Règlement n02/2008/CM/UEMOA, seules les personnes morales régulièrement constituées peuvent être agréées en qualité d'armateur communautaire. Est considérée comme armateur communautaire :

- soit la compagnie de transport maritime agréée, conformément aux règles en vigueur dans l'Union, dont le principal établissement est situé dans un État membre et dont le contrôle effectif est exercé dans cet État ;

- soit la compagnie de transport maritime agréée, conformément aux règles en vigueur dans l'Union, établie en dehors de celle-ci et contrôlée par des ressortissants de l'un des États membres, si ses navires sont immatriculés dans un État de l'UEMOA et battent pavillon de cet État membre conformément à sa législation. 
Les procédures d'octroi, de suspension et de retrait de l'agrément sont définies par la Commission de l'UEMOA, par voie de Règlement d'exécution ${ }^{197}$. En vertu de l'article $24 \mathrm{du}$ Traité de l'UEMOA, ce règlement d'exécution, pris par la Commission de l'Union a la même force juridique que le Règlement du Conseil des ministres, en exécution duquel il est pris.

Seuls les armateurs communautaires sont habilités à effectuer des services de transport maritime intérieur et/ou intracommunautaire. Le transport par feeder ${ }^{198}$, en tant que partie intégrante de l'exécution d'un transport international unique, n'est pas visé par les dispositions du Règlement $n^{\circ} 02 / 2008 / C M / U E M O A$.

\section{b) Conditions d'accès au transport international}

Le Règlement $n^{\circ} 02 / 2008 / \mathrm{CM} / \mathrm{UEMOA}$, en son article 13 , pose le principe du libre accès aux services de transport maritime international des États membres de l'Union, au profit des armateurs étrangers. Ce libre accès devra se faire sur une base commerciale et non discriminatoire, sous réserve de réciprocité.

À ce titre, les armateurs communautaires et les armateurs étrangers sont soumis aux mêmes conditions d'exploitation au départ ou à destination d'un port de l'Union et en provenance ou vers les pays tiers.

Entre autres conséquences de l'adoption du Règlement précité, les États membres de l'Union s'abstiennent, dès l'entrée en vigueur dudit Règlement, de conclure ou de maintenir avec les pays tiers, des accords maritimes bilatéraux sur des arrangements en matière de répartition des cargaisons.

Sans préjudice des redevances et taxes portuaires, les armateurs communautaires et étrangers exploitant un service de transport international, sont soumis au paiement d'une redevance sur le droit de trafic conformément à l'article 4 du Règlement n02/2008/CM/UEMOA. Le produit de cette redevance est destiné à alimenter des fonds nationaux et un fonds régional de développement du sous-secteur maritime de l'Union. Le taux et les modalités pratiques de perception et de répartition de cette redevance seront précisés par la Commission, par voie de Règlement d'exécution.

\section{Paragraphe 3: La soumission du Port aux normes communautaires anticoncurrentielles}

Les normes communautaires anticoncurrentielles prohibent, en général, les situations de monopole dans l'espace UEMOA (A). La situation observée au sein du PAA est loin de conforter absolument cette prohibition au regard de l'affaire ICTSI c. Groupement Bolloré (B).

197 Article $11 \mathrm{du}$ Règlement n02/2008/CM/UEMOA.

198 Feeder est le nom donné à un navire de petit tonnage qui effectue le pré et le post transports de conteneurs vers des ports où n'escale pas le navire mère de Ligne Régulière. Il permet donc l'éclatement sur différents ports d'une cargaison apportée sur un port principal par un grand bâtiment faisant peu d'escales ou inversement collecter les marchandises pour les regrouper sur le port principal. On parle de "feedering" pour décrire cette activité de transport sur de courte distance. $C f$. https://www.glossaireinternational.com/pages/tous-les-termes/feeder-navire.html. Document consulté le dimanche 10 février 2019. 


\section{A. La prohibition des situations de monopole dans l'espace UEMOA}

Le Traité de l'UEMOA, en son article 88, prohibe formellement :

a) Les accords, associations et pratiques concertées entre entreprises, ayant pour objet ou pour effet de restreindre ou de fausser le jeu de la concurrence à l'intérieur de l'Union;

b) Toutes pratiques d'une ou de plusieurs entreprises, assimilables à un abus de position dominante sur le marché commun ou dans une partie significative de celui-ci ;

c) Les aides publiques susceptibles de fausser la concurrence en favorisant certaines entreprises ou certaines productions.

L'article 88 précité a fait l'objet d'une mesure d'application intervenue au moyen du

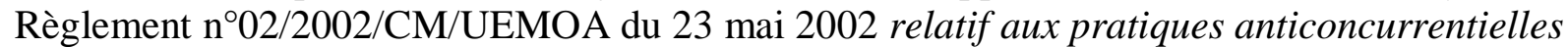
à l'intérieur de l'UEMOA. L'article 2 du Règlement de 2002 précité prohibe les pratiques anticoncurrentielles. Celles-ci consistent en des ententes anticoncurrentielles (article 3), des abus de position dominante (article 4), des aides d'État (article 5) et des pratiques anticoncurrentielles imputables aux États (article 6).

Afin d'éviter la constitution de situation monopolistique, le Règlement de 2002 précité pose le principe général de l'obligation pour les États membres de l'UEMOA à procéder à la libéralisation pour ce qui concerne les entreprises chargées de la gestion de services d'intérêt économique général ou présentant le caractère d'un monopole fiscal ${ }^{199}$. Il s'agit d'une prohibition implicite qui ne revêt pourtant pas un caractère absolu. La Commission de l'UEMOA peut donc, sur le fondement de l'article $6 \S 2$ du Règlement $\mathrm{n}^{\circ} 02 / 2002 / \mathrm{CM} / \mathrm{UEMOA}$, octroyer des exemptions à l'application des articles $88 a$ ) et $88 b$ ) du Traité de l'UEMOA. Ces exemptions se justifient par le souci de ne pas faire échec à l'accomplissement de la mission assignée à l'entreprise chargée de la gestion de services d'intérêt économique général ou présentant le caractère d'un monopole fiscal.

Toutefois, sur le fondement de l'article $89 \S 3$ du Traité de l'UEMOA, le Conseil des ministres peut prévoir des exceptions limitées aux interdictions contenues dans l'article $88 \mathrm{du}$ Traité de l'UEMOA afin de tenir compte de situations spécifiques.

En application de l'article $89 \S 3$ du Traité de l'UEMOA, l'article 7 du Règlement de 2002 sur les pratiques anticoncurrentielles investit la Commission de l'UEMOA de la compétence de définir des exemptions (individuelle et par catégorie) aux prohibitions contenues dans l'article 88 du Traité de l'UEMOA ${ }^{200}$. Le Règlement précité de 2002

199 En vertu de l'article $6 \S 2$ du Règlement n02/2002/CM/UEMOA, les entreprises chargées de la gestion de services d'intérêt économique général ou présentant le caractère d'un monopole fiscal sont soumises aux règles du Traité relatives à la concurrence. Cette disposition implique une interdiction (relative) pour les entreprises de cette catégorie d'évoluer en dehors des règles de la concurrence telles qu'énoncées par l'article 88 du Traité de l'UEMOA. Sur ce point, il est possible un article du professeur Coulibaly Abou Saïb. $C f$. COULIBALY Abou Saïb, «Le droit de la concurrence de l'Union économique et monétaire ouest-africaine », Revue burkinabé de droit, ${ }^{\text {os }} 43-44,1^{\text {er }}$ et $2^{\text {ème }}$ semestres, 2003, p. 55.

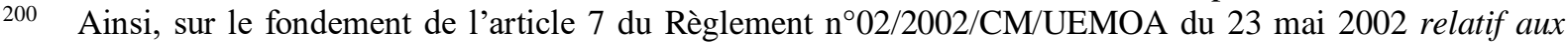
pratiques anticoncurrentielles à l'intérieur de l'UEMOA, les exemptions peuvent concerner :

- Tout accord ou catégories d'accords ;

- Toute décision ou catégorie de décisions d'associations d'entreprises ;

- Et toute pratique concertée ou catégorie de pratiques concertées ;

qui contribuent à améliorer la production ou la distribution des produits ou à promouvoir le progrès technique ou économique, tout en réservant aux utilisateurs une partie équitable du profit qui en résulte, et sans : 
s'applique de plein droit dans l'ordre juridique ivoirien en vertu de l'article 43 du Traité instituant l'UEMOA $^{201}$. Cette disposition, elle-même, est la manifestation du principe de l'applicabilité immédiate qui caractérise le droit communautaire, comparativement au droit international public, précisément celui des traités. En effet, l'application du traité, dans l'ordre interne étatique, à bien des égards, est conditionnée par la procédure de la ratification par l'État signataire. Le principe de l'applicabilité immédiate du Règlement du 23 mai 2002 n'a pas cependant inhibé la volonté du législateur ivoirien de légiférer sur la question des pratiques anticoncurrentielles. Il s'agit visiblement d'une législation secundum legem $^{202}$ intervenue au moyen de l'ordonnance $\mathrm{n}^{\circ} 2013-662$ du 20 septembre 2013 relative à la concurrence. Le législateur ivoirien a reconduit, dans l'ensemble, les dispositions du Règlement précité du 23 mai 2002. Cette ordonnance vient donc compléter le droit communautaire en la matière ${ }^{203}$.

\section{B. $\quad$ La pratique observée au niveau du Port autonome d'Abidjan dans l'affaire ICTSI c. Groupement Bolloré}

La lutte contre les situations de monopole à travers notamment la prohibition des ententes anticoncurrentielles $^{204}$ au sein du Port autonome d'Abidjan ne semble pas avoir retenu l'attention des autorités étatiques ivoiriennes. Ainsi, on a pu voir l'attribution au groupe Bolloré $^{205}$ de l'exploitation du deuxième terminal à conteneurs alors que cette entité était déjà

a) Imposer aux entreprises intéressées des restrictions qui ne sont pas indispensables pour atteindre ces objectifs ;

b) Donner à des entreprises la possibilité, pour une partie substantielle des produits en cause, d'éliminer la concurrence.

201 L'article $43 \mathrm{du}$ Traité de l'UEMOA dispose: «Les règlements ont une portée générale. Ils sont obligatoires dans tous leurs éléments et sont directement applicables dans tout État membre ».

202 Une norme est qualifiée de secundum legem lorsqu'elle est établie conformément au texte clair de la norme juridique, hiérarchiquement supérieure, à laquelle elle se réfère. La norme secundum legem se distingue de la norme praeter legem, celle-ci intervenant en cas de silence de la loi.

203 On remarquera que l'ordonnance précitée du 20 septembre 2013 élargit l'éventail des pratiques anticoncurrentielles prévues par le Règlement du 23 mai 2002. En sus des ententes anticoncurrentielles et des abus de position dominante, l'ordonnance du 20 septembre 2013 prévoit les pratiques restrictives de concurrence qui, elles, sont constitutives de fautes pénales. S'inscrit dans cette catégorie, la vente à perte faite dans l'intention de limiter la concurrence. Celle-ci est constitutive d'une infraction pénale punie d'une peine d'une amende de cent mille à cinquante millions de francs CFA sans préjudice des sanctions particulières prévues par le Code des douanes (article 18 Ordonnance du 20 septembre 2013). En outre, l'ordonnance prévoit une nouvelle catégorie, celle des pratiques restrictives constitutives de fautes civiles (article 22). Enfin, elle prévoit la catégorie des pratiques de concurrence déloyale (article 23). La sanction de cette pratique anticoncurrentielle est une amende de cinq millions à cinq cent millions de francs CFA (5.000.000 à 500.000.000 de francs CFA) sans préjudice de toute autre action devant les juridictions de droit commun (article 24).

204 Les ententes anticoncurrentielles sont prohibées par l'article 3 du Règlement $n^{\circ}$ 02/2002/CM/UEMOA du 23 mai 2002 sur les pratiques commerciales anticoncurrentielles.

205 L'attribution de la concession du second terminal à conteneurs au groupement Bolloré et autres a obéi à une procédure assez complexe. Ainsi, suite à l'examen des offres financières qui a eu lieu à la séance du 08 mars 2013, la Commission d'Ouverture des Plis et de Jugement des Offres (COJO), a désigné comme attributaire provisoire de la concession pour la réalisation et l'exploitation du second Terminal à Conteneurs (TC 2) du Port d'Abidjan, le groupement APM TERMINALS/BOLLORE AFRICA LOGISTICS/BOUYGUES TP qui a été classé premier avec 100 points sur 100, après avoir offert un ticket d'entrée portant sur la somme de cent vingt millions (120.000.000) d'euros, une redevance fixe annuelle de vingt-deux millions (22.000.000) d'euros, une baisse du Tarif Public Plafond de 25\% et une prévision de transbordement de 450.000 TEU (Twenty Equivalent Unit). Par correspondance $\mathrm{n}^{\circ}$ 0610/2013/MPMEF/DGBF/DMP/27 du 14 mars 2013, la Direction des Marchés Publics a donné son avis de non objection et a invité l'autorité concédante à engager les négociations avec l'attributaire provisoire dans les conditions fixées par l'article 181 du Code des marchés publics. Par correspondance 
le concessionnaire du premier terminal à conteneurs du Port autonome d'Abidjan. Cette attribution avait donné lieu à une plainte des autres soumissionnaires, réunis en un collectif, auprès successivement de l'Autorité Nationale de Régulation des Marchés Publics (ANRMP) (1) et de la Commission de la concurrence de l'UEMOA ${ }^{206}$ (2).

\section{La saisine de l'ANRMP}

La saisine de l'ANRMP s'est effectuée au moyen d'une lettre datée du 16 avril 2013, adressée à ladite institution.

La plainte du groupement ICTSI/CMA-CGMT/TERMINAL LINK/MOVIS/NECOTRANS portait essentiellement sur l'acceptation de la candidature du groupement $A P M$ Terminals/Bollore Africa Logistics/Bouygues déjà concessionnaire du premier Terminal à Conteneurs et exploitant plusieurs autres terminaux à conteneurs en Afrique de l'ouest d'expression française ${ }^{207}$. De manière plus précise, le groupement ICTSI/CMACGMT/TERMINAL LINK/MOVIS/NECOTRANS dénonce quatre (4) faits ayant entaché, à leur avis, l'attribution du deuxième Terminal à conteneurs (TC 2) au groupement $A P M$ Terminals/Bollore Africa Logistics/Bouygues. Ce sont :

- Le non-respect des conditions de présélection ;

- Les irrégularités contenues dans le règlement particulier d'appel d'offres ;

- La violation des principes fondamentaux régissant les marchés publics ;

- Le caractère arbitraire du jugement d'attribution.

$\mathrm{n}^{\circ}$ 00800/DGPAA/DM/TC du 21 mars 2013, le Port Autonome d'Abidjan (PAA) a notifié les résultats de cet appel d'offres aux différents groupements soumissionnaires. $C f$. Décision n 009/2013/ANRMP/CRS du 08 mai 2013 sur la dénonciation faite par le groupement International Container Terminal Services Inc. (ICTSI)/CMA-CGMT/TERMINAL LINK/MOVIS/NECOTRANS pour irrégularités commises dans la procédure de passation de l'appel d'offres international avec présélection $N^{\circ} S 31 / 2012$ portant mise en concession de la réalisation et de l'exploitation du deuxième terminal à conteneurs (TC 2) du port d'Abidjan, pp. 2-3.

GRISOT Maureen, «Le monopole de Bolloré sur le Port d'Abidjan est de plus en plus contesté : Le gendarme de la concurrence de l'Afrique de l'ouest parle de violation des règles de la concurrence ». Article de journal accessible en ligne sur : jeanlouisbillon.net/wp-content/uploads/.../JLB_RevueDePresse_08_Septembre2014.pdf. Document consulté le 11 février 2019.

Port autonome de Lomé (Togo), Port de Conakry (Guinée). En dehors des terminaux à conteneurs, le groupe Bolloré s'avère être un empire en Afrique ainsi que le souligne l'hebdomadaire français Le Point. Dans une de ses publications, Le Point révèle : "Du stockage au transport des marchandises, Bolloré Africa Logistics est incontournable en Afrique de l'Ouest. Le groupe gère directement les terminaux à conteneurs de 10 ports de la région, de Conakry, en Guinée, à Pointe-Noire, au Congo. Il opère aussi dans 16 terminaux à conteneurs sur le continent par l'intermédiaire de partenariats public-privé. En Côte d'Ivoire, Bolloré a annoncé pour juin 2019 la construction dans la capitale économique Abidjan d'un deuxième terminal portuaire capable d'accueillir les plus grands porte-conteneurs fréquentant les côtes africaines. Le groupe assure déjà depuis 2004 la gestion et l'exploitation du premier terminal du port d'Abidjan, leader en Afrique de l'Ouest et façade maritime des pays de la sous-région (Mali, Niger et Burkina Faso). En 2017, le groupe a racheté une partie de son concurrent Necotrans, peu après le placement en redressement de cette société, au terme d'un long affrontement judiciaire. Le groupe Bolloré avait obtenu la gestion du port de Conakry suite à une intervention du gouvernement guinéen en 2011, alors qu'une filiale de Necotrans gérait le terminal à conteneurs depuis 2008. Bolloré avait été condamné en 2013 à verser plus de 2 millions d'euros à Necotrans. Le groupe Bolloré détient la majorité dans trois concessions ferroviaires en Afrique: Sitarail (Côte d'Ivoire, Burkina Faso), Camrail (Cameroun) et Benirail (Bénin) ». Cf. Anonyme, « Ce qu'est le groupe Bolloré en Afrique ». Article accessible en ligne sur : http://afrique.lepoint.fr/economie/ce-qu-est-le-groupe-bollore-en-afrique-24-04-2018-2213227_2258.php. Document consulté le dimanche 10 février 2019. 
Le choix de ce groupement, expliquent les plaignants, "tendrait à instituer, favoriser ou entretenir la constitution de monopoles privés et de concentrations qui sont interdits par le règlement $n^{\circ} 02 / 2002 / C M / U E M O A »$.

Cependant, dans sa décision n ${ }^{\circ} 009$ du 08 mai 2013, l'ARNMP considère que la plainte du groupement ICTSI/CMA-CGMT/TERMINAL LINK/MOVIS/NECOTRANS, " est mal fondé ». Par conséquent, l'ANRMP l'en déboute au profit du groupement APM Terminals/Bollore Africa Logistics/Bouygues.

Pour parvenir à cette décision, l'ANRMP a réfuté, l'une après l'autre, les moyens invoqués par le plaignant.

Relativement au non-respect des conditions de présélection, il se décline en deux rubriques : d'une part, la pré-qualification du groupement adjudicataire de l'appel d'offres alors que ses rapports d'activités étaient défectueux; et, d'autre part, la violation des règles de la libre concurrence.

Sur la première rubrique, l'ANRMP a considéré que la production de rapports d'activités par le groupement APM Terminals/Bollore Africa Logistics/Bouygues, allant du 7 août 2007 au 31 décembre 2008, ne constitue pas une irrégularité vu que ledit groupement n'a été immatriculé que le $1^{\mathrm{er}}$ août 2007. En outre, la production des rapports d'activités des années 2008, 2009 et 2010, en anglais, ne constitue pas un obstacle à la réception de la candidature dudit groupement ${ }^{208}$.

On pourrait s'interroger sur la pertinence de cette affirmation de l'ANRMP vu que le français est la langue officielle de la République de Côte d'Ivoire. Devrait-on déduire que si un soumissionnaire à un marché public produisait des rapports d'activités en langue russe (alphabet cyrillique) ou en langue chinoise (avec son alphabet pas du tout maîtrisé par l'Administration ivoirienne), un tel raisonnement tiendrait-il ? Il appartient, à notre avis, à l'Administration ivoirienne de veiller à une rigueur certaine dans la production des documents aussi cruciaux que les rapports d'activités annuels ; ceux-ci permettent de cerner le sérieux ou non d'une personne qui se porte candidate à l'obtention d'un marché public.

En ce qui concerne les règles de la concurrence, l'ANRMP a considéré que le principe du libre accès à la commande publique lui interdit de rejeter a priori la soumission de tout candidat même s'il est déjà bénéficiaire d'une concession d'exploitation d'un terminal à conteneur $^{209}$.

Relativement aux irrégularités contenues dans le Règlement Particulier d'Appel d'Offres, l'ANRMP a réfuté le moyen des plaignants selon lequel "l'attribution de la concession (au profit du groupe Bolloré et autres) s'est faite uniquement sur la base de l'offre financière, occultant ainsi l'étape de l'évaluation technique ".

Relativement à la violation des principes fondamentaux régissant les marchés publics, l'ANRMP réfute aussi bien la violation de l'égalité de traitement des candidats ${ }^{210}$ que la violation du principe de transparence ${ }^{211}$.

«Qu'ainsi, la production par les candidats des rapports annuels d'activités dans la langue de leur choix ne constitue pas une violation du règlement de la présélection dès lors que ceux-ci ne comportent pas de réserves ou de commentaires émanant des commissaires aux comptes».

«Qu'en conséquence, la mention dans le dossier de présélection d'une disposition tendant à faire croire que le groupement dont fait partie la société Bolloré, titulaire de l'actuel terminal à conteneurs au Port d'Abidjan, est écarté d'avance de la commande publique, est contraire à la réglementation des marchés publics, norme supérieure, ...».

210 "Considérant que la violation du principe d'égalité de traitement s'analyse comme une faveur accordée par la COJO à l'un des soumissionnaires, et le respect de ce principe sous-entend que tous les candidats soient traités sur le même pied d'égalité [...] Considérant, cependant, qu'il est constant que le plaignant ne démontre pas en quoi, la COJO a posé des actes de nature à favoriser l'attributaire au détriment des autres candidats; Qu'il convient de dire et juger qu'il n'y a pas en l'espèce de violation du principe de l'égalité de traitement ». Soulignons que l'acronyme de COJO signifie Commission d'Ouverture des Plis et de Jugement des Offres (COJO). 
Relativement au caractère arbitraire du jugement d'attribution ${ }^{212}$, l'ANRMP réfutera chacun des moyens invoqués par le plaignant sous ce chef de dénonciation.

Selon l'ANRMP, le groupement ICTSI/CMA-CGMT/TERMINAL LINK/MOVIS/NECOTRANS, auteur de la plainte, est "mal fondé en sa dénonciation contre la décision d'attribution prise au profit du groupement APM Terminals/Bollore Africa Logistics/Bouygues et l'en déboute ».

Débouté par l'ANRMP, le groupement conduit par le philippin ICTSI, s'en remet à la Commission de la concurrence de l'Union économique et monétaire ouest-africaine (UEMOA).

\section{La saisine de la Commission de la concurrence de l'UEMOA ${ }^{213}$}

La Commission de la concurrence, précisément le Comité consultatif de ladite Commission, estimera recevable la plainte et constatera la «violation des règles de la concurrence au sein de l'UEMOA ». Il est à remarquer que si la version numérique de la décision de l'ANRMP est accessible en ligne, il en va autrement de l'avis rendu par le Comité consultatif de la Commission de la concurrence qui, elle, ne l'est pas. Aussi, sommes-nous référé à des articles de certains quotidiens et autres publications français pour en avoir un éclairage partielle, il est vrai.

Ainsi à la lecture de ces publications, il apparaît qu'un avis du Comité consultatif de la Commission de la concurrence de l'Union économique et monétaire ouest-africaine (UEMOA), révélé par le quotidien Le Monde et la Radio France Internationale (RFI), remet en question l'attribution en 2013 du deuxième terminal à conteneurs du port d'Abidjan au consortium composé de Bolloré et APMT. Le feuilleton de l'attribution du deuxième terminal à conteneurs (TC2) du port d'Abidjan au consortium Bolloré Logistics Africa, APMT et Bouygues est relancé. Dans un document que se sont procurés le journal Le Monde et la station radiophonique $R F I$, le Comité consultatif de la commission de la concurrence de l'Union économique et monétaire ouest-africaine (UEMOA) a livré des conclusions sans appel : cette attribution est "assimilable à un abus de position dominante » et le Comité se demande si le "comportement fautif de la part d'APMT et de Bolloré Logistics Africa ne devrait pas, a posteriori, amener l'État de Côte d'Ivoire à remettre en cause l'attribution de la concession », selon les éléments divulgués par Le Monde ${ }^{214}$.

«Qu'en l'espèce, les termes réalisation et construction ayant la même signification, c'est à tort que le plaignant invoque une modification de l'objet de l'appel d'offres, pour prétendre à la violation du principe de la transparence ; Qu'il y a lieu de débouter le plaignant sur ce chef de dénonciation».

212 Il importe de ne pas se laisser abuser par l'utilisation de la notion de «jugement» relativement aux décisions rendues par la COJO. Celle-ci est un organe de l'ANRMP qui, lui, est une Autorité administrative indépendante créée par le décret $\mathrm{n}^{\circ} 2009-260$ portant organisation et fonctionnement de l'Autorité Nationale de Régulation des Marchés Publics. En Côte d'Ivoire, la création des juridictions ressortit à la compétence de la loi stricto sensu (en vertu de l'article 101 de la loi n²016-886 du 08 novembre 2016 portant Constitution de la République de Côte d'Ivoire, ou de tout autre acte juridique ayant une valeur juridique égale [notamment l'ordonnance, en période normale (article 106 de la Constitution), ou une décision présidentielle, en période de crise (article 73)].

213 L'absence d'informations de première main relative à cette rubrique des présents travaux nous a contraints, hélas, de nous rabattre sur certaines coupures de journaux. Cette situation est due à la non-publication par l'UEMOA, jusqu'à ce jour, de l'avis rendu par le Comité consultatif de la Commission de la concurrence. Les visites répétées sur le site de l'UEMOA se sont avérées infructueuses.

214 GRISOT Maureen, «Le monopole de Bolloré sur le Port d'Abidjan est de plus en plus contesté : Le gendarme de la concurrence de l'Afrique de l'ouest parle de violation des règles de la concurrence ». Article de journal accessible en ligne sur: jeanlouisbillon.net/wp-content/uploads/.../JLB_RevueDePresse_08_Septembre2014.pdf. ; Anonyme, «Côte d'Ivoire : corruption et favoritisme 
Il suggère en outre « des sanctions pécuniaires, (...) et la cession d'une partie des parts (...) détenues par APMT et Bolloré sur le capital de l'entreprise attributaire de la concession pour éviter le monopole de l'exploitation des deux terminaux ». Si l'appel d'offre insistait sur la nécessité d'une exploitation du terminal dans un cadre concurrentiel, la candidature de Bolloré et APMT avait toutefois été validée par les autorités ivoiriennes.

Il importe cependant de noter que l'avis du Comité consultatif n'est qu'un avis (un avis, il est vrai, obligatoire mais qui n'est pas un avis conforme). À ce titre, cet avis ne lie pas la Commission de la concurrence. Celle-ci n'a d'ailleurs pas encore pris une décision définitive et mène une enquête qui reste "en cours ». La Commission de la concurrence est la seule habilitée à prendre des sanctions et demander, par exemple, l'annulation du contrat.

La décision finale de la Commission de la concurrence de l'UEMOA sur cette question reste jusqu'ici inaccessible. Cependant, force est de constater que le second Terminal à conteneurs de Vridi est effectivement exploité par le groupement APM Terminals/Bollore Africa Logistics/Bouygues. Cette situation porte à croire que ce groupement mené par Bolloré a obtenu gain de cause sans que la Commission de la concurrence ne veuille publier la décision d'adjudication de la concession du second terminal.

Cette opacité ne milite nullement en faveur de la transparence dans la gestion des affaires dévolues à la compétence de l'UEMOA Cette situation pourrait s'expliquer par le manque d'indépendance de la Commission de la concurrence, précisément son démembrement dénommé Comité consultatif de la concurrence, à l'égard de la Commission de l'UEMOA, un organe principal et originaire de ladite organisation d'intégration. Ce dysfonctionnement, car cela en est un exemple, a d'ailleurs été souligné dans un rapport commandé par l'UEMOA, elle-même.

Ce rapport note : «Conséquence directe de son ancrage dans l'appareillage institutionnel communautaire, la direction de la concurrence ${ }^{215}$ de la Commission de l'UEMOA n'a pas les coudées franches pour opérer en toute indépendance et en toute flexibilité comme l'exige sa mission de surveillance du marché communautaire. Toutes les actions de la direction de la concurrence en rapport avec les enquêtes doivent être autorisées par le président de la Commission. Par exemple, la Commission doit, avant toute enquête dans un État membre ou dans une entreprise, justifier de la nécessité de faire une enquête avant d'obtenir l'autorisation ainsi que les fonds nécessaires pour effectuer le déplacement. Le président de la Commission autorise toutes les actions de la direction de la concurrence. Même les demandes de renseignements à envoyer aux entreprises et aux États pour des compléments d'information doivent être signées par le président de la Commission. Par ailleurs, les actes en cours de procédures relatives à une affaire pendante doivent être signés par la Commission. En résumé, de bout en bout, les actes et documents sont signés par le président de la Commission qui centralise la prise de décision $»^{216}$.

$\mathrm{Au}$ regard de ce rapport, il est possible de situer clairement les responsabilités dans cette opacité couvrant la décision relative à l'attribution du second terminal à conteneurs du PAA. Ainsi, la non publication de la décision finale, si décision il y a eu, ne saurait être imputée à la Commission de la concurrence. D'ailleurs, les bribes d'information lâchées par les organes de presse français, en la matière, incline à penser que la Commission de la concurrence, à travers

demeurent sous Ouattara », AEUD.INFO : L'action prend corps, p. 4. Article accessible en ligne sur : aeud.fr/IMG/article_PDF/article_a10780.pdf. Document consulté le dimanche 10 février 2019.

215 Sous l'appellation de «direction de la concurrence » est plutôt désignée la Commission de la concurrence, un démembrement de la Commission (tout court) de l'UEMOA.

216 BAKHOUM Mor, Étude sur la révision du cadre institutionnel de mise en ouvre des règles communautaires de concurrence de l'UEMOA Rapport final, UEMOA, 14 mars 2012, pp. vi à v. 
son démembrement dénommé Comité consultatif de la concurrence, a adopté une position défavorable au groupement APM Terminals/Bollore Africa Logistics/Bouygues ${ }^{217}$.

En sus du droit communautaire généré par les organes de l'UEMOA, le Port autonome d'Abidjan est régi par les normes pertinentes du droit de l'OHADA.

217 Dans un document que se sont procurés le journal Le Monde et la station radiophonique RFI, le Comité consultatif de la commission de la concurrence de l'UEMOA a livré des conclusions sans appel : cette attribution est "assimilable à un abus de position dominante » et le Comité se demande si le " comportement fautif de la part d'APMT et de Bolloré Logistics Africa ne devrait pas, a posteriori, amener l'État de Côte d'Ivoire à remettre en cause l'attribution de la concession », selon les éléments divulgués par Le Monde. Cf. GRISOT Maureen, « Le monopole de Bolloré sur le Port d'Abidjan est de plus en plus contesté : Le gendarme de la concurrence de l'Afrique de l'ouest parle de violation des règles de la concurrence ». Article de journal accessible en ligne sur: jeanlouisbillon.net/wp-content/uploads/.../JLB_RevueDePresse_08_Septembre2014.pdf. Document consulté le dimanche 10 février 2019. 


\section{CHAPITRE 2: LE PORT AUTONOME D'ABIDJAN ET LE DROIT DE L'OHADA}

La soumission du PAA au droit de l'OHADA résulte d'un ensemble de textes juridiques (Section 1). Théoriquement, les normes pertinentes de l'OHADA érodent fortement les prérogatives de puissance publique reconnues au PAA en sa qualité d'entreprise publique. Cependant, une analyse du statut juridique du port établit la virtualité du caractère obligatoire des normes OHADA applicables à celui-ci (Section 2).

\section{SECTION 1: Le fondement de la soumission du Port au droit de l'OHADA}

Le PAA étant une société d'État, donc une personne morale de droit privé, sa soumission au droit commercial (paragraphe 1) résulte de deux catégories de textes juridiques. La première relève du droit interne ivoirien à savoir la loi du 04 septembre 1997 sur les sociétés d'État ainsi que deux décrets fixant successivement la nature juridique du PAA. Ce sont respectivement le décret $\mathrm{n}^{\circ} 92-940$ du 23 décembre 1992 portant transformation $d u$ Port autonome d'Abidjan en société d'État, puis le décret n²001-143 du 14 mars 2001 portant approbation des Statuts $d u$ Port autonome d'Abidjan (PAA) et reclassification des

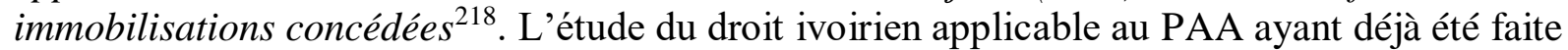
dans la première partie de la présente étude, on se consacrera seulement à l'analyse des dispositions pertinentes de l'Acte uniforme sur les sociétés commerciales et les groupements d'intérêt public (AUSCGIE), en ce qu'elles s'appliquent à la société de forme commerciale qu'est le PAA (paragraphe 2).

\section{Paragraphe 1: Le principe de la soumission du Port autonome d'Abidjan à l'AUSCGIE}

Ce principe découle de l'article premier de l'AUSCGIE qui dispose : «Tout commerçant, personne physique ou morale y compris toutes sociétés commerciales dans lesquelles un État ou toute autre personne de droit public est associé, [...], est soumis aux dispositions du présent Acte uniforme».

L'analyse de cette disposition laisse transparaître la capacité de l'État de même que les autres personnes morales de droit public à créer des sociétés commerciales, seul ou en association avec d'autres personnes privées ou publiques.

On note également dans la disposition précitée l'indifférence du législateur à l'égard de la qualité juridique de l'État. En effet, le législateur OHADA perçoit l'État comme un simple actionnaire de la société commerciale. L'AUSCGIE ne distingue donc pas entre l'actionnaire de droit public et l'actionnaire de droit privé. En posant le principe de la soumission de

218 Ces deux décrets ont été publiés respectivement au JORCI n8, 25 février 1993, p. 159 et ss (en ce qui concerne le décret du 23 décembre 1992) et JORCI n ${ }^{\circ} 17,26$ avril 2001, p. 313 et ss (en ce qui concerne le décret du 14 mars 2001). 
l'entreprise publique à l'AUSCGIE, le législateur africain a assimilé l'État actionnaire à un actionnaire ordinaire ${ }^{219}$.

En ce qui concerne le PAA, on note que l'État est le seul actionnaire au capital de celui-ci. En référence à la disposition précitée, il apparaît que le PAA relèvera du champ d'application matérielle de l'AUSCGIE Cette inclusion du PAA dans le champ d'application de l'AUSCGIE comporte des implications.

\section{Paragraphe 2: Les implications de la soumission du Port autonome d'Abidjan à l'AUSCGIE}

L'assimilation du PAA à tout autre sujet de droit privé soumis aux normes de l'OHADA comporte comme première implication, l'obligation d'immatriculer le PAA au registre du commerce. Cela ressort de l'article 6 de la loi n'97-519 du 4 septembre 1997 portant définition et organisation des sociétés d'État. Selon cette disposition, "La société d'État jouit de la personnalité morale à dater de son immatriculation, aucun acte ne peut être effectué par la société, à l'exception de ceux de son mandataire ad hoc personne physique, désigné par le ministre chargé de l'Économie et des Finances au seul effet de la réalisation des formalités de constitution. Le mandataire ad hoc effectue les formalités de constitution de la société d'État conformément aux dispositions de la présente loi et, à titre subsidiaire, aux règles applicables en matière de sociétés anonymes ».

L'assimilation de l'entreprise publique, en général, et du PAA, en particulier, aux autres personnes morales de droit privé devrait en outre impliquer une forte minoration (à défaut d'une éradication) de ses prérogatives de puissance publique lorsque le Port se livre à des activités de type commercial. Cette déduction est loin d'être confortée aussi bien par la pratique que par certaines dispositions du droit de l'OHADA

\section{SECTION 2: La virtualité du caractère obligatoire du droit de l'OHADA à l'égard du Port autonome d'Abidjan}

La portée du droit de l'OHADA appliqué au PAA est fortement tempérée par deux écueils. Le premier est l'immunité d'exécution reconnue aux entreprises publiques par le droit de l'OHADA (paragraphe 1). En outre, on note les réticences du juge ivoirien à appliquer le droit de l'OHADA au PAA (paragraphe 2).

\section{Paragraphe 1: L'immunité d'exécution reconnue aux entreprises publiques par le droit de l'OHADA}

Le droit de l'OHADA pose le principe de l'immunité d'exécution des entreprises publiques $^{220}$ (A). Cette affirmation textuelle est mise en œuvre par la Cour commune de justice et d'arbitrage (B).

BOUKARI Salifou, L'application des textes de l'OHADA aux entreprises publiques : l'exemple de l'AUSC et GIE, Thèse unique, Droit privé, 2015, Université de Maastricht/Université de Lomé, p. 42.

220 Il est vrai que la notion d'entreprise publique est difficile à définir. On peut cependant regrouper sous cette appellation les établissements publics industriels et commerciaux ainsi que les sociétés anonymes dans lesquelles l'État ou d'autres personnes morales de droit public sont actionnaires. Selon les professeurs Vedel et Delvolvé, l'entreprise publique est «une personne morale à caractère industriel et commercial 


\section{A. L'affirmation de l'immunité d'exécution des entreprises publiques}

Certains motifs sont avancés pour justifier l'immunité d'exécution des entreprises publiques (1). L'Acte uniforme portant organisation des procédures simplifiées de recouvrement et des voies d'exécution la consacre en son article $1^{\mathrm{er}}(2)$.

\section{Les motifs justifiant l'immunité d'exécution}

Selon le professeur Nam-Tchougli, le principe de l'immunité d'exécution ou de saisie des entreprises publiques trouve son origine dans le principe de la séparation des autorités administratives et judiciaires ${ }^{221}$. Ce dernier principe interdit au juge judiciaire de connaître des actions dirigées contre l'État et d'une manière générale, les personnes publiques ${ }^{222}$.

En droit français, on pourrait faire remonter l'immunité d'exécution des personnes publiques, en général, et des entreprises publiques, en particulier, à la deuxième décennie du $\mathrm{XIX}^{\mathrm{e}}$ siècle dans l'arrêt Enregistrement c/ Jousselin rendu le 31 mars 1819 par la Cour de cassation. Cet arrêt consacre l'immunité d'exécution au profit de l'État. Selon la Cour, un particulier persévérant et obstiné, soucieux avant tout de ses légitimes et égoïstes intérêts au mépris de l'intérêt général, ne pouvait ni obliger, ni contraindre l'autorité publique ${ }^{223}$.

dont, la totalité ou la majorité du capital est soustraite à l'appropriation privée ». (VEDEL George et DELVOLVÉ Pierre, Droit administratif, Thémis, PUF, 1992, pp. 1019-1020). Selon François Chevallier, «les entreprises publiques sont des personnes morales ayant une activité industrielle et commerciale, placées sous la direction des pouvoirs publics à raison de l'appropriation collective dont elles font l'objet». Cf. CHEVALLIER François, «Les entreprises publiques en France», Notes et études documentaires, $\mathrm{n}^{\circ} 4507-4508,9$ mars 1979, p. 14).

Le lecteur pourra approfondir la lecture sur la notion d'entreprise publique en se référant, entre autres, à la thèse de Salifou Boukari. Cf. BOUKARI Salifou, L'application des textes de l'OHADA aux entreprises publiques: l'exemple de l'AUSC et GIE, Thèse unique, Droit privé, 2015, Université de Maastricht/Université de Lomé, Uitgeverij BOXPress, p. 7.

221 NAM-TCHOUGLI Guy, «L'immunité d'exécution ou de saisie des entreprises publiques dans l'espace OHADA », Revue Africaine de Droit, d'Économie et de Développement, volume 1, n6, 2005, p. 573.

222 Il est fait ici application de la loi (française) des 16 et 24 août 1790 sur l'organisation judiciaire. Cette loi, en son article 13, dispose : «Les fonctions judiciaires sont distinctes et demeureront toujours séparées des fonctions administratives. Les juges ne pourront, à peine de forfaiture, troubler de quelque manière que ce soit les opérations des corps administratifs ni citer devant eux les administrateurs pour raison de leurs fonctions ». Cette loi a été confirmée par un autre texte juridique : le décret du 16 fructidor An III (2 septembre 1795). L'intitulé de ce décret est caractéristique : décret qui défend aux tribunaux de connaître des actes d'administration et annule toute procédure et jugements intervenus à cet égard. Le décret comporte un seul article: "Défenses itératives sont faites aux tribunaux de connaître des actes d'administration, de quelque espèce qu'ils soient, avec peine de droit». Cf. BRAIBANT Guy et STIRN Bernard, Le droit administratif français, $6^{\text {ème }}$ édition, Coll. Les Presses de Sciences Po, Dalloz, 2002, p. 30 ; De VILLIERS et De BERRANGER Thibaut (dir.),Droit public général: Institutions politiques, administratives et européennes, Droit administratif, Finances publiques et droit fiscal, 7 ème édition, Paris,

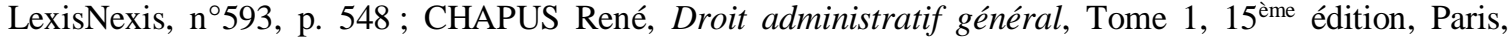
Montchrestien, $\mathrm{n}^{\text {os }} 1659$ à 1661, pp. 1316-1318; CHAPUS René, Droit administratif général, Tome 1, $15^{\text {ème }}$ édition, Collection Domat, Montchrestien, 2001, n², p. 2.

223 «Attendu que les lois citées interdisent expressément à toute autorité civile et militaire de disposer sous quelque prétexte que ce soit, des deniers déposés dans les caisses publiques; que si les articles 561 et 569 du Code de procédure civile parlent des saisies-arrêts à exercer dans les mains des receveurs de deniers publics, cela ne doit s'entendre que des saisies faites sur des particuliers envers lesquels le fisc est redevable, et à l'égard seulement des deniers appartenant à ces particuliers; mais que les deniers appartenant au fisc ne peuvent jamais être saisies dans les caisses publiques à la requête de ses créanciers, sauf à ceux-ci à se pourvoir administrativement pour obtenir le paiement de leurs créances... ». 
L'immunité d'exécution fut ensuite étendue aux collectivités publiques territoriales ${ }^{224}$ et aux établissements publics administratifs ${ }^{225}$ avant d'être appliqué aux établissements publics à caractère industriel et commercial ${ }^{226}$.

Dans l'espace OHADA, l'immunité d'exécution a été étendue aux entreprises publiques ayant le statut de personnes morales de droit privé. Sont comprises dans cette catégorie les sociétés d'État et les sociétés d'économie mixte (désignée en Côte d'Ivoire sous l'appellation de société à participation financière publique).

Selon le professeur Nam-Tchougli, la personnalité publique et son corollaire la puissance publique justifient le bénéfice de l'immunité d'exécution ou de saisie aux entreprises publiques, nonobstant le fait que celles-ci fonctionnent selon les règles de droit privé. C'est, sans doute, cette jurisprudence établie qui a influencé la rédaction de l'Acte Uniforme portant organisation des procédures simplifiées de recouvrement et des voies d'exécution dans le cadre de l'OHADA ${ }^{227}$.

\section{Le fondement juridique de l'immunité d'exécution}

Le principe de l'immunité d'exécution des entreprises publiques, dans l'espace OHADA, trouve son fondement dans l'article 30 de l'Acte uniforme portant organisation des procédures simplifiées de recouvrement et des voies d'exécution (AUPSRVE). Selon l'alinéa premier de cette disposition, "l'exécution forcée et les mesures conservatoires ne sont pas applicables aux personnes qui bénéficient d'une immunité d'exécution ».

La portée de cette règle est adoucie par l'alinéa deux du même article aux termes duquel il ressort que «les dettes certaines, liquides et exigibles des personnes morales de droit public ou des entreprises publiques, quelles qu'en soit la forme et la mission, donnent lieu à compensation avec les dettes également certaines, liquides et exigibles dont quiconque sera tenu envers elles, sous réserve de réciprocité ».

On notera le laconisme de l'article 30 précité à l'égard des entités juridiques bénéficiant de l'immunité d'exécution. Il en résulte un pouvoir d'appréciation assez étendu implicitement conféré au juge chargé d'appliquer le droit de l'OHADA pour en déterminer les bénéficiaires.

Cf. Cour de cassation,31 mars 1819, Enregistrement c/ Sieur Jousselin, Journal du Palais, Recueil le plus ancien et le plus complet de la jurisprudence française, 1819, pp. 193-194.

224 Les professeurs Charles Huberlant et Francis Delpérée, dans leur commentaire sous deux avis rendus par le Conseil d'État ont soutenu : "Pour obtenir un paiement forcé, le créancier d'une commune ne peut jamais s'adresser qu'à l'Administration"; "il n'y a lieu ni à délivrance de contrainte contre le receveur, ni à citation devant les tribunaux, ni à saisie-arrêt entre les mains du receveur de la commune ou des débiteurs de la commune... ». Une seule solution : « se pourvoir par-devant le préfet ». Cf. HUBERLANT Charles et DELPÉRÉE Francis, «Les personnes de droit public bénéficiaires de l'immunité d'exécution », in Colloque sur Les immunités des États en droit international, 31 janvier et $1^{\text {er }}$ février 1969, Bruxelles, p. 39. Les deux avis ayant fait l'objet de commentaires de la part des professeurs Huberlant et Delpérée sont : Conseil d'État, 12 août 1807, Avis sur la libération des mandats délivrés par la Caisse d'amortissement et sur les effets des oppositions relatives aux cautionnements des fonctionnaires publics, in CARETTE A-A., Lois, Décrets, Ordonnances, Avis du Conseil d'État, etc. (1ère série 1789-1830), Paris, 1843, p. 750 ; Conseil d'État, 26 mai 1813, Avis sur le mode à suivre pour obtenir le paiement des sommes dues par les communes, in DUVERGIER J.-B., Collection complète des Lois, Décrets, Ordonnances, Règlements, Avis

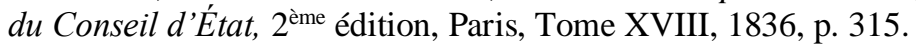

225 Tribunal des Conflits, 9 déc. 1899, Association Syndicale du canal de Gignac, Rec. Leb., 731, S, 1900, 3 , 49, note Hauriou. Selon un considérant de cet arrêt, «les voies d'exécution instituées par le Code de procédure civile pour le recouvrement des créances entre particuliers ne peuvent être suivies vis-à-vis des établissements publics ».

226 Cass. civ. 21 déc. 1987, Bureau de Recherches Géologiques et Minières, CJEG, 1988, p. 107.

227 NAM-TCHOUGLI Guy, «L'immunité d'exécution ou de saisie des entreprises publiques dans l'espace OHADA », Revue Africaine de Droit, d'Économie et de Développement, volume 1, nº6, 2005, p. 576. 
L'analyse de la jurisprudence, en la matière, présente deux catégories de bénéficiaires : la première catégorie concerne les établissements publics des États membres de l'OHADA ${ }^{228}$. La seconde catégorie est celle des sociétés anonymes dont le capital peut être détenu totalement ou partiellement par l'État ou d'autres personnes morales de droit public. Sont comprises dans la catégorie des sociétés anonymes qui bénéficient de l'immunité de juridiction, les sociétés d'État ${ }^{229}$. En revanche, les sociétés d'économie mixte ne sont pas admises au rang des entités juridiques bénéficiant de l'immunité d'exécution sur le fondement de l'arrêt MBULU Museso c/ Société Grands Hôtels du Congo rendu par la CCJA, le 26 avril $2018^{230}$.

Ce dernier arrêt imprime une nouvelle orientation à l'immunité d'exécution des entreprises.

\section{B. L'application de l'immunité d'exécution par la Cour commune de justice d'arbitrage}

La Cour commune de justice et d'arbitrage (CCJA), dans sa jurisprudence, a connu deux étapes : la tendance initiale était favorable à une application indifférenciée de l'immunité d'exécution (1). Le revirement jurisprudentiel opéré le 26 avril 2018 procède à une distinction entre société d'État et société d'économie mixte (2).

\section{La tendance initiale : L'application indifférenciée de l'immunité d'exécution}

La jurisprudence commerciale, celle élaborée dans le cadre du droit de l'OHADA, a semblé opter pour une application indifférenciée de l'immunité de juridiction au profit des entreprises publiques. Peu lui importait que l'entreprise relevât d'un statut de droit public ou de droit privé.

Ainsi, dans l'affaire Société SAS ALCATEL Space c/ SOTEL-TCHAD, la Cour, dans un attendu, a estimé : "les entreprises publiques quelles qu'en soient la forme et la mission échappent à l'exécution forcée et aux mesures conservatoire ». Tirant les conséquences de cet attendu, la CCJA a cassé l'arrêt n $166 /$ CIV rendu le 08 janvier 2008 par la Cour d'appel de N'Djamena. Selon la Cour, "l'arrêt querellé, en ordonnant le maintien de la saisie sur SOTEL, a violé la disposition visée au moyen et encourt la cassation ». Il importe de souligner que la SOTEL-TCHAD est une société d'État.

La CCJA distingue cependant entre immunité de juridiction et immunité d'exécution. La première - l'immunité de juridiction - empêche que son bénéficiaire puisse être attrait devant une juridiction donnée et, le cas échéant, être jugé par celle-ci. La seconde - l'immunité d'exécution - empêche l'application à son bénéficiaire des décisions juridictionnelles ou autres actes de contrainte. Dans l'affaire Hôpital Général de Référence Nationale $(H G R N)$ cl Société Total Elf Finio, la Cour a estimé que la "simple condamnation [de l'HGRN, un établissement public national] en paiement des causes d'une saisie et de dommages et intérêts, [...] ne relève pas des mesures conservatoires ou d'exécutions forcées visées aux

228

CCJA Ass. Plénière, Arrêt nº123/2014, 11 novembre 2014, Hôpital Général de Référence Nationale $(H G R N)$ c/ Société Total Elf Finio, www.OHADAcom>jurisprudence>Ohadata.

229 CCJA $2^{\text {ème }}$ Chambre, Arrêt nº9/2014, 27 février 2014, Société SAS ALCATEL Space c/ SOTEL-TCHAD, www.OHADAcom>jurisprudence>Ohadata; CCJA lère Chambre, Arrêt n44/2016, 18 mars 2016, GNANKOU Goth Philippe c/ Fonds d'entretien routier (FER), www.OHADA.com>jurisprudence>Ohadata.

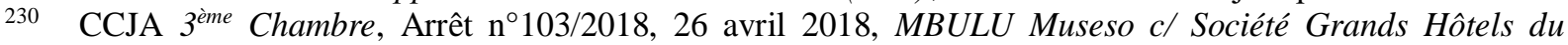
Congo, www.OHADAcom>jurisprudence>Ohadata. 
dispositions de l'article 30 précitées $»^{231}$. Il en aurait été autrement si l'arrêt querellé avait décidé de recourir à une voie d'exécution et autre contrainte à l'encontre de l'HGRN. Cette dernière hypothèse, seule, aurait pu justifier l'application de l'immunité d'exécution au profit de l'HGRN. La conséquence de la distinction précitée est que l'arrêt confirmatif rendu par la Cour d'appel de N'Djamena par lequel cette dernière rejette la demande en rétraction de l'Ordonnance $n^{\circ} 106 / 07$ du 27 septembre 2007, n'a pas violé l'article 30 de l'AUPSRVE. Ledit arrêt n'ayant pas validé une voie d'exécution ou autre contrainte à l'encontre de l'établissement public national qu'est l'HGRN.

La CCJA attache une importance incontestable à l'immunité d'exécution des entreprises publiques au point qu'aucune mesure d'exécution ne peut être appliquée à une entreprise publique bénéficiant de l'immunité d'exécution au sens de l'article 30 de l'AUPSRVE. Il en est ainsi même si une disposition de droit interne soumet ladite entreprise publique aux règles de droit privé ${ }^{232}$, cette disposition étant inopérante en application de l'article $10 \mathrm{du}$ Traité OHADA $^{233}$.

Dans l'affaire Société AES SONEL c/ Henri NGALLE MONONO et autres, la Cour a estimé : "la société AES SONEL, figurant dans la catégorie des entreprises publiques, bénéficie, conformément à la jurisprudence de la Cour de céans, de l'immunité d'exécution; ... en conséquence, il convient d'ordonner la mainlevée des saisies pratiquées les 16 et 17 mars 2005 sur ses comptes $»^{234}$.

Dans cet arrêt, la Cour semble distinguer d'une part entre personnes morales de droit public et entreprises publiques. Si l'application du droit public à la première catégorie - celle des personnes morales de droit public ${ }^{235}$ - ne fait l'objet d'aucun doute, en revanche, la nature des règles juridiques applicables aux entreprises publiques ne ressort pas clairement de l'attendu de la Cour. Aussi, convient-il de déduire que les entreprises auxquelles fait allusion la CCJA, en ce qui concerne le droit interne ivoirien, sont les sociétés d'État et les sociétés d'économie mixte ${ }^{236}$. Cette interprétation semble être désormais battue en brèche par le revirement jurisprudentiel opéré par la CCJA dans son arrêt du 26 avril 2018.

231 CCJA Ass. Plénière, Arrêt $\mathrm{n}^{\circ} 123 / 2014,11$ novembre 2014, Hôpital Général de Référence Nationale (HGRN) c/ Société Total Elf Finio, www.OHADA.com>jurisprudence>Ohadata.

232 «Attendu qu'il résulte de ce qui précède que le FER réunit les attributs d'une entreprise publique lui permettant de se prévaloir de l'immunité d'exécution prévue par l'article 30 alinéa 1 de l'Acte uniforme portant organisation des procédures simplifiées de recouvrement et des voies d'exécution, et que ce faisant, la loi $n^{\circ} 97-519$ du 04 septembre 1997 portant définition et organisation des sociétés d'État qui le soumet aux règles de droit privé est inopérante à cet égard en vertu de l'article 10 du Traité OHADA ; qu'ainsi, en confirmant l'ordonnance $n^{\circ} 2300$ du 15 mai 2012 ayant ordonné la mainlevée de la saisie attribution pratiquée sur ses avoirs dans les livres de la société ECOBANK CI, la Cour d'appel d'Abidjan $n$ 'a en rien violé l'article 30 alinéa 1 de l'Acte uniforme susmentionné ... ». Cf. CCJA 1 ère Chambre, Arrêt n44/2016, 18 mars 2016, GNANKOU Goth Philippe cl Fonds d'entretien routier (FER), www.OHADA.com $>$ jurisprudence〉Ohadata.

233 «Les actes uniformes sont directement applicables et obligatoires dans les États-Parties, nonobstant toute disposition contraire de droit interne, antérieure ou postérieure » (Article 10 Traité OHADA).

234 CCJA Ass. Plénière, Arrêt n ${ }^{\circ}$ 105/2014, 04 novembre 2014, Société AES SONEL c/ Henri NGALLE MONONO, Georges EYOMBO ANGANDZIE et Célestin BALENG MAAH, www.OHADA.com>jurisprudence>Ohadata.

235 Dans la catégorie des personnes morales de droit public bénéficiant de l'immunité d'exécution sont comprises les organisations intergouvernementales que sont respectivement l'ASECNA et la BCEAO ainsi que cela ressort de deux arrêts rendus par la CCJA : CCJA Ass. Plénière, Arrêt n¹36/2014, 11 novembre 2014, ASECNA c/ Ex-employés de l'ASECNA, www.OHADA.com〉jurisprudence〉Ohadata; CCJA, $I^{\text {ère }}$ Chambre, Arrêt n¹49/2015, 26 novembre 2015, BCEAO cl El Hadj Rabiou DJITAOU, www.OHADA.com>jurisprudence>Ohadata.

236 Le professeur Djè Bi Djè relevait à ce sujet que la notion d'entreprise publique, en Côte d'Ivoire tout comme en France, ne recouvre aucune réalité juridique. L'on regroupe sous ce vocable, les établissements publics à caractère industriel et commercial, des sociétés d'État et des sociétés d'économie mixte. Les sociétés d'État sont des sociétés à capital entièrement public, les sociétés d'économie mixte sont des sociétés de droit privé dans lesquelles les capitaux privés sont associés aux capitaux publics. $C f$. DJÈ Bi 


\section{Le revirement jurisprudentiel opéré le 26 avril 2018}

L'arrêt du 26 avril 2018, en maints passages, se démarque de ces prédécesseurs. Pour en saisir la portée, il importe, au préalable, d'en présenter succinctement les faits et la procédure suivie.

Dans une affaire opposant le sieur MBULU Museso à la Société Grands Hôtels du Congo, le premier nommé pratiquait, au préjudice de la société Grands Hôtels du Congo, des saisiesattributions de créances auprès des différents établissements bancaires de la place, pour avoir paiement de la somme de 59.696, 7 USD. Ces saisies étaient régulièrement dénoncées par la société débitrice qui éleva contestation le 12 août 2015. Par ordonnance M.U. 095 du 02 septembre 2015, la juridiction présidentielle du tribunal de Travail de Kinshasa/Gombe annulait lesdites saisies et en ordonnait la mainlevée. Sur appel de sieur MBULU Museso, la Cour de Kinshasa/Gombe rendait, en date du 05 novembre 2015, un arrêt confirmatif. Le sieur MBULU Museso se pourvu alors en cassation auprès de la CCJA ${ }^{237}$.

En première instance, tout comme en appel, le juge congolais a ordonné la mainlevée des saisies-attributions pratiquées par le sieur MBULU Museso sur les comptes de la société Grands Hôtels du Congo en se fondant sur l'immunité d'exécution dont jouissent les entreprises publiques en vertu de l'article 30 de l'AUPSRVE. À première vue, cette position du juge congolais s'inscrit dans le sillage d'une jurisprudence constante de la CCJA ébauchée dans son arrêt du 07 juillet 2005 dans l'affaire TOGO TELECOM ${ }^{238}$. Cette tendance sera confortée, entre autres, dans deux autres arrêts ${ }^{239}$.

Cependant, l'arrêt de la CCJA rendu le 26 avril 2018 opère un revirement en procédant à la distinction entre société d'État et société d'économie mixte. Il transparaît des motifs de l'arrêt que l'immunité d'exécution des entreprises publiques ne profite pas aux sociétés d'économie mixte. En effet, selon la Cour, "au regard de la législation congolaise, la défenderesse n'est pas une entreprise publique mais une société d'économie mixte soumise au régime des sociétés privées [...] en lui accordant l'immunité d'exécution, les juges ont violé [...] l'article 30 susvisé [de l'AUPSRVE]... ${ }^{240}$.

DJÈ Christiane, «La réorganisation du secteur public en Côte d'Ivoire : La réforme du 13 septembre $1980 », R I D 1986, \mathrm{n}^{\text {os }} 1-2$, p. 18 , note infra-paginale ${ }^{\circ} 4$.

237 CCJA $3^{\text {ème }}$ Chambre, Arrêt nº3/2018, 26 avril 2018, MBULU Museso c/ Société Grands Hôtels du Congo, www.OHADA.com $>$ jurisprudence $>$ Ohadata.

238 CCJA Arrêt n ${ }^{\circ} 043 / 2005,7$ juillet 2005, A. Y. et autres c/ Société TOGO TELECOM, Recueil de Jurisprudence de la CCJA, ${ }^{\circ}$ 6, juin-décembre 2005, p. 25.

239 CCJA $3^{\text {ème}}$ Chambre, $\mathrm{n}^{\circ} 024 / 2014,13$ avril 2014, KOUTOUATI A. AKAKPO Danwodina et 18 autres c/ Société TOGO-PORT dite Port Autonome de Lomé, Ohadata J-15-115. Dans cette affaire, la Cour a estimé que la soumission du Port autonome de Lomé aux règles de droit privé, conformément aux dispositions nationales togolaises s'appliquant aux entreprises publiques, ne fait pas obstacle à ce que ledit Port puisse bénéficier de l'immunité d'exécution prévue par l'article $30 \S 1$ de l'AUPSRVE. Ce faisant, la CCJA a confirmé l'arrêt rendu par le juge des référés par lequel celui-ci ordonne le sursis à exécution du jugement rendu en 1 ère instance à l'encontre du Port autonome de Lomé. Dans l'affaire GNANKOU GOTH Philippe, la Cour a estimé que le Fonds d'entretien routier (FER) étant une société d'État, elle bénéficie de plein droit de l'immunité d'exécution prévue par l'article $30 \S 1$ de l' nonobstant la loi n'97-519 du 04 septembre 1997 portant définition et organisation des soci AUPSRVE étés d'État qui soumet le F.E.R. aux règles de droit privé. Selon la Cour, cette disposition de la loi précitée est inopérante eu égard à la prévalence de l'AUPSRVE sur le droit interne des États membres de l'OHADA conformément à l'article $10 \mathrm{du}$ Traité OHADA. Cf. CCJA, $1^{\text {èr }}$ Chambre, Arrêt n ${ }^{\circ} 044 / 2016,18$ mars 2016, GNANKOU GOTH Philippe c/ Fonds d'Entretien Routier dit «FER».

240 CCJA $3^{\text {ème }}$ Chambre, Arrêt n n'103/2018 du 26 avril 2018, MBULU Museso c/ Société Grands Hôtels du Congo, www.OHADA.com $>$ jurisprudence $>$ Ohadata. 
Dans les motifs de l'arrêt, la Cour reconduit la distinction opérée par le législateur de l'OHADA entre, d'une part, les biens saisissables dont la détermination ressortit à la compétence du droit national en vertu de l'article 51 de l'AUPSRVE., et, d'autre part, les bénéficiaires de l'immunité d'exécution, dont les critères d'identification sont prévus à l'article 30 de l'AUPSRVE, maintenant ainsi la compétence de la CCJA ${ }^{241}$.

Sur le premier point relatif à la détermination des bénéficiaires de l'immunité d'exécution prévue à l'article 30 de l'AUPSRVE, la CCJA juge que "l'[AUPSRVE] n'ayant nullement renvoyé au droit national la question de la détermination des personnes bénéficiaires de l'immunité d'exécution, comme il l'a fait pour les biens insaisissables, celle-ci entre dans la compétence de la Cour de céans; (...) il s'en suit que [l'exception d'incompétence de la CCJA soulevée au motif que "le recours est en réalité dirigé contre une violation alléguée du droit interne de la République Démocratique du Congo ; que la détermination des entreprises bénéficiaires de l'immunité d'exécution étant renvoyée au droit interne de chaque État partie de l'OHADA, la CCJA doit se déclarer incompétente"] ne peut être accueillie ${ }^{242}$.

Sur la seconde question, la Cour indique désormais que le critère fondamental qui confère ou non l'immunité d'exécution prévue à l'article 30 de l'AUPSRVE à une personne morale est la nature de son activité en fonction de la forme sociétale adoptée. La simple présence de l'État ou d'une entité infra-étatique de droit public dans l'actionnariat d'une personne morale ne suffit pas à lui conférer l'immunité dès lors qu'exerçant son activité sous une forme sociétale prévue par l'Acte uniforme relatif aux sociétés commerciales (AUSCGIE), cette personne morale demeure inévitablement "une entité de droit privé soumise comme telle aux voies d'exécution sur ses biens propres ${ }^{243}$.

L'ensemble des arrêts de la CCJA analysés ci-dessus traduit incontestablement l'application du droit de l'OHADA aux entreprises publiques dès lors qu'elles empruntent une forme sociétale. Cependant, cette évolution ne semble pas recueillir entièrement l'assentiment du juge ivoirien qui a priori rechigne à appliquer le droit de l'OHADA au PAA.

\section{Paragraphe 2: Les réticences du juge ivoirien à appliquer le droit de l'OHADA au Port autonome d'Abidjan}

Il importe sur cette question de distinguer la position des juridictions d'appel de celle de la Chambre administrative de la Cour suprême. Les premières adoptent une position favorable à l'application du droit de l'OHADA aux entreprises publiques constituées sous une forme sociétale (A). En revanche, la Chambre administrative de la Cour suprême marque sa réticence à appliquer le droit de l'OHADA (B).

\section{A. La position favorable de la Cour d'appel d'Abidjan à l'égard du droit de I'OHADA}

Le juge judiciaire ivoirien se montre favorable à l'application du droit commercial, singulièrement le droit de l'OHADA, au Port autonome d'Abidjan.

241 «L'Acte uniforme portant organisation des procédures simplifiées de recouvrement et des voies d'exécution n'ayant nullement renvoyé au droit national la question de la détermination des personnes bénéficiaires de l'immunité d'exécution, comme il l'a fait pour les biens insaisissables, celle-ci entre dans la compétence de la Cour de céans».

242 KODO Mahutodji Jimmy Vital, «Évolution de la jurisprudence de la Cour Commune de Justice et d'Arbitrage de l'OHADA en matière d'immunité d'exécution », Document accessible en ligne sur www.OHADA.com>imprimer`actualités.

243 Ibidem. 
Ainsi, dans l'affaire Port autonome d'Abidjan (PAA) c. Entreprises Gravier et sables $(E G S)^{244}$, il apparaît que par une convention en date du 3 août 1977, le PAA accordait à la société EGS l'autorisation d'occuper privativement (pour une durée de 30 ans et à compter du $1^{\mathrm{er}}$ juillet 1977) une portion du domaine public portuaire. En 2002, le PAA, invoquant le nonrespect des clauses contractuelles par la société EGS, abroge l'autorisation d'occupation privative du domaine public portuaire et invite instamment la société EGS à libérer les lieux. Sur saisine de la société EGS, le juge des référés ordonnait la réintégration de la société EGS dans les locaux nonobstant l'exception d'incompétence soulevée par le PAA. Statuant en appel, la Cour éponyme d'Abidjan confirme l'ordonnance du juge des référés.

Pour ce faire, la Cour d'appel d'Abidjan se fonde sur certaines considérations. Selon la Cour, le PAA est une société d'État régie par la loi n97-519 du 04 septembre 1997 portant définition et organisation des sociétés d'État. En vertu de l'article 4 de ladite loi, la société d'État est une personne morale de droit privé, commerciale par sa forme. À ce titre, elle est soumise aux dispositions de l'Acte Uniforme relatif au droit des sociétés commerciales et des groupements d'intérêt économique. Au vu de ce qui précède, la Cour a estimé que le litige entre le PAA et la société EGS portait sur un bail commercial (un contrat de droit privé) et non pas une concession de voirie (un contrat administratif), comme l'excipait le PAA. Au regard de la catégorie dont relevait le contrat liant le PAA à la société EGS, le contentieux ressortissait à la compétence du juge commercial qui appliquerait le droit commercial. Cette décision de la Cour prenait nettement le contre-pied de l'argumentation du PAA selon laquelle le contrat litigieux était un contrat administratif par application du décret-loi du 17 juin 1938. Selon ce décret-loi, tous les contrats comportant occupation privative du domaine public sont des contrats administratifs par détermination de la loi.

Dans une autre affaire, à savoir l'affaire Port Autonome d'Abidjan c. Société TRANSIVOIRE portant également sur l'occupation privative du domaine public portuaire ${ }^{245}$, la Cour a considéré que le Port Autonome d'Abidjan est une société d'État ainsi qu'il en résulte de la loi n97-519 du 04 septembre 1997. En tant que telle, le Port Autonome d'Abidjan est soumis au Traité de l'OHADA en vertu de l'article $1^{\text {er }}$ de l'Acte Uniforme relatif aux sociétés commerciales et groupement d'intérêt économique et de l'article $1^{\text {er }}$ de l'Acte Uniforme portant Droit Commercial général ${ }^{246}$. Dès lors, le bail conclu par le Port Autonome d'Abidjan avec la Société TRANS-IVOIRE est un bail commercial et les conflits qui en découlent relèvent de la compétence des juridictions de droit commun. La Cour d'appel d'Abidjan a été confortée dans son raisonnement par le fait que le Port Autonome d'Abidjan a saisi le Tribunal de première Instance d'Abidjan qui a rendu le 27 mars 1995, le jugement n ${ }^{\circ} 88$ du 27 mars 1995 par lequel le Tribunal de première instance d'Abidjan a procédé à la résolution judiciaire du contrat liant le PAA à la Société TRANS-IVOIRE ${ }^{247}$.

244 CAA, Chambre civile et commerciale, Arrêt n ${ }^{\circ} 615$ du 20 mai 2003, Port autonome d'Abidjan (PAA) $c$. Entreprises Gravier et Sables (EGS).

245 Cour d'appel d'Abidjan, Chambre civile et commerciale, Arrêt n ${ }^{\circ} 904$ du 08 juillet 2003, Port autonome d'Abidjan c. Trans Ivoire.

246 Selon l'article premier de l'Acte uniforme relatif au droit commercial général, "Tout commerçant, personne physique ou morale y compris toutes sociétés commerciales dans lesquelles un État ou une personne de droit public est associé, ainsi que tout groupement d'intérêt économique, dont l'établissement ou le siège social est situé sur le territoire de l'un des États parties au Traité relatif à l'harmonisation du Droit des Affaires en Afrique (ci-après dénommés «États parties »), est soumis aux dispositions du présent Acte Uniforme ». Cf. Acte uniforme relatif au droit commercial général adopté le 17 avril 1997, Journal Officiel de l'OHADA, ${ }^{\circ} 1$ du $1^{\text {er }}$ octobre 1997.

247 En conséquence de cette cessation du lien contractuel par l'effet du jugement du 27 mars 1995, la Cour d'appel d'Abidjan à débouté la Société TRANS-IVOIRE de sa demande de cessation de voie de fait par suite des travaux de construction entrepris sur le lot que lui avait auparavant attribué le PAA. 
Dans une troisième affaire, en l'occurrence l'affaire Port autonome d'Abidjan c. Société PEXAGR $I^{248}$, la Cour d'appel d'Abidjan a considéré que les actes juridiques par lesquels le PAA accorde puis abroge une autorisation d'occupation privative du domaine public portuaire étaient des baux commerciaux, et non pas des concessions de voirie. Pour soutenir cette affirmation, la Cour se fonde sur les articles 3 et 4 de la loi n' $97-519$ du 4 septembre 1997 portant définition et organisation des sociétés d'État. Sur le fondement de ces dispositions, il apparaît que le PAA est une société d'État, relevant de la catégorie des sociétés commerciales au regard de sa forme juridique ${ }^{249}$. Il est donc soumis aux lois applicables aux sociétés commerciales. De ce qui précède, la Cour estime que les actes par lesquels le PAA a accordé puis retiré à la société PEXAGRI l'autorisation d'occuper le site litigieux sont des actes commerciaux dont le contentieux ressortit à la compétence du juge commercial.

$\mathrm{Au}$ vu des trois arrêts précités, il apparait que la Cour d'appel d'Abidjan a une inclination à appliquer le droit commercial, en général, et le droit de l'OHADA, en particulier, dans certains litiges dans lesquels le PAA est partie.

Cet enthousiasme contraste avec la réticence de la Chambre administrative de la Cour suprême à recourir au droit de l'OHADA dans les litiges où le PAA est partie.

\section{B. La réticence de la Chambre administrative de la Cour suprême à appliquer le droit de l'OHADA}

L'analyse des arrêts rendus, en la matière, par la Chambre administrative de la Cour suprême situe sur sa position diamétralement opposée à celle de la Cour d'appel d'Abidjan.

Trois (3) arrêts de la Chambre administrative de la Cour suprême ivoirienne nous donneront un aperçu du contentieux relatif à l'occupation privative du domaine public. Les deux premiers intéressent le PAA. En revanche, le troisième arrêt met aux prises la société AERIA, une société anonyme chargée d'une concession de service public, à savoir l'exploitation de l'aéroport Félix Houphouët-Boigny de Port-Bouët. Ce sont, respectivement, l'affaire Port Autonome d'Abidjan c/ Entreprises Graviers et Sables (EGS) ${ }^{250}$, l'affaire Port autonome d'Abidjan c. Société Pexagri ${ }^{251}$ et l'affaire Turkish Airlines ${ }^{252}$.

\section{L'affaire Port Autonome d'Abidjan c/ Entreprises Graviers et Sables}

Dans l'affaire Port Autonome d'Abidjan c/ Entreprises Graviers et Sables, le PAA a, par convention en date du 3 août 1977, accordé à l'Entreprise Graviers et Sables (EGS), l'autorisation d'occuper de manière exclusive le lot n³49 ter de la zone des industries navales de Vridi, pour une durée de 30 ans, à compter du $1^{\text {er }}$ juillet 1977. L'EGS est autorisée à élever, sur le lot concédé, des constructions composées d'un des hangars, d'un bureau, d'une pompe station-service et d'un magasin de stockage devant servir exclusivement à abriter des véhicules et au stockage de pièces détachées. Durant l'année 2002, le PAA fait constater par huissier que l'EGS avait sous-loué, sans l'avertir au préalable, une partie du lot

\footnotetext{
248 CAA, Chambre civile et commerciale, Arrêt n ${ }^{\circ} 160$ du 14 février 2006, Port autonome d'Abidjan c. Société PEXAGRI.

249 CAA, Chambre civile et commerciale, Arrêt nº615 du 20 mai 2003, Port autonome d'Abidjan (PAA) c. Entreprises Gravier et Sable (EGS).

250 CSCA 23 mars 2005, Arrêt n¹4, Port Autonome d'Abidjan c/ Entreprises Graviers et Sables (EGS), req. n 2003-453 CASS/AD.

251 CSCA 28 juillet 2010, Arrêt n81, Port autonome d’Abidjan c. Société Pexagri, req. n²009-008 CASS/ADM.

252 CSCA, 27 avril 2016, Société A.E.R.I.A c/ Compagnie aérienne Turkish Airlines, État de Côte d'Ivoire, A.N.A.C, A.S.E.C.N.A, Arrêt $\mathrm{n}^{\circ} 67$, inédit.
} 
concédé à un autre opérateur économique privé, la société SOCOP-CI. Excipant de la violation des stipulations de la concession de voirie, le PAA met unilatéralement fin à ladite convention et invite l'EGS à "libérer les lieux». Saisie en cassation après bien de péripéties, la Chambre administrative de la Cour suprême décide que la convention liant le PAA à l'EGS est un contrat administratif qui, à ce titre, est soustrait aux dispositions de l'Acte Uniforme de l'OHADA relatif au droit des sociétés commerciales et des groupements d'intérêt économique.

\section{L'affaire Port autonome d'Abidjan c. Société Pexagri}

Dans l'affaire Port autonome d'Abidjan c. Société Pexagri, par décision n01222 du 23 mai 2005, le Port Autonome d'Abidjan a retiré à la Société d'Exploitation Agricole dite PEXAGRI l'autorisation d'occuper le lot n²-ZE-049-73 ter qu'elle lui avait accordée par un acte du 26 mai 2004 au motif que cette entreprise qui n'exerçait plus elle-même aucune activité sur ce site l'avait sous-loué. Après avoir, vainement, demandé au Port Autonome d'Abidjan de rapporter sa décision, la société PEXAGRI a saisi le juge des référés d'une demande aux fins de faire défense au Port Autonome d'Abidjan qui lui en avait fermé l'accès, de le troubler dans la jouissance des lieux. Déboutée de cette demande par le juge des référés, la Société PEXAGRI interjette appel auprès de la Cour d'Appel d'Abidjan. Celle-ci, par arrêt $\mathrm{n}^{\circ} 160$ du 14 février 2006 infirmant l'ordonnance de référée $\mathrm{n}^{\circ} 2233$ du 16 novembre 2005, ordonne la cessation des troubles de jouissance sur le lot litigieux causés à la Société PEXAGRI, sous astreinte comminatoire de 500.000 francs par jour de retard. Excipant du fait que l'arrêt infirmatif de la Cour d'appel d'Abidjan méconnait les dispositions du décret n²001-143 du 14 mars 2001 portant approbation des statuts du Port Autonome d'Abidjan et du décret-loi du 17 juin 1938, le PAA se pourvoit en cassation. La Chambre administrative de la Cour suprême reconnaît le caractère administratif de la décision du PAA par laquelle il a donné, puis retiré l'autorisation d'occuper un bien immobilier dépendant du domaine public portuaire. Selon la haute juridiction, ce sont des actes administratifs dont le contentieux relève de la juridiction administrative suivant la procédure du recours en annulation pour excès de pouvoir. Aussi, a-t-elle cassé l'arrêt de la Cour d'appel d'Abidjan et a-t-elle invité la société PEXAGRI à mieux se pourvoir.

\section{L'affaire Turkish Airlines ${ }^{253}$}

Dans une espèce plus récente, l'affaire Turkish Airlines, la Chambre administrative de la Cour suprême a réitéré la présomption (simple) de faute qui pèse sur l'exploitant d'un ouvrage public ${ }^{254}$.

Pour ce faire, la Cour a considéré «qu'il est de principe que l'action en responsabilité dirigée contre un organisme privé gérant un service public ne peut être engagée que sur le fondement du droit administratif, lorsque le dommage se rattache à un travail public ou à un ouvrage public dont il a la garde ».

\footnotetext{
253 La société AERIA est concessionnaire de l'Aéroport international Félix Houphouët-Boigny d'Abidjan depuis 1996. Après la première concession de quinze (15) ans qui a permis la transformation de cet aéroport d'une capacité initiale de 600.000 passagers en un hub régional d'une capacité de plus de 2 millions de passagers, l'État de Côte d'Ivoire a renouvelé en 2010 la concession avec AERIA pour une durée de 20 ans. $C f$. https://www.abidjan-aeroport.com/societe/. Document consulté le 22 mars 2019.

254 CSCA, 27 avril 2016, Société A.E.R.I.A c/ Compagnie aérienne Turkish Airlines, État de Côte d'Ivoire, A.N.A.C, A.S.E.C.N.A, Arrêt $\mathrm{n}^{\circ} 67$, inédit.
} 
Après avoir déterminé le droit applicable, la Cour poursuit en «considérant, par ailleurs, qu'il est constant qu'en cas de délégation de la construction ou de l'exploitation d'un ouvrage public à un concessionnaire, sa responsabilité ou celle du concédant est engagée, lorsqu'un tiers à la convention subit un dommage imputable à l'existence ou au fonctionnement de l'ouvrage public ».

Pour parvenir à cette déduction, la Cour a, au préalable, exclu que l'action en responsabilité à l'encontre de la Société A.E.R.I.A. puisse relever de la catégorie d'actes de commerce. Selon la Cour, «En retenant sa compétence à l'égard de la société A.E.R.I.A., au motif que celle-ci est une société commerciale par la forme alors qu'en l'espèce, d'une part, cette société n'a accompli aucun acte de nature commerciale et que, d'autre part, la société A.E.R.I.A. est chargée de la gestion et de la garde d'un ouvrage public, le Tribunal de Commerce a violé toutes les règles de compétence édictées par l'article 7 de la loi $n^{\circ} 2014$ 424 du 14 juillet 2014 portant création, organisation, fonctionnement et déterminant surtout limitativement la compétence d'exception des juridictions de commerce, l'article 3 de l'acte uniforme de l'OHADA sur le droit commercial général et l'article 5 du code de procédure civile, commerciale et administrative ${ }^{255}$.

Dans l'affaire Turkish Airlines, on note que l'action en responsabilité est intentée contre la Société A.E.R.I.A., une société anonyme, donc commerciale par la forme.

Sur ce point, on note une convergence entre la Société A.E.R.I.A. et le PAA. Toutes deux relèvent de la catégorie de personne morale de droit privé. Aussi, n'est-il pas exclu que la responsabilité administrative du PAA puisse être retenue dans l'hypothèse où un ouvrage public construit ou exploité par celui-ci était la cause d'un dommage à un usager dudit port. En faisant du droit comparé, en se référant singulièrement à la jurisprudence de la Cour de cassation française, on note la pertinence de la déduction ci-dessus. Ainsi, la Cour de cassation considère comme des dommages de travaux publics, les dommages occasionnés par la construction d'un port ${ }^{256}$. En outre, sont considérés comme des dommages de travaux publics, les blessures subies par une personne lors d'une chute provoquée par la présence d'un cordage délimitant un dépôt de matériaux sur un terre-plein portuaire en vue de réaliser des travaux d'aménagement sur celui-ci ${ }^{257}$.

\section{Observation :}

$\mathrm{Au}$ regard de ces trois arrêts, on note la propension du juge ivoirien, singulièrement la Chambre administrative de la Cour suprême, à appliquer le droit administratif au contentieux contractuel et au contentieux de la responsabilité impliquant deux personnes de droit privé, dont l'une présente la qualité de société d'État. Cette option paraît a priori critiquable, au regard de l'article premier de l'article premier de l'Acte uniforme relatif au droit commercial général (AUDCG) dans sa version de 1997, demeure cependant celle qui fait autorité en droit ivoirien eu égard à la prééminence de la Cour suprême (juridiction de cassation) sur la Cour d'appel (juge d'appel). Au regard de l'article premier de l'AUDCG, le droit commercial s'applique à tout commerçant, y compris les sociétés commerciales dans lesquelles l'État ou une personne morale de droit public est associé et dont le siège social est situé sur le territoire de l'un des États parties ${ }^{258}$. En outre, l'article 71 de l'AUDCG, dans sa version de 1997,

255 CSCA, 27 avril 2016, Société A.E.R.I.A c/ Compagnie aérienne Turkish Airlines, État de Côte d'Ivoire, A.N.A.C, A.S.E.C.N.A, Arrêt $\mathrm{n}^{\circ} 67$, inédit.

256 Cass. Civ. $1^{\text {ère }}, 15$ février 1975, Société du yacht club de Marina Baie des Anges, Bull. civ. I, nº8.

257 Cass. Civ. $1^{\text {ère }}, 20$ février 1973, n $72-10,174$, Bull. civ. I, n ${ }^{\circ} 69$.

258 Dans son ancienne version, celle de 1997, l'article premier de l'Acte uniforme relatif au droit commercial général disposait: "Tout commerçant, personne physique ou morale y compris toutes sociétés commerciales dans lesquelles un État ou une personne de droit public est associé, ainsi que tout groupement d'intérêt économique, dont l'établissement ou le siège social est situé sur le territoire de l'un des États parties au Traité relatif à l'harmonisation du Droit des Affaires en Afrique (ci-après dénommés « 
disposait : "Est réputée bail commercial toute convention, même non écrite, existant entre le propriétaire d'un immeuble ou d'une partie d'un immeuble compris dans le champ d'application de l'article 69, et toute personne physique ou morale, permettant à cette dernière, d'exploiter dans les lieux avec l'accord du propriétaire, toute activité commerciale, industrielle, artisanale ou professionnelle ».

Au moment où la Chambre administrative de la Cour suprême (CSCA) rendait ses arrêts respectivement dans les affaires Port autonome d'Abidjan c/ Entreprises Graviers et Sables $^{259}$, d'une part, et Port autonome d'Abidjan c/ Société Pexagri ${ }^{260}$, d'autre part, l'AUCDG de 1997 était celui en vigueur. Le PAA étant une société commerciale par sa forme, en vertu de l'article premier du décret n²001-143 du 14 mars 2001 261 , était normalement régi par le droit de l'OHADA en vertu du critère organique (celui de commerçant) tiré de l'article premier précité de l'AUDCG Par voie de conséquence, l'application du critère organique (celui tiré de la qualité de commerçant) explique que la Cour d'appel d'Abidjan ait choisi de soumettre le PAA aux règles s'appliquant au bail commercial par suite des conventions conclues par le Port avec des personnes privées; conventions qui leur permettaient d'occuper un bien immeuble du PAA afin d'y exercer une activité commerciale, industrielle, artisanale ou professionnelle.

À vrai dire, la position de la CSCA traduit un conflit entre le droit de l'OHADA et le décret-loi du 17 juin $1938^{262}$; un conflit entre une norme de droit communautaire et une norme de valeur législative édictée par un État membre de l'OHADA. Par application du principe de l'effet immédiat du droit communautaire, et du principe de la primauté de la norme communautaire sur la norme nationale, il est clair que le décret-loi du 17 juin 1938 devrait céder le pas. On note, en outre, un conflit entre le Traité de l'OHADA et une norme interne de valeur législative ${ }^{263}$. Dans un tel cas de figure, les Constitutions respectives de 2000 et de 2016 de la République de Côte d'Ivoire, optent pour la primauté du traité régulièrement ratifié sur la loi stricto sensu ${ }^{264}$.

Cependant, une telle lecture bien qu'elle soit juridiquement fondée ne tiendrait pas compte des implications énormes et ruineuses pour le patrimoine de l'État. En effet, les règles spéciales et dérogatoires ${ }^{265}$ conçues pour s'appliquer à cette portion du patrimoine étatique

États parties »), est soumis aux dispositions du présent Acte Uniforme ». Cf. Acte uniforme relatif au droit commercial général adopté le 17 avril 1997, Journal Officiel de l'OHADA, n¹ du $1^{\text {er }}$ octobre 1997.

259 CSCA 23 mars 2005, Arrêt n¹4, Port Autonome d’Abidjan c/ Entreprises Graviers et Sables (EGS), req. $\mathrm{n}^{\circ}$ 2003-453 CASS/AD.

260 CSCA 28 juillet 2010, Arrêt ${ }^{\circ} 81$, Port autonome d'Abidjan c. Société Pexagri, req. n²009-008 CASS/ADM.

261 Décret n²001-143 du 14 mars 2001 portant approbation des Statuts du Port autonome d'Abidjan (PAA) et reclassification des immobilisations concédées, JORCI n 17, 26 avril 2001, p. 313.

262 En vertu du décret-loi du 17 juin 1938, tous les contrats touchant au domaine public sont des contrats administratifs par détermination de la loi. Il en résulte que, selon le système de dualité de juridiction en vigueur en France, le contentieux des contrats comportant occupation privative du domaine public ressortit à la compétence du juge administratif, juge du contrat. En Côte d'Ivoire, par application du décret-loi du 17 juin 1938, et en vertu du monisme juridictionnel, le contentieux des contrats administratifs relèvera de la compétence du juge de droit commun. Cependant, il devra appliquer le droit administratif, celui des contrats administratifs.

263 En vertu de l'article 10 du Traité de l'OHADA, «Les Actes uniformes sont directement applicables et obligatoires dans les États-parties, nonobstant toute disposition contraire de droit interne, antérieure ou postérieure ».

264 En vertu de l'article 87 de la Constitution du $1^{\mathrm{er}}$ août 2000, «les traités ou accords régulièrement ratifiés ont, dès leur publication, une autorité supérieure à celle des lois, sous réserve, pour chaque traité ou accord, de son application par l'autre partie ». Cette disposition a reprise in extenso par l'article 123 de la loi n²2016-886 du 08 novembre 2016 portant Constitution de la République de Côte d'Ivoire.

265 Ce sont, entre autres, le principe de l'inaliénabilité, le principe de l'imprescriptibilité et le principe de l'insaisissabilité du domaine public. Ces principes trouvent une application au moyen du décret-loi du 17 
que l'on nomme domaine public, s'explique par la volonté de ses concepteurs de préserver le domaine de l'État de tout démembrement, de toute dilapidation. Cela explique d'ailleurs l'institution des principes de l'inaliénabilité, de l'imprescriptibilité et de l'insaisissabilité, principes dont l'application rigoureuse a permis tant bien que mal de préserver la consistance et l'affectation du domaine public. Faire table rase de ces principes au motif que la qualité de commerçant du PAA emporterait une application stricte et totale des règles commerciales à celui-ci, reviendrait à soumettre le domaine public aux transactions diverses observées, en droit privé, sur les biens immeubles.

Opter pour une telle approche ne reviendrait-il pas à nier la satisfaction des missions d'intérêt général qui nimbe l'exploitation des dépendances domaniales ? Autrement dit, peuton satisfaire l'intérêt général en grevant, de manière incontrôlée, le domaine public de servitudes, d'hypothèques voire en aliénant le domaine public surtout lorsqu'on sait que ces divers actes ou opérations juridiques, par essence, ne profitent qu'à leurs titulaires ou à ceux qui s'y livrent ? Devrait-on, de ce fait, faire la part belle à l'intérêt particulier au détriment de l'intérêt général ?

L'appellation de "domaine public" en lieu et place de "immeuble" comme on le voit en droit civil, témoigne de cette volonté de marquer la dissociation entre ces deux catégories de bien. Le "domaine public', comme l'indique son appellation, est le bien de la collectivité. Il est destiné à satisfaire l'intérêt général ; intérêt général dans lequel s'inscrit nécessairement l'intérêt particulier. Il n'empêche que le législateur ivoirien, au moyen de l'ordonnance du 03 août 2016 a prévu des contrats et autres actes juridiques par lesquels les occupants privatifs puissent consolider les droits que leur confèrent leurs titres d'occupation temporaire et privative du domaine public des collectivités publiques ${ }^{266}$.

Abstraction faite de la prééminence organique de la Cour suprême (juridiction suprême) sur la Cour d'appel (juge d'appel), nous sommes d'avis que l'interprétation de la Cour d'appel d'Abidjan tendant à appliquer, de manière indifférenciée, le droit commercial aux sociétés d'État ne devrait pas être retenue. Il est vrai que les sociétés d'État seront soumises, le cas échéant, aux règles de droit commercial. Cela se comprend vu que l'État lui-même en les créant leur a conféré la qualité de commerçant. Cependant, on le répète, le contentieux relatif à l'utilisation du domaine public par les concessionnaires du domaine public ne devrait nullement être régi par les règles de droit privé. Il est vrai qu'on nous objecterait que le droit de l'OHADA, droit communautaire, prime sur le droit interne des États membres. Et qu'à ce titre, l'application indifférenciée du droit de l'OHADA devrait être de mise. Une telle interprétation, si elle devait être adoptée, signifierait que les États (africains) signataires du traité instituant l'OHADA ont choisi de se saborder en tirant un trait sur une de leurs sources majeures de revenue pour faire la part belle à la logique commerciale. Ces États africains, à défaut d'être industrialisés, perçoivent essentiellement leurs revenus de l'exportation de matières premières, de la perception des droits de douanes, des prélèvements d'impôts ainsi que des redevances perçues à travers l'octroi des permissions de voirie, des concessions de voirie, des concessions à objet multiple, etc. Ces dernières opérations ont pour assiette le domaine public. En somme, on retiendra que le droit applicable au domaine public recouvre une double dimension : préserver le domaine public contre tout démembrement, d'une part, et exploiter le domaine public pour en retirer des utilités financières, d'autre part. Ces deux objectifs n'ont pas varié y compris en République Française. D'ailleurs dans ce pays développé disposant d'un domaine public très étendu, l'État continue de veiller, à travers la dualité de juridiction et la dualité du contentieux, à ce que le domaine public soit protégé

juin 1938 qui soustrait les occupations temporaires du domaine public, de la compétence des juridictions judiciaires et de l'application des règles de droit privé.

266 Voir notamment les autorisations d'occupation temporaire (AOT) constitutives de droits réels sur le domaine publique (articles 33 à 40), le bail emphytéotique administratif (articles 41 à 43). 
contre toute espèce de démembrement par suite de l'application du droit commercial audit domaine.

$\mathrm{Au}$ regard de tout ce qui précède, nous comprenons parfaitement les réticences de la CSCA à appliquer le droit commercial au contentieux relatif à l'occupation privative du domaine public. Il est vrai que la CSCA lorsqu'elle statue n'évoque pas ouvertement les raisons ci-dessus. Il n'empêche que sa propension à ne pas accorder, en la matière, la primauté au droit commercial de l'OHADA sur le droit interne ivoirien répond à des considérations plus pratiques que juridiques. Il appartient, dès lors, aux États (africains) membres de l'OHADA (qui, indéniablement, se trouvent dans la même situation économique que la Côte d'Ivoire) de procéder aux ajustements textuels nécessaires afin de soulager leurs juridictions nationales qui seraient confrontées à un tel dilemme. 


\section{CONCLUSION DE LA PREMIÈRE PARTIE}

Le statut juridique du PAA, on l'a vu, a connu une évolution. Ce statut juridique était initialement constitué exclusivement de textes juridiques adoptés par le législateur ivoirien. Actuellement, ce statut est investi par le droit communautaire de l'UEMOA et de l'OHADA. Cette évolution témoigne de l'imbrication croissante de la Côte d'Ivoire, en général, et du PAA, en particulier, dans un espace économique plus vaste regroupant les États d'Afrique occidentale ayant en partage la langue française.

En outre, on note que le statut juridique du PAA évolue de plus en plus pour intégrer le droit commercial eu égard à certaines activités menées par le PAA. Il n'empêche que la nature juridique particulière du PAA (une société d'État) et sa mission de service public (l'exploitation et la conservation du domaine public portuaire) impliquent une marge incompressible de droit public manifestée par les prérogatives de puissance publique dont il use à l'égard de ses usagers, des permissionnaires de voirie ou des opérateurs privés liés au PAA par un contrat de concession. Ce statut spécial conféré au PAA emporte nécessairement que l'on bride quelque peu la propension à le soumettre intégralement aux règles de droit commercial avec tous les risques de démembrements que cela comporte pour le domaine public. 


\section{DEUXIEME PARTIE : UN STATUT JURIDIQUE PERFECTIBLE EN VUE DE L'EXPLOITATION OPTIMALE DU PORT AUTONOME D'ABIDJAN}

Le cadre juridique actuel régissant le PAA comporte des failles qui en affaiblissent substantiellement les performances (Titre 1). Aussi, convient-il de les surmonter en adaptant la législation existante (Titre 2). 



\section{TITRE I : LES FAIBLESSES DU CADRE JURIDIQUE ACTUEL DE GESTION DU DOMAINE PUBLIC PORTUAIRE}

Ces faiblesses se perçoivent surtout à travers les pesanteurs qui grèvent l'occupation privative du domaine public, en général (Chapitre 1). Celles-ci découlent de l'application rugueuse du droit public au port autonome d'Abidjan (Chapitre 2). 



\section{CHAPITRE 1 : LES PESANTEURS DE L'OCCUPATION PRIVATIVE DU DOMAINE PUBLIC}

Le domaine public, en général, et celui du PAA, en particulier, est régie, entre autres, par le principe de précarité qui s'applique aux titulaires d'autorisation d'occupation temporaire de ce patrimoine de la personne publique (Section 1). Cette précarité emporte des incidences sur la situation juridique de l'occupant privatif du domaine public géré par le PAA (Section 2).

\section{SECTION 1: Le caractère précaire des occupations privatives du domaine public}

L'affirmation du caractère temporaire de l'occupation privative du domaine public découle des effets cumulés des principes d'inaliénabilité et d'imprescriptibilité (paragraphe 1). Cette précarité se fonde indéniablement sur une raison, celle de la préservation de la consistance du domaine et son affectation (paragraphe 2).

\section{Paragraphe 1 : La précarité de l'occupation privative, une résultante de l'inaliénabilité et de l'imprescriptibilité du domaine public}

La précarité désigne le caractère de ce qui est librement révocable au gré du maître d'une chose, notamment de l'Administration propriétaire ${ }^{267}$. Cette précarité résulte de l'application combinée des principes d'inaliénabilité et d'imprescriptibilité. Ces deux principes visent la défense de l'intérêt général. Chacun d'eux revêt un contenu particulier qu'il faudrait analyser (A). En République de Côte d'Ivoire, le fondement juridique de la précarité des occupations privatives du domaine public réside, actuellement, dans l'ordonnance du 03 août 2016 relative au domaine public ${ }^{268}(\mathrm{~B})$.

\section{A. Le contenu des principes d'inaliénabilité et d'imprescriptibilité}

Chacun de ces deux principes se distingue par sa signification particulière. Aussi, l'analyse du principe d'inaliénabilité (1) précèdera-t-elle celui d'imprescriptibilité (2).

\section{Le principe d'inaliénabilité269}

En droit administratif des biens, l'inaliénabilité est la qualité juridique d'un bien qui ne peut valablement être l'objet d'une aliénation dès lors que ce bien est inclus dans le domaine

CORNU Gérard (dir.), Vocabulaire juridique, 9ème édition, Paris, Quadrige/Puf, 2011, p. 778.

Ordonnance $\mathrm{n}^{\circ} 2016-588$ du 03 août 2016 portant titres d'occupation du domaine public.

Établi au Moyen-âge en réaction contre la prodigalité des monarques, insérés par les premiers Valois dans le serment du sacre, le principe d'inaliénabilité est solennellement consacré "loi fondamentale du Royaume » par l'édit de Moulins en 1566. Le principe d'inaliénabilité, sous l'Ancien Régime, s'étendait à l'ensemble des biens de la Couronne sans distinction. Désormais, elle ne s'adresse qu'à une catégorie de biens: ceux du domaine public que l'on distingue du domaine privé. $C f$. MORAND-DEVILLER Jacqueline, Cours de droit administratif des biens, $3^{\text {ème }}$ édition, Paris, Montchrestien, 2003, pp. 157 et 159. 
public d'une personne morale de droit public (l'État, les collectivités territoriales, les établissements publics).

À vrai dire, l'inaliénabilité n'a pas une portée absolue. En effet, il serait plus approprié de dire que les dépendances du domaine public ne peuvent pas être cédées à des tiers aussi longtemps qu'elles n'auraient pas, au préalable, fait l'objet d'un déclassement. Il en résulte qu'en fait d'inaliénabilité, on est plutôt en présence d'une "aliénabilité conditionnelle ${ }^{270}$. Selon le professeur Morand-Deviller, "l'inaliénabilité est relative ${ }^{271}$ et potestative ${ }^{272}$ puisque l'administration reste libre de supprimer l'affectation (du moins s'agissant du domaine public artificiel) et de disposer ensuite des biens comme elle l'entend ${ }^{273}$.

Quoi qu'il en soit, le principe d'inaliénabilité fait obstacle à ce qu'une personne, autre que l'Administration délivrant la concession ou la permission de voirie, exerce un droit de propriété sur la dépendance domaniale. Il en résulte que le permissionnaire ou le concessionnaire de voirie (l'occupant privatif) exerce un droit réel démembré sur la dépendance domaniale à savoir l'usus, le fructus sans l'abusus. L'usus correspond au droit qu'a l'occupant d'user de la chose et le fructus celui d'en percevoir les fruits. Titulaire d'un droit de jouissance, l'occupant du domaine public peut user de la chose et d'en percevoir les fruits, mais il ne peut en disposer ou d'en altérer la substance ${ }^{274}$.

\section{Le principe d'imprescriptibilité}

L'imprescriptibilité est le caractère des biens composant le domaine public et qui, complétant leur inaliénabilité, s'oppose à ce que les dépendances de celui-ci puissent faire l'objet d'une prescription tant de la propriété que de ses démembrements (imprescriptibilité qui s'étend aux actions en justice protégeant le domaine public) $)^{275}$.

L'imprescriptibilité interdit d'acquérir par prescription, c'est-à-dire par possession prolongée, la propriété d'une dépendance du domaine public ou tout autre droit réel immobilier sur ces biens ${ }^{276}$. Elle permet de s'opposer aux revendications des particuliers qui ont profité de la négligence de l'Administration pour s'établir sans titre sur une partie du domaine public, parfois de bonne foi lorsque les limites du domaine ne sont pas clairement établies $^{277}$. Ainsi, dans l'affaire Couach, le Tribunal des conflits (en France), a rappelé

270 MORAND-DEVILLER Jacqueline, Cours de droit administratif des biens, $3^{\text {ème }}$ édition, Paris, Montchrestien, 2003, pp. 163-164.

271 Dans sa décision rendue le 18 septembre 1986, le Conseil constitutionnel français considère : «Sans qu'il soit besoin de rechercher si le principe d'inaliénabilité du domaine public a valeur constitutionnelle ... ce principe s'oppose seulement à ce que des biens du domaine public soient aliénés sans qu'ils aient été au préalable déclassés ». La deuxième portion de la citation démontre le caractère relatif de l'inaliénabilité, du fait de la possibilité de déclassement.

272 Dans sa décision du 21 juillet 1994, le Conseil constitutionnel français souligne : «Il importe au législateur, lorsqu'il modifie les dispositions relatives au domaine public, de ne pas priver de garanties légales les exigences constitutionnelles qui résultent de l'existence et de la continuité des services publics auxquels il est affecté ». Ce qui signifie que l'inaliénabilité est potestative : elle repose sur l'affectation et son maintien.

273 MORAND-DEVILLER Jacqueline, Cours de droit administratif des biens, op. cit., p. 164.

274 KANE Ababacar Khalifa, Le droit portuaire en Afrique: Aspects juridiques de la gestion et de l'exploitation portuaires au Sénégal, Paris, L'Harmattan, 2012, p. 86.

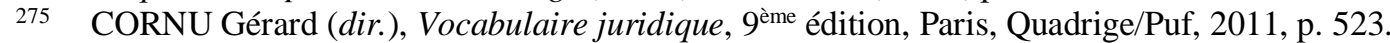

276 MORAND-DEVILLER Jacqueline, Cours de droit administratif des biens, op. cit., p. 165.

277 Dans l'affaire Cazeaux, l'Administration avait laissé des particuliers occuper des parcelles du littoral dans le bassin d'Arcachon et renoncé à réclamer la domanialité publique des parcelles. Pour le Conseil d'État, " une telle circonstance n'a pu en dépit d'une possession prolongée faire acquérir aucun droit de propriété aux occupants de ces parcelles qui, faisant partie du domaine public, sont inaliénables et imprescriptibles ». Cf. CE sect., 13 octobre 1967, Cazeaux, n 58332. 
l'impossibilité d'engager une quelconque action possessoire contre l'Administration propriétaire ou affectataire d'une dépendance domaniale. Selon le Tribunal des conflits, «Du fait de l'imprescriptibilité et de l'inaliénabilité du domaine public, aucune possession utile ne peut être opposée à la libre disposition par l'autorité domaniale d'un élément de ce domaine ${ }^{278}$.

\section{B. Le fondement juridique de la précarité des occupations privatives en droit ivoirien}

La précarité, en droit ivoirien, tire actuellement sa source de l'article 8 de l'ordonnance du 03 août 2016 portant titres d'occupation du domaine public ${ }^{279}$. En vertu de cette disposition, "l'autorisation d'occupation ou d'utilisation du domaine public présente un caractère précaire et révocable».

La précarité de l'occupation privative du domaine public s'applique aussi bien aux permissions de voirie qu'aux concessions de voirie. La permission de voirie est une autorisation d'occupation temporaire (AOT) du domaine public, délivrée sous la forme d'un acte unilatéral par l'Administration propriétaire ou affectataire de la dépendance domaniale. La concession de voirie, quant à elle, est une AOT empruntant la forme d'une convention entre l'Administration propriétaire ou affectataire de la dépendance domaniale, d'une part, et l'occupant privatif, d'autre part. Quelle que soit sa forme, l'AOT peut être retirée (permission de voirie) ou résiliée (concession de voirie) à tout moment pour tout motif d'intérêt général ${ }^{280}$.

En outre, la précarité de la permission de voirie ainsi que de la concession de voirie transparaît de l'article 23 de l'ordonnance précitée. En vertu de cette disposition, les permissions de voirie et les concessions de voirie ne sont pas constitutives de droits réels. Elles sont accordées à titre personnel et ne sont pas transmissibles à des tiers, sauf accord préalable et expresse de la personne morale propriétaire ou affectataire du domaine public.

Il est vrai que le titulaire d'une permission de voirie ou d'une concession de voirie bénéficie des actions possessoires et en responsabilité contre les tiers qui le troublent dans sa jouissance. Toutefois, cela ne lui confère pas un droit à un délai ferme d'occupation du domaine public.

Quoi qu'il en soit, les effets combinés de l'inaliénabilité et de l'imprescriptibilité débouchent, on l'a vu, sur la précarité des occupations privatives du domaine public portuaire. Cette précarité se fonde sur une raison qu'il faudrait expliquer.

\section{Paragraphe 2 : La raison de la précarité de l'occupation privative}

La raison essentielle de la précarité de toute occupation privative du domaine public est celle de protéger la consistance du domaine public et son affectation (A). Eu égard aux pesanteurs inhérentes à cette précarité, il importe de s'interroger sur la possibilité de l'alléger (B).

278 TC 24 février 1992, Couach. $\mathrm{n}^{\circ} 02685$.

279 Ordonnance $\mathrm{n}^{\circ} 2016-588$ du 03 août 2016 portant titres d'occupation du domaine public.

280 En vertu respectivement de l'article 26 (permission de voirie) et de l'article 29 (concession de voirie) de l'ordonnance $\mathrm{n}^{\circ} 2016-588$ du 03 août 2016 portant titres d'occupation du domaine public. 


\section{A. La protection de la consistance du domaine public et son affectation}

Ce souci n'est nullement l'apanage du domaine public en République de Côte d'Ivoire. On le retrouve aussi sous d'autres cieux. Cette volonté de protection excède le cadre du domaine public portuaire pour embrasser le domaine public, en général, des personnes morales de droit public.

Ainsi au Sénégal, l'État sénégalais, dépositaire du patrimoine national, doit préserver l'intégrité dudit patrimoine tant que celle-ci est nécessaire à l'exercice des missions de service public. Cela emporte des effets tant pour l'État qui ne peut, par exemple, pas prendre des engagements hypothécaires sur le domaine public, que pour les tiers contre les empiètements desquels il faut préserver le domaine. Il en découle que le domaine public ne peut pas faire l'objet d'une vente, d'une appropriation à caractère permanent, ou d'une sujétion patrimoniale ou commerciale 281 .

En République Française, les autorisations unilatérales ou conventionnelles d'utilisation du domaine sont nécessairement délivrées à un moment donné pour une certaine durée. La notion de précarité est inhérente à toute occupation privative. Elle est visée à deux niveaux par le Code général de la propriété des personnes publiques (CGPPP).

1. L'occupation ou l'utilisation du domaine public ne peut être que temporaire (article L. 2122-2 du CGPPP) $^{282}$. Le titre juridique par lequel est autorisée l'utilisation privative est tenu d'indiquer la durée pour laquelle ladite utilisation est consentie au bénéficiaire. Cette mention est une condition de légalité de l'autorisation. Cette limite temporelle contient la précarité.

2. L'autorisation administrative permettant une utilisation privative du domaine public présente un caractère précaire et révocable (article L. 2122-3 du CGPPP) ${ }^{283}$. Aucun titre juridique ne saurait constituer un obstacle à la libre disposition des dépendances du domaine public par l'Administration. L'obligation de fixer une durée de validité initiale du titre juridique et de l'occupation privative elle-même ne remet nullement en cause le pouvoir qu'a l'autorité compétente de provoquer une fin anticipée de ladite occupation privative. L'autorité administrative est recevable à se fonder soit sur des motifs d'intérêt général ${ }^{284}$, soit sur la nécessité de protéger le domaine public en raison de l'incompatibilité constatée de l'utilisation avec l'affectation ou du non-respect par l'occupant de ses engagements.

Lorsque la révocation de l'autorisation est fondée sur un motif d'intérêt général, l'occupant privatif se voit reconnaître un droit à indemnité. Aucune indemnité n'est due lorsque la violation par l'occupant privatif de ses engagements est à la base du retrait de l'autorisation.

KANE Ababacar Khalifa, Le droit portuaire en Afrique: Aspects juridiques de la gestion et de l'exploitation portuaires au Sénégal, Paris, L'Harmattan, 2012, p. 86.

282 Selon l'article L. 2122-2 du Code général de la propriété des personnes publiques (CGPPP), «L'occupation ou l'utilisation du domaine public ne peut être que temporaire. Lorsque le titre mentionné à l'article $L$. 2122-1 permet à son titulaire d'occuper ou d'utiliser le domaine public en vue d'une exploitation économique, sa durée est fixée de manière à ne pas restreindre ou limiter la libre concurrence au-delà de ce qui est nécessaire pour assurer l'amortissement des investissements projetés et une rémunération équitable et suffisante des capitaux investis, sans pouvoir excéder les limites prévues, le cas échéant, par la $l o i »$.

283 En vertu de l'article L. 2122-3 du CGPPP, «L'autorisation mentionnée à l'article L. 2122-1 présente un caractère précaire et révocable ».

284 CE 14 octobre 1991, Helié, Rec. p. 680. 
Selon la théorie générale des contrats administratifs, cette révocabilité des titres juridiques est jugée inhérente à toute occupation du domaine public. Pour cette même raison, toute clause contractuelle excluant la possibilité d'exercice du pouvoir reconnu à l'Administration de provoquer une fin anticipée du contrat d'occupation privative est nulle. Cette nullité est tirée de l'incompatibilité avec les principes de la domanialité publique ${ }^{285}$. Une disposition législative spécifique pourrait écarter, par exception, le principe de précarité de l'occupation privative du domaine public. L'article L. 2122-10 du CGPPP confère une certaine stabilité aux occupations domaniales constitutives de délégation de service public, sur le fondement tiré de la continuité du service public ${ }^{286}$.

\section{B. Une possible atténuation de la rigueur inhérente à la précarité ?}

Cette interrogation se justifie par le fait que la précarité, appliquée de manière rigoureuse, s'avère incompatible avec la mise en valeur du domaine public par les opérateurs économiques désireux d'y investir. Cette préoccupation a certainement guidé le législateur ivoirien. Aussi, a-t-il adopté, entre autres, l'ordonnance précitée du 03 août 2016 afin d'adoucir quelque peu les effets rigoureux de la précarité. Par ce texte, il a reconnu certaines garanties aux concessionnaires de voirie (1). En outre, il reconnaît des droits réels à certaines catégories de titulaires d'une autorisation d'occupation temporaire (AOT) du domaine public (2).

\section{La reconnaissance de garanties aux concessionnaires de voirie}

La concession de voirie, tout comme la permission de voirie, est rangée dans la catégorie des AOT classiques. À ce titre, elle ne confère pas des droits réels au concessionnaire de voirie, conformément à l'article 23 de l'ordonnance précitée du 03 août $2016^{287}$. Le concessionnaire de voirie bénéficie plutôt d'un droit d'usage, "temporaire et révocable » par le propriétaire ou le gestionnaire du domaine public.

Ce régime juridique manifeste, en l'état, la précarité de cette occupation privative du domaine public. Il n'est pas à exclure qu'elle inhibe les projets d'investissement de certaines ampleurs auxquels voudraient se livrer un opérateur économique, sur le domaine public. En d'autres termes, qu'est-ce qui inciterait un opérateur économique à investir sur le domaine public lorsqu'il n'a aucune garantie qu'il amortirait, dans un premier temps, son investissement, et en réaliserait, dans un deuxième temps, un bénéfice ?

Afin de minorer quelque peu cette perspective peu engageante, le législateur ivoirien prévoit certaines garanties au profit du concessionnaire de voirie. Celles-ci sont de deux ordres :

CE 4 février 1983, Ville de Charleville-Mézières, Rec. p. 45 ; CE 6 mai 1985, Association Eurolat et Crédit Foncier, Rec. p. 141 ; AJDA 1985, p. 621.

GILLET-LORENZI Emmanuelle et TRAORÉ Seydou, Droit administratif des biens, 1 ère édition, Édition du CNFPT, 2007, pp. 108 et ss.

En vertu de l'article 23 , les permissions de voirie et les concessions de voirie «ne sont pas constitutives de droits réels. Elles sont accordées à titre personnel et ne sont pas transmissibles à des tiers, sauf accord préalable et express de la personne morale de droit public ou de droit privé, propriétaire ou gestionnaire du domaine public ». Les AOT classiques - à savoir les permissions de voirie et les concessions de voirie se distinguent des AOT constitutives de droits réels et du bail emphytéotique qui, eux, sont régis respectivement par le chapitre 3 (articles 33 à 40) et le chapitre 4 (articles 41 à 43) de l'ordonnance du 03 août 2016. 
- Les premières protègent le concessionnaire contre tout empiètement des tiers ;

- Les secondes le protègent contre l'Administration concédante.

Dans la première catégorie de garanties, figurent l'action possessoire et l'action en responsabilité contre les tiers qui troublent la jouissance de ses droits d'usage ${ }^{288}$.

L'action possessoire est celle tendant à protéger un fait juridique, la possession et même la détention paisible d'un immeuble ${ }^{289}$. Il est à remarquer que dans le cas du domaine public, on ne saurait valablement invoquer un droit de propriété au profit de l'occupant privatif vu que le domaine public est inaliénable et imprescriptible. Aussi, l'action possessoire dont il est question, en la matière, renvoie plutôt à la possessio juris ${ }^{290}$, et non pas à la possessio rei ${ }^{291}$.

L'action en responsabilité contre les tiers se vérifierait dans l'hypothèse où une personne tierce viendrait à endommager, à abîmer une construction ou une installation du concessionnaire de voirie. Celui-ci pourrait intenter une action indemnitaire aux fins d'obtenir de l'auteur du dommage la réparation (pécuniaire) du préjudice subi.

En sus des garanties à l'encontre des tiers, le concessionnaire bénéficie de certains droits à l'égard de l'Administration propriétaire ou gestionnaire du domaine public. Ainsi, la résiliation avant terme de la concession de voirie ouvre droit, sous certaines conditions, à une indemnitée ${ }^{292}$. Au regard de la théorie générale des contrats administratifs, le droit à indemnité apparaît comme la contrepartie au pouvoir de résiliation unilatérale reconnue à l'Administration concédante ${ }^{293}$. L'indemnité est ainsi due lorsque les ouvrages et les investissements réalisés sur le domaine public n'ont pas été amortis (damnum emergens). De même, l'indemnisation du contractant évincé (avant l'expiration de la concession) devra aussi comprendre le "gain manqué» (lucrum cessans) lorsqu'il n'aura pas pu engranger les bénéfices escomptés de l'exploitation de l'ouvrage public ou du service public concédé par suite de l'exercice du pouvoir de résiliation unilatérale par l'Administration concédante.

En outre, l'article 31 de l'ordonnance du 03 août 2016 reconnaît au concessionnaire un droit de propriété sur certaines catégories de constructions et installations qu'il implante sur le domaine public pendant toute la durée de l'occupation. Sont exclus du droit de propriété, les outillages publics ou les ouvrages grevés d'une clause de retour obligatoire.

En sus des garanties, certaines catégories d'AOT accordent à leurs titulaires de bénéficier de droits réels sur le domaine public.

En vertu de l'article 24 ordonnance du 03 août 2016.

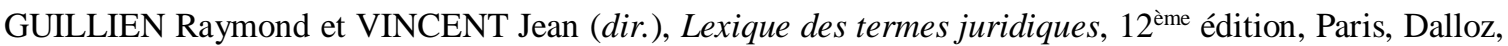
1999, p. 17.

La possessio juris est une expression latine signifiant «possession d'un droit » qui sert aujourd'hui à désigner toute possession correspondant à un droit réel autre que la propriété et conduisant à l'acquisition de celui-ci. $C f$. CORNU Gérard (dir.), Vocabulaire juridique, 9ème édition, Paris, Quadrige/Puf, 2011, p. 770 .

La possessio rei est une expression latine signifiant "possession d'une chose » servant aujourd'hui à désigner la possession qui correspond au droit de propriété et conduit à l'acquisition de celui-ci, par l'accomplissement d'actes de maître dans l'affirmation de cette qualité. $C f$. CORNU Gérard (dir.), Vocabulaire juridique, $9^{\text {ème }}$ édition, Paris, Quadrige/Puf, 2011, p. 771.

En vertu de l'article 30 de l'ordonnance du 03 août 2016.

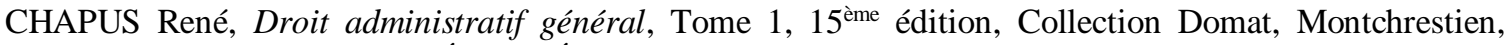
2001, n¹377, p. 1205; DÉGNI-SÉGUI René, Droit administratif général, Tome 2 : L'action administrative, $3^{\text {ème }}$ édition, Abidjan, CEDA, pp. 589-590; LOMBARD Martine et DUMONT Gilles, Droit administratif, $9^{\mathrm{ème}}$ édition, Paris, Dalloz, 2011, n 522 , p. 287 ; MORAND-DEVILLER Jacqueline,

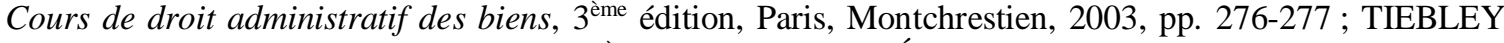

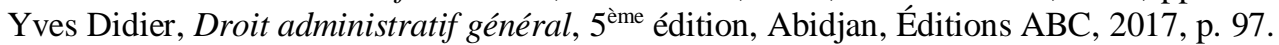




\section{La reconnaissance des droits réels sur le domaine public}

Le législateur ivoirien prévoit la possibilité de constituer de tels droits dans des cas précis : celui des AOT constitutives de droit réels (a) et celui du bail emphytéotique administratif (b).

\section{a) Les autorisations d'occupation temporaire constitutives de droits réels}

Au regard de l'article 34 de l'ordonnance du 03 août 2016, elles empruntent la forme soit d'un acte administratif unilatéral soit celle d'une convention. Ce droit réel confère à son titulaire les prérogatives et obligations du propriétaire, pour la durée de l'autorisation et dans certaines conditions et limites. Ainsi, les droits réels conférés à l'occupant sont assortis de conditions et limites.

Les droits réels conférés à l'occupant. Contrairement aux permissions et aux concessions de voirie qui ne confèrent qu'un droit personnel, le titulaire d'une AOT constitutive de droit réel, conformément à l'appellation de celle-ci, possède un droit réel sur les ouvrages, constructions et installations de caractère immobilier qu'il réalise pour l'exercice de cette activité.

Ainsi, les constructions réalisées sur le domaine public en vertu des AOT constitutives de droit réel peuvent donner lieu à la conclusion de contrat de crédit-bail. Dans ce cas, le contrat comporte des clauses permettant de préserver les exigences du service public ${ }^{294}$.

En outre, le droit réel conféré par le titre sur les ouvrages, constructions et installations de caractère immobilier peuvent être cédés, ou transmis dans le cadre des mutations entre vifs ou de fusion, absorption ou scission de sociétés, pour la durée du titre restant à courir. Lors du décès d'une personne physique titulaire d'un titre d'occupation constitutif de droit réel, celuici peut être transmis au conjoint survivant ou aux héritiers sous réserve que le bénéficiaire, désigné par accord entre eux, soit présenté à l'agrément de l'autorité compétente dans un délai de six mois à compter du décès ${ }^{295}$.

Enfin, l'occupant peut hypothéquer ses droits réels sur le titre, les ouvrages, les constructions et les installations pour garantir les emprunts qu'il a contractés pour financer la réalisation, l'extension ou la modification des ouvrages, constructions et installations situées sur le domaine public ${ }^{296}$.

Cependant, l'exercice des droits réels ci-dessus doit obéir à certaines conditions définies par le législateur.

Les limites et conditions assorties à l'exercice des droits réels. L'occupant désireux de conclure un contrat de crédit-bail relatif aux ouvrages, constructions et installations sur le domaine public est tenu de respecter les lois du service public ${ }^{297}$. Il est vrai que l'occupant n'est pas un service public au sens organique du terme. Il n'empêche que le fait qu'il occupe une dépendance domaniale le soumet d'office au respect des lois du service public, en vertu de la théorie du service public virtuel ${ }^{298}$.

\footnotetext{
Article 35 de l'ordonnance du 03 août 2016.

Article 36 de l'ordonnance du 03 août 2016.

Article $37 \S 1$ ordonnance du 03 août 2016.
}

297 Les lois du service public sont au nombre de quatre. Ce sont le principe de mutabilité du service public, le principe de continuité du service public, le principe d'égalité devant le service public, le principe de neutralité du service public. Ce dernier principe apparaît comme le corollaire du principe d'égalité devant le service public.

298 Le service public virtuel est une activité qui présentant, un caractère suffisant d'intérêt général, sans cependant avoir été érigée en service public, est considérée, dans une certaine conception comme constituant virtuellement un service public, ce qui permettrait à l'Administration d'assujettir son exercice à des obligations de droit public. $C f$. CORNU Gérard (dir.), Vocabulaire juridique, op. cit., p. 951. La théorie 
Par ailleurs, la transmission des droits réels entre vifs ou par legs est conditionnée par l'agrément de l'autorité compétente au sein de l'organisme propriétaire ou gestionnaire du domaine public. En outre, l'utilisation des droits réels résultant de la transmission entre vifs ou par legs doit être compatible avec l'affectation du domaine public occupée ${ }^{299}$.

Relativement aux emprunts contractés au moyen des hypothèques, ils ne peuvent servir qu'au financement des ouvrages, constructions et installations situées sur le domaine public, pas ailleurs ${ }^{300}$.

Quoi qu'il en soit, l'ampleur de la dérogation que revêt la constitution de droit réels sur le domaine public a conduit le législateur ivoirien à enfermer la durée de ce type d'AOT dans un délai n'excédant pas cinquante ans ${ }^{301}$.

En sus des AOT constitutives de droit réel, le législateur ivoirien a prévu le bail emphytéotique administratif.

\section{b) Le bail emphytéotique administratif}

Le bail emphytéotique (tout court) est une institution que l'on rencontre en droit privé, particulièrement en droit civil. Le Vocabulaire juridique définit le bail emphytéotique comme un bail par lequel un propriétaire concède un immeuble pour une durée de 18 à 99 ans, moyennant une redevance annuelle modique appelée canon emphytéotique et sous l'obligation de planter ou d'améliorer l'immeuble loué, à un preneur nommé emphytéote qui acquiert le droit réel d'emphytéose ${ }^{302}$. De manière concise, Le lexique des termes juridiques définit le bail emphytéotique comme un bail (location) de longue durée, pouvant atteindre 99 ans, portant sur un immeuble et conférant au preneur un droit réel ${ }^{303}$.

Il apparaît donc que le bail emphytéotique est un contrat synallagmatique qui met en rapport deux parties, à savoir le propriétaire de l'immeuble en location et le preneur de l'immeuble loué (encore appelé l'emphytéote). L'une des caractéristiques du bail emphytéotique est qu'il confère au preneur un droit réel, à savoir le droit réel d'emphytéose. Ainsi, l'emphytéote est juridiquement habilité à sous-louer l'immeuble qu'il loue. Il peut également vendre, échanger ou hypothéquer son droit réel d'emphytéose ${ }^{304}$.

Le bail emphytéose est désormais une institution juridique non confinée au droit civil. On le rencontre désormais en droit administratif où il est appelé bail emphytéotique administratif. La particularité de ce type de contrat est qu'il porte sur le domaine public, pourtant réputé inaliénable, et qui, de ce fait, ne peut servir de support de droits réels au profit des tiers.

À l'origine, le bail emphytéotique administratif, en droit ivoirien, a été prévu par un arrêté du Gouverneur général de l'Afrique occidentale française (A.O.F.). Il s'agit précisément de l'Arrêté GG n²895 A.E. du 24 novembre 1928, réglementant les conditions d'application du décret du 29 septembre 1928 sur le Domaine et les servitudes d'utilité publique. En vertu de l'article 14 dudit arrêté, "Les occupations temporaires du Domaine public peuvent correspondre soit à un besoin individuel, soit à un intérêt économique d'ordre collectif ou

\footnotetext{
du service public virtuel a été élaboré à travers deux arrêts majeurs, à savoir : CE Sect. 5 mai 1944, Compagnie maritime de l'Afrique orientale, Rec. p. 129 ; CE Sect. 29 janvier 1932, Société des autobus antibois, Rec. p. 117.

299 Article $36 \S 1$ de l'ordonnance du 03 août 2016.

$300 \quad$ Article $37 \S 1$ ordonnance du 03 août 2016.

301 Article 35 ordonnance du 03 août 2016.

302 CORNU Gérard (dir.), Vocabulaire juridique, op. cit., p. 118.

303 GUILLIEN Raymond et VINCENT Jean (dir.), Lexique des termes juridiques, op. cit., p. 221.

304 En vertu de l'article premier de la loi du 25 juin 1905 sur le bail emphytéotique qui dispose en son alinéa 1 : «Le bail emphytéotique de biens immeubles confère au preneur un droit réel susceptible d'hypothèque; ce droit peut être cédé et saisi dans les formes prescrites par la saisie immobilière ».
} 
général [...] Dans le deuxième cas (cales de halage publiques, bassins de radoub, appontements en vue d'un service public, magasins généraux, entrepôts de consignataires, transitaires, commissionnaires ou armateurs, permis d'occuper délivrés à une commune ou à un établissement public, etc.), la forme du bail renouvelable peut être adopté sous réserve d'une résiliation toujours possible de la part de l'Administration après préavis de six mois au plus...».

À l'heure actuelle, le bail emphytéotique administratif est régi par l'ordonnance du 03 août $2016^{305}$.

À certains égards, le bail emphytéotique administratif se rapproche du bail emphytéotique du droit civil. Tous deux ont une durée s'étalant de dix-huit (18) à quatre-vingt-dix-neuf (99) ans. En outre, le preneur a, durant toute la durée du bail emphytéotique administratif, des obligations similaires à celles de l'emphytéote de droit civil. Ce sont, entre autres, l'amélioration, la construction, l'entretien ..., le versement d'un loyer et le paiement des charges. Le bail emphytéotique administratif, tout comme celui du droit civil, confère des droits réels à l'emphytéote.

Cependant, l'exercice du droit réel, dans le cas du bail emphytéotique administratif n'est pas libre ${ }^{306}$; il est plutôt conditionné. Ainsi, le preneur ne peut céder ses droits réels qu'avec l'agrément du propriétaire ou du gestionnaire du domaine public ${ }^{307}$. En plus, les droits réels sont susceptibles d'hypothèque uniquement pour la garantie des emprunts contractés en vue de la réalisation ou de l'amélioration des ouvrages situés sur l'immeuble loué ${ }^{308}$. Le contrat constituant l'hypothèque doit par ailleurs être approuvé par le propriétaire ou le gestionnaire du domaine public, sous peine de nullité ${ }^{309}$.

À l'expiration du bail emphytéotique administratif, les réalisations de caractère immobilier existant sur la dépendance reviennent de plein droit et gratuitement au propriétaire du domaine public ${ }^{310}$.

L'occupation du domaine public au moyen du bail emphytéotique administratif, tout comme les autres modalités d'occupation privative du domaine public, est précaire. Cela emporte des incidences.

\section{SECTION 2 : Les incidences du principe de précarité}

La précarité comporte des incidences sur la situation de l'occupant. Celui-ci ne jouit pas du droit au maintien sur le domaine public. En d'autres termes, il ne peut se prévaloir, à l'égard du propriétaire ou du gestionnaire du domaine public, de la législation sur les baux commerciaux (paragraphe 1). On pourrait s'interroger sur la possibilité de constituer un fonds de commerce sur le domaine public (paragraphe 2).

Ordonnance $\mathrm{n}^{\circ} 2016-588$ du 03 août 2016 portant titres d'occupation du domaine public.

Au regard de l'article 2 de l'ordonnance du 03 août 2016, «les droits réels conférés par le bail emphytéotique ne sont pas librement cessibles et hypothécables ».

307 Article $42 \S 1$ de l'ordonnance du 03 août 2016.

308 Article $42 \S 1$ de l'ordonnance du 03 août 2016.

309 Article $42 \S 2$ de l'ordonnance du 03 août 2016.

310 Article $43 \S 1$ de l'ordonnance du 03 août 2016.
} 


\section{Paragraphe 1 : L'absence de droit au maintien de l'occupant dans les lieux}

L'inapplicabilité du droit au maintien, on le devine, est le corollaire du caractère temporaire et révocable des occupations privatives du domaine public. Cela ressort particulièrement d'un arrêt rendu par la chambre administrative de la Cour suprême ivoirienne l'affaire Port Autonome d'Abidjan c/ Entreprises Graviers et Sables. La présentation succincte des faits et de la procédure suivie dans l'arrêt (A) précèdera nos observations (B).

\section{A. Faits et procédure suivie dans l'affaire Port Autonome d'Abidjan c/ Entreprises Graviers et Sables $(E G S)^{311}$}

Comme l'indique son intitulé, cette affaire a opposé le PAA à l'Entreprise Graviers et Sables (EGS). En application d'une convention conclue le 03 août 1977, l'EGS était juridiquement habilitée à occuper le lot ${ }^{\circ} 349$ ter de la zone des industries navale de Vridi, pour une durée de 30 ans à compter du $1^{\mathrm{er}}$ juillet 1977. Durant toute cette période, l'EGS était autorisée à élever, sur le domaine concédé, des constructions composées d'un hangar, d'un bureau, d'une pompe station-service et d'un magasin de stockage devant servir exclusivement à abriter des véhicules et aux stockages de pièces détachées.

Dans le courant de l'année 2002, le PAA fait constater par huissier de justice que l'EGS avait sous-loué les locaux de la dépendance domaniale concédée à la société SOCOP-CI, en violation de l'article 2 de la convention du 03 août 1977. En effet, cette disposition interdisait la sous-location de tout ou partie du lot. Aussi, le PAA, en application de l'article 13 de la convention précitée, a prononcé la résiliation avant terme de ladite convention, dans l'intérêt du public et, dans la foulée, invitée l'EGS à libérer les lieux.

Saisi par l'EGS, le juge des référés a, par ordonnance du n 5340 du 21 novembre 2002, rejeté l'exception d'incompétence soulevée par le PAA et ordonné la réintégration de l'EGS dans les locaux. Saisie par appel interjeté par le PAA, la Cour d'appel d'Abidjan a confirmé le jugement querellé en excipant la personnalité morale de droit qui est celle du PAA.

\section{B. Observations}

En faisant abstraction de la nature juridique du contrat liant le PAA à l'EGS, on s'appesantira sur l'injonction faite au PAA de réintégrer l'EGS dans les locaux desquels elle venait d'être évincée. Cette mesure induit à penser à un droit de maintien dans les lieux, au profit de l'EGS. Ce faisant, elle relève du contentieux de l'expulsion de locataire tel qu'il se rencontre en droit OHADA. En effet, la décision du juge des référés intervenue dans l'affaire précitée s'inscrit dans la jurisprudence constante de la Cour d'appel d'Abidjan. En effet, la Cour d'appel d'Abidjan invalide les décisions d'expulsion (de fait) lorsque celles-ci ne reposent pas sur une décision judiciaire pertinente. Ainsi dans une espèce, la Cour d'appel d'Abidjan a décidé qu'un locataire doit être maintenu dans le local à usage commercial, dès lors qu'il a été expulsé de fait, aucune décision de justice ne l'ayant expulsé dudit local ${ }^{312}$. Visiblement, la décision du juge des référés et celle de la Cour d'appel d'Abidjan invalidant

311 CSCA 23 mars 2005, Arrêt n ${ }^{\circ}$ 14, Port Autonome d'Abidjan c/ Entreprises Graviers et Sables (EGS), req. n 2003-453 CASS/AD.

312 Cour d'Appel d'Abidjan, Arrêt n³61 du 27 mars 2001, N. c/ A., in Le JurisOHADA, n'1/2003, janviermars 2003, p. 54. Ohadata J-03-118; Cf. également ISSA-SAYEGH Joseph, Répertoire OHADA 20002005 : Jurisprudence et bibliographie, UNIDA, p. 62. Accessible en ligne sur: http://www.tribunalcommerceniamey.org/images/REPERTOIRE_OHADA_2000-2005.pdf. Document consulté le 19 mai 2017. 
l'expulsion de l'EGS du domaine public portuaire se fondent sur le fait qu'elle ne repose pas sur une décision judiciaire. La Cour d'appel ne semble donc pas admettre l'expulsion du locataire décidé unilatéralement par le bailleur. Cette orientation du juge commercial résulte de l'interprétation de l'article 83 de l'Acte uniforme portant sur le droit commercial général (AUDCG) ${ }^{313}$ dans sa version de 1997, actuellement remplacée par celle de 2010.

Au regard de l'affaire $P A A c / E G S$, la décision du juge des référés et celle d'appel tendent à assimiler le régime juridique du bail emphytéotique (de droit civil) à celui du bail emphytéotique administratif. Cette option appelle des réserves vu que le bail emphytéotique administratif est caractérisé, entre autres, par les caractères précaire et révocable. En droit ivoirien, ces caractères trouvaient, initialement, leur fondement dans le décret du 29 septembre $1928^{314}$ et l'arrêté du 24 novembre $1928^{315}$ respectivement en leur article 6 et 14 . À l'heure actuelle, la précarité et la révocabilité du bail emphytéotique administratif découlent de l'article 8 de l'ordonnance du 03 août 2016 laquelle disposition pose le principe selon lequel toute occupation privative du domaine public est précaire et révocable.

Quoi qu'il en soit, le législateur ivoirien entend désormais confier à la Chambre administrative de la Cour suprême la quasi-exclusivité du contentieux lié au domaine public. Ainsi, par dérogation à l'article 54 du Code de procédure civile, commerciale et administrative (C.P.C.C.A.), l'article 55 de l'ordonnance du 03 août 2016 investit la Chambre administrative de la compétence pour connaître du contentieux lié à l'occupation du domaine public quand bien même une personne morale de droit public ne serait pas partie au procès ${ }^{316}$. Toutefois, la compétence de la Chambre administrative n'exclut pas le recours administratif préalable que devrait, au préalable, intenter le titulaire d'une permission de voirie ou de tout acte administratif unilatéral constitutif de droit réel sur le domaine public. En outre, le bailleur et l'occupant du domaine public peuvent librement recourir à l'arbitrage dans les conditions prévues par l'Acte uniforme de l'OHADA sur l'arbitrage ${ }^{317}$.

Eu égard à la précarité qui frappe l'occupation du domaine public, on peut s'interroger sur la possibilité du locataire à maintenir son fonds de commerce à l'expiration du bail.

313 Selon l'article 83 de l'AUDCG, «À l'expiration du bail, le preneur qui, pour une cause autre que celle prévue à l'Article 94 ci-après, se maintient dans les lieux contre la volonté du bailleur doit verser une indemnité d'occupation égale au montant du loyer fixé pendant la durée du bail, sans préjudice d'éventuels dommages et intérêts ».

314 Décret du 29 septembre 1928 portant réglementation du Domaine public et des servitudes d'utilité publique en Côte d'Ivoire modifié par D. du 7 septembre 1935 et D. n॰52-679 du 3 juin 1952. En vertu de l'article 6 dudit décret, «Le ministre chargé des Domaines accorde, par arrêté, les autorisations d'occuper le Domaine public et les dérogations aux servitudes de passage, sous la réserve que ces autorisations et dérogations sont à tous moments révocables, sans indemnité, pour un motif d'intérêt général ... ».

315 Arrêté GG n²895 A.E. du 24 novembre 1928, réglementant les conditions d'application du décret du 29 septembre 1928 sur le Domaine et les servitudes d'utilité publique. En vertu de l'article 14 de l'arrêté cidessus, «... la forme du bail renouvelable peut être adopté sous réserve d'une résiliation toujours possible de la part de l'Administration après préavis de six mois au plus... ».

316 Sur ce point, on note une dérogation à l'article 54 du CPCCA qui prévoit que la Chambre administrative connaît des pourvois en cassation dirigés contre les décisions rendues en dernier ressort dans les procédures où une personne morale de droit public est partie. L'extension des attributions de la Chambre administrative de la Cour suprême découle de l'article 55 de l'ordonnance du 03 août 2016. En vertu de cette disposition, la Chambre administrative est compétente pour connaître de la totalité du contentieux lié à l'occupation du domaine public, en dépit du fait que les parties au procès soient toutes deux de droit privé.

317 Article 56 de l'ordonnance du 3 août 2016. 


\section{Paragraphe 2: Possibilité de constituer un fonds de commerce sur le domaine public?}

La réponse à cette interrogation, à la lueur des documents en notre disposition, ne semble pas avoir été abordée par le juge ivoirien. Aussi, aura-t-on recours au droit comparé, précisément au droit français. Il apparaît que la réponse donnée à cette question émane du juge français (A) et sera, par la suite, consacrée par le législateur, au moyen de la "loi Pinel » (B).

\section{A. La position fluctuante du juge français}

Relativement à la possibilité pour l'occupant de constituer un fonds de commerce sur le domaine public, on note une divergence d'appréciation entre la Cour de cassation et le Conseil d'État. La première, par une interprétation hardie, admet la possibilité de constituer un fonds de commerce sur le domaine public (1). Le Conseil d'État, en revanche, se montre intransigeant et refuse une telle possibilité (2).

\section{La hardiesse de la Cour de cassation}

La Cour de cassation admet l'existence de fonds de commerce sur le domaine public. Selon la haute juridiction, le fonds de commerce ne constitue pas un droit de nature immobilière, mais une "universalité mobilière ${ }^{318}$. Aussi, la cession du fonds de commerce n'implique pas celle d'un droit au bail ${ }^{319}$.

Pour saisir la justesse de la décision de la Cour de cassation, il est nécessaire de cerner la notion de fonds de commerce. Celui-ci est défini comme l'ensemble des éléments corporels (matériel, outillage, marchandises) et incorporels (droit au bail, nom, enseigne, brevets et marques, clientèle et achalandage) qui, appartenant à un commerçant ou à un industriel et réunis pour lui permettre d'exercer son activité, constitue une universalité juridique et un meuble incorporel soumis à des règles particulières (notamment en cas de vente ou de nantissement) $)^{320}$.

De cette définition, il apparaît que le fonds de commerce constitue une universalité, c'està-dire un tout soumis à un régime juridique distinct du régime applicable aux éléments qui le composent. Ainsi, le fonds de commerce en tant qu'entité peut faire l'objet de conventions différentes de celles qui porteraient sur chacun des éléments le composant ${ }^{321}$. En outre, on peut relever que la composition du fonds peut varier ; par exemple, il peut ne plus avoir de

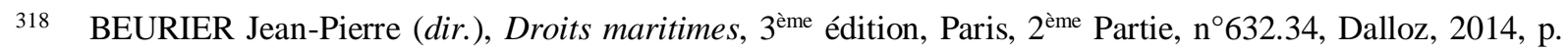
1263.

319 Com. 17 décembre 1996, n²113, Époux Cavret c/ Denis, Gazette du Palais, 1997, $2^{\mathrm{ème}}$ partie, p. 199 ; Com. 17 décembre 1996, Époux Cavret c/ Denis, Revue Trimestrielle de Droit commerciale, 1997, p. 25, observations J. Derrupé.

320 CORNU Gérard (dir.), Vocabulaire juridique, op. cit., p. 465.

321 BEIRA Ehi Marc, Droit commercial général. Droit des sociétés commerciales, 12 ème édition, Abidjan, Éditions ABC, 2014, p. 147. Sur les difficultés pour appréhender de manière unanime la notion d'universalité, le lecteur pourra se référer, entre autres, à un article de doctrine de Fermanel de Winter Anne-Sophie. $C f$. FERMANEL de WINTER Anne-Sophie, «Universalité de fait et universalité de droit (Première partie) », Revue juridique de l'Ouest, 2008, n 4, pp. 409-455 et FERMANEL de WINTER Anne-Sophie, «Universalité de fait et universalité de droit (Deuxième partie) », Revue juridique de l'Ouest, 2009, ${ }^{\circ} 1$, pp. 5-34. 
droit au bail en cours d'exploitation par suite de l'acquisition de l'immeuble servant à l'exploitation du commerçant; et pourtant le fonds va demeurer en tant qu'entité ${ }^{322}$.

Le caractère distinct des règles juridiques s'appliquant respectivement au fonds de commerce et aux éléments qui le composent explique, à notre avis, que la Cour de cassation ait admis la possibilité pour l'occupant privatif de bénéficier d'un fonds de commerce lequel existe, on le rappelle, indépendamment au droit de bail.

Il s'agit, en la matière, d'une jurisprudence constante du juge judiciaire français selon laquelle la titularité d'un droit au bail n'est pas une condition nécessaire à l'existence d'un fonds de commerce ${ }^{323}$. Ainsi, le titulaire d'un bail emphytéotique occupe les lieux en application d'un droit réel de jouissance lui interdisant, en dépit de son exploitation d'un fonds de commerce, de revendiquer un droit au bail commercial ${ }^{324}$.

La situation de l'exploitant sur le domaine public sera donc similaire à celle du titulaire d'un bail superficiaire. À vrai dire, on assiste, en la matière, à une transposition du droit de superficie consacré par le droit privé. Le droit de superficie est défini comme "le droit réel appartenant à une autre personne que le propriétaire du sol sur ce qui se trouve dessus ou dessous $»^{325}$.

Cette conception diffère de celle du Conseil d'État français.

\section{L'intransigeance du Conseil d'État}

Cette intransigeance se manifeste par certains arrêts (a) et s'explique au regard du régime juridique du domaine public (b).

\section{a) Arrêts manifestant le refus de l'existence d'un fonds de commerce sur le domaine public}

Contrairement à la Cour de cassation, le Conseil d'État a, de manière constante, refusé l'existence de fonds de commerce sur le domaine public. Il suffit, pour s'en convaincre, de se référer aux arrêts les plus récents rendus par ladite juridiction relativement à cette question.

Dans l'affaire Société Jonathan Loisirs c. Communauté des communes du Haut Buëch, le Conseil d'État a considéré : «Eu égard au caractère révocable, pour motif d'intérêt général, d'une convention portant autorisation d'occupation du domaine public, ainsi que le caractère personnel et non cessible de cette occupation, celle-ci ne peut donner lieu à la constitution d'un fonds de commerce dont l'occupant serait propriétaire $»^{326}$.

Cette position du juge administratif se retrouve également dans une autre espèce plus récente : celle de l'affaire Société les remontées mécaniques Les Houches-Saint-Gervais c. Société Champenoise. Dans les motifs de son arrêt, le Conseil d'État considère « ...qu'eu égard au caractère révocable et personnel, déjà rappelé, d'une autorisation d'occupation du domaine public, celle-ci ne peut donner lieu à la constitution d'un fonds de commerce dont l'occupant serait propriétaire ${ }^{327}$.

BEIRA Ehi Marc, op. cit., p. 147.

Cass. Com. 27 avril 1993, n ${ }^{\circ} 1-19.819$, RJDA 11/93, n896 ; Cass. Com. 4 avril 2014, n $12-25.528$.

CA Aix-en-Provence 20 octobre 1987, $4^{\mathrm{ème}}$ chambre.

La Cour de cassation, dans un arrêt de principe rendu dans l'affaire Cart, consacre le droit de superficie comme « un droit de propriété distinct et séparé du fonds». Cf. Cass. Civ. 16 décembre 1873, Cart, DP 1874, I, 249 ; S. 1874, I, 457, note J.E. Labbé.

CE 31 juillet 2009, Société Jonathan Loisirs c. Communauté des communes du Haut Buëch, n³16534.

CE 24 novembre 2014, Société les remontées mécaniques Les Houches-Saint-Gervais c. Société Champenoise, $\mathrm{n}^{\circ} 352402$. 
L'intransigeance du Conseil d'État se manifeste par le maintien de son refus d'admettre l'existence d'un fonds de commerce sur le domaine public, en dépit des dispositions de la «loi Pinel ${ }^{328}$. En effet, le juge administratif circonscrit les effets de la loi Pinel aux autorisations d'occupation temporaire délivrées depuis l'entrée de ladite loi. Il en résulte que les AOT délivrées avant l'entrée en vigueur de ladite loi continuent d'être régies par l'impossibilité de constituer un fonds de commerce sur le domaine public au profit de l'occupant privatif ${ }^{329}$.

Cette précision du juge administratif est une application du principe de la non-rétroactivité de la loi. Ce principe s'inspire de l'article 2 du Code civil en vertu duquel : "La loi ne dispose que pour l'avenir; elle n'a pas d'effet rétroactif ». Il n'empêche que la loi nouvelle a un effet immédiat. Cela signifie que la loi nouvelle "s'applique immédiatement aux effets à venir des situations juridiques non contractuelles en cours au moment où elle entre en vigueur ${ }^{330}$.

Cependant, il va autrement en matière contractuelle. En effet, le régime juridique applicable à un contrat s'apprécie par rapport à la législation en vigueur lors de la conclusion dudit contrat. Sur cette question, le professeur De Juglart écrit : "Au contraire, si nous prenons un contrat, par exemple un contrat de vente, nous dirons que cet acte juridique est gouverné pour toutes ses conséquences, par la loi qui a présidé à sa création » ${ }^{331}$.

\section{b) Explication de la position du juge administratif}

L'antinomie entre fonds de commerce et domaine public pourrait se justifier au regard de certaines considérations.

Le domaine public est inaliénable. Pour ce motif, les autorisations d'occupation privative sont délivrées à titre précaire. Elles sont donc révocables à tout moment, incessibles et personnelles. Au contraire, le fonds de commerce est cessible et appartient à l'occupant. Dès lors, l'exploitation d'un fonds de commerce sur le domaine public en contravention de cette interdiction pouvait alors avoir plusieurs conséquences.

Tout d'abord, la convention d'occupation pouvait être résiliée pour un motif d'intérêt général sans aucune indemnisation de l'occupant pour la perte de son fonds de commerce. Il pouvait seulement prétendre à l'indemnisation de la perte de bénéfices ${ }^{332}$.

Ensuite, en cas de cession de son fonds de commerce, l'autorisation d'occupation du domaine public ne pouvait pas être transférée sans l'autorisation préalable de la collectivité propriétaire qui pouvait toujours refuser. Dans ce cas, il était nécessaire de demander une nouvelle autorisation sans aucune assurance de l'obtenir, l'Administration détenant une liberté de choix. Par conséquent, l'exploitation d'un fonds de commerce sur le domaine public n'était

Loi $\mathrm{n}^{\circ}$ 2014-626 du 18 juin 2014 relative à l'artisanat, au commerce et aux très petites entreprises.

«Que si la loi du 18 juin 2014 relative à l'artisanat, au commerce et aux très petites entreprises a introduit dans le Code général de la propriété des personnes publiques un article L. 2124-32-1, aux termes duquel "Un fonds de commerce peut être exploité sur le domaine public sous réserve de l'existence d'une clientèle propre", ces dispositions ne sont, dès lors que la loi n'en a pas disposé autrement, applicables qu'aux fonds de commerce dont les exploitants occupent le domaine public en vertu de titres délivré à compter de son entrée en vigueur; que par suite, l'exploitant qui occupe le domaine public ou doit être regardé comme l'occupant en vertu d'un titre délivré avant cette date, qui n'a jamais été légalement propriétaire d'un fonds de commerce, ne peut prétendre à l'indemnisation de la perte d'un tel fonds ». Cf. CE 24 novembre 2014, Société les remontées mécaniques Les Houches-Saint-Gervais c. Société Champenoise, $\mathrm{n}^{\circ} 352402$.

Cet exemple est tiré de l'article 12 de la loi (française) du 3 janvier 1972 sur la filiation.

De JUGLART Michel, Cours de droit civil (Avec plans de devoirs et études de questions pratiques), $10^{\text {ème }}$ édition, Tome 1 : Introduction, Personnes-Famille, Montchrestien, 1980, $\mathrm{n}^{\text {os }} 44-45$, pp. 51-52.

FAYAT Muriel, «La création d'un fonds de commerce sur le domaine public est désormais possible », Paroles d'experts, mai 2016, p. 8. 
pas reconnue avant l'entrée en vigueur de la loi Pinel, ce qui limitait les moyens des collectivités publiques pour valoriser leur domaine public ${ }^{333}$.

\section{B. La « loi Pinel »ou la consécration de l'existence du fonds de commerce sur le domaine public ${ }^{334}$}

La loi Pinel $^{335}$, on l'a dit, introduit une innovation majeure qui met un terme à la jurisprudence du Conseil d'État relative au fonds de commerce sur le domaine public ${ }^{336}$. La loi précitée introduit certaines innovations relatives au fonds de commerce sur le domaine public (1). Ces innovations laissent cependant certaines questions en suspens (2).

\section{Les innovations de la loi Pinel}

La loi Pinel, à travers son article 72, introduit des innovations relatives à l'existence d'un fonds de commerce sur le domaine public. Cette disposition se décline respectivement à travers les articles L. 2124-32-1, L. 2124-33, L. 2124-34, L. 2124-35 du Code général de la propriété des personnes publiques (CGPPP).

En vertu de l'article L. 2124-32-1 du CGPPP, «un fonds de commerce peut être exploité sur le domaine public sous réserve de l'existence d'une clientèle propre».

La fin de la disposition ci-dessus se caractérise par l'exigence d'une clientèle propre au fonds de commerce. On pressent, sur ce point, une difficulté qui ne manquera pas de se poser. En effet, comment saisir la clientèle propre à l'occupant du domaine public, une clientèle qui se distingue des autres usagers qui viendraient à utiliser le domaine public ?

Le Conseil d'État ne s'étant pas encore prononcé sur cette question, il est possible de se référer à la jurisprudence de la Cour de cassation pour entrevoir l'ampleur de la tâche qui attend le juge administratif dans la détermination d'une clientèle propre à l'occupant du domaine public jouissant d'un fonds de commerce sur ledit domaine.

Ainsi, dans une espèce, la Cour de cassation a exigé, pour caractériser un fonds de commerce, que l'occupant dispose d'une clientèle propre, autonome et indépendante. Aussi, a-t-elle jugé que l'exploitant des cafés-buvettes et comptoirs sur un champ de courses (privé) ne disposait pas d'une clientèle personnelle distincte de celle de la société des courses, dès lors que l'activité "était limitée [...] à l'enceinte du champ de courses et réduites aux seules journées de réunions hippiques» et que «le public était venu sur l'hippodrome et avait fréquenté les buffets buvettes s'était rendu avant tout sur les lieux pour assister aux courses de chevaux ${ }^{337}$.

Dans une autre espèce, la Cour de cassation a considéré que le commerçant situé dans un supermarché, et qui «ne bénéficiait d'aucune autonomie de gestion, son stand étant dans l'enceinte de l'établissement et les heures d'ouverture ainsi que de fermeture déterminés

333 Ibidem.

334 Il est à préciser que l'innovation introduite par la loi Pinel ne concerne que le domaine public artificiel et ne portent donc pas sur le domaine public naturel. En sont donc exclues, les concessions de plages, montagnes et domaines fluviaux.

335 Loi n²014-626 du 18 juin 2014 relative à l'artisanat, au commerce et aux très petites entreprises.

336 HANSEN Philippe S., «L'exploitation d'un fonds de commerce sur le domaine public », JCP/La Semaine juridique-Éditions Administrations et collectivités territoriales, $\mathrm{n}^{\circ} 36,8$ septembre 2014, p. 1.

337 Cass. Ass. Plén., 24 avril 1970, Bayait cl Sté courses rouennaises, JurisData n¹970-095993; Bull. civ. 1970, n³ ; Dalloz 1970, jurispr. p. 381. 
discrétionnairement par la société [gestionnaire du supermarché] »n'avait d'autre clientèle que celle de cette sociétéé ${ }^{338}$.

Les exigences du juge judiciaire telles qu'elles ressortent de ces deux espèces ci-dessus pourraient se retrouver dans des affaires similaires mais intéressant, cette fois-ci, le domaine public. En effet, les clients des fonds de commerce tels que ceux des restaurants dans les aéroports, par exemple, sont avant tout des usagers du domaine public qui ne viennent pas en raison de la réputation du restaurant. Dès lors, la preuve d'une clientèle propre et d'une autonomie de gestion de l'occupant semble difficile à apporter ${ }^{339}$.

Comme on le voit, l'exigence d'une clientèle propre à l'occupant du domaine public tempère fortement les avantages espérés de la constitution d'un fonds de commerce sur le domaine public. Ce bémol est accentué par l'impossibilité de constituer un fonds de commerce sur le domaine public nature ${ }^{340}$.

\section{Les limites}

Les articles L. 2124-3 et L. 2124-34 du CGPPP (reproduisant partiellement le contenu de l'article 72 de la loi Pinel) organisent la transmission du fonds de commerce constitué sur le domaine public. Cependant, la transmission du fonds de commerce constitué sur le domaine public se distingue de celle en vigueur en droit privé. Elle résulte soit d'une cession (article L. 2124-3) 341 $^{34 i t}$ d'une succession (article L. 2124-34) ${ }^{342}$.

\section{a) La cession du fonds de commerce}

Relativement à la cession du fonds de commerce, on rappellera que le droit au bail (et, plus précisément, le droit au renouvellement du bail) fait partie du fonds de commerce et se trouve ainsi cédé avec le fonds. Il importait donc que la consécration de la possibilité de constituer un fonds de commerce sur le domaine public s'accompagne de dispositions propres

Cass. $3^{\text {ème }}$ civ., 9 juillet 1979, $\mathrm{n}^{\circ}$ 77-13.452, SARL Services minute c/ SA Carrefour, Bull. civ. 1979, III, $\mathrm{n}^{\circ} 153$; Dalloz 1980, p. 64.

339 FAYAT Muriel, «La création d'un fonds de commerce sur le domaine public est désormais possible », Paroles d'experts, mai 2016, p. 9.

340 En vertu de L. 2124-35 du Code général de la propriété des personnes publiques (CGPPP). Cette disposition reproduit, en partie, le contenu de l'article 72 de la loi n²014-626 du 18 juin 2014 (couramment désignée sous l'appellation de loi Pinel de 2014).

341 «Toute personne souhaitant se porter acquéreur d'un fonds de commerce ou d'un fonds agricole peut, par anticipation, demander à l'autorité compétente une autorisation d'occupation temporaire du domaine public pour l'exploitation de ce fonds. L'autorisation prend effet à compter de la réception par l'autorité compétente de la preuve de la réalisation de la cession du fonds» (article L. 2124-33 CGPPP). Cette disposition reproduit, en partie, le contenu de l'article 72 de la loi n²014-626 du 18 juin 2014 (loi Pinel de 2014).

342 «En cas de décès d'une personne physique exploitant un fonds de commerce ou un fonds agricole en vertu d'une autorisation d'occupation temporaire du domaine public, l'autorité compétente délivre à la demande de ses ayants droit, sauf si un motif d'intérêt général s'y oppose, une autorisation d'occupation temporaire du domaine public identique à celle accordée à l'ancien titulaire pour la seule poursuite de l'exploitation du fonds, durant trois mois. Si les ayants droit ne poursuivent pas l'exploitation du fonds, ils peuvent, dans le délai de six mois à compter du décès, présenter à l'autorité compétente une personne comme successeur. En cas d'acceptation de l'autorité compétente, cette personne est subrogée dans les droits et obligations de l'ancien titulaire. La décision est notifiée aux ayants droit ayant sollicité l'autorisation ou ayant présenté un successeur ainsi que, le cas échéant, au successeur présenté. Toute décision de refus est motivée » (article L. 2124-34 CGPPP). Cette disposition reproduit, en partie, le contenu de l'article 72 de la loi n²014-626 du 18 juin 2014 (loi Pinel de 2014). 
à la cession du fonds et au sort de l'autorisation d'occupation domaniale dont le propriétaire du fonds est titulaire ${ }^{343}$.

La loi Pinel ne crée cependant pas directement de mécanisme de cession de titre d'occupation. Elle organise plutôt la présentation à l'Administration d'un successeur par le titulaire de l'autorisation. Une fois le successeur agréé par l'Administration, cet agrément permettra la transmission du fonds qui prendra alors toute sa valeur ${ }^{344}$.

\section{b) La transmission successorale du fonds de commerce}

Ce mode de transmission du fonds de commerce est prévu, on le rappelle, par l'article L. 2124-33 du CGPPP. En vertu de cette disposition, "En cas de décès d'une personne physique exploitant un fonds de commerce ou un fonds agricole en vertu d'une autorisation d'occupation temporaire du domaine public, l'autorité compétente délivre à la demande de ses ayants droit, sauf si un motif d'intérêt général s'y oppose, une autorisation d'occupation temporaire du domaine public identique à celle accordée à l'ancien titulaire pour la seule poursuite de l'exploitation du fonds, durant trois mois ».

Cette disposition organise une période de transition dans laquelle les ayant droits peuvent soit décider de poursuivre l'exploitation du fonds - et ils devront alors obtenir une autorisation d'occupation plus pérenne -, soit présenter à l'Administration gestionnaire du domaine public un successeur. En cas d'accord de l'Administration, le successeur sera subrogé dans les droits et obligations de l'ancien titulaire. Les ayant droits disposent, pour cela, d'un délai de six (06) mois à compter du décès ${ }^{345}$.

L'institution, en droit ivoirien, d'un fonds de commerce au profit de l'occupant privatif sur le domaine public portuaire est une proposition visant à remédier au problème de la vive concurrence entre les ports de la façade atlantique de l'Afrique. Cette proposition se présente comme une mesure d'incitation à plus d'investissements consistants sur le domaine public portuaire à travers la possibilité pour l'occupant privatif de maximiser les utilités financières retirées de ses activités industrielles ou commerciales menées sur le domaine public portuaire.

Il est vrai que cette proposition n'empêchera pas la précarité de la situation de l'occupant privatif. Cependant, l'occupant privatif pourra accroître les retombées lucratives de son investissement en cédant, le cas échéant, son fonds de commerce à une personne tierce. En outre, en cas de résiliation unilatérale du bail emphytéotique, par exemple, le titulaire du fonds de commerce pourra obtenir un dédommagement substantiel de la part du gestionnaire du domaine public portuaire. Cette perspective l'encouragera à investir substantiellement sur le domaine public concédé en dépit de la précarité qui frappe le concessionnaire ou l'emphytéote.

L'application rugueuse des principes du droit administratif des biens au Port autonome d'Abidjan se manifeste à certains égards.

\footnotetext{
343 HANSEN Philippe S., «L'exploitation d'un fonds de commerce sur le domaine public », JCP/La Semaine juridique - Éditions Administrations et collectivités territoriales, $\mathrm{n}^{\circ} 36,8$ septembre 2014, p. 3.

344 Ibidem.

345 HANSEN Philippe S., «L'exploitation d'un fonds de commerce sur le domaine public », JCP/La Semaine juridique, $\mathrm{n}^{\circ} 36,8$ septembre 2014, p. 3.
} 



\section{CHAPITRE 2 : LES MANIFESTATIONS DE L'APPLICATION RUGUEUSE DU DROIT PUBLIC AU PORT AUTONOME D'ABIDJAN}

Le droit public est cette partie du droit qui régit l'organisation de l'État et des collectivités publiques ainsi que leurs rapports avec les particuliers. Il se caractérise, entre autres, par la propension de l'État ou de ses démembrements à édicter de manière unilatérale les normes destinées à régir les sujets ou les objets de droit. Ainsi que le notait le professeur Weil, «il est dans la nature des choses qu'un gouvernant croie, de bonne foi, être investi du pouvoir de décider discrétionnairement $d u$ contenu et des exigences de l'intérêt général ${ }^{346}$. Le gouvernement, dans ce passage, renvoie à l'État dont il est l'organe ayant bénéficié de la part léonine de la souveraineté ${ }^{347}$. Par ricochet, les sujets de droit créés par le gouvernement et investis par ce dernier d'une portion de l'imperium ont, eux aussi, cette inclination à user des prérogatives de puissance publique. Le PAA, excroissance de l'État ivoirien qui en est d'ailleurs l'actionnaire exclusif, se distingue par sa propension à l'unilatéralisme lorsqu'il statue sur les affaires impliquant les différents opérateurs économiques de la communauté portuaire (Section 1). En sus des actes administratifs unilatéraux, le PAA use des procédés autoritaires à travers les prérogatives de puissance publique qu'il exerce dans les contrats comportant occupation privative du domaine public portuaire (Section 2).

\section{SECTION 1: Une tendance accentuée du PAA à recourir aux actes administratifs unilatéraux}

Les normes adoptées par le PAA à l'attention de ses usagers se caractérisent, entre autres, par l'absence de consultation de ces derniers. Ces procédés autoritaires se traduisent par l'édiction de certains actes juridiques: les actes administratifs unilatéraux (paragraphe 1). Ceux-ci empruntent des appellations diverses constituant, de la sorte, une panoplie assez large des actes unilatéraux usités pour les activités se déroulant sur la plateforme portuaire d'Abidjan (paragraphe 2).

\section{Paragraphe 1 : La notion d'acte administratif unilatéral}

En consultant le Vocabulaire juridique, on note que l'acte administratif unilatéral revêt plusieurs significations. Celles-ci varient selon que l'on retienne la définition organique, la définition fonctionnelle ou la définition matérielle. D'un point de vue organique, il désigne l'acte qui émane d'une autorité administrative, par opposition aux actes émanant d'une autorité législative, d'une autorité juridictionnelle ou d'un organisme privé. D'un point de vue fonctionnel, la notion exclut les actes d'autorités administratives agissant à un autre titre (ex. les actes du maire en qualité d'officier de police judiciaire), mais englobe au contraire les actes de personnes ou d'organismes privés chargés d'une mission de service public, dès lors que ces actes intéressent l'organisation du service ou son exécution à l'aide de prérogatives de

346

347

WEIL Prosper et POUYAUD Dominique, Le droit administratif, 17 ${ }^{\text {ème }}$ édition, Paris, Coll. "Que saisje? », 1997, p. 3.

Ibidem. 
puissance publique. D’un point de vue matériel, il désigne l'acte unilatéral à caractère individuel, par opposition aux actes de portée générale qui seraient qualifiés de législatifs ${ }^{348}$.

Le doyen Hauriou, dans son ouvrage intitulé Précis de droit administratif, donnait une définition de l'acte administratif qui reflétait la configuration de l'action administrative de son époque. Cette Administration, vers la fin du XIX ${ }^{\mathrm{e}}$ siècle, était la seule entité juridique investie de la mission de satisfaire l'intérêt général en usant, le plus souvent, de prérogatives de puissance publique que manifeste l'acte administratif unilatéral. Selon Hauriou, "l'acte d'administration est une décision exécutoire, prise au nom d'une personne administrative par son représentant légal, en vue de produire un effet de droit et qui, par conséquent, est relative à l'exercice d'un droit ${ }^{349}$.

On remarquera dans cette définition, la place prépondérante assignée au caractère unilatéral, le caractère décisoire de l'acte (exécutoire) et la nature de l'auteur de l'acte, en l'occurrence, une autorité administrative (représentant légal de l'Administration).

La définition émanant du doyen Hauriou est corroborée par d'autres auteurs. C'est ainsi que le professeur Philippe Bouvier considère que l'acte unilatéral est celui « qui, en lui-même, est doté d'une valeur juridique et qui, par lui-même, modifie l'ordonnancement juridique existant ${ }^{350}$. En d'autres termes, il fait naître des droits et obligations dans le chef de destinataire sans que le consentement de ce dernier ne soit recherché. Les éléments cruciaux de cette définition sont le caractère exécutoire de l'acte (doté d'une valeur juridique par luimême) et la modification de l'ordre juridique existant (à travers la création ou la restriction des droits du destinataire de l'acte).

Un autre auteur, le professeur Erkut Celâl, donne également une définition de l'acte administratif qui, en substance, reconduit les éléments contenus dans les définitions précédentes. Ainsi, "l'acte administratif est tout d'abord un acte juridique et il se réalise par l'unique volonté de l'Administration, sans le consentement des tiers. Alors, l'unilatéralité est le caractère le plus significatif de l'acte administratif pour le distinguer de l'acte juridique $»^{351}$.

En filigrane, on remarquera qu'un acte devient administratif lorsqu'il est pris dans le cadre de l'activité exercée par l'Administration. L'acte administratif est un acte juridique en ce sens qu'il constitue une manifestation de la volonté de l'Administration dont le but est de produire des effets juridiques vis-à-vis des administrés. Quant à l'unilatéralité, elle signifie généralement, ce qui vient d'un seul côté. Dans le cadre des actes administratifs, l'unilatéralité implique la manifestation de la seule volonté de l'autorité administrative ou, de plus en plus souvent, d'une personne de droit privé lorsque celle-ci est investie de la compétence de prendre des décisions administratives.

En résumé, on retient que l'acte administratif unilatéral est un acte juridique décisoire ${ }^{352}$ pris par une personne publique ou par une personne de droit privé lorsque cette dernière est investie d'une mission de service public et qu'elle use de prérogatives de puissance publique $^{353}$.

348 CORNU Gérard (dir.), Vocabulaire juridique, $9^{\mathrm{ème}}$ édition, Association Henri Capitant, Quadrige/PUF, 2012, p. 20.

349 HAURIOU Maurice, Précis de droit administratif, contenant le droit public et le droit administratif, $2^{\mathrm{ème}}$ édition, Paris, Éditions Larose \& Forcel, 1893, n68, p. 185.

350 BOUVIER Philippe, Éléments de droit administratif, Bruxelles, De Boeck, 2002, p. 93.

351 ERKUT Celâl, «L'identification de l'acte administratif selon la recevabilité d'un recours pour excès de pouvoir », Journal of Istanbul University Law Faculty, Vol. 53, n ${ }^{\text {os }} 1-4$, pp. 101-137. Article accessible en ligne sur : https://dergipark.org.tr/tr/download/article-file/96018. Document consulté le 24 septembre 2019.

352 La notion de décisoire renvoie à l'idée que l'acte administratif unilatéral soit crée des droits au profit de son ou ses destinataires soit restreint l'exercice des droits de son ou ses destinataires.

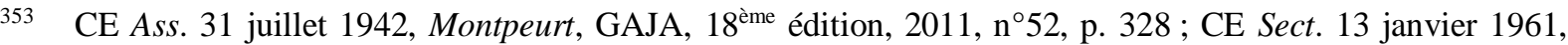

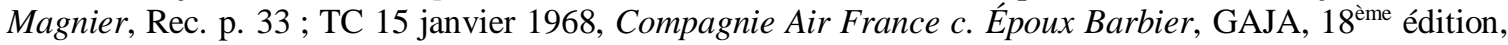
2011, n ${ }^{\circ} 68$, p. 567. 


\section{Paragraphe 2 : La panoplie des actes unilatéraux usités pour régir les activités sur la plateforme portuaire d'Abidjan}

Il importe, dans cette rubrique, de donner une vue synoptique des actes unilatéraux usités au PAA (A), avant d'en analyser le régime juridique (B).

\section{A. Aperçu des actes unilatéraux usités au Port autonome d'Abidjan}

La particularité de ces actes administratifs unilatéraux est qu'ils sont destinés à régir le comportement de personnes qui sont étrangères à son édiction ${ }^{354}$.

Le PAA, à l'image de l'État dont il est un démembrement, recourt fréquemment aux actes administratifs unilatéraux pour régir les activités des différents usagers du port. Ces actes définissent le régime juridique de l'utilisation collective ou privative du domaine public portuaire.

Ces actes administratifs unilatéraux sont consubstantiels à l'imperium ${ }^{355}$ reconnu à l'Administration. Aussi, note-t-on l'édiction fréquente de décisions administratives émanant du directeur général ou son délégataire pour exiger un comportement donné de la part des usagers du port. Ces décisions empruntent l'appellation de "notes » adressés aux usagers du port. L'appellation neutre de "notes » ne devraient pas occulter la question de la nature juridique de tels documents. Serait-ce des circulaires? Serait-ce des règlements ? Ou des actes individuels?

L'analyse d'un échantillon relativement fourni de notes émanées du PAA laisse transparaître une variété qui embrasse les trois catégories précitées. Ce sont soit des injonctions adressées aux usagers du port soit des communiqués portant à l'attention des usagers une situation juridique préexistante ${ }^{356}$.

\section{B. Régime juridique des actes unilatéraux édictés par le Port autonome d'Abidjan}

On peut s'interroger sur le contentieux de tels actes émanés du PAA. En d'autres termes, les «notes» émises par le PAA peuvent-elles, le cas échéant, faire l'objet d'un recours en annulation devant la Chambre administrative de la Cour suprême ?

La réponse à cette interrogation dépendra de l'application aux notes précitées du régime juridique de la circulaire tel que dégagé par le juge administratif. En droit ivoirien, au regard de la jurisprudence Institution notre Dame du Kreisker ${ }^{357}$, les notes se bornant à rappeler l'existence et la nécessité d'appliquer la législation existante ne constituent pas des actes

CHAPUS René, Droit administratif général, $15^{\mathrm{ème}}$ édition, Tome 1, Paris, Montchrestien, 2001, nº53, p. 492.

355 L'imperium est le terme latin signifiant «pouvoir de donner des ordres », "autorité », employé en doctrine par opposition à jurisdictio pour désigner la parcelle de puissance publique dont l'arbitre, à la différence du juge étatique, est démuni (du fait qu'il tient son pouvoir juridictionnel non d'une investiture officielle mais d'une convention d'arbitrage); le terme désigne, par voie de conséquence, l'ensemble des pouvoirs qui ont leur principe dans la détention d'une fraction de la puissance publique : pouvoir de disposer de la force publique, d'ordonner une astreinte, etc. Cf. CORNU Gérard (dir.), Vocabulaire juridique, $9^{\text {ème }}$ édition, Paris, Quadrige/Puf, 2011, p. 520.

356 Voir les notes et autres circulaires émanant du Port autonome d'Abidjan, présentées en annexe des présents travaux de recherche.

357 CE Ass. 29 janvier 1954, Institution Notre-Dame du Kreisker, Rec. 64. 
administratifs décisoires susceptibles, à ce titre, d'être déférées à la censure de la Chambre administrative de la Cour suprême. Ce faisant, le droit ivoirien établit la distinction entre la circulaire interprétative et la circulaire réglementaire. La première (la circulaire interprétative) est celle qui se borne à rappeler l'existence d'un texte juridique existant ${ }^{358}$. La seconde, à savoir la circulaire réglementaire, ne se borne pas à rappeler la législation existante ; elle ajoute des exigences nouvelles que les destinataires de la circulaire voire des personnes tierces sont obligées de suivre. À ce titre, la circulaire réglementaire constitue un acte administratif susceptible d'être déféré à la censure du juge administratif par la voie du recours pour excès de pouvoir ${ }^{359}$.

Il en irait autrement si l'on faisait référence au droit français à travers la jurisprudence Madame Duvignères ${ }^{360}$. Au regard des considérants de la jurisprudence Madame Duvignères, il apparaît qu'une circulaire qui se bornerait à rappeler la législation existante pourrait cependant constituer un acte décisoire, donc censurable par le juge administratif, dès lors qu'elle enjoindrait à ses destinataires de l'appliquer ${ }^{361}$. La circulaire sera aussi censurable par le juge de l'excès de pouvoir lorsque, en interprétant la législation existante, la circulaire est entachée d'erreur ou réitère une illégalité préexistante ${ }^{362}$.

Les prérogatives de puissance publique reconnues à l'Administration contractante, en général, et au PAA, en particulier, se manifeste également lorsqu'il contracte avec les tiers.

\section{SECTION 2: L'usage systématique des prérogatives de puissance publique reconnues au PAA à l'égard de ses cocontractants}

La notion de prérogatives de puissance publique recouvre un sens précis (paragraphe 1). Le PAA a recours fréquemment à de telles prérogatives dans ses relations avec ses cocontractants (paragraphe 2).

358 «... le sous-préfet de Morlaix s'est borné à inviter le directeur de l'institution Notre-Dame du Kreisker à compléter selon les prescriptions de la circulaire du ministre de l'éducation nationale, en date du 11 janvier 1950, le dossier constitué à l'appui de la demande de subvention adressée à la commune de SaintPol-de-Léon, qu'ainsi cette lettre ne comporte pas de décision susceptible d'être déférée au Conseil d'État statuant au contentieux ». Cf. CE Ass. 29 janvier 1954, Institution Notre-Dame du Kreisker, Rec. 64.

359 «... le ministre de l'éducation nationale ne s'est pas borné à interpréter les textes en vigueur mais a, dans les dispositions attaquées, fixé des règles nouvelles relatives à la constitution des dossiers de ces demandes de subvention, que, par suite, ladite circulaire a, dans ses dispositions, un caractère réglementaire ; que dès lors, l'institution Notre-Dame du Kreisker est recevable à déférer au Conseil d'État les prescriptions contestées de cette circulaire ». Cf. CE Ass. 29 janvier 1954, Institution Notre-Dame du Kreisker, Rec. 64. CE Sect. 18 décembre 2002, Mme Duvignères, GAJA, $18^{\mathrm{ème}}$ édition, 2011, n¹10, p. 841 et ss.

361 «Considérant que l'interprétation que par voie, notamment, de circulaires ou d'instructions l'autorité administrative donne des lois et règlements qu'elle a pour mission de mettre en ouvre n'est pas susceptible d'être déférée au juge de l'excès de pouvoir lorsque, étant dénuée de caractère impératif, elle ne saurait, quel qu'en soit le bien-fondé, faire grief ; qu'en revanche, les dispositions impératives à caractère général d'une circulaire ou d'une instruction doivent être regardées comme faisant grief, tout comme le refus de

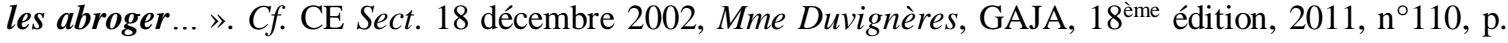
842 .

362 «... qu'il en va de même s'il est soutenu à bon droit que l'interprétation qu'elles prescrivent d'adopter, soit méconnait le sens et la portée des dispositions législatives ou réglementaires qu'elle entendrait expliciter, soit réitère une règle contraire à une norme juridique supérieure ». Cf. CE Sect. 18 décembre

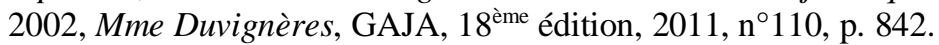




\section{Paragraphe 1 : La notion de prérogatives de puissance publique}

Une prérogative est une compétence ou droit reconnu ou attribué à une personne ou à un organe en raison de sa fonction et impliquant pour lui une certaine supériorité, puissance ou immunité ${ }^{363}$. La différence de traitement évoquée ci-dessus profite généralement à l'Administration étatique, l'Administration de la collectivité décentralisée ou une autre entité juridique (de droit privé) investi de pouvoirs exorbitants du droit commun par l'État. Dans cette dernière catégorie, sont visées les sociétés d'État, les sociétés à participation financière publique majoritaire, ou les délégataires de service public.

Les prérogatives de puissance publique sont inhérentes à tout contrat administratif. En droit français, le Conseil d'État a considéré que l'Administration contractante détient les prérogatives de puissance publique même si elles ne sont pas formellement inscrites dans le contrat $^{364}$. Elle ne peut non plus renoncer par convention à l'exercice de ses prérogatives de puissance publique. Ainsi, dans l'affaire Association Eurolat-Crédit foncier de France, le Conseil d'État a considéré que la renonciation de l'Administration, dans le cadre d'un contrat, à ses prérogatives de puissance publique est illicite ${ }^{365}$.

Les prérogatives de puissance publique, en matière contractuelle, sont au nombre de quatre. Ce sont : le pouvoir de direction et de contrôle, le pouvoir de modification unilatérale $^{366}$, le pouvoir de sanction ${ }^{367}$ et le pouvoir de résiliation unilatérale ${ }^{368}$.

«Considérant enfin qu'en disposant, dans l'article al. 1, que l'autorité organisatrice peut, au cours de contrat, apporter unilatéralement des modifications à la consistance des services et à leurs modalités d'application, que l'usage de cette prérogative peut entraîner une révision des clauses financières du contrat, et enfin que les modifications ainsi apportées ne doivent pas être incompatibles avec le mode de gestion choisi, les auteurs du décret attaqué se sont bornés à faire application des règles générales applicables aux contrats administratifs ». Cf. CE 2 février 1983, Union des transports publics et régionaux, 34027, publié au recueil Lebon.

365 «Que ces clauses, incompatibles avec les principes de la domanialité publique comme avec les nécessités $d u$ fonctionnement d'un service public, doivent être regardées comme nulles ». (CE 6 mai 1985, Association Eurolat, Crédit foncier de France, Rec. 141).

366 C'est la théorie de la mutabilité du contrat administratif. Cf. CE 10 janvier 1902, Compagnie nouvelle de gaz de Déville-lès-Rouen, Rec. 5 ; CE 11 mars 1910, Compagnie générale française des tramways, GAJA,

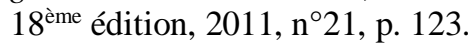

367 Les sanctions peuvent être soit des sanctions pécuniaires (amendes, dommages-intérêts, pénalités) soit des sanctions coercitives variables suivant les types de contrats (mise sous séquestre pour la concession, mise en régie pour le marché de travaux publics) ou enfin des sanctions (sanctions pécuniaires : CE 9 mars 1928, Compagnie des scieries africaines, RDP, 1928, p. 323. Cette sanction pécuniaire s'applique de plein droit sans que l'Administration n'ait à prouver qu'elle a subi un préjudice quelconque).

368 Pour mettre en œuvre son pouvoir de résiliation unilatérale, l'Administration doit, selon le Conseil d'État, rassembler les deux conditions suivantes :

- Seul l'intérêt du service justifie la résiliation ;

- Le cocontractant a seulement droit à une indemnisation.

(CE 2 mai 1958, Distillerie de Magnac Laval ; CE 2 février 1987, Société TV). L'importance de ce pouvoir de résiliation est telle que le Conseil d'État annule les clauses d'un contrat administratif qui auraient pour objet d'exclure cette résiliation (CE 6 mai 1985, Association Eurolat, Crédit Foncier de France). Il importe de préciser, relativement à la deuxième condition, le contractant évincé qui conteste le montant de l'indemnisation allouée par l'Administration contractante dispose de la latitude de saisir le juge du contrat aux fins d'obtenir un rehaussement du montant de l'indemnisation. 


\section{Paragraphe 2: Les manifestations de prérogatives de puissance publique usitées par le PAA}

Relativement au pouvoir de sanction, le PAA en a fait usage dans l'affaire Société Entreprise Graviers et Sables (EGS) cl Port Autonome d'Abidjan, l'affaire SIVCOGE Industrie c/ Port autonome d'Abidjan et l'affaire Port autonome d'Abidjan (PAA) c/ PEXAGRI.

Dans l'affaire Société Entreprise Graviers et Sables (EGS) c/ Port Autonome d'Abidjan, le PAA avait conclu avec la société EGS une concession de voirie en vertu de laquelle cette dernière était habilitée à occuper le lot n ${ }^{\circ} 349$ ter de la zone des industries navales de Vridi, pour une durée de 30 ans. Ayant fait constater par huissier de justice que la société EGS avait sous-loué une portion de son domaine public à une tierce personne, le PAA met fin à la concession de voirie le liant à la société EGS.

De même, dans l'affaire SIVCOGE Industrie c/ Port autonome d'Abidjan, le PAA a retiré l'autorisation d'occupation qu'il a octroyée à la SIVCOGE Industrie en mars et mai 2005.

Enfin, dans l'affaire Port autonome d'Abidjan (PAA) c/PEXAGRI, le PAA a, par décision $\mathrm{n}^{\circ} 01222$ du 23 mai 2005, retiré à la Société PEXAGRI l'autorisation d'occuper le lot n²-ZE049-73 ter qu'elle lui avait accordée par un acte du 26 mai 2004. Le PAA a invoqué le motif suivant lequel la société PEXAGRI n'exerçait plus elle-même d'activité sur le lot à elle attribué et qu'elle avait sous-loué le lot qui lui avait été attribué.

Il est à remarquer que dans chacune des espèces ci-dessus, le PAA recourt à un acte unilatéral qui met fin à la concession de voirie ou, à défaut, à l'autorisation d'occupation privative du domaine public portuaire. Le fait remarquable ne réside pas en ce que le PAA soit compétent pour procéder à ces abrogations, mais plutôt dans l'absence récurrente de toute volonté du PAA d'explorer des solutions consensuelles avec les usagers du PAA.

Le corpus juridique s'appliquant au PAA n'est pas exempt de reproche eu égard aux failles qui en altèrent significativement sa portée. Aussi, importe-t-il de surmonter les faiblesses de cette législation. 


\section{TITRE 2: LA NÉCESSITÉ DE SURMONTER LES FAIBLESSES OBÉRANT LES PERFORMANCES DU PORT AUTONOME D'ABIDJAN}

Le PAA est confronté à certains écueils qui obèrent quelque peu ses performances. Aussi, est-il nécessaire de procéder à certaines réformes nécessaires à l'accroissement des performances dudit port. Les réformes structurelles pourraient emprunter une diversité de formes. Il est bien entendu que la gestion du Port d'Abidjan sous la forme de régie ne retiendra pas notre attention eu égard aux limites dont elle a fait montre dans le passé. De même, toute réforme tendant à la dévolution totale du Port d'Abidjan à des capitaux privés est à exclure. En effet, le PAA est actuellement la première entreprise (publique) de Côte d'Ivoire au regard des revenus générés par son exploitation.

$\mathrm{Au}$ regard de toutes ces restrictions, il apparaît qu'une cogestion dans le cadre d'un partenariat public-privé emporte notre adhésion. En d'autres termes, certains procédés contractuels permettrait aux autorités étatiques compétentes d'associer certains partenaires privés détenteurs de capitaux aux fins de rehausser le niveau actuel de performance. L'énoncé de propositions (pertinentes) relatives à la libéralisation du PAA implique nécessairement que l'on ait une vue d'ensemble des modèles de gestion portuaire en vigueur en Afrique.

La connaissance des modèles existants et de leurs limites permettraient de formuler des propositions qui, on l'espère, ne reconduiront plus les faiblesses actuelles. Aussi, la présentation de la variabilité et de l'évolution des modèles et techniques juridiques de gestion portuaire (Chapitre1) précédera-t-elle la présentation des propositions relatives au rehaussement du dynamisme du PAA. Les propositions consistent en des ajustements relatifs à la nature juridique du Port autonome d'Abidjan (Chapitre 2). 



\section{CHAPITRE 1: VARIABILITÉ ET ÉVOLUTION DES MODÈLES ET TECHNIQUES JURIDIQUES DE GESTION PORTUAIRE}

Si extérieurement, les ports tendent à se ressembler au regard des activités qui y sont menées, il n'en demeure pas moins qu'il existe une diversité de modèles de gestion qui permettent de les distinguer (Section 1). Quant aux techniques, on note l'affection croissante des autorités portuaires pour les modèles concessifs d'exploitation du port. Sur ce point, l'apparition des concessions domaniales à objet complexe semblent être la réponse aux limites des concessions domaniales classiques (Section 2).

\section{SECTION 1 : Variabilité des modèles de gestion portuaire}

La variabilité des modèles de gestion portuaire a pour corollaire une diversité de catégories juridiques (paragraphe 1). En Afrique, la multitude de ports se répartit en fonction du modèle véhiculé respectivement par les anciennes puissances coloniales anglaise ou française (paragraphe 2).

\section{Paragraphe 1 : Les principales catégories juridiques observables}

Il existe quatre (4) grands modèles de gestion portuaire : les ports de services publics, les ports outils, les ports propriétaires et les ports de services privés. Chaque modèle possède ses propres caractéristiques pour ce qui est de la propriété des infrastructures, les équipements, les opérations de terminal et la prestation de services portuaires aux navires comme le pilotage, le remorquage et le mouillage. Les ports de services publics et les ports outils insistent particulièrement sur la réalisation de l'intérêt public. Les ports propriétaires visent à promouvoir un équilibre entre l'intérêt public (les autorités portuaires) et l'intérêt privé (l'industrie portuaire). Les ports entièrement privatisés sont tournés vers l'intérêt privé (les actionnaires).

\section{A. Les ports de services publics}

L'autorité portuaire possède les infrastructures et assure l'ensemble des services nécessaires au fonctionnement du système portuaire. En d'autres termes, elle possède, entretient et exploite toutes les infrastructures, la superstructure, les équipements et les actifs portuaires, y compris la manutention des cargaisons. Certains services auxiliaires peuvent être confiés à des sociétés privées. Les services portuaires sont en général une émanation du ministère d'un État. Le nombre de ports de services publics diminue ${ }^{369}$.

369 HOFFMANN Jan (dir.), Étude sur les transports maritimes 2017, New York et Genève, CNUCED, Côte UNCTAD/RMT/2017, p. 77. 


\section{B. Les ports outils}

Analogue aux ports de services publics, ils s'en distinguent en cela que les opérations sur marchandises sont assurées par le secteur privé. Cependant, les équipements de terminal tels que les grues de quai et les chariots élévateurs à fourche appartiennent à l'autorité portuaire. La manutention des cargaisons à bord des navires et à quai est prise en charge par des sociétés privées de manutention. Dans certains cas, les ports outils servent à effectuer la transition des ports de services publics aux ports propriétaires ${ }^{370}$.

\section{Les ports propriétaires}

C'est le modèle de gestion le plus courant : l'autorité portuaire joue le rôle d'organisme réglementaire tandis que les opérations portuaires - en particulier la manutention des cargaisons - sont assurées par des sociétés privées. Les infrastructures, en particulier les terminaux, sont données à bail à des exploitants privés ou à des industries telles que des raffineries, des terminaux céréaliers, des terminaux à citernes et des usines chimiques. Dans ce cas, l'autorité portuaire conserve la propriété du foncier. La forme de bail la plus courante est un contrat de concession aux termes duquel une société privée se voit octroyer un bail à long terme contre le versement d'un loyer, généralement calculé en fonction de la taille de l'installation et de l'investissement nécessaire à la construction, à la mise à niveau ou à l'extension d'un terminal. Les exploitants privés sont également chargés de fournir des équipements de terminal pour veiller au respect des normes opérationnelles. Les exploitants portuaires privés fournissent et entretiennent leur propre superstructure, y compris les bâtiments (par exemple, bureaux, entrepôts, centres de groupage et dégroupage des conteneurs et ateliers). La main-d'œuvre portuaire est employée par les exploitants de terminaux privés, quoique dans certains cas, elle peut en partie être mise à disposition par l'autorité portuaire ${ }^{371}$.

\section{Les ports de services privés}

Ces installations portuaires sont entièrement privatisées, mais conservent un rôle maritime. L'autorité portuaire est elle aussi entièrement privatisée. La plupart des fonctions portuaires sont contrôlées par le secteur privé, mais le secteur public exerce des pouvoirs ordinaires de surveillance réglementaire et peut détenir des actions du port ${ }^{372}$.

\section{Paragraphe 2: La répartition des ports africains selon les modèles anglais ou français}

Ces modèles diffèrent en fonction du modèle alors en vigueur dans l'ancienne puissance coloniale à laquelle est rattaché l'État du port. En d'autres termes, les États africains, en général, ont reconduit le modèle de gestion portuaire tel qu'il se rencontrait dans l'ancienne puissance colonisatrice. On distingue grosso modo deux différents modèles. Ce sont notamment le modèle retenu en Afrique anglophone (A), et celui de l'Afrique francophone (B).

\footnotetext{
370 Ibidem.

371 Ibidem.

372 Ibidem.
} 


\section{A. L'approche retenue en Afrique anglophone}

La particularité principale du port en Afrique anglophone, du moins dans sa configuration initiale, réside dans le fait que celui-ci est un opérateur. Il en résulte qu'il contrôle et gère toutes les opérations portuaires. Aussi, la concurrence est-elle absence ou, dans le meilleur des cas, est-elle fortement minimisée.

Dans le modèle initial précité, le port cumule les fonctions de régulation et la réalisation d'opérations matérielles telles que la manutention, l'acconage, l'entreposage, etc. ${ }^{373}$

Il est vrai que ce modèle initial est appelé, à terme, à être amendé pour tenir compte des réformes en cours ou à venir par lesquels les États du port d'expression anglaise procéderont à la libéralisation (partielle) de leur outil portuaire ${ }^{374}$.

\section{B. L'approche retenue en Afrique francophone}

Le modèle en vigueur en Afrique francophone diffère de celui de l'Afrique anglophone. Dès la période coloniale, les ports de l'Afrique occidentale française (A.O.F.), en général, et celui de la colonie de Côte d'Ivoire, en particulier, étaient confinés dans le rôle de port propriétaire foncier (Landlord); laissant aux personnes de droit privé la réalisation des opérations matérielles telles que la manutention, la consignation, etc.

Cette orientation résulte, en ce qui concerne l'Afrique occidentale française, de la lecture combinée de deux textes juridiques pris par l'Administration coloniale. Ce sont : le décret du 29 septembre 1928 sur le domaine public ${ }^{375}$, d'une part, et l'arrêté du 24 novembre 1928 d'application du décret précité ${ }^{376}$, d'autre part.

Les ports et rades ont été inclus dans le domaine public de la colonie de Côte d'Ivoire au moyen de l'article premier litter. f) du décret précité du 29 septembre 1928. L'article 6 du décret du 28 septembre 1928 habilite le ministre chargé des domaines d'accorder des autorisations d'occuper privativement le domaine public sous réserve, entre autres, de la précarité desdites occupations. Cette possibilité d'occupation privative a été confortée par l'arrêté précité du 24 novembre 1928. L'article 14 dudit arrêté prévoit la possibilité pour l'Administration gestionnaire $\mathrm{du}$ domaine public portuaire de conclure des baux emphytéotiques par lesquelles pourront être constitués, entre autres, des entrepôts de consignataires, transitaires, commissionnaires ou armateurs, etc. On remarquera que les opérations de manutention, d'entreposage, de consignation, etc. sont exercées par des personnes de droit privé, autres que l'Administration coloniale.

Tableau : Modèles de gestion portuaire en Afrique francophone et anglophone

\begin{tabular}{|l|l|l|}
\hline Modèle dominant & \multicolumn{1}{|c|}{ Modèle francophone } & \multicolumn{1}{c|}{ Modèle anglophone } \\
\hline Autorité portuaire & $\begin{array}{l}\text { Port propriétaire foncier } \\
\text { (Landlord): Manutention, } \\
\text { acconage, magasinage, } \text { etc. par des } \\
\text { opérateurs privés }\end{array}$ & $\begin{array}{l}\text { Port opérateur : contrôle et gère } \\
\text { toutes les opérations }\end{array}$ \\
\hline
\end{tabular}

373 CNUCED, Réformes et place du secteur privé dans les ports africains, Rapport UNCTAD/SDTE/TLB/5, Version française, 31 mars 2003, p. 8

374 Ibidem.

375 Décret du 29 septembre 1928 portant réglementation du Domaine public, des servitudes d'utilité publique en Côte d'Ivoire et le décret du 7 septembre 1935 et le décret n57-679 du 3 juin 1952.

376 Arrêté GG n²895 A.E. du 24 novembre 1928 réglementant les conditions d'application du décret du 29 septembre 1928 sur le Domaine public et les servitudes d'utilité publique. 


\begin{tabular}{|c|c|c|}
\hline Concurrence & $\begin{array}{l}\text { Concurrence ouverte } \\
\text { Exemples: Sénégal, Côte d'Ivoire, } \\
\text { Djibouti, Bénin, Cameroun, etc. }\end{array}$ & $\begin{array}{l}\text { Peu de concurrence } \\
\text { Exemples: Ghana, Nigéria, Kenya, } \\
\text { Tanzanie, etc. Autres groupes : } \\
\text { Maroc, Tunisie, Soudan, etc. }\end{array}$ \\
\hline Réformes portuaires & $\begin{array}{l}\text { Pas de séparation entre les } \\
\text { fonctions de régulation et les } \\
\text { opérations }\end{array}$ & $\begin{array}{l}\text { Séparation entre les fonctions de } \\
\text { régulation et les opérations }\end{array}$ \\
\hline Partenariat avec le privé & $\begin{array}{ll}\text { - } & \text { Concession des terminaux } \\
\text { - } & \text { Appel au privé pour la } \\
\text { construction des nouveaux } \\
\text { terminaux }\end{array}$ & $\begin{array}{ll}\text { - } & \text { Concession des terminaux } \\
\text { - } & \text { Privatisation de la manutention } \\
& \text { et des autres opérations }\end{array}$ \\
\hline
\end{tabular}

Source: CNUCED, Réformes et place du secteur privé dans les ports africains, Rapport UNCTAD/SDTE/TLB/5, Version française, 31 mars 2003, p. 8.

À la vue synoptique des modèles portuaires rencontrés en Afrique, succède l'étude des modèles concessifs susceptibles de remédier aux limites des concessions portuaires classiques. La nouvelle catégorie juridique des concessions portuaires est constituée des concessions portuaires à objet complexe.

\section{SECTION 2 : Les concessions domaniales à objet complexe : un remède aux limites des concessions portuaires classiques ?}

La concession de voirie - une concession portuaire de type classique - au regard de son régime juridique rigide se révèle, à certains égards, être involontairement un frein à la mise en exploitation conséquente du domaine public portuaire. En revanche, un autre type de concession domaniale, en l'occurrence les concessions domaniales à objet complexe, au regard de leur particularité (paragraphe 1), se révèlent être un vecteur de développement économique (paragraphe 2).

\section{Paragraphe 1 : Les particularités des concessions domaniales à objet complexe $^{377}$}

Les concessions domaniales à objet complexe présentent, en général, des traits caractéristiques (A). Leur adaptabilité au contexte économique actuel pourrait expliquer le fait que d'autres pays africains aient recours à ce type de montage. Cela ne devrait cependant pas faire oublier qu'il est loin d'être adopté par la totalité des ports africains. Ces nouveaux modèles concessifs connaissent donc des fortunes diverses comme en témoignent les cas du Maroc et du Sénégal (B).

\section{A. Les traits caractéristiques des concessions domaniales à objet complexe}

Ce type de concessions domaniales s'inscrit dans la dynamique du partenariat public-privé (PPP). Sous cet angle, les concessions domaniales à objet complexe contribuent à la

377 Cette portion des travaux s'appuiera, en grande partie, sur la thèse de SÉKA Aba Clément. Cf. ABA SÉKA Clément, Contribution à l'étude juridique des concessions juridiques, Collection «Affaires Maritimes et Transports », L'Harmattan, 2015, pp. 419-422. 
modernisation de la gouvernance portuaire africaine (1) et constituent, par la même occasion, un outil au service du développement des ports africains (2).

\section{Les concessions à objet complexe, un outil de modernisation de la gouvernance portuaire}

La modernisation de la gouvernance des ports africains impose la mutation des outils juridiques qui articulent les partenariats public-privé. "Ces contrats doivent être obligatoirement soumis à un régime équilibré et minutieusement réglementé, ainsi qu'à un cahier des charges fixant clairement les droits et obligations de chacun ${ }^{378}$.

Il faut appliquer pleinement les règles de la concurrence dans le choix des opérateurs privés et remettre en cause la précarité qui entoure, dans de nombreux ports africains, les autorisations d'occupation privative des espaces domaniaux. Plus précisément, trois recommandations peuvent être formulées.

Le droit de la domanialité publique, tout d'abord, doit s'adapter au contexte spécifique des économies africaines et favoriser leur participation au commerce maritime mondial. En effet, il faut admettre que certaines dépendances domaniales ayant une vocation économique prépondérante (comme les ports maritimes) doivent faire l'objet d'une protection juridique plus souple et plus dynamique, favorable aux partenaires privés. Ces dépendances doivent être affranchies des règles qui privilégient le gestionnaire du port et pénalisent les investisseurs privés sans justification juridique véritable ${ }^{379}$.

Par ailleurs, rien n' interdit aux gestionnaires des ports africains de proposer des contrats sui generis, adaptés aux besoins de leurs zones portuaires, dans le respect des règles de la domanialité publique ${ }^{380}$.

Enfin, les gestionnaires peuvent envisager le déclassement de parcelles domaniales en vue de permettre des implantations industrielles; ces accords peuvent prendre la forme de contrats de droit privé, comme les baux à construction ${ }^{381}$.

L'exigence de cette nouvelle gouvernance portuaire transparait du droit communautaire, singulièrement du droit de l'UEMOA. En effet, le préambule du Traité de l'UEMOA prévoit que les États membres doivent "se conformer aux principes d'une économie de marché ouverte, concurrentielle et favorisant l'allocation optimale des ressources ». L'article 4 dudit traité dispose que parmi les objectifs poursuivis, figure la nécessité de "renforcer la compétitivité des activités économiques et financières des États membres dans le cadre d'un marché ouvert et concurrentiel et d'un environnement juridique rationalisé et harmonisé ${ }^{382}$.

En conséquence, la gestion du domaine public portuaire doit s'inscrire dans ce contexte.

Une recommandation ${ }^{383}$ de l'UEMOA du 27 juin 2002 invite les États membres à « ouvrir le secteur de la manutention dans les ports de l'Union au secteur privé, tout en assurant les

378 NDENDÉ Martin, «Les pays africains doivent se doter de législations portuaires adaptées », Jeune Afrique, 8 août 2013. Article accessible en ligne sur: www.jeuneafrique.com/17870/economie/les-paysafricainss-doivent-se-doter-de-legislations-portuaires-adapt-es/. Document consulté le 30 juillet 2019.

379 ABA SÉKA Clément, « Des outils juridiques au service du développement des ports africains », Secteur Privé et Développement, $\mathrm{n}^{\circ}$ 26, mars-avril-mai 2017, p. 17.

380 Ibidem.

381 Ibidem.

382 TOURÉ Ousmane et RÉZENTHEL Robert, « L'avenir des concessions portuaires en Afrique de l'Ouest et du Centre », Neptunus, e.revue, Université de Nantes, vol. 22, 2016/3, p. 5. Article accessible en ligne sur : https://cdmo.univ-nantes.fr/medias/fichier/renzenthle_1478006882478.pdf?ID. Document consulté le 30 juillet 2019.

383 Article 5-I de la Recommandation n02/2002/CM/UEMOA du 27 juin 2002 relative à la simplification et à l'harmonisation des procédures administratives et de transit portuaire au sein de l'UEMOA. Une directive $n^{\circ}$ 04/2008/CM/UEMOA du 28 mars 2008 porte mise en place d'un cadre institutionnel harmonisé du sous- 
conditions d'une saine concurrence et la promotion des petites et moyennes entreprises du secteur ».

À l'instar du Traité de fonctionnement de l'Union européenne, le traité de l'UEMOA prévoit l'application de droits dérivés à travers les règlements et les directives. L'article 43 de ce traité dispose que : "Les directives lient tout État membre quant aux résultats à atteindre ». Au regard de cette disposition, les États membres doivent intégrer dans leur droit interne les objectifs fixés par les directives ${ }^{384}$.

Deux directives ont été adoptées par l'UEMOA, l'une ${ }^{385}$ concernant les procédures de passation, d'exécution et de règlement des marchés publics et des délégations de service public, l'autre ${ }^{386}$, relative au contrôle et la régulation des marchés publics et des délégations de service public. La procédure de mise en concurrence, la présentation et la sélection des dossiers de candidature sont détaillées dans la première, tandis que des mesures de contrôle sont prescrites dans la seconde. Un dispositif d'éthique est mis en place afin d'éviter les pratiques frauduleuses et les actes de corruption. Ces directives consacrent néanmoins la préférence nationale dans l'attribution des concessions et marchés publics ${ }^{387}$.

Les concessions portuaires sont soumises aux prescriptions des directives dans la mesure où relèvent du régime de la commande publique. Cependant, les activités de manutention portuaires, de stockage et de transport des marchandises à l'intérieur des ports ne doivent pas être qualifiées de missions de service public.

\section{Les concessions à objet complexe, un outil au service du développement des ports africains}

Les concessions domaniales à objet complexe peuvent être définies comme des contrats portant occupation du domaine public portuaire ouverts à toute autre qualification spéciale car combinant plusieurs objets ${ }^{388}$. On remarquera que les concessions domaniales à objet complexe ne confèrent pas à leurs titulaires le droit d'occuper uniquement une installation portuaire qui est incluse dans le domaine public. En effet, ces concessions peuvent conférer aux opérateurs portuaires le droit de financer, réaliser et exploiter une installation portuaire. Ce faisant, ce type de concession s'inscrit dans une nouvelle catégorie des contrats concessifs telle que définie par le décret $\mathrm{n}^{\circ} 2012-1151$ du 19 décembre 2012 relatif aux contrats de partenariats public-privé. Au regard de l'article premier du décret précité, sont inclus dans les modes concessifs :

- la concession de service public ;

- le contrat de conception, construction, financement, exploitation ;

- et le contrat de construction, exploitation, transfert.

secteur maritime au sein de l'UEMOA On note également une directive n ${ }^{\circ}$ 3/2008/CM/UEMOA du 28 mars 2008 relative aux fournisseurs de services portuaires au sein de l'UEMOA.

TOURÉ Ousmane et RÉZENTHEL Robert, op. cit., p. 5.

Directive ${ }^{\circ}$ 04/2005/CM/UEMOA du 9 décembre 2005 portant procédures de passation, d'exécution et de règlement des marchés publics et des délégations de service public dans l'Union Économique et Monétaire Ouest Africaine.

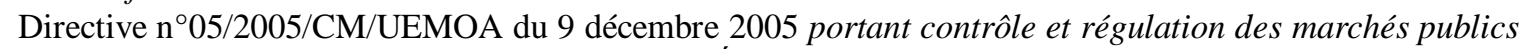
et des délégations de service public dans l'Union Économique et Monétaire Ouest Africaine.

TOURÉ Ousmane et RÉZENTHEL Robert, op. cit., p. 5.

ABA SÉKA Clément, Contribution à l'étude juridique des concessions juridiques, Collection « Affaires Maritimes et Transports », L’Harmattan, 2015, n796, p. 419. 
Ces deux derniers types de contrat constituent indéniablement une nouveauté dans le corpus juridique ivoirien.

A priori, trois objectifs majeurs sont assignés aux concessions domaniales à objet complexe : valoriser le domaine public portuaire, équiper et accroître la performance des installations portuaires et, finalement, positionner l'État propriétaire du domaine public (en l'occurrence la Côte d'Ivoire) comme un hub portuaire régional ${ }^{389}$.

En plus de dégager des revenus pour l'État propriétaire du domaine public portuaire, ces concessions se révèlent un outil de renforcement du partenariat public-privé, précisément entre l'Administration portuaire et les opérateurs privés du transport multimodal. Il en résulte que l'activité exercée dans le cadre des concessions domaniales à objet complexe n'est pas forcément une mission de service public. Elle est plutôt une activité génératrice de ressources financières profitables aussi bien à l'Administration portuaire concédante qu'au concessionnaire.

En dépit des énormes avantages qu'elles procurent, le recours aux concessions domaniales à objet complexe, au niveau des ports africains, connaît des fortunes diverses. En effet, si les autorités marocaines ont été adopté ce nouveau mode de concession pour réaliser le complexe portuaire Tanger Méditerranée, il est, en revanche, quelque peu méconnu au Port autonome de Dakar, au Sénégal.

\section{B. Les fortunes diverses des nouveaux modèles concessifs dans les ports africains : cas du Maroc et du Sénégal}

Afin d'analyser les concessions domaniales à objet complexe, nous étudierons respectivement le cas du complexe portuaire Tanger-Méditerranée et celui du Port autonome de Dakar. On note, dans le premier cas, un essor des nouveaux modes de concession portuaire (1) tandis que, dans le second, persiste le mode classique de concession portuaire (2).

\section{L'essor des nouveaux modes de concession au niveau du complexe portuaire Tanger-Méditerranée}

Un élément essentiel du montage concessif du complexe portuaire Tanger Méditerranée est l'application des règles de la concurrence dans le choix du concessionnaire, précisément du consortium d'opérateurs privés chargé d'exploiter le terminal à conteneurs ${ }^{390}$. En outre, le législateur marocain reconnaît un droit de superficie sur les ouvrages construits, équipements fixes et installations à caractère immobilier au profit du concessionnaire. Ce dernier bénéficie en sus du droit d'hypothéquer les biens concernés pour garantir les emprunts contractés par l'opérateur en vue de leur financement, leur réalisation, leur modification ou leur extension ${ }^{391}$.

En contrepartie, le consortium de concessionnaires s'engage à garantir, dès les premières années d'exploitation, l'utilisation dans une large proportion, de la capacité du terminal $(1,5$ millions d'EVP) qui s'inscrit dans un schéma favorisant une meilleure compétitivité logistique des opérateurs économiques de l'arrière-pays. Enfin, le consortium de

\footnotetext{
389 Ibidem.

390 Dans le cas de Tanger Med 1, il s'agit du consortium Horizon Tangiers Terminals SA comprenant Horizon Terminal (EAU), IPG (Koweit) et Afriquia (Maroc). Concernant Tanger Med 2, le consortium comprend : Besix (Belgique), Bouygues Travaux Publics (France), Bymaro (Maroc), Saipem (Italie) et Somagec (Maroc).

391 ABA SÉKA Clément, op. cit., n810, p. 430.
} 
concessionnaires s'engage à verser des redevances domaniales mensuelles dont le montant global actualisé sur la période de concession dépasse les 100 millions d'euros ${ }^{392}$.

De manière pratique, le complexe portuaire Tanger Méditerranée correspond à un investissement global de l'ordre de 35 milliards de dirhams, soit 3 milliards d'euros. Il comprend les ports Tanger Med 1 et Tanger Med 2, l'infrastructure, les superstructures et les équipements de l'ensemble des terminaux. Cet investissement aura été réalisé dans le cadre d'un schéma de partenariat entre secteurs public et privé.

Le partenariat entre public et privé dans le cadre de Tanger Med 2 s'apparente en tout point à celui, déjà éprouvé, qui a été mis en place dans le cadre de la réalisation du port Tanger Med 1 est entré en exploitation en 2007. Il s'agit de s'appuyer sur de grands opérateurs portuaires spécialisés dans le cadre d'un schéma rapproché de partenariat publicprivé (PPP) permettant, d'une part, d'alléger et faciliter les montages financiers de l'infrastructure portuaire et, d'autre part, de tirer avantage de l'expertise de ces opérateurs privés dans l'exploitation des terminaux et activités portuaires ${ }^{393}$.

Le contrat pour la conception et la construction de ces nouvelles infrastructures a été attribué à un consortium de partenaires formé - à parts égales (20\% chacun) - de Besix (Belgique), Bouygues Travaux Publics (France), Bymaro (Maroc), Saipem (Italie) et Somagec (Maroc), pour un montant global de 9,25 milliards de dirhams (environ 825 millions d'euros).

Le montage financier du port Tanger Med 2, portant sur un montant global de 1 milliard d'euros dans le cadre d'une société de projet, est assuré, d'une part, par un apport en fonds propres à hauteur d'environ 350 millions euros, répartis à parts égales entre l'État et l'Autorité portuaire de Tanger Med et, d'autre part, par un endettement qui totalisera à terme 650 millions d'euros.

Contrairement au complexe Tanger-Méditerranée, le Port autonome de Dakar, à l'image de celui d'Abidjan, persiste dans l'utilisation des modes classiques de concession.

\section{La persistance des modes classiques de concession au Port autonome de Dakar}

Le droit applicable aux concessions portuaires au Sénégal, dans l'ensemble, s'apparente à celui en vigueur en Côte d'Ivoire. Cette situation ne saurait surprendre vu que le Sénégal et la Côte d'Ivoire ont reconduit, en général, les principes et les techniques juridiques de la République Française, l'ancienne puissance colonisatrice. En matière d'exploitation du domaine public portuaire, les deux États ont opté pour la permission de voirie, la concession de voirie et le bail emphytéotique administratif ${ }^{394}$.

Quelle que soit la forme qu'emprunte l'autorisation d'occupation temporaire (AOT) du domaine public portuaire, la situation du permissionnaire, du concessionnaire ou de

\footnotetext{
392 Ibidem.

393 DEBOHI Landry Jocelyn, Financement de projets internationaux : cas de Tanger Med, p. 9. Document accessible en ligne sur: https://www.academia.edu/33110863/THEME_FINANCEMENT_DE_PROJETS_INTERNATIONAUX_CAS_DE_TANGER_MED_Pr\%C3\%A9sent\%C3\%A9. Document consulté le 30 juillet 2019.

394 Le bail emphytéotique administratif, en Afrique occidentale française (A.O.F.), a été prévu par un arrêté du Gouverneur général de l'A.O.F. Il s'agit précisément de l'Arrêté GG n²895 A.E. du 24 novembre 1928, réglementant les conditions d'application du décret du 29 septembre 1928 sur le Domaine et les servitudes d'utilité publique. En vertu de l'article 14 dudit arrêté, "Les occupations temporaires du Domaine public peuvent correspondre soit à un besoin individuel, soit à un intérêt économique d'ordre collectif ou général [...] Dans le deuxième cas (cales de halage publiques, bassins de radoub, appontements en vue d'un service public, magasins généraux, entrepôts de consignataires, transitaires, commissionnaires ou armateurs, permis d'occuper délivrés à une commune ou à un établissement public, etc.), la forme du bail renouvelable peut être adopté sous réserve d'une résiliation toujours possible de la part de l'Administration après préavis de six mois au plus... ».
} 
l'emphytéote (selon le cas) est marquée du sceau de la précarité. En d'autres termes, l'Administration portuaire peut mettre prématurément fin à l'occupation privative du domaine public portuaire. Cette situation se rencontre assez couramment au Port autonome de Dakar (PAD). On note, en la matière, la non actualisation des textes juridiques régissant l'exploitation du domaine public, en général, et celui du Port autonome de Dakar, en particulier.

Pour s'en convaincre, il importe de garder à l'esprit que les textes juridiques relatifs à la gestion du PAD optent, pour l'essentiel, pour une gestion étatique dudit port. Ainsi, la loi du 18 août $1987^{395}$, en son article premier, dispose : "la société nationale a pour objet l'exploitation, l'entretien du port maritime de Dakar et de ses dépendances, la gestion de son domaine immobilier et l'exécution des travaux d'amélioration et d'extension de ses installations ».

On note à travers cette disposition que le $\mathrm{PAD}$ cumule les fonctions régaliennes et les fonctions économiques. Ce faisant, le PAD se distingue de l'approche en vigueur au complexe portuaire Tanger-Méditerranée où le législateur marocain a créé deux entités juridiques distinctes pour remplir, chacune, l'une des deux fonctions précitées ${ }^{396}$.

La précarité des concessions octroyées par le PAD influe, à n'en point douter, négativement sur le niveau d'investissement des opérateurs privés. En effet, comment inciter un opérateur privé à réaliser des investissements lourds s'il n'avait pas la certitude de jouir d'une présence pérenne sur la parcelle concédée afin de lui permettre aussi bien d'amortir ses investissements que de réaliser des marges bénéficiaires générées par ses activités sur la parcelle concédée. Le dilemme de la législation portuaire actuelle est mis en relief par Aminata Diop lorsqu'elle affirme : "comment concilier les intérêts privés avec l'intérêt général, tout en assurant l'efficacité de ses prestations, en tenant compte d'une nécessité de réactualisation de ses textes pour s'accommoder aux nouvelles lois du marché de la concurrence internationale $»^{397}$.

La nécessité de remédier aux implications négatives de la précarité des concessions domaniales portuaires a conduit le professeur Rézenthel à s'interroger : "la stabilité des activités industrielles ou commerciales peut-elle être compromise pour le seul motif qu'elles s'exercent sur le domaine public? Ou encore peut-on priver de manière discrétionnaire les occupants de ce domaine du bénéfice de la valeur ajoutée créée par l'exploitation de leur activité ? ${ }^{398}$.

En filigrane, l'interrogation de Rézenthel ci-dessus tente de mettre en évidence les conséquences sociales de la précarité de l'occupation du domaine public, à savoir le sort des salariés en cas de retrait de l'autorisation domaniale accordée à leur employeur ${ }^{399}$. Pour sa part, Khalifa Ababacar Kane déplore l'inadaptation du régime d'occupation du domaine

395 Loi n87-28 du 18 août 1987 autorisant la création de la Société nationale du Port autonome de Dakar, JOS, 12 septembre 1987.

396 Loi $\mathrm{n}^{\circ}$ 15-02 relative aux ports et portant création de l'Agence nationale des ports et de la Société d'exploitation des ports, Bulletin officiel, n5378, 13 kaada 1426 (15-12-2005), pp. 846-855. Cette loi, en son préambule, crée l'Agence nationale des ports et la Société d'exploitation des ports. La première l'Agence - est chargée principalement des missions d'autorité. La seconde - la Société - est chargée, concurremment avec des opérateurs et des exploitants portuaires, des missions à caractère commercial. En conséquence, il a été procédé à la dissolution de l'Office d'exploitation des ports, dont les missions d'autorité ont été dévolues à l'Agence nationale des ports et les activités commerciales à la Société d'exploitation des ports.

397 DIOP Aminata, Les problèmes juridiques liés à l'exploitation du port autonome de Dakar, Mémoire, Maîtrise droit des affaires, Université Cheick Anta Diop, Dakar, 2006, p. 7. Cité par ABA SÉKA Clément, op. cit., $\mathrm{n}^{\circ} 815$, p. 433.

398 RÉZENTHEL Robert, «Vers une meilleure protection contre la précarité de l'occupation du domaine public », Actualité juridique, vol. 57, n¹2, 2001, p. 1031.

399 KANE Khalifa Ababacar, Le droit portuaire en Afrique. Aspects juridiques de la gestion et de l'exploitation portuaires au Sénégal, Paris, L'Harmattan, 2012, p. 90. 
portuaire (à titre précaire et révocable) eu égard à l'accroissement des concessionnaires et au souci de stabilisation de leurs droits ${ }^{400}$.

La précarité et la révocabilité des occupations domaniales inclinent à penser qu'elles ne sont pas adaptées pour régir, en totalité, les activités de l'opérateur Dubai Port World (D.P.W.). En effet, si l'on s'en tient la législation sénégalaise qui s'appliquait à la conclusion du contrat liant le PAD au DPW, il apparaît que ce contrat est une simple concession domaniale $^{401}$. Au regard de l'article 5 des statuts du PAD approuvés par le décret du 19 septembre 1987, "le Port autonome de Dakar pourra procéder à la concession ou à la location des parcelles du domaine mis à sa disposition par l'État ». La loi du 22 décembre $1992^{402}$ dispose en son article premier : "le Port autonome de Dakar peut par convention portant cahier des charges consentir sur le domaine public qui lui est transféré par l'État des autorisations d'occupation d'une durée au plus égale à 25 ans».

On remarquera que ni la loi du 18 août 1987 ni le décret du 19 décembre $1987^{403}$ n'ont prévu les concessions portuaires de type Build-Operate-Transfer (BOT). La concession portuaire liant le PAD à D.P.W. ne pouvait, au moment de sa conclusion, trouver de fondement juridique en dehors des textes juridiques susmentionnés. Aussi, incline-t-on à penser que ladite concession est un montage concessif de type classique.

Le raisonnement ci-dessus pourrait s'appliquer valablement aux concessions domaniales conclues par le Port autonome d'Abidjan avec les opérateurs privés de la plateforme portuaire. Cependant, on note une évolution du régime des contrats administratifs en Côte d'Ivoire. En effet, le décret du 19 décembre $2012^{404}$, en son article premier, institue la catégorie juridique des contrats administratifs avec l'adoption des montages concessifs tels que le contrat de conception, construction, financement, exploitation ${ }^{405}$; et le contrat de construction, exploitation, transfert ${ }^{406}$.

L'analyse de la convention de concession pour la gestion et l'exploitation du terminal à conteneurs de Vridi permettra de cerner les retombées économiques de ce type de concession.

\section{Paragraphe 2 : Les concessions domaniales à objet complexe, un vecteur de développement économique}

La convention de concession pour la gestion et l'exploitation du terminal à conteneurs de Vridi $^{407}$, dans l'ensemble, obéit aux règles juridiques s'appliquant aux contrats administratifs. Ainsi, le PAA, gestionnaire du domaine public portuaire, jouit des prérogatives de puissance publique reconnues à toute Administration contractante, à savoir pouvoir de direction et de contrôle, pouvoir de résiliation unilatérale, pouvoir de modification unilatérale et pouvoir de sanction. Cependant, les différends concernant l'interprétation, l'exécution ou la validité de la convention de concession se règle d'abord à l'amiable. À défaut d'entente à l'issue de la

Idem, p. 202. Voir surtout les pages 86 à 104 traitant de la précarité des occupations domaniales.

ABA Séka Clément, op. cit., n815, p. 436.

Loi $\mathrm{n}^{\circ}$ 92-63 du 22 décembre 1992 modifiant l'article 3 de la loi du 18 août 1987 autorisant la création de la Société nationale du Port autonome de Dakar, JOS, 30 janvier 1993.

Décret du 19 décembre 1987 portant statuts du Port autonome de Dakar, JOS, 19 mars 1988.

Décret n²012-1152 du 19 décembre 2012 relatif aux contrats de partenariats public-privé.

En anglais, Design, Build, Finance, Operate (DBFO).

En anglais, Build, Operate, Transfer (BOT).

Il importe de noter que Vridi est la portion du domaine public portuaire où se trouve le premier terminal à conteneur. Vridi est aussi l'appellation d'un quartier de la commune de Port-Bouët. Cette dernière et Treichville sont les deux communes (du District autonome d'Abidjan) dont les territoires accueillent le Port autonome d'Abidjan. 
procédure amiable, la compétence revient à la Cour commune de justice et d'arbitrage (CCJA). Le droit applicable est l'Acte uniforme OHADA relatif au droit de l'arbitrage.

Au-delà de ces considérations purement juridiques, la concession entre le PAA et la SETV se révèle être un investissement fructueux pour la Côte d'Ivoire. À la date du 31 décembre 2009, l'état des investissements (conformément à l'annexe $\mathrm{n}^{\circ} 8$ de la Convention de concession PAA-SETV) fait ressortir un montant de 7.467 milliards de francs CFA d'investissement en 2009. De 2004 à 2008, plus de 37 milliards de francs CFA ont été investis relativement au programme quinquennal d'investissement. Le nouveau programme quinquennal d'investissement d'un montant de 30.174 milliards de francs CFA porte sur la période 2009-2014.

Au regard des retombées financières intéressantes pour la Côte d'Ivoire, il apparaît que les conventions de concession telles que celle conclue entre le PAA et la SETV, permettent de renflouer substantiellement les caisses de l'État sans pour autant dessaisir ce dernier ou son mandataire (le PAA) de ses prérogatives de puissance. Il est vrai que pour une question d'équilibre du contrat, certaines clauses renvoient le contentieux de l'exécution de la concession à la compétence d'une juridiction extra-ivoirienne, en l'occurrence la CCJA, créée par le Traité instituant l'OHADA Cependant, cette option ne constitue pas une nouveauté en droit ivoirien. Dans le cadre du contentieux relatif à l'exécution des contrats d'État, la Côte d'Ivoire s'est vue attraire devant le CIRDI. En effet, la Côte d'Ivoire a eu, dans le passé, à conclure des contrats en matière d'investissement avec des sociétés commerciales dont le capital était entièrement ou majoritairement détenu par des non nationaux. Les litiges résultant de l'exécution de ces contrats d'État n'ont pas été tranchés par les juridictions ivoiriennes. Ils l'ont plutôt été par le Centre international de règlement des différends relatifs aux investissements (CIRDI) ${ }^{408}$, une émanation de la Banque mondiale, créé par la Convention de Washington du 18 mars $1965^{409}$.

La proposition relative au recours massif aux concessions portuaires à objet complexe, tout comme la proposition relative à la constitution d'un fonds de commerce sur le domaine portuaire, s'inscrit dans le cadre des propositions visant à adapter le statut juridique actuel du PAA à la vive concurrence interportuaire en Afrique de l'ouest et du centre. De manière concrète, recourir de plus en plus aux concessions portuaires à objet complexe vise à atténuer la propension des autorités portuaires à l'unilatéralisme. Ces concessions sont en réalité des contrats de partenariat public-privé conclus avec des entreprises transnationales. Ce sont donc des contrats transnationaux dont le contentieux, à bien des égards, échappent aux juridictions nationales pour être connu par le Centre international de règlement des différends relatifs aux investissements (CIRDI), une excroissance de la Banque mondiale. La qualité du cocontractant, une société transnationale, et l'application partielle du droit international au litige éventuel entre l'investisseur et l'État d'accueil de l'investissement aura pour conséquence d'atténuer les incidences très fầcheuses de l'unilatéralisme du gestionnaire du domaine public portuaire.

Le recours au partenariat public-privé, particulièrement le procédé Build-OperateTransfer (BOT), pourrait être accompagné, comme nous le verrons plus loin, de la restructuration du PAA en deux entités juridiques distinctes. À l'heure actuelle, la concession portuaire entre le PAA (mandataire de l'État) et la SETV (désormais appelée Abidjan Terminal) est un contrat de type BOT. D'un point de vue chronologique, cette concession

408 Adriano Gardella c. Côte d'Ivoire, Affaire CIRDI n ARB/74/1, Sentence du 29 août 1977 ; Compagnie Française pour le Développement des Fibres Textiles c. Côte d'Ivoire, Affaire CIRDI n ARB/97/8, Sentence du 4 avril 2000 ; Société Resort Company Invest Abidjan, Stanislas Citerici and Gérard Bot v. Republic of Côte d'Ivoire (ICSID Case NARB/16/11), $1^{\text {st }}$ August 2017, Decision on the Respondent's Preliminary. Objection to Jurisdiction.

409 Convention de Washington du 18 mars 1965 pour le règlement des différends relatifs aux investissements entre États et ressortissants d'autres États. 
prend fin, au plus tard, en 2029. À la fin de cette concession, il sera loisible à la République de Côte d'Ivoire de procéder à la refonte structurelle du PAA. Celle-ci vise l'amélioration des performances des deux entités juridiques devant se substituer au PAA. 


\section{CHAPITRE 2: LES AJUSTEMENTS STATUTAIRES POSSIBLES À LA NATURE JURIDIQUE DU PORT AUTONOME D'ABIDJAN}

Ces ajustements, dans l'ensemble, conduiront à la scission du PAA en deux entités juridiques distinctes. Le procédé de la scission permet de distinguer, d'une part, les fonctions de prescription, celles s'opérant au moyen d'actes administratifs unilatéraux, et, d'autre part, les fonctions de prestation manifestées par les missions de service public ${ }^{410}$. Les fonctions régaliennes pourraient s'exercer dans le cadre d'un établissement public national ou d'une société d'État (Section 1), tandis que les missions de prestation seraient menées dans le cadre d'une société d'économie mixte, appelée, en droit ivoirien, société à participation financière publique. Celle-ci sera chargée d'exploiter l'outillage et les portiques du PAA (Section 2).

\section{SECTION 1 : La dévolution des activités de réglementation à un établissement public national ou une société d'État}

Cette première option commande que l'on en présente le contenu (paragraphe 1) avant de suggérer la forme qui paraît, selon nous, la plus adaptée (paragraphe 2).

\section{Paragraphe 1 : Présentation des deux choix possibles}

Le premier choix consisterait en la création d'un établissement public national (E.P.N.) chargé de gérer le domaine public portuaire. Il est clair que la mission assignée à l'E.P.N. ne sera nullement de "produire, acheter et/ou vendre » mais plutôt de définir des règles juridiques qui, d'une part, viseront la conservation de la consistance du domaine public portuaire et, d'autre part, définiront le statut des occupants privatifs du domaine public portuaire. Sous ces deux aspects, la mission assignée à l'E.P.N. relèverait de la réglementation ou de la prescription. Il est évident qu'un établissement public administratif sera l'option la plus adaptée en la matière (A). Le second choix pourrait consister en la création d'une société d'État chargée des mêmes attributions (B).

410 Cette approche dualiste n'est pas une utopie. Elle est d'ailleurs expérimentée au Maroc au moyen de la loi $\mathrm{n}^{\circ}$ 15-02 relative aux ports et portant création de l'Agence nationale des ports et de la Société d'exploitation des ports, Bulletin officiel, n5378, 13 kaada 1426 (15-12-2005), pp. 846-855. Cette loi, en son préambule, crée l'Agence nationale des ports et la Société d'exploitation des ports. La première l'Agence - est chargée principalement des missions d'autorité. La seconde - la Société - est chargée, concurremment avec des opérateurs et des exploitants portuaires, des missions à caractère commercial. En conséquence, il a été procédé à la dissolution de l'Office d'exploitation des ports, dont les missions d'autorité ont été dévolues à l'Agence nationale des ports et les activités commerciales à la Société d'exploitation des ports. 


\section{A. Un établissement public national chargé de la gestion du domaine public portuaire...}

Un établissement public est un service public doté de la personnalité morale ${ }^{411}$. L'article premier de la loi du 2 juillet $1998^{412}$ définit l'établissement public national comme une "personne morale de droit public créée par l'État, disposant de l'autonomie financière, dont l'objet exclusif et spécialisé est de remplir une mission de service public, en suivant les règles adaptées à sa mission, et comportant des contraintes et des prérogatives de droit public ».

$\mathrm{Au}$ regard de cette définition, l'établissement public (national) se distingue de l'établissement d'utilité publique. Le premier, ainsi que le précise l'article premier de loi précitée du 2 juillet 1998, est une personne morale de droit public. Le second, même s'il a été créé dans un but d'intérêt général et d'utilité publique, est néanmoins un établissement privé. Par conséquent, il n'a pas le caractère d'établissement public, et est régi par le droit privé ${ }^{413}$.

L'établissement public échappe aux règles des services en régie. La propension de l'Administration étatique (française) à recourir immodérément à la formule "établissement public » a été critiquée par le Conseil d'État français. Selon la haute juridiction, "la création de la plupart des établissements publics nouveaux»s'explique par le fait qu'elle "apparaît comme le moyen d'échapper ou de déroger à certaines règles des services en régie jugées trop rigides, trop contraignantes ou simplement gênantes, que ce soit en fait de fonction publique, de budget, de comptabilité, de passation de marchés, de gestion du domaine, etc. $»^{414}$. La position du Conseil d'État se justifiait au regard de la création de certains établissements publics (administratifs) qui, visiblement, ne reposait pas sur des motifs sérieux. Aussi, leur existence fut-elle de courte durée ${ }^{415}$.

Nous sommes d'avis que ces critiques, pour justifiées qu'elles soient, ne sauraient s'appliquer à l'établissement public national qui viendrait à être créé aux fins d'aménager et entretenir les ouvrages portuaires, d'une part, et réglementer les utilisations privatives du domaine public portuaire, d'autre part. D'ailleurs, l'État a déjà confié ces deux attributions au PAA. À ces deux attributions s'ajouterait, entre autres, la réalisation des travaux de construction, d'extension, d'amélioration, de renouvellement, de reconstruction et de dragage

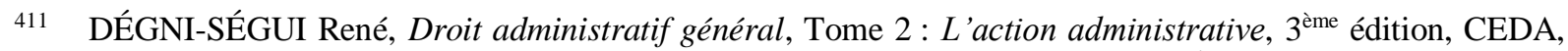

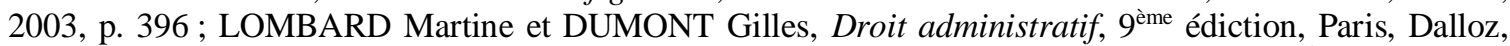
2011, n³54, p. 202 ; TIEBLEY Yves Didier, Droit administratif général, 5 ème édition, Éditions ABC, 2017, pp. 87-88.

412 Loi ${ }^{\circ} 98-388$ du 2 juillet 1998 fixant les règles générales relatives aux établissements publics nationaux et portant création de catégories d'établissements publics et abrogeant la loi n80-1080 du 13 septembre 1980.

413 Sur la distinction entre établissement public et établissement d'utilité publique, le lecteur pourra se référer à un arrêt de la Cour de cassation française rendue en 1856. La Cour de cassation s'était trouvée dans la nécessité de répondre à la question de savoir si les caisses d'épargne peuvent faire l'objet des voies d'exécution du droit commun, c'est-à-dire si des saisies peuvent être pratiquées à leur encontre au profit de leurs créanciers impayés. La réponse, qui dépend de la nature juridique de ces caisses (les voies d'exécution étant exclues à l'égard des personnes publiques), est dans le sens de leur caractère privé. "Les caisses d'épargne, créées dans un but d'intérêt général et d'utilité publique, sont néanmoins des établissements privés »; elles n'ont pas «le caractère d'établissements publics » (Cass. civ. 5 mars 1856, D. 1856.1.121; S. 1856.1.517).

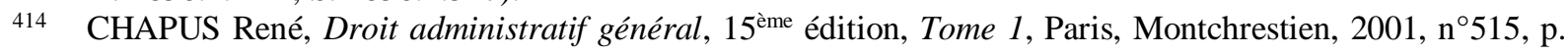
376.

415 Ex. le Service des examens des permis de conduire, créé par la loi des finances du 21 décembre 1967 (article 89) et supprimé par la loi des finances du 29 décembre 1982 (article 100); le Fonds spécial des grands travaux, créé par la loi du 3 août 1982 et supprimé par la loi de finances du 30 décembre 1987 (article 104). 
du domaine public portuaire. Toutes ces attributions relèvent d'une mission de service public administratif que remplit déjà le PAA, sur le fondement de l'article 4 de ses Statuts ${ }^{416}$.

À défaut de privilégier l'option en faveur de l'établissement public, l'État pourrait envisager celle de la société d'État.

\section{B. $\quad . . . O u$ une société d'État ${ }^{417}$ chargée de la gestion du domaine public portuaire?}

L'option en faveur de la société d'État, une société commerciale par sa forme, s'expliquerait par sa soumission à un régime de droit privé et la possibilité d'ouvrir son capital à d'autres sujets de droit public ivoiriens ${ }^{418}$.

Le régime de droit privé lui conférerait les avantages inhérents aux sociétés de type commercial que sont, entre autres, la flexibilité résultant de l'application du Code du travail au lieu de la rigidité du Statut général de la Fonction publique, le recours aux règles relativement malléables s'appliquant à l'exécution de la dépense, les relations de droit privé la liant aux personnes tierces à la société d'État.

Le second avantage de la société d'État serait que l'effort financier nécessaire à la constitution du capital serait réparti entre plusieurs actionnaires. Il appartiendrait donc à l'État ivoirien qui, vraisemblablement, sera l'actionnaire principal voire exclusif de la société qui reprendrait, à son compte, la mission de service public administratif actuellement dévolue au PAA, d'ouvrir ou d'augmenter son capital en incluant les entités infra-étatiques ivoiriennes régies par le droit public. Ce dernier point imprimerait une orientation nouvelle aux activités des collectivités territoriales et les établissements publics nationaux : à leurs attributions purement administratives se grefferont celles découlant de la création de richesses par des activités de type commercial.

Ces deux présentations n'occultent pas le fait que l'établissement public administratif paraît, à nos yeux, la forme la plus appropriée par laquelle la nouvelle entité juridique exercerait efficacement ses attributions relevant d'une mission de service public administratif.

\section{Paragraphe 2 : L'établissement public administratif, la forme juridique appropriée?}

Le choix de l'établissement public administratif pourrait se justifier au regard des sujétions de puissance publique (A) et des prérogatives de puissance publique (B) qui s'appliquent à ce type de collectivité publique.

\section{A. Les sujétions de puissance publique}

Une sujétion de puissance publique pourrait s'appréhender comme une obligation à laquelle est astreinte l'Administration lorsqu'elle exerce ses activités en vue de satisfaire l'intérêt général. Parmi les nombreuses sujétions de puissance auxquelles est soumise

416 Ces attributions découlent de l'article 4 des Statuts du PAA tels qu'annexés au décret n²001-143 du 14 mars 2001 portant approbation des Statuts du Port autonome d'Abidjan (PAA) et reclassification des immobilisations concédées.

417 Les caractéristiques essentielles de la société d'État ayant été traitée en amont, nous nous garderons d'y revenir en détail. Cet ajustement a vu la transformation de l'établissement public d'alors en société d'État.

418 La société d'État se singularise par le fait que son capital est constitué uniquement des actions des personnes morales de droit public ivoirien en vertu de l'article 2 de la loi n97-519 du 4 septembre 1997 portant définition et organisation des sociétés d'État. 
l'Administration, figurent le principe de spécialité, et le respect des règles de la comptabilité publique.

Par application du principe de spécialité, la personnalité morale d'un établissement public ne lui est conférée que dans le but de réaliser la mission qui lui est attribuée ${ }^{419}$. Ainsi, le Conseil d'État considère que les caisses des écoles ayant pour mission de faciliter la fréquentation des seules écoles publiques, elles ne peuvent s'employer à faciliter aussi celle des écoles privées ${ }^{420}$. De même, un bureau de bienfaisance devait se cantonner dans la spécialité qu'indique sa dénomination, il ne pouvait pas prendre en charge l'exploitation d'une salle de cinéma municipale ${ }^{421}$. Si une chambre d'agriculture peut créer ou subventionner tous établissements d'intérêt agricole, elle ne peut, sans méconnaître "la spécialisation de ses attributions », assurer (comme maître d'œuvre) la construction d'un «foyer de jeunes ${ }^{422}$. Une conséquence du principe de spécialité est qu'un établissement public ne peut pas accepter un legs grevé de charge si le respect de la charge devait conduire l'établissement public à sortir de sa spécialité ${ }^{423}$.

Le principe de spécialité gouverne l'activité de toute personne morale, publique ou privée, à l'exception nécessaire de l'État ${ }^{424}$. Ainsi, en vertu de l'article $3 \S 2$ de la loi du 2 juillet $1998^{425}$, l'établissement public national qui viendrait à reprendre les activités de service public administratif actuellement dévolues au PAA, ne pourra accomplir "aucun acte étranger à son objet, obligatoirement limité à la réalisation de la mission de service public qui lui est confié par le décret en portant création». L'établissement public national, conformément au principe de spécialité, ne saurait méconnaître ses missions sans être rappelé à l'ordre par ses autorités de tutelle ${ }^{426}$.

Le respect des règles de la comptabilité publique s'imposerait à l'établissement public national. Celui-ci sera tenu non seulement de veiller aux règles de la comptabilité publique (article 5) mais aussi de se soumettre aux procédures de passation des marchés publics prévues par le Code des marchés publics et les textes subséquents pris pour son application (article 26) ainsi qu'au contrôle de la Cour des comptes (article 34).

Ces sujétions de puissance publique se combinent avec des prérogatives de puissance publique au moyen desquelles, les autorités étatiques espèrent atteindre la réalisation des missions de service public assignées à l'établissement public national.

LOMBARD Martine et DUMONT Gilles, Droit administratif, 9ème édition, Paris, Dalloz, 2011, $\mathrm{n}^{\circ} 366$, p.

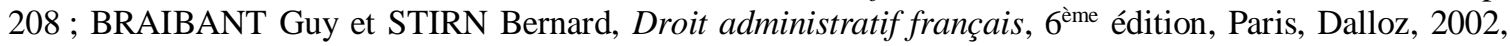

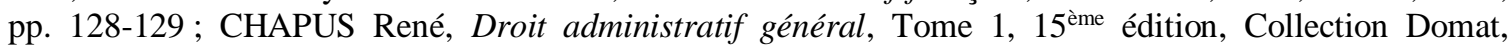
Montchrestien, 2001, n518, p. 377 ; De VILLIER Michel et De BERRANGER Thibaut (dir.), Droit public général (Institutions politiques, administratives et européennes. Droit administratif, finances publiques et

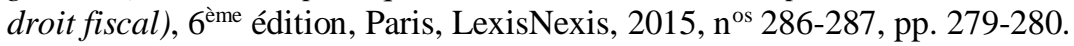

420 CE 22 mai 1906, Caisse des écoles du $6^{\text {ème }}$ arrondissement de Paris, S 1905.3.33, $1^{\text {ère }}$ espèce, note Hauriou.

421 CE 13 décembre 1939, Séguinaud, Rec. p. 388.

422 CE 28 septembre 1984, Conseil régional de l'ordre des architectes de Bourgogne, Rec. p. 309.

423 CE 10 août 1917, Commune de Vivonne, Rec. p. 634 : À propos d'un legs fait à un bureau de bienfaisance, sous la condition qu'il serve à des fins d'enseignement.

424 CE 29 avril 1970, Société Unipain, Rec. p. 280.

425 Loi n $98-388$ du 2 juillet 1998 fixant les règles générales relatives aux établissements publics nationaux et portant création de catégories d'établissements publics et abrogeant la loi n80-1080 du 13 septembre 1980.

426 Sur le fondement de l'article 6 de la loi du 2 juillet 1998, deux autorités de tutelle sont investies de ce pouvoir de tutelle. Ce sont le ministre en charge de l'économie et des finances, d'une part, et le ministre dont relève l'activité principale de l'EPN, d'autre part. Cette deuxième autorité est vraisemblablement le ministre en charge des infrastructures économiques. 


\section{B. Les prérogatives de puissance publique}

On appréhende par la notion de prérogatives de puissance publique les moyens juridiques de l'activité administrative qui se singularisent par leur unilatéralité et leur caractère décisoire à l'égard de leurs destinataires. Les prérogatives de puissance se répartissent entre prérogatives d'action ${ }^{427}$ et les prérogatives de protection. Dans cette deuxième catégorie, sont rangés deux principes que sont :

- L'intangibilité de l'ouvrage public ;

- L’insaisissabilité des biens de l'établissement public.

L'intangibilité de l'ouvrage public résulte d'un vieil adage selon lequel «les ouvrages publics mal plantés ne se détruisent pas ». L'ouvrage qui a été construit sur un terrain privé, sans l'autorisation du propriétaire et sans qu'aucune procédure préalable d'expropriation ait joué, donc irrégulièrement, ne sera pas détruit ; il sera maintenu en raison de son utilité publique, de telle sorte que le dommage subi par le propriétaire sera simplement réparé par une indemnité ${ }^{428}$. En droit ivoirien, le principe de l'intangibilité de l'ouvrage public, en ce qui concerne les établissements publics nationaux, trouve son fondement juridique dans l'article 27 de la loi précitée du 2 juillet 1998. Ainsi, les travaux immobiliers exécutés par l'établissement public ou pour son compte, auront le caractère de travaux publics dès lors qu'ils sont entrepris dans un but d'intérêt général ${ }^{429}$. Les ouvrages résultant de ces travaux seront des ouvrages publics ${ }^{430}$. À ce titre, ils bénéficieront du principe de l'intangibilité de l'ouvrage public. Il en résulte que le juge ne pourra valablement pas ordonner la destruction d'un ouvrage bâti par ou pour le compte de l'établissement public dès lors que ledit ouvrage est affecté à l'intérêt général.

L'insaisissabilité des biens de l'établissement public découle de l'article 28 de la loi du 2 juillet 1998. En vertu de cette disposition, "les établissements publics ne sont pas soumis aux voies d'exécution ». Cette disposition reconduit la solution adoptée par la jurisprudence administrative et civile française. Dans l'affaire Association du canal de Gignac, le Tribunal des conflits a affirmé sans ambages l'impossibilité d'exercer des voies de recours à l'encontre des établissements publics en considérant : "lesdites associations présentent les caractères essentiels, d'établissements publics, vis-à-vis desquels ne peuvent être suivies les voies d'exécution instituées par le code de procédure civile pour le recouvrement des créances sur les particuliers ${ }^{431}$. La Cour de cassation (française) a réitéré l'insaisissabilité des biens des établissements publics en visant "le principe général de droit suivant lequel les biens des

La particularité des prérogatives d'action permet à l'Administration d'agir alors que les prérogatives de protection lui permettent de se prémunir contre toute action extérieure venant d'une personne tierce. $C f$. CHAPUS René, Droit administratif général, op. cit., $\mathrm{n}^{\text {os }} 638$ à 642, pp. 470-475.

428 BRAIBANT Guy et STIRN Bernard, Droit administratif français, $6^{\text {ème }}$ édition, Paris, Dalloz, 2002, pp. 221-222.

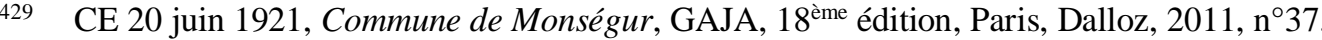

430 Un ouvrage public est un immeuble résultant d'un travail ou d'un aménagement et affecté à l'intérêt général. $C f$. MORAND-DEVILLER Jacqueline, Cours de droit administratif des biens, $3^{\text {ème }}$ édition, Paris, Montchrestien, 2003, p. 617. L'ouvrage public est aussi défini comme un bien immobilier affecté par une personne publique (ou par une personne privée agissant pour le compte d'une personne publique) à une fonction d'intérêt général, et soumis en raison de son affectation à un régime de droit public, quel qu'en soit le propriétaire. $C f$. De VILLIER Michel et De BERRANGER Thibaut (dir.), Droit public général (Institutions politiques, administratives et européennes. Droit administratif, finances publiques et droit fiscal), $6^{\text {ème }}$ édition, Paris, LexisNexis, 2015, nº1615, p. 1268.

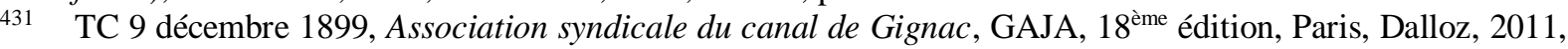
$n^{\circ} 7$. 
personnes publiques sont insaisissables », même lorsqu'elles exercent une activité industrielle et commerciale ${ }^{432}$.

\section{SECTION 2 : La gestion de l'outillage et des portiques par une société à participation financière publique majoritaire}

La société à participation financière publique (autrefois dénommée société d'économie mixte) jouit de certains avantages incontestables qui en font le sujet de droit approprié pour mener les activités à caractère industriel et commercial susceptibles de lui être dévolues (paragraphe 1). Ces activités consisteraient essentiellement en l'exploitation de l'outillage et des portiques nécessaires à l'embarquement et au débarquement des marchandises moyennant une redevance perçue sur les usagers. Cependant, certains écueils devraient être évités afin de ne pas dévoyer la mission conférée à la SPFP (paragraphe 2).

\section{Paragraphe 1 : Les avantages de la constitution d'une SPFP majoritaire}

L'une des caractéristiques de la SPFP (majoritaire) est d'être une société anonyme, commerciale par sa forme ${ }^{433}$. Son capital est constitué d'actions appartenant aussi bien à des personnes morales de droit public ivoirien ainsi qu'à des sujets de droit privé (ivoiriens ou non-ivoiriens). Cette dernière possibilité permettra un apport de capitaux frais de la part des actionnaires (ivoiriens ou non-ivoiriens) ayant la qualité de sujets de droit privé. Elle permet, de ce fait, de surmonter les difficultés financières qui tendent à plomber les actions entreprises par l'État ivoirien et ses démembrements.

En outre, la SPFP, de par sa forme commerciale, bénéficie de la flexibilité dans la gestion telle qu'observée au niveau des sociétés anonymes. Ce faisant, elle échappe aux pesanteurs inhérentes aux exigences de la comptabilité publique, particulièrement celles de la dépense publique.

Un autre avantage, non négligeable, est la possibilité de constituer un actionnariat de droit public, c'est-à-dire composé de sujets de droit public ivoiriens. Pour ce faire, il importe que l'État associe les collectivités territoriales et les établissements publics nationaux de la Côte d'Ivoire au capital de la SPFP majoritaire, qui sera chargée d'exploiter l'outillage et autres portiques utilisés sur le domaine public portuaire. Il est donc nécessaire que le législateur ivoirien permette aux sujets infra-étatiques de droit public, de recourir à la technique de la cession-bail ${ }^{434}$. Par ce moyen, ils pourront bénéficier des sommes (conséquentes) nécessaires à leur entrée au capital de la SPFP majoritaire. À terme, ces nouveaux actionnaires deviendront les propriétaires des actions précédemment détenues par la banque prêteuse.

Il est indéniable qu'eu égard au dynamisme du PAA et surtout des ressources financières (considérables) engrangées par le PAA, les collectivités territoriales et les E.P.N. verraient sensiblement s'accroître leurs ressources financières. D'ailleurs, rien n'interdirait que le

432 Cass. 22 décembre 1987, Bureau de recherches géologiques et minières, GAJA, 13 ème édition, Paris, Dalloz, 2001, n 100 .

433 En vertu de l'article 3 de la loi n97-520 du 4 septembre 1997 relatives aux sociétés à participation financière publique.

434 La cession-bail est une technique de crédit dans laquelle l'emprunteur, par une vente dont le prix représente le montant du prêt, transfère dès l'origine au prêteur la propriété d'un bien offert en garantie et conserve ce bien à titre de locataire, tout en le rachetant progressivement, en vertu d'une promesse unilatérale de vente jointe au bail qui accompagne la vente initiale. $C f$. CORNU Gérard (dir.), Vocabulaire juridique, op. cit., p. 160. 
nouvel EPN (chargée de la réglementation des activités sur le domaine public portuaire ainsi que de l'exploitation du domaine public portuaire) soit actionnaire de la SPFP majoritaire ainsi constituée.

Ainsi, au lieu d'être confinés à la perception des taxes et autres prélèvements locaux qui, d'ailleurs, ne suffisent pas à les rendre financièrement autonomes à l'égard de l'État - ce dernier étant souvent amené à les subventionner - les sujets de droit public infra-étatiques ajouteraient, à leurs attributions purement administratives, celles de businessman (selon la connotation anglo-saxonne du terme). L'option en faveur de la SPFP majoritaire pourrait, en pratique, débuter à l'expiration de la convention d'exploitation du terminal qui le lie le PAA à la Société d'exploitation du terminal de Vridi (SETV $)^{435}$.

Cette présentation peut paraitre alléchante. Cependant, il existe des écueils à éviter pour ne pas que l'esquisse ci-dessus ne se mue en esquive.

\section{Paragraphe 2 : Les écueils à éviter}

Le premier écueil à éviter serait que l'État ivoirien veille à ce que la SPFP majoritaire ne se mue en une SPFP minoritaire. Dans ce dernier cas, la majorité des capitaux serait détenue par des intérêts privés. Ces derniers ne seront pas forcément sensibles à la réalisation des missions d'intérêt général qui sont une des caractéristiques essentielles des entreprises publiques.

Le risque est donc grand d'assister à un dévoiement des missions de service public qui seraient assignées à la SPFP majoritaire. En outre, le risque (avéré, celui-là) est la réorientation des ressources financières (considérables) générées par les activités du Port vers des intérêts purement privés.

Il n'est nul besoin de relever la position très inconfortable qui serait celle de l'État ivoirien, qui serait dès lors confiné au rôle de percepteur d'impôt sur le bénéfice des sociétés, alors qu'il dispose pleinement de la latitude de créer véritablement de la richesse à partir de l'exploitation du Port.

Comme on le constate, la proposition traitée tout le long de ce dernier chapitre tend à procéder à une refonte statutaire du PAA. Celle-ci se traduira par la création de deux entités distinctes : un établissement public administratif chargé des fonctions de réglementation, d'une part, et une société d'économie mixte (appelée en Côte d'Ivoire société à participation financière publique), d'autre part. La majorité du capital de cette société d'économie mixte sera détenu par l'État ivoirien et les personnes morales de droit public ivoirien. Une telle société, on l'espère, pourra prendre en compte les intérêts aussi bien des personnes publiques ivoiriennes que des personnes privées impliquées dans la gestion du port d'Abidjan. Les premières pourront accroître significativement leurs revenus, les secondes pourront, en plus des revenus engrangés, être partie prenante à la gestion du port d'Abidjan avec pour corollaire, l'atténuation du modèle coercitif au profit du modèle participatif. Ce faisant, elle vise à surmonter les impasses résultant de la tendance des autorités portuaires à recourir systématiquement aux prérogatives de puissance publique décelables aussi bien dans les actes administratifs unilatéraux que dans les contrats administratifs.

435 Cette convention est prévue prendre fin, au plus tard, le $1^{\text {er }}$ mars 2029 si l'on inclut la prorogation maximum de 10 ans prévue à l'article $38 \S 2$ de la C.E.T. liant le PAA à la SETV. 


\section{CONCLUSION DE LA DEUXIÈME PARTIE}

Le statut juridique du PAA a connu une évolution dans le temps depuis la création dudit port en 1951. Initialement, ce statut juridique était exclusivement constitué d'actes unilatéraux émanant des autorités compétentes de la Côte d'Ivoire. Ceux-ci consistent en des actes administratifs (arrêté du gouverneur général de l'AOF, décrets pris en conseil des ministres) et en des lois stricto sensu adoptées par le parlement ivoirien. Relèvent également des normes juridiques régissant le PAA, certains arrêts rendus par la Chambre administrative de la Cour suprême dans des contentieux opposant le PAA à des personnes tierces.

L'intégration économique croissante des États de l'Afrique occidentale d'expression française aura une incidence sur la nature des normes juridiques applicables au PAA. Désormais, aux normes juridiques édictées par les autorités compétentes ivoiriennes viendront se greffer des normes communautaires générées dans le cadre de l'UEMOA et de l'OHADA. Cette dernière catégorie de normes revêt une diversité et se décline en directive, règlement, décision émanant des organes de l'UEMOA. À cette panoplie, s'ajoutent les Actes uniformes de l'OHADA, ainsi que la jurisprudence de la CCJA, l'organe juridictionnel de l'OHADA.

En dépit de ce statut juridique diversifié, le cadre juridique actuel de gestion du domaine public portuaire comporte des faiblesses préjudiciables à la mise en valeur dudit domaine. Les entraves résultent principalement de la précarité des occupations privatives du domaine public portuaire. Il importe d'en atténuer la rigueur pour inciter davantage la réalisation d'investissements privés plus consistants sur ledit domaine. Pour ce faire, l'institution des concessions domaniales à objet complexe s'avère nécessaire. Elles permettront d'ancrer juridiquement les montages concessifs du type Build-Operate-Transfer (BOT), plus adaptés à l'exploitation des terminaux à conteneurs.

La nécessité de lutter contre la forte emprise de l'État sur la gestion du port autonome d'Abidjan devrait conduire à explorer les moyens de surmonter les faiblesses structurelles qui obèrent les performances du port.

Cela pourrait être réalisé à travers, d'une part, la lutte contre la lourdeur des procédures administratives et, d'autre part, des réformes institutionnelles qui conduiraient, à terme, à la dissociation entre les fonctions de réglementation et les fonctions d'exploitation économique. Il s'avère donc nécessaire de créer deux entités juridiques chargées respectivement des missions de prescription (police administrative) et des missions de prestation (service public industriel et commercial). L'entité juridique chargée des missions de prescription pourrait revêtir la forme d'un établissement public national tandis que celle investie des missions de prestation - à savoir l'exploitation des portiques, grues et autres outillages - emprunterait la forme d'une société à participation financière publique (SPFP) majoritaire. Cette dernière option permettrait l'ouverture du capital de la SPFP à des intérêts privés désireux d'effectuer des investissements plus consistants afin de réaliser, à terme, des bénéfices plus consistants. 


\section{CONCLUSION GÉNÉRALE}

Les normes régissant le Port autonome d'Abidjan peuvent-elles permettre de hisser le Port autonome d'Abidjan au rang de port incontournable de la façade Atlantique de l'Afrique et, partant, de premier plan africain ?

Les transformations statutaires progressives du PAA visent indéniablement la réalisation de cet objectif. Elles ont été accompagnées de réorganisations structurelles, du management et de la gestion financière.

À l'heure actuelle, prévaut le statut de société d'État, un statut impliquant l'application du droit privé au port. Cependant, sa soumission aux règles de droit privé n'est pas absolue. En effet, si nominalement, le PAA est assimilée à une personne morale de droit privé, il est à souligner que matériellement il fonctionne comme une entité juridique de droit public. $\mathrm{Ce}$ constat s'explique au regard de diverses raisons. En premier lieu, le capital du PAA - une société d'État - est entièrement détenu par l'État ivoirien. Deuxièmement, la gestion du domaine portuaire, propriété de l'État, a été exclusivement confiée au PAA Celui-ci use, à cet effet, des prérogatives de puissance publique reconnue à l'Administration propriétaire ou gestionnaire du domaine public. La troisième raison, cette fois-ci d'ordre économique, tient à l'importance primordiale du PAA dans la génération des ressources financières alimentant les caisses de l'État ivoirien.

L'intégration économique des États de l'Afrique de l'ouest francophone a permis d'étoffer qualitativement et quantitativement le statut juridique du PAA Celui-ci se décline désormais en lois stricto sensu, ordonnances, règlements, jurisprudence (nationale et/ou communautaire) ainsi qu'en un large éventail d'actes unilatéraux émanant de l'UEMOA et de l'OHADA.

L'implication sans ambages du gouvernement ivoirien dans le repositionnement du PAA au premier plan ouest-africain manifeste éloquemment la place prépondérante du PAA dans l'économie ivoirienne. Pour tout dire, le PAA est pour l'État ivoirien une poule aux œufs d'or. Nécessairement, la perpétuation de la manne financière provenant des activités menées sur le domaine portuaire influence l'attitude du gouvernement ivoirien à l'égard du port. Il n'est donc pas surprenant que l'État se réserve la gestion exclusive du PAA en étant l'actionnaire unique du capital. En outre, il assure son emprise par des contrôles multiples et variés (contrôle administratif, financier et juridictionnel). La présence très marquée de l'État dans le fonctionnement du port se traduit, entre autres, par des réflexes de monopole influant à la hausse sur le coût du passage portuaire.

Quoi qu'il en soit, le cadre juridique actuel de gestion du domaine public portuaire comporte des faiblesses préjudiciables à la mise en valeur dudit domaine. L'application rigoureuse du principe de précarité des occupations privatives du domaine public portuaire pourrait dissuader les investisseurs privés de constituer des investissements lourds sur le domaine public portuaire. Il importe de ce fait d'atténuer la rigueur de la précarité des autorisations d'occupation temporaire (AOT) pour inciter davantage la réalisation d'investissements privés plus consistants sur ledit domaine. Pour ce faire, le recours aux nouveaux montages concessifs, notamment les concessions domaniales à objet complexe, s'avère nécessaire pour minimiser fortement la vétusté et l'inadaptation du droit domanial ivoirien aux nouveaux défis suscités par une concurrence interportuaire très vive, particulièrement dans le Golfe de Guinée.

La nécessité de surmonter les faiblesses structurelles qui obèrent les performances du port pourrait également être réalisée à travers, d'une part, la lutte contre la lourdeur des procédures administratives et, d'autre part, des réformes institutionnelles qui conduiraient, à terme, à la dissociation, d'ailleurs en vigueur au Maroc, entre les fonctions de réglementation et les fonctions d'exploitation économique. 
La réalisation de cette deuxième proposition nécessiterait la création de deux entités juridiques chargées respectivement des missions de prescription (police administrative) et des missions de prestation (service public industriel et commercial). L'entité juridique chargée des missions de prescription pourrait revêtir la forme d'un établissement public administratif tandis que celle investie des missions de prestation - à savoir l'exploitation des portiques, grues et autres outillages - emprunterait la forme d'une société à participation financière publique (SPFP) majoritaire. Cette dernière option permettrait l'ouverture du capital de la SPFP à des collectivités décentralisées ivoiriennes ainsi qu'à des intérêts privés désireux d'effectuer des investissements plus consistants afin de réaliser, à terme, des bénéfices plus consistants.

La mise en œuvre des propositions ci-dessus contribuerait, on l'espère, à réaliser l'objectif ambitieux de premier port d'Afrique que visent les autorités ivoiriennes. 


\section{Bibliographie}

\section{OUVRAGES GÉNÉRAUX}

- BOUVIER Philippe, Éléments de droit administratif, Bruxelles, De Boeck, 2002.

- BRAIBANT Guy et STIRN Bernard, Le droit administratif français, $6^{\text {ème }}$ édition, Paris, Presses de Sciences po et Dalloz, 2002.

- CHAPUS René, Droit administratif général, $15^{\text {ème }}$ édition, Collection Domat, Montchrestien, 2001.

- COLSON Jean-Philippe et IDOUX Pascale, Droit public économique, $4^{\text {ème }}$ édition, LGDJ, 2008.

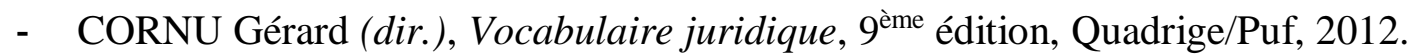

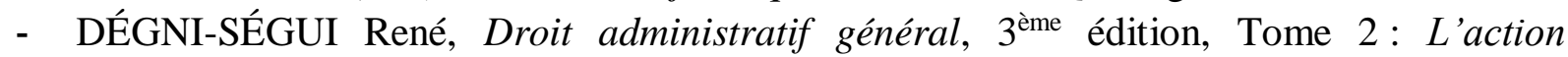
administrative, CEDA, 2002.

- De JUGLART Michel, Cours de droit civil (Avec plans de devoirs et études de questions

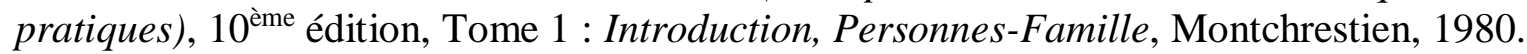

- De VILLIERS Michel et De BERRANGER Thibaut (dir.), Droit public général: Institutions politiques, administratives et européennes, Droit administratif, Finances

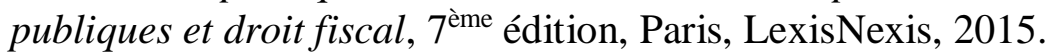

- GILLET-LORENZI Emmanuelle et TRAORÉ Seydou, Droit administratif des biens, 1 ère édition, Édition du CNFPT, 2007.

- GUILLIEN Raymond et VINCENT Jean (dir.), Lexique des termes juridiques, $12^{\text {ème }}$ édition, Dalloz, 1999.

- HAURIOU Maurice, Précis de droit administratif, contenant le droit public et le droit administratif, $2^{\text {ème }}$ édition, Paris, Éditions Larose \& Forcel, 1893.

- ISSA-SAYEGH Joseph, Répertoire OHADA 2000-2005 : Jurisprudence et bibliographie, UNIDA, p. 62. Accessible en ligne sur: http://www.tribunalcommerceniamey.org/images/REPERTOIRE_OHADA_2000-2005.pdf. Document consulté le 19 mai 2017.

- LOMBARD Martine et DUMONT Gilles, Droit administratif, $9^{\text {ème }}$ édition, Paris, Dalloz, 2011.

- MELEDJE Djedjro Francisco, Les grands arrêts de la jurisprudence constitutionnelle ivoirienne, GIZ/CNDJ, 2012.

- MORAND-DEVILLER Jacqueline, Cours de droit administratif des biens, $3^{\text {ème }}$ édition, Paris, Montchrestien, 2003.

- VEDEL George et DELVOLVÉ Pierre, Droit administratif, Thémis, PUF, 1992.

- WEIL Prosper et POUYAUD Dominique, Le droit administratif, 17 $7^{\text {ème }}$ édition, Paris, Coll. «Que sais-je? », 1997.

\section{OUVRAGES SPÉCIALISÉS}

- ABA Séka Clément, Contribution à l'étude juridique des concessions juridiques, Collection « Affaires Maritimes et Transports », L'Harmattan, 2015.

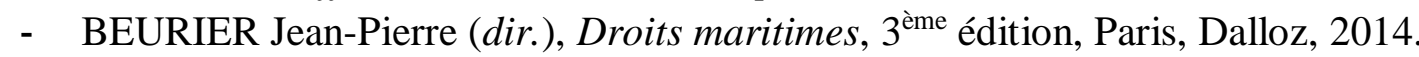

- BORDEREAUX Laurent et BRAUD Xavier, Droit du littoral, Paris, Coll. Master Pro, Gualino, 2009. 
- De CET BERTIN (Cécile), Introduction au droit maritime, Paris, Ellipses, 2008.

- DURAND René-Jean, DUFOUR Philippe, GUIRAL Daniel et ZABI Soko Guillaume François (dir.), Environnement et ressources aquatiques en Côte d'Ivoire : Les milieux lagunaires, Éditions de l'ORSTOM, 1994.

- KANÉ Khalifa Ababacar, Droit portuaire en Afrique : Aspects juridiques de la gestion et de l'exploitation portuaires au Sénégal, Paris, Collection Études africaines, L'Harmattan, 2012.

- SEMI Bi Zan, La politique coloniale des travaux publics en Côte d'Ivoire (1900-1940), Annales de l'Université d'Abidjan, Série 1, Tome 2, 1973-1974.

\section{THÈSES ET MÉMOIRES}

A. THÈSE

- BOUKARI Salifou, L'application des textes de l'OHADA aux entreprises publiques: l'exemple de l'AUSC et GIE, Thèse unique, Droit privé, 2015, Université de Maastricht/Université de Lomé, 360 p.

- LIHOUSSOU Messan, Port et désenclavement territorial : cas de l'arrière-pays du port de Cotonou, Thèse de Géographie, Spécialité : Transport et logistique, Université du Havre, 07 juillet 2014, 461 p.

- SEMI Bi Zan, Équipement public et changements socio-économiques en Côte d'Ivoire (1930-1957), $4^{\text {ème }}$ partie: Conséquences de la mise en place de l'équipement public, Atelier national de reproduction des thèses, Université de Lille, 1986.

B. MÉMOIRES

- ROSGOVAS Julien, L'utilisation du domaine public portuaire, Mémoire, Master 2 Droit maritime et des transports, Université Paul Cézanne, Aix Marseille 3, 2005.

\section{COURS}

- BEIRA Ehi Marc, Droit commercial général. Droit des sociétés commerciales, $12^{\text {ème }}$ édition, Abidjan, Éditions ABC, 2014.

- KOBO Pierre-Claver, Droit administratif des biens: Le domaine des personnes publiques, l'expropriation, Abidjan, Éditions ABC, 2004.

- MAMBO Paterne, Cours de droit administratif des biens, inédit, Abidjan, 2018-2019.

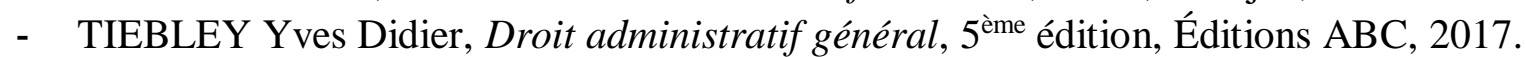

\section{ARTICLES DE DOCTRINE}

- ALIX Yann, «Afrique de l'ouest : les ports ne seront pas tous des hubs », Journal de la Marine Marchande, $\mathrm{n}^{\circ} 4878$, vendredi 7 juin 2013, pp. 12-14.

- CHEVALLIER François, «Les entreprises publiques en France», Notes et études documentaires, $\mathrm{n}^{\text {os }} 4507-4508,9$ mars 1979, pp. 7-101. 
- DJÈ Bi DJÈ Christiane, «La réorganisation du secteur public en Côte d'Ivoire : La réforme du 13 septembre $1980 », R I D$ 1986, nos 1-2, pp. 13-90.

- DURAND René-Jean et ZABI Soko Guillaume François, «Repères historiques », in DURAND René-Jean, DUFOUR Philippe, GUIRAL Daniel et ZABI Soko Guillaume François (dir.), Environnement et ressources aquatiques en Côte d'Ivoire : Les milieux lagunaires, Éditions de l'ORSTOM, 1994, pp. 25-34.

- ERKUT Celâl, «L'identification de l'acte administratif selon la recevabilité d'un recours pour excès de pouvoir », Journal of Istanbul University Law Faculty, Vol. 53, n ${ }^{\text {os } 1-4, ~ p p . ~}$ 101-137.

- FERMANEL de WINTER Anne-Sophie, «Universalité de fait et universalité de droit (Première partie) », Revue juridique de l'Ouest, 2008, n, pp. 409-455.

- FERMANEL de WINTER Anne-Sophie, «Universalité de fait et universalité de droit (Deuxième partie) », Revue juridique de l'Ouest, 2009, n¹, pp. 5-34.

- GALLAIS BOUCHET Anne, «L'économie maritime en France, un service portuaire garant de la sécurité », Note de synthèse $\mathrm{n}^{\circ} 166$, ISEMAR, juin 2014, pp. 1-4.

- FAYAT Muriel, «La création d'un fonds de commerce sur le domaine public est désormais possible », Paroles d'experts, mai 2016, pp. 8-9.

- HANSEN Philippe S., "L'exploitation d'un fonds de commerce sur le domaine public », JCP/La Semaine juridique- Éditions Administrations et collectivités territoriales, $\mathrm{n}^{\circ} 36,8$ septembre 2014, pp. 1-4.

- HUBERLANT Charles et DELPÉRÉE Francis, « Les personnes de droit public bénéficiaires de l'immunité d'exécution », in Colloque sur Les immunités des États en droit international, 31 janvier et $1^{\text {er }}$ février 1969, Bruxelles.

- KODO Mahutodji Jimmy Vital, «Évolution de la jurisprudence de la Cour Commune de Justice et d'Arbitrage de l'OHADA en matière d'immunité d'exécution », Document accessible en ligne sur www.ohada.com>imprimer actualités.

- LACHAUME Jean-François, «Brèves remarques sur les services publics à double visage », RFDA, 2003, pp. 362 et ss.

- MEYER Gilbert, «L'insertion des ports africains dans les flux mondiaux : atouts et faiblesses », Secteur privé et Développement, $\mathrm{n}^{\circ} 26$, mars-avril-mai 2017, pp. 22-24.

- NAM-TCHOUGLI Guy, «L'immunité d'exécution ou de saisie des entreprises publiques dans l'espace OHADA », Revue Africaine de Droit, d'Économie et de Développement, volume $1, \mathrm{n}^{\circ} 6,2005$, pp. 574-582.

- NDJAMBOU Léandre Edgard, «Échanges maritimes et enclavement en Afrique de l'ouest : le cas des ports d'Abidjan et de Cotonou », Les Cahiers d'Outre-mer, nos 226 227, avril-septembre 2004, pp. 1-18. Article accessible en ligne sur: http://www.com.revues.org/555. Document consulté le 23 février 2016.

- ROTHÉ P.L., «Influence de l'ouverture du port d'Abidjan sur le commerce extérieur des bois de la Côte d'Ivoire », Revue Bois et Forêts des tropiques, $2^{\mathrm{e}}$ et $3^{\mathrm{e}}$ trimestres, 1951, pp. 151-156. Ce document est accessible en ligne sur: www.bft.cirad.fr/cd/BFT_018_151-156.pdf. Document consulté le 27 mai 2016.

- SIDIBÉ Sogona, «Côte d'Ivoire : Port Autonome d'Abidjan - Une croissance de 3\% du trafic global enregistrée », article accessible en ligne sur : http://www.fr.allafrica.com/stories/201601110748.html Document consulté le 27 mai 2016.

- RÉZENTHEL Robert, «Vers une meilleure protection contre la précarité de l'occupation du domaine public », Actualité juridique, vol. 57, n¹2, 2001, pp. 1025-1033.

- TOURÉ Ousmane et RÉZENTHEL Robert, «L'avenir des concessions portuaires en Afrique de l'Ouest et du Centre », Neptunus, e.revue, Université de Nantes, vol. 22, 
2016/3, p. 5. Article accessible en ligne sur: https://cdmo.univ-nantes.fr/medias/fichier/renzenthle_1478006882478.pdf?ID. Document consulté le 30 juillet 2019.

\section{DOCUMENTS DIVERS}

- $\quad$ AGGRÉ Albert, Codes et lois usuelles de Côte d'Ivoire, Tome VI, 1985.

- Anonyme, «Ce qu'est le groupe Bolloré en Afrique ». Article accessible en ligne sur : http://afrique.lepoint.fr/economie/ce-qu-est-le-groupe-bollore-en-afrique-24-04-20182213227_2258.php. Document consulté le dimanche 10 février 2019.

- Anonyme, «Côte d'Ivoire: corruption et favoritisme demeurent sous Ouattara», AEUD.INFO : L'action prend corps, p. 4. Article accessible en ligne sur: aeud.fr/IMG/article_PDF/article_a10780.pdf. Document consulté le dimanche 10 février 2019.

- Anonyme, «Côte d'Ivoire : Abidjan inaugure le canal de Vridi élargi et approfondi », $R F I, 21$ février 2019.

- Anonyme, «Infrastructures : le port d'Abidjan renforce ses capacités », @bidj@n.net, 22 février 2019.

- Anonyme, «Abidjan Terminal accueil le plus gros navire de son histoire », @bidj@n.net, 7 juin 2019.

- CARETTE A-A., Lois, Décrets, Ordonnances, Avis du Conseil d'État, etc. (1 ${ }^{\text {ère }}$ série 1789-1830), Paris, 1843.

- CNUCED, Réformes et place du secteur privé dans les ports africains, Rapport UNCTAD/SDTE/TLB/5, Version française, 31 mars 2003.

- DEBOHI Landry Jocelyn, Financement de projets internationaux : cas de Tanger Med, p. 9. Document accessible en ligne sur: https://www.academia.edu/33110863/THEME_FINANCEMENT_DE_PROJETS_INTERNATIONAUX_CAS_DE_TANGER_MED_Pr 3\%A9sent\%C3\%A9. Document consulté le 30 juillet 2019.

- Discours du Gouverneur Geay prononcé le 30 novembre 1951 à l'ouverture de la deuxième session ordinaire du Conseil général de la Côte d'Ivoire, in Journal officiel de la Côte d'Ivoire (JOCI), n²7, $1^{\text {er }}$ décembre 1957, p. 745.

- EHOUMAN Faustin, «Canal de Vridi élargi et approfondi : le Port autonome d'Abidjan accessible à tous types de navires », Fratmatmat.Info, 22 février 2019.

- HOFFMANN Jan (dir.), Étude sur les transports maritimes 2016, CNUCED, New York et Genève, Côte UNCTAD/RMT/2016, 2016.

- HOUDAILlE (Cdt), Mission d'études du chemin de fer et du port. Historique. Description. Voies et moyen d'exécution, Notice dactylographiée, Paris, $1^{\mathrm{er}}$ mai 1900, 16 p.

- GRISOT Maureen, «Le monopole de Bolloré sur le Port d'Abidjan est de plus en plus contesté : Le gendarme de la concurrence de l'Afrique de l'ouest parle de violation des règles de la concurrence ». Article de journal accessible en ligne sur : jeanlouisbillon.net/wp-content/uploads/...JLB_RevueDePresse_08_Septembre2014.pdf. Document consulté le 11 février 2019.

- NDENDÉ Martin, «Les pays africains doivent se doter de législations portuaires adaptées », Jeune Afrique, 8 août 2013. Article accessible en ligne sur: www.jeuneafrique.com/17870/economie/les-pays-africainss-doivent-se-doter-delegislations-portuaires-adapt-es/. Document consulté le 30 juillet 2019. 
- OCEAN SHIPPING CONSULTANTS Ltd, Diagnostics des infrastructures nationales en Afrique. Au-delà des goulots d'étranglement : les ports en Afrique subsaharienne, Banque mondiale, Programme AICD, Document de référence 8, juin 2008, 11 p.

- Rapport d'activités 2017 du Port Autonome d'Abidjan, 42 p.

\section{TEXTES JURIDIQUES}

\section{A. RÉPUBLIQUE DE CÔTE D'IVOIRE}

\section{Lois et ordonnance}

- Loi n60-85 du 10 février 1960 portant création d'un établissement public qui prendra le nom de "Port d'Abidjan », JORCI, n¹5, 20 février 1960, pp. 220-221.

- Loi des finances $n^{\circ} 70-726$ du 31 décembre 1970 portant loi des finances pour la gestion 1971, JORCI, n¹5, 2 février 1971, p. 162.

- Loi n83-788 du 2 août 1983 déterminant les règles d'emprise et de classement des voies de communication et des réseaux divers de l'État et des collectivités territoriales.

- Loi n94-440 du 16 août 1994 déterminant la composition, l'organisation, les attributions et le fonctionnement de la Cour suprême et abrogeant la loi $n^{\circ} 78-663$ du 5 août 1978 relative à la Cour suprême, JORCI n³9 du 22 septembre 1994, pp. 714-729.

- Loi n97-243 du 25 avril 1997 modifiant et complétant la loi n94-440 du 16 août 1994 déterminant la composition, l'organisation, les attributions et le fonctionnement de la Cour suprême, JORCI n²4 du 12 juin 1997, pp. 603-609.

- Loi n96-766 du 3 octobre 1996 portant Code de l'environnement, JORCI nº du 6 février 1997, pp. 114-123.

- Loi n97-519 du 04 septembre 1997 portant définition et organisation des sociétés d'État, JORCI n40, 2 octobre 1997, pp. 1060-1065.

- Loi n ${ }^{\circ} 7-520$ du 4 septembre 1997 relatives aux sociétés à participation financière publique, JORCI n40, du 2 octobre 1997, pp. 1066-1070.

- Loi n98-388 du 2 juillet 1998 fixant les règles générales relatives aux établissements publics nationaux et portant création de catégories d'établissements publics et abrogeant la loi $n^{\circ} 80-1070$ du 13 septembre 1980, JORCI n..., du 23 juillet 1998, pp. 707-712.

- Loi n98-755 du 23 décembre 1998 portant Code de l'eau.

- Loi n²012-1128 du 13 décembre 2012 portant organisation des collectivités territoriales.

- $\quad$ Loi n²017-442 du 30 juin 2017 portant Code maritime, JORCI, numéro spécial du mardi 13 novembre 2018, pp. 129-208.

- Ordonnance $\mathrm{n}^{\circ} 2016-588$ du 03 novembre 2016 portant titres d'occupation du domaine public, JORCI n ${ }^{\circ} 3 \mathrm{du} 21$ novembre 2016, pp. 1401-1405.

\section{Décrets et arrêtés}

- Décret du 29 septembre 1928, portant réglementation du Domaine public et des servitudes d'utilité publiques en Côte d'Ivoire modifié par le décret du 7 sept 1935 et le décret $n^{\circ} 52$ 679 du 3 juin 1952.

- Décret n60-110 du 16 mars 1960 portant organisation administrative du Port d'Abidjan, JORCI, n²0, pp. 343 à 348 . 
- Décret n`72-07 du 11 janvier 1972 fixant les modalités de fonctionnement du Fonds d'emploi des bénéfices réalisés par les sociétés d'État et les sociétés d'économie mixte, JORCI 1972, p. 122.

- Décret n72-08 du 11 janvier 1972 fixant les règles de gestion et de contrôle des sociétés à participation financière publique, JORCI 1972, p. 122.

- Décret n72-86 du 27 janvier 1972 portant statut du personnel des établissements publics industriels et commerciaux et les sociétés d'État, JORCI 1972, p. 309.

- Décret no80-12 du 3 janvier 1980 portant règlement sur la comptabilité des dépenses publiques en ce qui concerne les dépenses de matériel de l'État à l'échelon central, JORCI n², 3 janvier 1980.

- Décret n̊81-137 du 18 février 1981 portant régime financier et comptable des établissements publics nationaux.

- Décret n82-402 du 21 avril 1982 portant organisation administrative des établissements publics nationaux, JORCI n 23, 27 mai 1982, p. 410 et ss.

- Décret n92-940 du 23 décembre 1992 portant transformation du Port autonome d'Abidjan en société d'État, JORCI n8, 25 février 1993, p. 159 et ss.

- Décret n98-151 du 25 mars 1998 portant délimitation des zones d'extension du Port autonome d'Abidjan (Locodjro, Île Boulay, Cordon littoral) ' JORCI 1998, n¹8, p. 455.

- Décret n99-318 du 21 avril 1999 portant règlement de police du Port autonome d'Abidjan, JORCI n 32, 12 août 1999, p. 661 et ss.

- Décret n²001-143 du 14 mars 2001 portant approbation des Statuts du Port autonome d'Abidjan (PAA) et reclassification des immobilisations concédées, JORCI ${ }^{\circ} 17,26$ avril 2001, p. 313 et ss.

- Décret n²018-358 du 29 mars 2018 définissant les règles relatives aux contrats de partenariats public-privé.

- Arrêté GG n ${ }^{\circ} 895$ A.E. du 24 novembre 1928, réglementant les conditions d'application du décret du 29 septembre 1928 sur le Domaine et les servitudes d'utilité publique.

- Arrêté GG n6286/TP du 10 novembre 1950 portant organisation et fonctionnement de ses services.

\section{B. LÉGISLATION COMMUNAUTAIRE}

- Protocole additionnel $\mathrm{n}^{\circ} 1$ relatif aux organes de contrôle de l'UEMOA et l'Acte additionnel n¹0/96 du 10 Mai 1996 portant statuts de la Cour de Justice de l’UEMOA.

- Acte additionnel n¹0/96 du 10 Mai 1996 portant statuts de la Cour de Justice de l'UEMOA.

- Règlement $\mathrm{n}^{\circ} 02 / 2002 / \mathrm{CM} / \mathrm{UEMOA} \mathrm{du} 23$ mai 2002 relatif aux pratiques anticoncurrentielles à l'intérieur de l'UEMOA.

- Recommandation $\mathrm{n}^{\circ}$ 02/2002/CM/UEMOA du 27 juin 2002 relative à la simplification et à l'harmonisation des procédures administratives et de transit portuaire au sein de l'UEMOA.

- Directive $\mathrm{n}^{\circ} 05 / 2005 / \mathrm{CM} / \mathrm{UEMOA}$ du 9 décembre 2005 portant contrôle et régulation des marchés publics et des délégations de service public dans l'Union Économique et Monétaire Ouest Africaine.

- Directive $\mathrm{n}^{\circ} 06 / 2005 / \mathrm{CM} / \mathrm{UEMOA}$ du 16 décembre 2005 relative à la libre circulation et à l'établissement des médecins ressortissants de l'Union au sein de l'espace UEMOA.

- Règlement n05/2006/CM/UEMOA du 2 mai 2006 relatif à la libre circulation et à l'établissement des experts-comptables et des comptables agréés ressortissants de l'Union au sein de l'espace UEMOA. 
- Règlement $n^{\circ} 10 / 2006 / \mathrm{CM} / \mathrm{UEMOA}$ du 25 juillet 2006 relatif à la libre circulation et à l'établissement des avocats ressortissants de l'Union au sein de l'espace UEMOA.

- Règlement n02/2008/CM/UEMOA du 28 mars 2008 relatif aux transports maritimes au sein de l'UEMOA.

- Règlement $n^{\circ} 03 / 2008 / \mathrm{CM} / \mathrm{UEMOA}$ du 28 mars 2008 relatif aux conditions d'exercice des professions d'intermédiaires de transport maritime au sein de l'UEMOA.

- Directive $\mathrm{n}^{\circ}$ 03/2008/CM/UEMOA du 28 mars 2008 relative aux fournisseurs de services portuaires au sein de l'UEMOA.

- Directive $n^{\circ} 04 / 2008 / \mathrm{CM} / \mathrm{UEMOA}$ du 28 mars 2008 portant mise en place d'un cadre institutionnel harmonisé du sous-secteur maritime au sein de l'UEMOA.

- Directive $\mathrm{n}^{\circ} 06 / 2008 / \mathrm{CM} / \mathrm{UEMOA}$ du 28 juin 2008 relative à la libre circulation et à l'établissement des pharmaciens ressortissants de l'Union au sein de l'espace UEMOA.

- Directive $n^{\circ} 07 / 2008 / \mathrm{CM} / \mathrm{UEMOA}$ du 28 juin 2008 relative à la libre circulation et à l'établissement des chirurgiens-dentistes ressortissants de l'Union au sein de l'espace UEMOA.

\section{RÉPUBLIQUE FRANÇAISE}

- Loi du 28 mars 1928 sur le régime du pilotage dans les eaux maritimes, JORF, 31 mars 1928.

- Décret-loi du 17 juin 1938 instituant un Code du domaine de l'État.

- Loi n65-491 du 29 juin 1965 sur les ports maritimes autonomes, JORF, 30 juin 1965 pp. 5436-5438.

- Loi n²009-526 du 12 mai 2009 de simplification et de clarification du droit et d'allègement des procédures.

- Ordonnance $\mathrm{n}^{\circ} 2010-1307$ du 28 octobre 2010 relative à la partie législative du code des transports.

- Loi n²014-626 du 18 juin 2014 relative à l'artisanat, au commerce et aux très petites entreprises.

\section{JURISPRUDENCE}

\section{A. RÉPUBLIQUE DE CÔTE D'IVOIRE}

- CSCJ, 23 février 1968, RID 1969, pp. 29-30.

- CSCA 23 mars 2005, Arrêt n¹4, Port Autonome d'Abidjan c/ Entreprises Graviers et Sables (EGS), req. 2003-453 CASS/AD.

- CSCA 21 janvier 2009, Arrêt n05, Sivcoge Industrie c/ Port Autonome d'Abidjan.

- CSCA 28 juillet 2010, Arrêt n81, Port autonome d'Abidjan (dite PAA) c/ Société Pexagri, req. $\mathrm{n}^{\circ}$ 2009-008 CASS/ADM.

- CSCA 30 mai 2012, Arrêt n94, Port autonome d'Abidjan c/ Sicpro \& autres, req. $\mathrm{n}^{\circ} 2008$-347 CIV.

- CSCA, 27 avril 2016, Société A.E.R.I.A c/ Compagnie aérienne Turkish Airlines, État de Côte d'Ivoire, ANAC, ASECNA, Arrêt nº7, inédit.

- Cour d'Appel d'Abidjan, Chambre civile et commerciale, Arrêt n615 du 20 mai 2003, Port autonome d'Abidjan (PAA) c/ Entreprises Gravier et Sables (EGS). 
- Cour d'Appel d'Abidjan, Chambre civile et commerciale, Arrêt n904 du 08 juillet 2003, Port autonome d'Abidjan c/ Trans Ivoire.

- Cour d'Appel d'Abidjan, Chambre civile et commerciale, Arrêt n¹60 du 14 février 2006, Port autonome d'Abidjan c/ Société PEXAGRI.

- Cour d'Appel d'Abidjan, Chambre civile et commerciale, Arrêt nº15 du 20 mai 2003, Port autonome d'Abidjan (PAA) c/ Entreprises Gravier et Sable (EGS).

- Cour d'Appel d'Abidjan, Arrêt n³61 du 27 mars 2001, N. c/ A., in Le Juris Ohada, $\mathrm{n}^{\circ} 1 / 2003$, janvier-mars 2003, p. 54. Ohadata J-03-118.

- Tribunal de commerce d'Abidjan, Ordonnance de référé, 11 octobre 2013, Société El Nasr Export-Import c/ Port autonome d'Abidjan, RG n ${ }^{\circ} 1456 / 13$.

- Tribunal de commerce d'Abidjan, 08 janvier 2015, Affaire La société Majorna Mobiliengesellschaft MBH \& CO.KG c/ La société Ivoirienne de Remorquage et de Sauvetage (IRES), RG N³660/2014.

\section{B. OHADA}

- CCJA Arrêt n043/2005, 7 juillet 2005, A. Y. et autres c/ Société TOGO TELECOM, Recueil de Jurisprudence de la CCJA, n6, juin-décembre 2005, p. 25.

- CCJA $2^{\text {ème }}$ Chambre, Arrêt no09/2014, 27 février 2014, Société SAS ALCATEL Space c/ SOTEL-TCHAD, www.ohada.com〉 jurisprudence >ohadata.

- CCJA $3^{\text {ème }}$ Chambre, n024/2014, 13 avril 2014, KOUTOUATI A. AKAKPO Danwodina et 18 autres c/ Société TOGO-PORT dite Port Autonome de Lomé, Ohadata J-15-115.

- CCJA Ass. Plénière, Arrêt n¹05/2014, 04 novembre 2014, Société AES SONEL c/ Henri NGALLE MONONO, Georges EYOMBO ANGANDZIE et Célestin BALENG MAAH, www.ohada.com $>$ jurisprudence $>$ ohadata.

- CCJA Ass. Plénière, Arrêt n¹23/2014, 11 novembre 2014, Hôpital Général de Référence Nationale (HGRN) c/ Société Total Elf Finio, www.ohada.com>jurisprudence>ohadata.

- CCJA Ass. Plénière, Arrêt nº136/2014, 11 novembre 2014, ASECNA c/ Ex-employés de l'ASECNA, www.ohada.com>jurisprudence>ohadata.

- CCJA, $I^{\grave{r} r}$ Chambre, Arrêt n 149/2015, 26 novembre 2015, BCEAO c/ El Hadj Rabiou DJITAOU, www.ohada.com $>$ jurisprudence $>$ ohadata.

- CCJA $1^{\text {ère }}$ Chambre, Arrêt n44/2016, 18 mars 2016, GNANKOU Goth Philippe c/ Fonds d'entretien routier (FER), www.ohada.com>jurisprudence>ohadata.

- CCJA $3^{\text {ème }}$ Chambre, Arrêt n ${ }^{\circ}$ 103/2018, 26 avril 2018, MBULU Museso c/ Société Grands Hôtels du Congo, www.ohada.com>jurisprudence >ohadata.

\section{RÉPUBLIQUE FRANÇAISE}

- CC, Décision n79-107 DC du 12 juillet 1979, Loi relative à certains ouvrages reliant les voies nationales ou départementales, Rec.1979.

- CE 12 août 1807, Avis sur la libération des mandats délivrés par la Caisse d'amortissement et sur les effets des oppositions relatives aux cautionnements des fonctionnaires publics, in CARETTE A-A., Lois, Décrets, Ordonnances, Avis du Conseil d'État, etc. (1 ${ }^{\text {ère }}$ série 1789-1830), Paris, 1843, p. 750.

- CE 26 mai 1813, Avis sur le mode à suivre pour obtenir le paiement des sommes dues par les communes, in DUVERGIER J.-B., Collection complète des Lois, Décrets, Ordonnances, Règlements, Avis du Conseil d'État, $2^{\text {ème }}$ édition, Paris, Tome XVIII, 1836, p. 315. 
- Cass. 31 mars 1819, Enregistrement c/ Sieur Jousselin, Journal du Palais, Recueil le plus ancien et le plus complet de la jurisprudence française, 1819, pp. 193-194.

- Cass. Civ. 16 décembre 1873, Cart, DP 1874, I, 249 ; S. 1874, I, 457, note J.E. Labbé.

- TC 9 déc. 1899, Association Syndicale du canal de Gignac, Rec., 731, S, 1900, 3, 49, note Hauriou; TC 9 décembre 1899, Association syndicale du canal de Gignac, GAJA, $18^{\text {ème }}$ édition, Paris, Dalloz, 2011, nº

- CE 10 janvier 1902, Compagnie nouvelle de gaz de Déville-lès-Rouen, Rec. 5.

- CE 22 mai 1906, Caisse des écoles du $6^{\text {ème }}$ arrondissement de Paris, S 1905.3.33, $1^{\text {ère }}$ espèce, note Hauriou.

- Cass. civ. 18 mai 1908, Sirey, 1909, I, 193, note Naquet.

- CE 11 mars 1910, Compagnie générale française des tramways, GAJA, 18 ème édition, 2011, n²1, p. 123.

- CE 30 mars 1916, Compagnie générale d'éclairage de Bordeaux, GAJA, n³0, $18^{\text {ème }}$ édition, 2011, p. 179.

- CE 10 août 1917, Commune de Vivonne, Rec. p. 634.

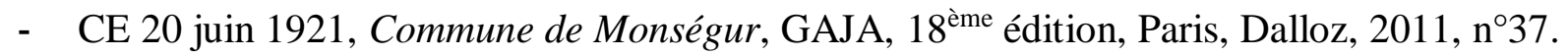

- CE 9 mars 1928, Compagnie des scieries africaines, RDP, 1928, 323.

- CE 18 juillet 1930, Compagnie des chemins de fer PLM et autres, RDP 1931, p. 141.

- CE Sect. 29 janvier 1932, Société des autobus antibois, Rec. p. 117.

- CE 6 mai 1932, Demoiselle Taillandier, Sirey, III, p. 65.

- CE 13 décembre 1939, Séguinaud, Rec. p. 388.

- CE Sect. 5 mai 1944, Compagnie maritime de l'Afrique orientale, Rec. p. 129.

- CE Ass. 29 janvier 1954, Institution Notre-Dame du Kreisker, Rec. 64.

- CE 2 mai 1958, Distillerie de Magnac Laval, Rec. 246.

- CE Sect. 17 avril 1959, Sieur Abadie, Rec. 239, Concl. Henry.

- CE 8 janvier 1960, Lafon, Rec. p. 15.

- CE 5 décembre 1962, Ville de Marseille, RDP, 63, p. 607.

- CE Sect., 13 octobre 1967, Cazeaux, n58332.

- Cass. Ass. Plén., 24 avr. 1970, Bayait cl Sté courses rouennaises, JurisData $\mathrm{n}^{\circ} 1970-$ 095993 ; Bull. civ. 1970, n³ ; Dalloz 1970, jurispr. p. 381.

- CE 29 avril 1970, Société Unipain, Rec. 280.

- Cass. civ. $1^{\text {ère }}, 20$ février 1973, n72-10, 174, Bull. civ. I, n69.

- Cass. civ. $1^{\text {ère }}, 15$ février 1975, Société du yacht club de Marina Baie des Anges, Bull. civ. I, n ${ }^{\circ} 88$.

- Cass. $3^{\text {ème }}$ civ., 9 juillet 1979, $\mathrm{n}^{\circ} 77-13.452$, SARL Services minute c/ SA Carrefour, Bull. civ. 1979, III, n¹53; Dalloz 1980, p. 64.

- Cass. com. 20 oct. 1981, Dalloz, 1982 S.C 121, obs. M. Vasseur.

- CE 2 février 1983, Union des transports publics urbains et régionaux, Rec. 33 ; RDP 1984, p. 212, note J.-M Auby ; RFDA n ${ }^{\circ}$ 0, p. 45, note Llorens.

- CE 4 février 1983, Ville de Charleville-Mézières, n²4912; CE 4 février 1983, Ville de Charleville-Mézières, Rec. p. 45.

- CE 28 septembre 1984, Conseil régional de l'ordre des architectes de Bourgogne, Rec. p. 309.

- CE 6 mai 1985, Association Eurolat, Crédit Foncier, Rec. p. 141 ; AJDA 1985, p. 621 ; CE 6 mai 1985, Association Eurolat, Crédit foncier de France, Rec. 141.

- CE 6 décembre 1985, Mademoiselle Boin-Favre, req. n44716, Rec., p. 353 ; RFDA 1986, p. 382, note Terneyre. 
- CE 2 février 1987, Société TV 6, Rec. 29.

- Cass. civ. 21 déc. 1987, Bureau de Recherches Géologiques et Minières, CJEG, 1988, p. 107 ; Cass. 22 décembre 1987, Bureau de recherches géologiques et minières, GAJA, $13^{\text {ème }}$ édition, Paris, Dalloz, 2001, $\mathrm{n}^{\circ} 100$.

- CE 14 octobre 1991, Helié, Rec. p. 680.

- TC 24 février 1992, Couach. ${ }^{\circ} 02685$.

- Cass. com. 27 avril 1993, $\mathrm{n}^{\circ} 91-19.819$, RJDA 11/93, n896 ; Cass. Com. 4 avril 2014, $\mathrm{n}^{\circ} 12-25.528$.

- Com. 17 décembre 1996, n²113, Époux Cavret c/ Denis, Gazette du Palais, 1997, $2^{\text {ème }}$ partie, p. 199 ; Com. 17 décembre 1996, Époux Cavret c/ Denis, Revue Trimestrielle de Droit commerciale, 1997, p. 25, observations J. Derrupé.

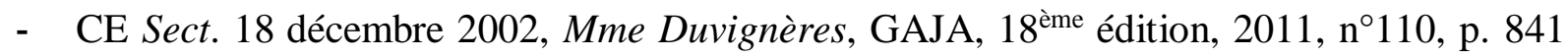
et $s s$.

- CE 31 juillet 2009, Société Jonathan Loisirs c. Communauté des communes du Haut Buëch, $\mathrm{n}^{\circ} 316534$.

- CE 10 juin 2010, Société des autoroutes Estérel-Côte d'Azur-Provence-Alpes (ESCOTA), $\mathrm{n}^{\circ} 305136$.

- CE 23 mai 2011, Établissement public pour l'aménagement de la région de la Défense (EPAD), $\mathrm{n}^{\circ} 328525$.

- CE 24 novembre 2014, Société les remontées mécaniques Les Houches-Saint-Gervais c. Société Champenoise, $\mathrm{n}^{\circ} 352402$.

- CA Aix-en-Provence 20 octobre 1987, $4^{\text {ème }}$ chambre.

\section{DOCUMENTATION ÉLECTRONIQUE}

- http://fr.wikipedia.org/Manutention_portuaire

- https://www.abidjan-aeroport.com/societe/

- www.cnrtl.fr>definition>outillage

- https://dergipark.org.tr/tr/download/article-file/96018

- https://www.glossaire-international.com/pages/tous-les-termes/feeder-navire.html

- https://www.jeuneafrique.com/704754/economie/cote-divoire-trafic-en-hausse-en-2018pour-le-port-dabidjan/

- http://www.larousse.fr/dictionnaires/francais/maritime/49520

- http://www.larousse.fr/dictionnaires/français/statut/74543\#vJ11YolBMRHJYYQu.99.

- https://www.glossaire-international.com/pages/tous-les-termes/roulier-navire.html.

- www.gouv.ci/impact-developpement/accueil/terrain_detail/extension-et-modernisationpour-accompagner-1-emergence 775/4.

\section{PÉRIODIQUES}

- Afrique Contemporaine

- Afrique et développement,

- Éthiopiques

- JOCI

- JORCI
- Outre-Terre

- Rapport Afrique

- RFDA

- RID

- Séries de monographies du 
- JORF

- Les Cahiers d'Outre-mer

- Note de synthèse
CODESRIA

- Synergies Afrique Centrale et de l'Ouest 



\section{RÉSUMÉ}

Le Port autonome d'Abidjan (PAA) est situé sur la façade atlantique de l'Afrique. Sa position géographique la place dans une rude concurrence avec la multitude de ports qui parsèment ladite région. Cette situation conduit à se demander si le statut juridique du PAA lui permet de surmonter cette rude concurrence et le positionner comme le premier port de cette région d'Afrique.

La réponse à cette interrogation commande d'analyser le statut juridique du PAA. Dans l'ensemble, on note que le PAA est régi par des textes juridiques variés. Ceux-ci ont été, dans un premier temps, définis par le Gouverneur général de l'Afrique occidentale française (AOF), puis, par les autorités nationales de la République de Côte d'Ivoire. Durant cette première phase, les textes juridiques étaient constitués d'un arrêté général du Gouverneur de l'AOF, auquel se substitueront d'autres textes juridiques qui transformeront successivement le Port d'Abidjan en un établissement public (en 1960), un établissement public industriel et commercial (en 1970) et une société d'État (en 1992). Cette dernière nature juridique sera confirmée en 2001 au moyen d'un décret portant reclassification des actifs du PAA.

À cette première phase, a succédé une nouvelle vague de textes juridiques consécutifs à l'avènement respectif de l'Union économique et monétaire ouest-africaine (UEMOA) et de l'Organisation pour l'harmonisation en Afrique du droit des affaires (OHADA). Les organes compétents de ces deux institutions d'intégration régionales (IER) ont élaboré des textes juridiques qui s'appliquent, sous certains aspects, au fonctionnement du PAA. Dans le cas de l'UEMOA, les normes communautaires se composent du Traité constitutif de 1994, des Actes ou Protocoles additionnels audit traité, des directives, des règlements, et de la jurisprudence de la Cour commune de justice et d'arbitrage (CCJA). Dans le cas de l'OHADA, les normes s'appliquant au PAA sont des Actes uniformes adoptés par le Conseil des ministres de ladite IER. L'ensemble de ces normes juridiques nationales ou communautaires constituent le statut juridique du PAA.

Le statut juridique du PAA, ainsi que son application, comporte des failles qui risquent de préjudicier à la volonté des autorités ivoiriennes d'en faire le port de référence en Afrique.

$\mathrm{Au}$ titre des faiblesses, on pourrait affirmer que la nature duale du statut juridique du PAA se solde parfois par des conflits résultant de l'application concomitante des deux catégories de normes précitées. On note précisément un conflit relatif à la soumission du PAA, une société d'État exclusivement étatique, aux normes commerciales de l'OHADA. Ce faisant, le PAA devient une société commerciale au même titre que les autres personnes privées. Cette situation se traduit par une différence d'appréciation entre le juge commercial et le juge administratif. Ce dernier continue de faire prévaloir, en dépit de la suprématie formelle du droit communautaire sur le droit national, un régime exorbitant tiré du droit administratif. Cette position du juge administratif rend virtuelle la suprématie formellement conférée au droit communautaire sur le droit national.

Une autre faiblesse décelable dans le fonctionnement du PAA est la propension du PAA à utiliser des règles impératives voire comminatoires à l'égard de ses usagers. Cela se reflète dans la situation très précaire (donc très inconfortable) des concessionnaires du PAA. La précarité accentuée des occupations privatives du domaine public portuaire dissuade, sous certains rapports, les usagers nationaux ou africains à réaliser des investissements significatifs sur le domaine public portuaire. Il en va autrement des sociétés transnationales qui, elles, bénéficient d'une stabilité plus enviable.

Il n'empêche que les deux séries de problèmes précitées requièrent des solutions qui permettraient au PAA de rehausser sa compétitivité. La première solution, à court terme, consiste pour le PAA à stabiliser la situation des occupants privatifs du domaine public portuaire qui se conforment à la législation en vigueur. Pour ce faire, il est nécessaire que le 
PAA minore sa propension à recourir à l'approche unilatérale et autoritaire, au profit d'une approche participative et consensuelle. Par conséquent, le PAA pourrait utilement privilégier les contrats de partenariat public-privé et admettre, le cas échéant, la possibilité pour les occupants privatifs du domaine public portuaire d'y constituer un fonds de commerce. Ces deux ajustements contribueraient à inciter les usagers nationaux ou africains, au même titre que les sociétés transnationales, à investir plus substantiellement sur le domaine public portuaire.

La seconde solution, à moyen ou long terme, s'attelle à surmonter les conflits résultant de l'application concomitante du droit national et du droit communautaire. À cet effet, il importe de diviser le port en deux entités distinctes : l'une sera un établissement public administratif (EPA) qui sera chargé de réglementer la situation des usagers du PAA; tandis que l'autre prendra la forme d'une société d'économie mixte avec pour mission d'exploiter principalement les terminaux à conteneurs. La première entité, à savoir l'EPA, continuera de bénéficier d'un régime exorbitant de droit public ; elle sera de ce fait soustraite à l'application des règles commerciales définies par l'OHADA. La seconde entité, à capitaux mixtes, sera soumise aux règles commerciales de l'OHADA eu égard à la nature de ses activités qui, indéniablement, revêtent un caractère industriel et commercial.

La mise en œuvre de ces différentes propositions contribuera, on l'espère, à rehausser la compétitivité du PAA pour en faire le port de référence tant souhaité par les autorités ivoiriennes. 


\section{SUMMARY}

The Autonomous Port of Abidjan (AAP) is located on the Atlantic coast of Africa. Its geographic position places it in stiff competition with the multitude of ports that dot this region. This situation raises the question whether the legal status of the AAP allows it to overcome this stiff competition and position it as the first port of this region of Africa.

The answer to this question calls for an analysis of the legal status of the AAP. Overall, it should be noted that the AAP is governed by various legal texts. These were first defined by the Governor General of French West Africa (FWA), then by the national authorities of the Republic of Côte d'Ivoire. During this first phase, the legal texts consisted of a general decree of the Governor of the FWA, which will be replaced by other legal texts which successively transformed the Port of Abidjan into a public establishment (in 1960), a public establishment industrial and commercial (in 1970) and a state-owned company (in 1992). The latter legal nature will be confirmed in 2001 by means of a decree reclassifying AAP assets.

This first phase was followed by a new wave of legal texts following the respective advent of the West African Economic and Monetary Union (WAEMU) and the Organization for the Harmonization in Africa of Business Law (OHADA). The competent bodies of these two regional integration institutions (RII) have drawn up legal texts which apply, in certain aspects, to the functioning of the PAA. In the case of WAEMU, the community standards consist of the 1994 Constitutive Treaty, Additional Acts or Protocols to the treaty, directives, regulations, and the jurisprudence of the Common Court of Justice and Arbitration (CCJA). In the case of OHADA, the standards applying to the AAP are Uniform Acts adopted by the Council of Ministers of the said RII. All of these national or community legal standards constitute the legal status of the AAP.

As weaknesses, it could be said that the dual nature of the legal status of the AAP sometimes results in conflicts resulting from the concomitant application of the two categories of standards mentioned above. There is precisely a conflict relating to the submission of the AAP, an exclusively state-owned state corporation, to OHADA commercial standards. In doing so, the AAP becomes a commercial company in the same way as other private individuals. This situation results in a difference of appreciation between the commercial judge and the administrative judge. The latter continues to prevail, despite the formal supremacy of Community law over national law, an exorbitant regime drawn from administrative law. This position of the administrative judge virtualizes the supremacy formally conferred on Community law over national law.

Another noticeable weakness in the functioning of the AAP is the propensity of the AAP to use imperative or even comminatory rules with regard to its users. This is reflected in the very precarious (and therefore very uncomfortable) situation of AAP concessionaires. The increased precariousness of private occupations in the port public domain dissuades, in certain respects, national or African users from making significant investments in the port public domain. It is a different story for transnational corporations, which enjoy more enviable stability.

Nevertheless, the two sets of problems mentioned above require solutions that would allow the PAA to enhance its competitiveness. The first solution, in the short term, is for the AAP to stabilize the situation of the private occupants of the port public domain who comply with the legislation in force. To do this, it is necessary for the AAP to minimize its propensity to use the unilateral and authoritarian approach, in favor of a participatory and consensual approach. Consequently, the AAP could usefully privilege public-private partnership contracts and admit, where appropriate, the possibility for private occupants of the port public domain to constitute a commercial property. These two adjustments would help encourage 
national or African users, in the same way as transnational companies, to invest more substantially in the public port domain.

The second solution, in the medium or long term, is to overcome the conflicts resulting from the concomitant application of national law and Community law. To this end, it is important to divide the port into two distinct entities: one will be a public administrative establishment (PAE) which will be responsible for regulating the situation of AAP users; the other will take the form of a semi-public company with the mission of operating mainly the container terminals. The first entity, the PAE, will continue to benefit from an exorbitant public law regime; it will therefore be excluded from the application of the commercial rules defined by OHADA. The second entity, with mixed capital, will be subject to OHADA trade rules having regard to the nature of its activities which, undeniably, are of an industrial and commercial nature.

The implementation of these various proposals will, it is hoped, help to enhance the competitiveness of the AAP to make it the benchmark port so much desired by the Ivorian authorities. 


\section{VALORISATION ADDENDUM}

Notre thèse a débouché sur certains résultats. La présente valorisation de nos travaux est nécessaire pour saisir de manière précise et concise les applications des points de droit abordés dans lesdits travaux. Cette présentation empruntera un double mouvement : d'une part, la présentation des résultats de la thèse (I) et, d'autre part, les modalités de la mise en œuvre de ces résultats (II).

\section{Présentation des résultats de la thèse}

L'étude du statut juridique du PAA a permis de saisir la diversité de celui-ci. Ce statut se décline en lois, ordonnance, règlements nationaux, actes unilatéraux communautaires, sans oublier la jurisprudence nationale et communautaire. Dans l'intérêt du PAA et des usagers, ce statut diversifié ne devrait pas être réservé à un cercle restreint de personnes. Il devrait faire l'objet de la plus large diffusion possible.

On note, sur certaines matières, une concurrence entre législation nationale et législation communautaire avec un risque de conflit entre ces deux sources de droit. Il est vrai que le droit communautaire jouit, formellement, de la primauté sur la législation nationale. Cependant, cette primauté apparaît plus virtuelle que réelle au regard de certaines décisions de justice $^{436}$.

Il est nécessaire d'adapter la législation relative aux concessions portuaires pour tenir compte de l'évolution des montages concessifs qui privilégient, de plus en plus, le partenariat public-privé. Cette difficulté est en voie de résolution avec l'adoption de deux textes juridiques majeurs : le décret $\mathrm{n}^{\circ} 2012-1151$ du 19 décembre 2012 relatif aux contrats de partenariats public-privé puis, du décret $\mathrm{n}^{\circ} 2018-358$ du 29 mars 2018 déterminant les règles relatives aux contrats de partenariat public-privé ; l'ordonnance $n^{\circ} 2016-588 \mathrm{du} 03$ novembre 2016 portant titres d'occupation du domaine public.

Le rehaussement des performances de l'Administration portuaire requiert, entre autres, une refonte du PAA par la dissociation des missions de prescription de celle d'exploitation du domaine portuaire. Autrement, il faudrait dissocier les missions d'autorite ${ }^{437}$ des missions de nature industrielle et commerciale ${ }^{438}$.

La mise en œuvre de ces résultats interviendra à travers des modalités.

\section{Modalités de la valorisation des résultats de la thèse}

Afin de surmonter les difficultés liées à la diversité et à l'éparpillement des textes juridiques relatifs au PAA, il est impérieux de procéder à une codification à droit constant. Celle-ci débouchera sur l'élaboration d'un Code portuaire qui regrouperait en un seul instrument juridique, l'ensemble des textes juridiques nationaux et/ou communautaires applicables au port d'Abidjan.

436 Exemple : les divergences d'appréciation entre la Chambre administrative de la Cour suprême et les juridictions d'instance et d'appel sur le droit applicable au contentieux relatif aux concessions de voirie conclues par le PAA. Le premier opte pour l'application du droit administratif, en vertu du décret-loi du 17 juin 1938, les seconds optent pour l'application du droit commercial eu égard à la forme commerciale du PAA. Ceux-ci s'appuient sur les dispositions pertinentes du droit de l'OHADA.

437 À savoir la police de la conservation du domaine public portuaire, celle de la conservation de l'outillage et celle de la réglementation des escales de navire au port d'Abidjan.

438 À savoir les prestations auprès des usagers du port d'Abidjan, perception de redevances auprès des usagers (désormais renommés clients) utilisant l'outillage du port d'Abidjan. 
Assurer régulièrement la formation du personnel et des usagers du port d'Abidjan, des étudiants et des professionnels du droit sur le contenu des normes s'appliquant audit port.

Mise à niveau des magistrats ivoiriens pour leur permettre de saisir le contenu des normes communautaires applicables au PAA. Cela est nécessaire afin d'éviter les interprétations divergentes entre les juridictions d'instance ou d'appel, et la Chambre administrative de la Cour suprême ou toute autre juridiction équivalente qui aurait tendance à appliquer systématiquement le droit administratif aux contentieux dans lesquels le PAA est partie.

Diffuser, auprès du personnel et des usagers du port d'Abidjan, le contenu du décret précité du 19 décembre 2012 relatifs aux contrats de partenariat public-privé puis, du décret n²018-358 du 29 mars 2018 déterminant les règles relatives aux contrats de partenariat public-privé et, enfin, celui de l'ordonnance du 03 août 2016 sur le domaine public.

En s'inspirant de l'exemple du Maroc ${ }^{439}$, créer deux entités juridiques distinctes qui se substitueront au PAA. La première sera chargée principalement des missions d'autorité. La seconde sera chargée, concurremment avec des opérateurs et des exploitants portuaires, des missions à caractère commercial.

439 Dissociation instituée au moyen d'une loi. $C f$. Loi $\mathrm{n}^{\circ} 15-02$ relative aux ports et portant création de l'Agence nationale des ports et de la Société d'exploitation des ports, Bulletin officiel, n5378, 13 kaada 1426 (15-12-2005), pp.846-855. Cette loi, en son préambule, crée l'Agence nationale des ports et la Société d'exploitation des ports. 


\section{CURRICULUM VITAE}

Nom : SALLY

Prénoms: Adou Mouah Félix Junior

Date et lieu de naissance : 3 décembre 1971 à Grand-Bassam (Cote d'Ivoire)

Nationalité : Française et Ivoirienne

FORMATION UNIVERSITAIRE

2001 : Diplôme d'études supérieures spécialisées (DESS) en droit maritime, droit des transports et gestion portuaire, Université de l'Atlantique (Abidjan - Côte d'Ivoire).

1997: Ingénieur commercial export de la Grande École dénommée AGITELFORMATION (Abidjan - Côte d'Ivoire).

\section{EXPÉRIENCE PROFESSIONNELLE}

Vingt-cinq (25) ans d'expérience professionnelle en tant qu'Expert en Droit Douanier, Droit du Transport et Commerce International.

1994: Stages à la Lushann Bradley Ventures (L.V.B.), Houston (Texas - U.S.A.)

1994 (fin) - 1996 : Stage à la Société Ivoirienne de Raffinage (S.I.R.), perfectionnement en Trading et Logistique internationale

1997 : Salarié à la société GOLF TRANSIT, Directeur commercial et Overseas (Abidjan - Côte d'Ivoire); Création de la société anonyme Universal Services Company (Abidjan Côte d'Ivoire).

2007: Accord de représentation en Côte d'Ivoire de la: Swift Freight International de Dubai, Émirats Arabes Unis (E.A.U.), founded by Chair Professor Issa S. BALUCH. Havard Kennedy School; Chairman, FIATA Logistics Academy; Chair Professor, College of Maritime Science and Management; China International Forwarders Association (CIFA).

2008: Accords de représentation en Côte d'Ivoire de la FRABEMAR, (Italie); l'OGEFREM (République Démocratique de Congo); la WWWPC Network (U.S.A.) ; Metrica Relocation San Antonio (U.S.A.) ; DICHWAY (China); South Star (Grèce); AMP China; SDIC China; AVERINDIA (Inde); ST-JOHN (Inde); GREENROAD China . Fondateur de USC Worldwide Group

Depuis 2014 : Consultant-Contributor de la Banque Mondiale - Doing Business.

Depuis 2018: Conseiller du Président Afrique chargé des relations internationales du Réseau des Chambres des Experts Européens, Département Afrique de l'Ouest (RCEEDAO).

\section{SÉMINAIRES ET SOMMETS}

2010 : Sommet Sino-européen organisé par la World Cargo Alliance (W.C.A.), Barcelone (Espagne)

2012: Participation à un dîner débat à Harvard Club à New York City (U.S.A.) sur invitation du Professeur DORSON de H ARVARD University

2013 et 2015: China Break Bulk, Shanghai (China)

2016 : La Table Ronde des Bailleurs de Fonds pour le financement pour

L'équipement naval pour la protection de la façade maritime du golfe de guinée, organisée par l'OMAOC (Organisation Maritime de l'Afrique de l'Ouest et du Centre)

2017 : Sommet annuel national relatif aux chargeurs, Libreville (Gabon)

Mai 2019: Bremen Break Bulk (Germany)

28 juin 2019 : Conférence sur la Responsabilité Sociétale, siège des Nations de Genève (Suisse). 
24 juillet 2019 : Conférence sur le développement durable de Sharjah aux Émirats Arabes Unis (E.A.U).

PRIX - DÉCORATION - AWARDS

2009 : Prix B.I.D. du Meilleur Manager du Secteur Maritime, Catégorie OR, Londres (Royaume-Uni)

2010 : Chevalier de l'Ordre Mérite Ivoirien

2014 : Prix West Africa Development du Meilleur Manager Ouest-africain dans le Secteur du Transit, de la Consignation et l'Offshore, Paris (France)

2015 : Médaille d'OR de la West Africa Development (WAD) pour l'Afrique de l'ouest, décernée à Abidjan-Plateau (Côte d'Ivoire)

2018: Docteur Honoris Causa de la Shri Sharada Institute of Indian ManagementResearch.

2019 : TOP 100 Mondial en transport et en logistique, Londres (Royaume-Uni); Brand Ambassador for Sustainable Development, Sharjah, Emirats Arabes Unis (E.A.U.)

\section{AUTRES ACTIVITÉS}

- Vice-président du Syndicat National des Transitaires de Côte d'Ivoire

- Administrateur à UCACI (Union des Consignataires et Armateurs de Côte d'Ivoire)

- Administrateur au SEMPA (syndicat des manutentionnaires-dockers)

- Membre de la Chambre de commerce et de l'industrie française

- Membre de la chambre de commerce et de l'industrie de Côte d'Ivoire

- Vice-président du Syndicat National des Transitaires de Côte d'Ivoire.

- Membre de la European Business Assembly

- Membre à vie de la Oxford Academy Union. 


\section{TABLE DES MATIÈRES}

DEDICACE

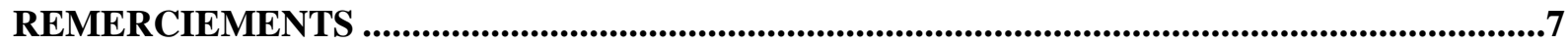

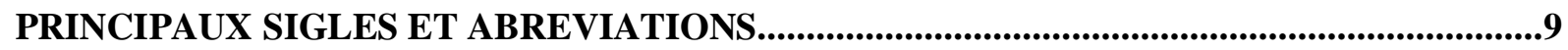

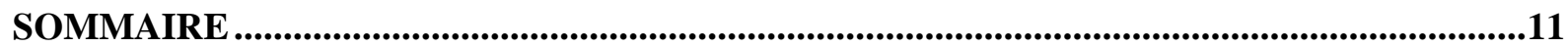

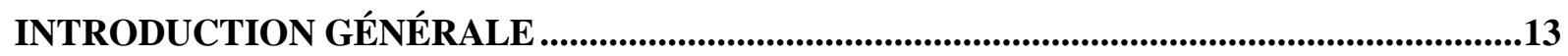

I. ANALYSE COMPARÉE DE L'IMPORTANCE DU PORT AUTONOME D'ABIDJAN ..........13

A. Le Port autonome d'Abidjan, une infrastructure relativement modeste .......................................13

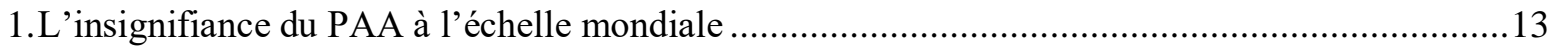

2.La place enviable du PAA à l'échelle ouest-africaine .................................................................15

B. Le défi du Port autonome d'Abidjan à se muer en un hub régional ............................................16

1.Une vocation apparemment compromise au départ...................................................................16

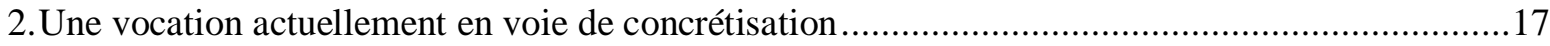

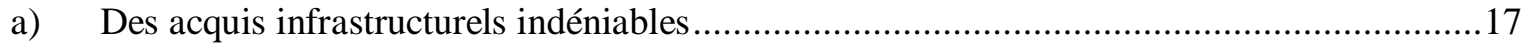

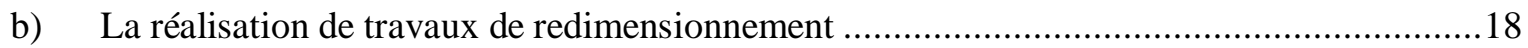

C. Le Port autonome d'Abidjan, une infrastructure d'importance capitale pour l'économie ivoirienne

1.Le Port autonome d'Abidjan et l'économie ivoirienne.

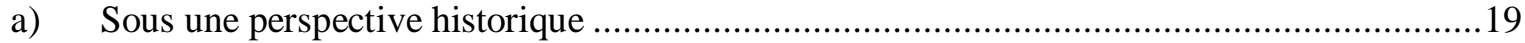

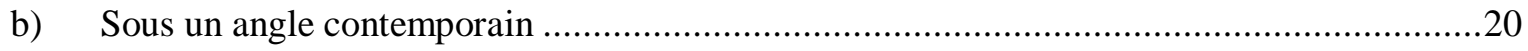

2.Le Port autonome d'Abidjan et les pays de l'hinterland..............................................................20

II. APERÇU DU RÉGIME JURIDIQUE DU PORT AUTONOME D’ABIDJAN ..........................21

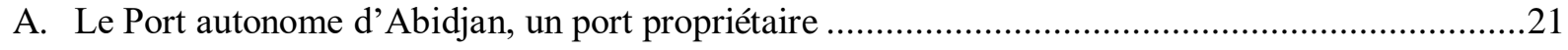

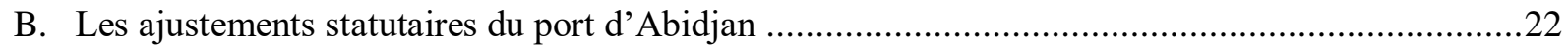

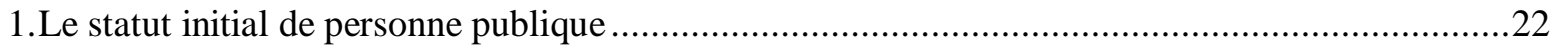

2.Le statut actuel de personne morale de droit privé …..............................................................23

3.La soumission du Port autonome d'Abidjan au droit communautaire de l'UEMOA et de

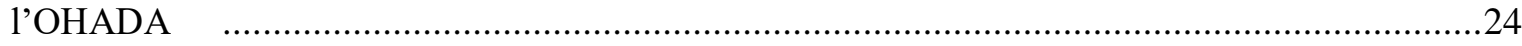

III. DÉFINITION DES NOTIONS FONDAMENTALES DE L'ÉTUDE........................................25

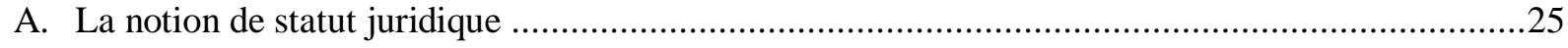

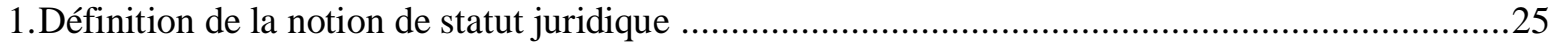

2.Aperçu des actes constituant le statut juridique du Port autonome d'Abidjan ...............................26

B. Notion de port autonome : une approche de droit comparé ......................................................28

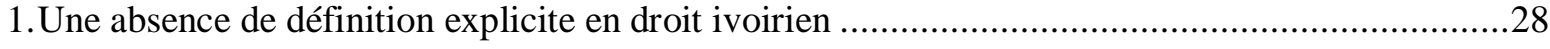


2.Une définition évolutive et précise en droit français .............................................................29

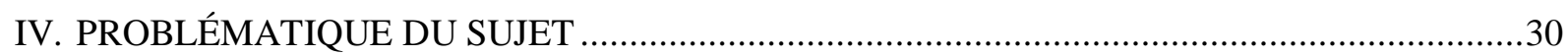

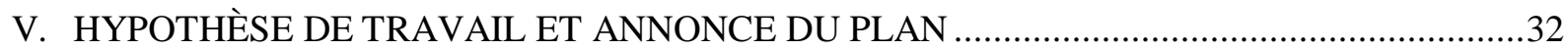

PREMIERE PARTIE : Le caractère diversifié et volontariste des normes constitutives du statut juridique du Port autonome d'Abidjan .....................................................................35

TITRE I : UN STATUT JURIDIQUE RELEVANT INITIALEMENT DE LA COMPÉTENCE

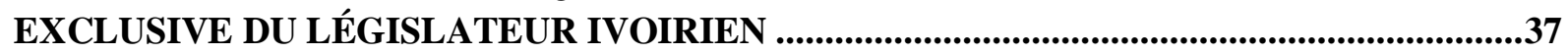

CHAPITRE 1 : LES ÉVOLUTIONS SUCCESSIVES DU STATUT JURIDIQUE DU PORT AUTONOME D'ABIDJAN ...........................................................................................................39

SECTION 1 : D'un statut relevant exclusivement du droit public................................................39

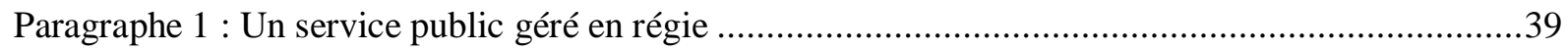

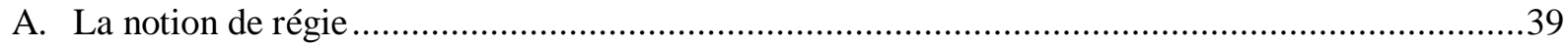

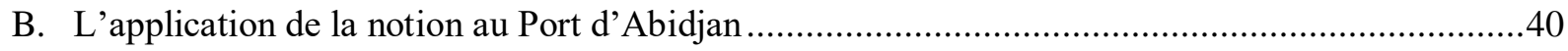

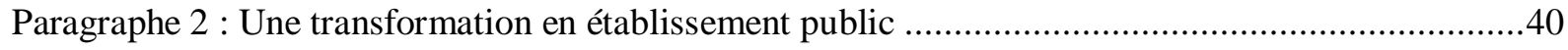

A. Le caractère imprécis de la catégorie d'établissement public ......................................................41

B. La précision sur le caractère industriel et commercial de l'établissement public ..........................42

1.Le fondement juridique de l'érection du Port en EPIC ...............................................................42

2.Les implications juridiques de la transformation du Port en EPIC................................................43

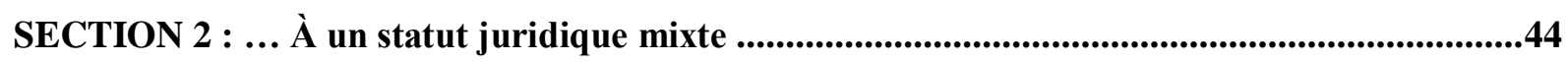

Paragraphe $1:$ La constitution du Port sous la forme d'une société d'État ..........................................44

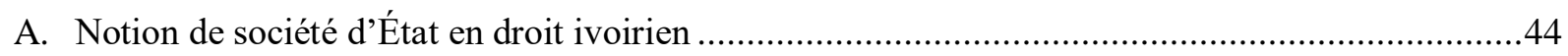

B. Le fondement juridique de la transformation du Port en société d'État .......................................45

Paragraphe 2 : Les implications juridiques de la nouvelle nature juridique du Port.............................46

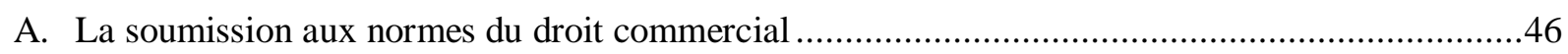

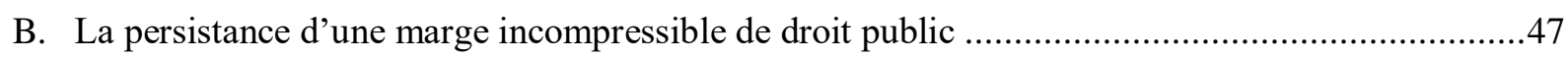

\section{CHAPITRE 2: LA DIVERSITÉ DES MISSIONS DÉVOLUES AU PORT AUTONOME}

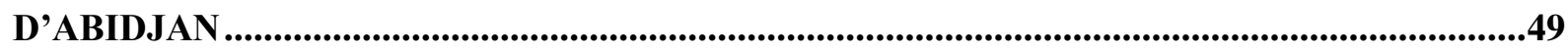

SECTION 1 : L'entretien du domaine portuaire et de l'outillage.............................................49

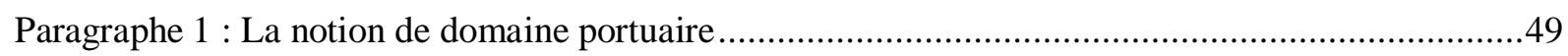

A. Absence de définition (conceptuelle) du domaine portuaire .....................................................49

1.Définition du domaine public au moyen de la méthode énumérative..........................................49

2.La définition négative ou résiduelle du domaine privé............................................................51

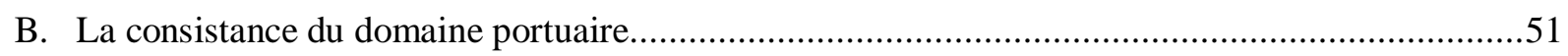




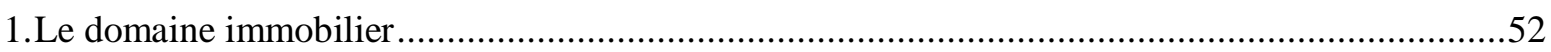

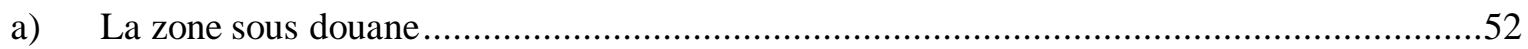

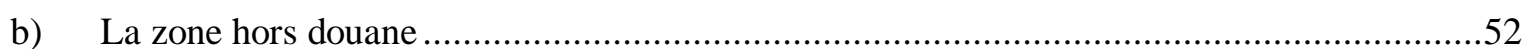

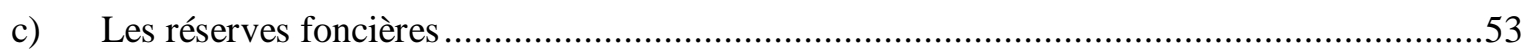

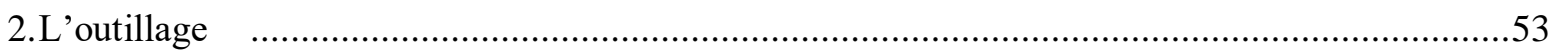

Paragraphe 2 : Les activités de police sur le domaine portuaire ........................................................54

A. La police de conservation du domaine public portuaire …..........................................................54

B. Les autres polices exercées sur le Port autonome d'Abidjan .......................................................55

SECTION 2 : Les missions de nature économique exercée par le Port autonome d'Abidjan.......55

Paragraphe $1:$ Les prestations de services aux usagers du PAA ..........................................................56

Paragraphe 2 : L'exploitation économique du domaine public portuaire ..........................................57

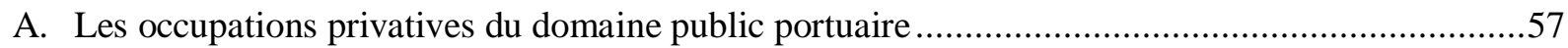

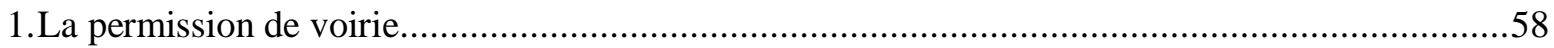

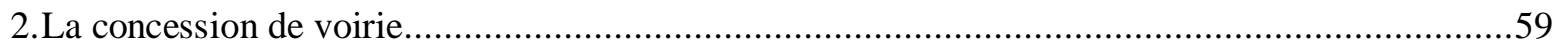

B. Les obligations et garanties du permissionnaire et du concessionnaire de voirie .........................60

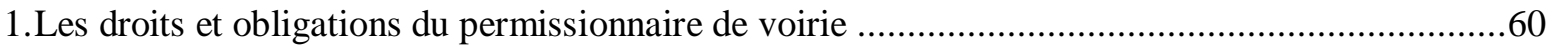

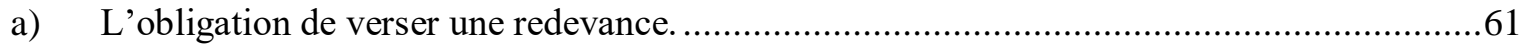

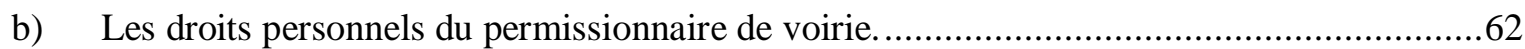

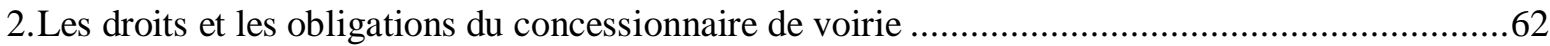

a) Les prérogatives reconnues au Port autonome d'Abidjan à l'égard du concessionnaire de

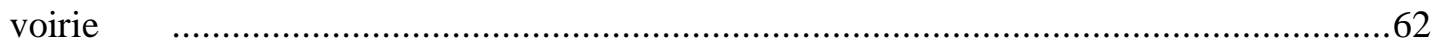

b) Les garanties reconnues au concessionnaire de voirie .......................................................63

TITRE DEUX: UN STATUT JURIDIQUE ACTUELLEMENT INVESTI PAR LE DROIT

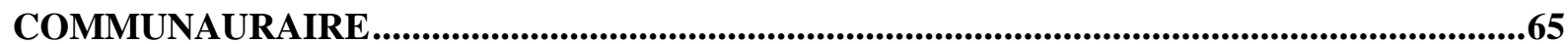

\section{CHAPITRE 1 : LA SOUMISSION DU PORT AUTONOME D'ABIDJAN AU DROIT DE}

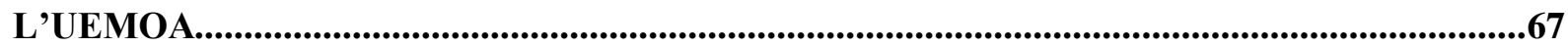

SECTION 1 : Le cadre général découlant du droit primaire de l'UEMOA ..............................67

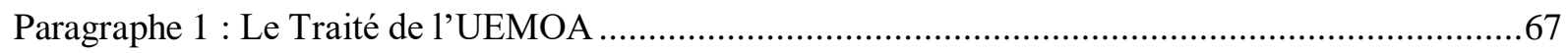

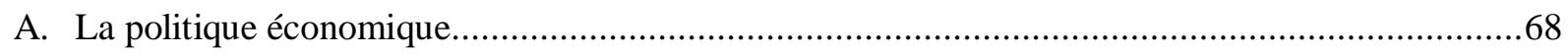

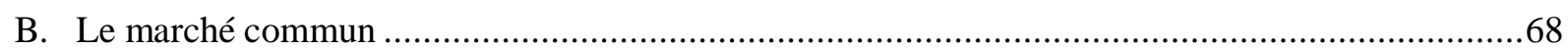

1.La libre circulation des personnes, des services et des capitaux ................................................69

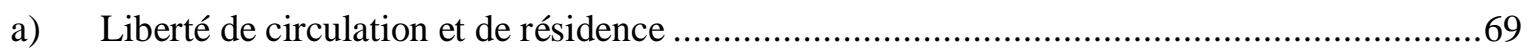

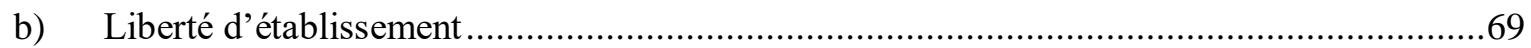

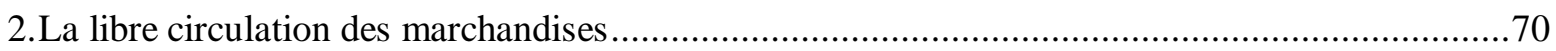




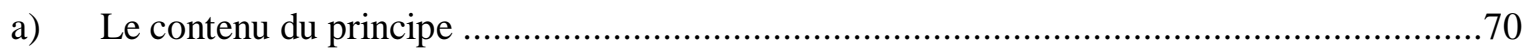

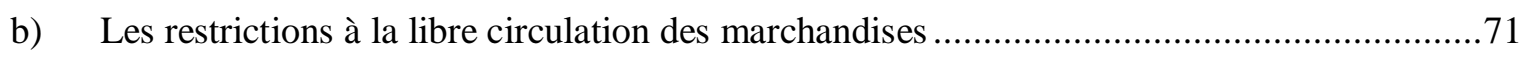

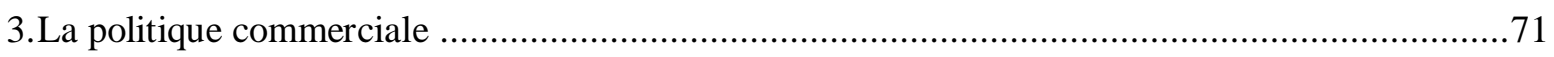

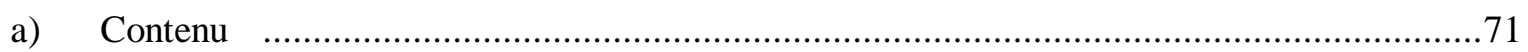

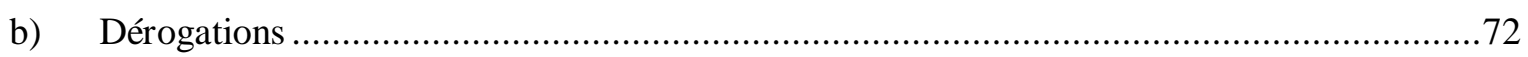

Paragraphe 2 : Le Protocole additionnel n'II relatif aux politiques sectorielles de l'UEMOA.............72

SECTION 2 : Le cadre spécifique découlant du droit dérivé de l’UEMOA ................................73

Paragraphe $1:$ Les exigences relatives à la simplification des procédures administratives portuaires..73

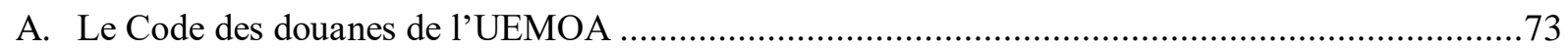

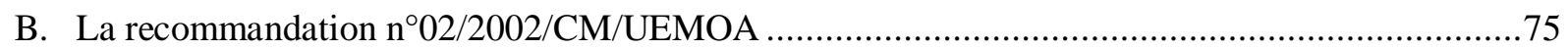

Paragraphe 2 : La réglementation d'activités connexes aux missions du Port ....................................76

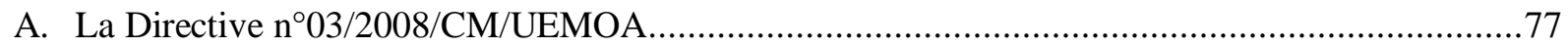

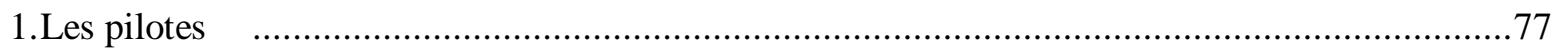

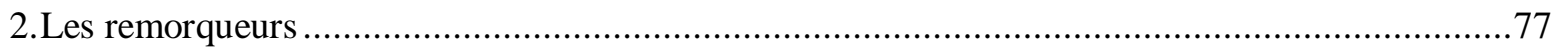

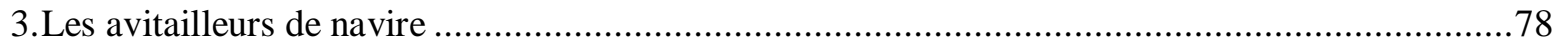

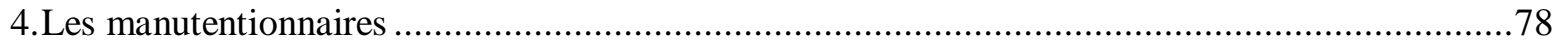

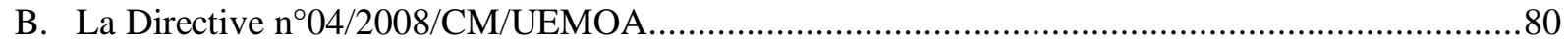

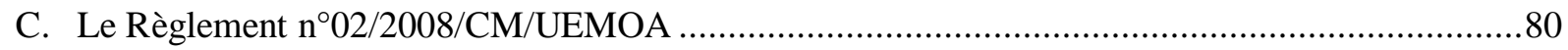

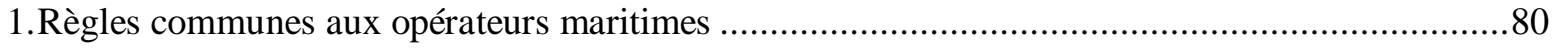

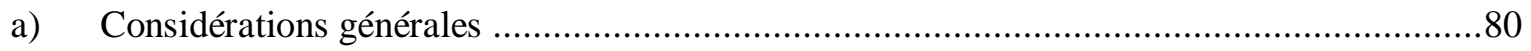

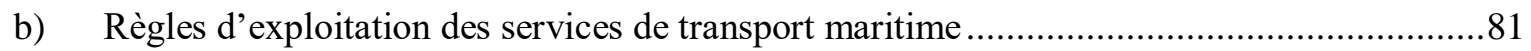

2.Règles spécifiques s'appliquant au transport maritime dans l'Union.........................................82

a) Conditions d'accès aux transports maritimes intérieur et intracommunautaire......................82

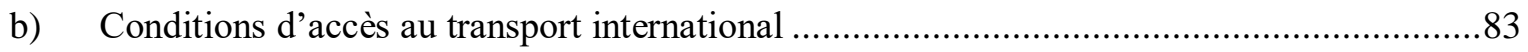

Paragraphe 3 : La soumission du Port aux normes communautaires anticoncurrentielles....................83

A. La prohibition des situations de monopole dans l'espace UEMOA …..........................................84

B. La pratique observée au niveau du Port autonome d'Abidjan dans l'affaire ICTSI c. Groupement

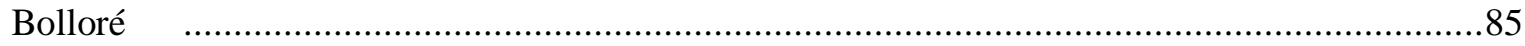

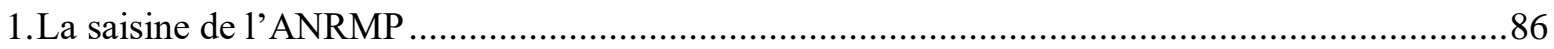

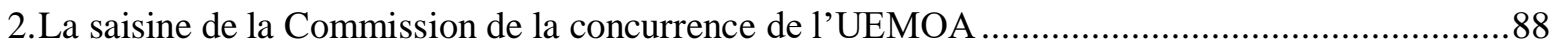

CHAPITRE 2 : LE PORT AUTONOME D'ABIDJAN ET LE DROIT DE L'OHADA .............91

SECTION 1 : Le fondement de la soumission du Port au droit de l'OHADA .................................91

Paragraphe 1 : Le principe de la soumission du Port autonome d'Abidjan à l'AUSCGIE ...................91

Paragraphe 2 : Les implications de la soumission du Port autonome d'Abidjan à l'AUSCGIE ...........92

SECTION 2 : La virtualité du caractère obligatoire du droit de l'OHADA à l'égard du Port autonome d'Abidjan 
Paragraphe 1 : L'immunité d'exécution reconnue aux entreprises publiques par le droit de l'OHADA.

A. L'affirmation de l'immunité d'exécution des entreprises publiques ...........................................93

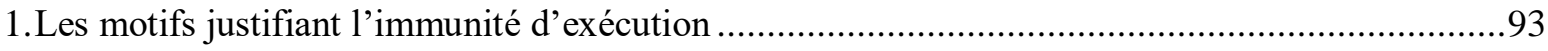

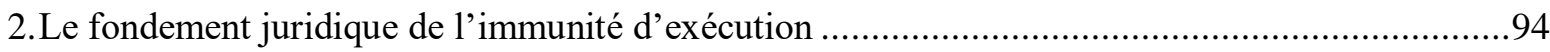

B. L'application de l'immunité d'exécution par la Cour commune de justice d'arbitrage .................95

1.La tendance initiale : L'application indifférenciée de l'immunité d'exécution .............................95

2.Le revirement jurisprudentiel opéré le 26 avril 2018 ...............................................................97

Paragraphe 2 : Les réticences du juge ivoirien à appliquer le droit de l'OHADA au Port autonome

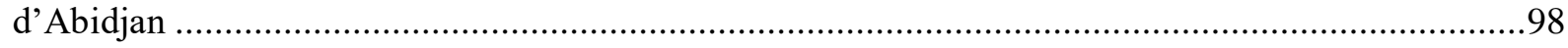

A. La position favorable de la Cour d'appel d'Abidjan à l'égard du droit de l'OHADA ...................98

B. La réticence de la Chambre administrative de la Cour suprême à appliquer le droit de

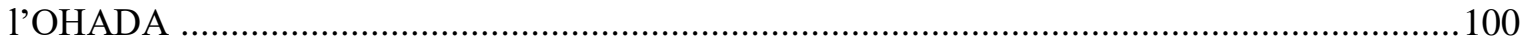

1.L'affaire Port Autonome d'Abidjan c/ Entreprises Graviers et Sables ........................................100

2.L'affaire Port autonome d'Abidjan c. Société Pexagri ..................................................................101

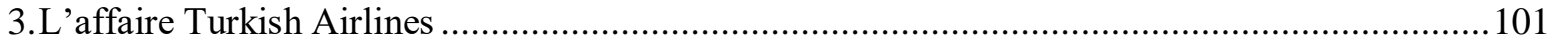

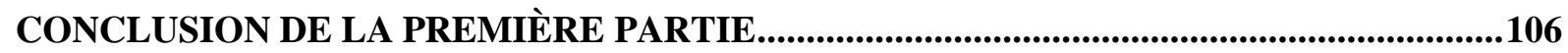

DEUXIEME PARTIE : UN STATUT JURIDIQUE PERFECTIBLE EN VUE DE

L'EXPLOITATION OPTIMALE

DU PORT AUTONOME D'ABIDJAN .......................................................................................107

TITRE I : LES FAIBLESSES DU CADRE JURIDIQUE ACTUEL DE GESTION DU

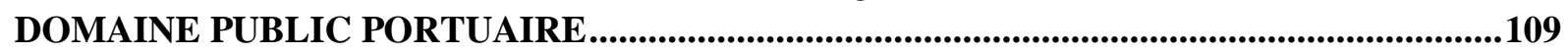

\section{CHAPITRE 1 : LES PESANTEURS DE L'OCCUPATION PRIVATIVE DU DOMAINE}

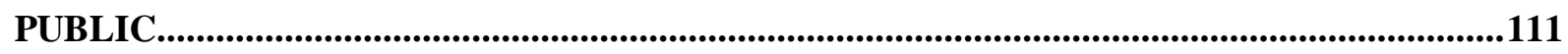

SECTION 1 : Le caractère précaire des occupations privatives du domaine public...................111

Paragraphe 1 : La précarité de l'occupation privative, une résultante de l'inaliénabilité et de

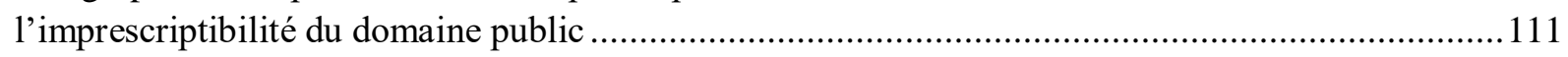

A. Le contenu des principes d'inaliénabilité et d'imprescriptibilité .............................................111

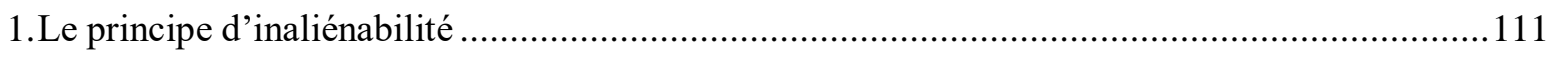

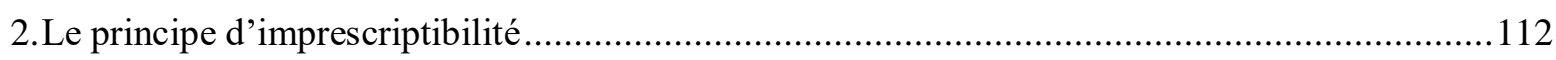

B. Le fondement juridique de la précarité des occupations privatives en droit ivoirien ...................113

Paragraphe 2 : La raison de la précarité de l'occupation privative ..................................................113

A. La protection de la consistance du domaine public et son affectation .........................................114

B. Une possible atténuation de la rigueur inhérente à la précarité ? ..............................................115 
1.La reconnaissance de garanties aux concessionnaires de voirie

2.La reconnaissance des droits réels sur le domaine public

a) Les autorisations d'occupation temporaire constitutives de droits réels ............................117

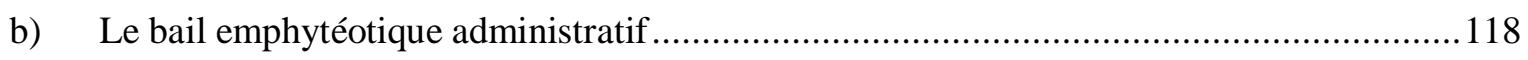

SECTION 2 : Les incidences du principe de précarité ..............................................................119

Paragraphe 1 : L'absence de droit au maintien de l'occupant dans les lieux

A. Faits et procédure suivie dans l'affaire Port Autonome d'Abidjan c/ Entreprises Graviers et Sables (EGS)

B. Observations.

Paragraphe 2 : Possibilité de constituer un fonds de commerce sur le domaine public ?

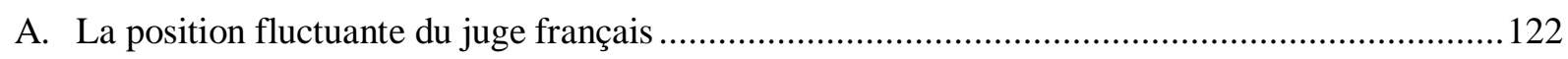

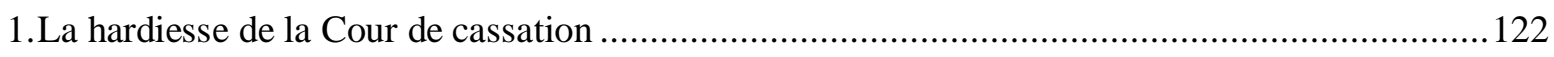

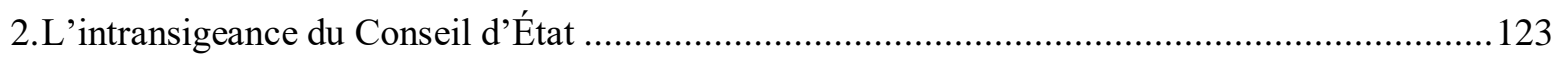

a) Arrêts manifestant le refus de l'existence d'un fonds de commerce sur le domaine public

b) Explication de la position du juge administratif

B. La « loi Pinel »ou la consécration de l'existence du fonds de commerce sur le domaine public.. 125

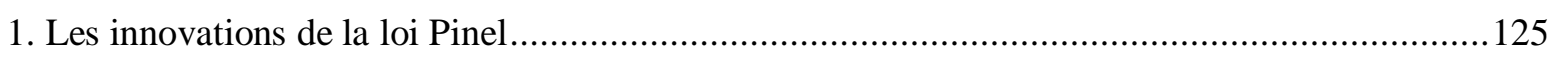

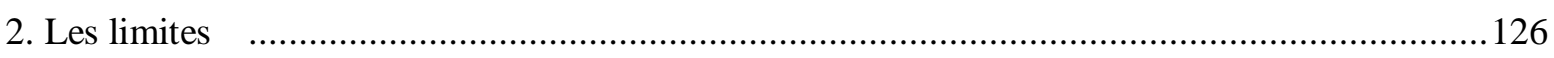

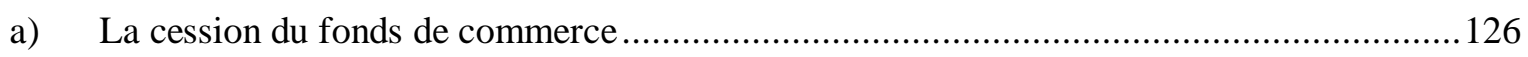

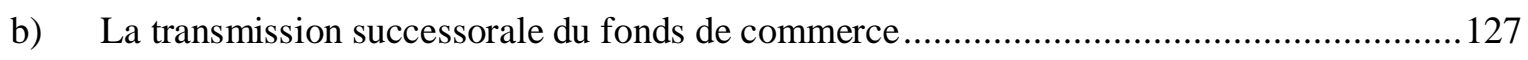

CHAPITRE 2 : LES MANIFESTATIONS DE L'APPLICATION RUGUEUSE DU DROIT

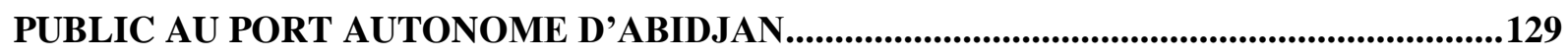

SECTION 1 : Une tendance accentuée du PAA à recourir aux actes administratifs unilatéraux

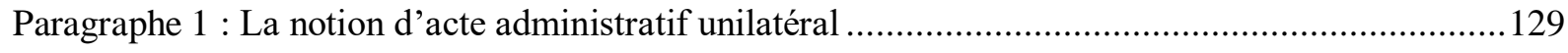

Paragraphe 2 : La panoplie des actes unilatéraux usités pour régir les activités sur la plateforme portuaire d'Abidjan

A. Aperçu des actes unilatéraux usités au Port autonome d'Abidjan............................................131

B. Régime juridique des actes unilatéraux édictés par le Port autonome d'Abidjan .......................131 
SECTION 2 : L'usage systématique des prérogatives de puissance publique reconnues au PAA à l'égard de ses cocontractants ...............................................................................................................132

Paragraphe $1:$ La notion de prérogatives de puissance publique ......................................................133

Paragraphe 2 : Les manifestations de prérogatives de puissance publique usitées par le PAA...........134

TITRE 2 : LA NÉCESSITÉ DE SURMONTER LES FAIBLESSES OBÉRANT LES PERFORMANCES DU

PORT AUTONOME D'ABIDJAN.

\section{CHAPITRE 1 : VARIABILITÉ ET ÉVOLUTION DES MODÈLES ET TECHNIQUES JURIDIQUES DE} GESTION PORTUAIRE.

SECTION 1 : Variabilité des modèles de gestion portuaire .137

Paragraphe 1 : Les principales catégories juridiques observables 137

A. Les ports de services publics 137

B. Les ports outils 138

C. Les ports propriétaires 138

D. Les ports de services privés 138

Paragraphe $2:$ La répartition des ports africains selon les modèles anglais ou français 138

A. L'approche retenue en Afrique anglophone. 139

B. L'approche retenue en Afrique francophone 139

SECTION 2 : Les concessions domaniales à objet complexe : un remède aux limites des concessions portuaires classiques ?

Paragraphe $1:$ Les particularités des concessions domaniales à objet complexe .

A. Les traits caractéristiques des concessions domaniales à objet complexe 140

1.Les concessions à objet complexe, un outil de modernisation de la gouvernance portuaire . 141

2.Les concessions à objet complexe, un outil au service du développement des ports africains

B. Les fortunes diverses des nouveaux modèles concessifs dans les ports africains : cas du Maroc et du Sénégal

1.L'essor des nouveaux modes de concession au niveau du complexe portuaire Tanger-Méditerranée

2.La persistance des modes classiques de concession au Port autonome de Dakar

Paragraphe 2 : Les concessions domaniales à objet complexe, un vecteur de développement économique

\section{CHAPITRE 2 : LES AJUSTEMENTS STATUTAIRES POSSIBLES À LA NATURE} JURIDIQUE DU PORT AUTONOME D'ABIDJAN..

SECTION 1 : La dévolution des activités de réglementation à un établissement public national ou une société d'État.

Paragraphe 1 : Présentation des deux choix possibles 149 
A. Un établissement public national chargé de la gestion du domaine public portuaire...

B. ...Ou une société d'État chargée de la gestion du domaine public portuaire ?

Paragraphe 2 : L'établissement public administratif, la forme juridique appropriée ?

A. Les sujétions de puissance publique

B. Les prérogatives de puissance publique

SECTION 2 : La gestion de l'outillage et des portiques par une société à participation

financière publique majoritaire 154

Paragraphe 1 : Les avantages de la constitution d'une SPFP majoritaire 154

Paragraphe 2 : Les écueils à éviter

CONCLUSION DE LA DEUXIÈME PARTIE 156

CONCLUSION GÉNÉRALE 157

BIBLIOGRAPHIE. 159

RESUME. .171

SUMMARY .173

VALORISATION ADDENDUM .175

CURRICULUM VITAE. 177

TABLE DES MATIÈRES 179 
ANNEXES 


\section{LISTE DES ANNEXES (TEXTES JURIDIQUES)}

1) Loi ${ }^{\circ} 60-85$ du 10 février 1960 portant création d'un établissement public qui prendra le nom de «Port d'Abidjan »;

2) Loi $\mathrm{n}^{\circ} 70-726$ du 31 décembre 1970 portant loi de finances pour la gestion 1971 ;

3) Ordonnance $n^{\circ} 2016-588$ du 03 août 2016 portant titres d'occupation du domaine public ;

4) Décret $n^{\circ 97-614 ~ d u ~} 16$ octobre 1997 relatif à l'exercice des professions de manutentionnaire portuaire et consignataire maritime dans les ports ivoiriens ;

5) Décret $n^{\circ} 97-615$ du 16 octobre 1997 portant réglementation à l'exercice de la profession d'avitailleur maritime dans les ports ivoiriens ;

6) Décret n²001-143 du 14 mars 2001 portant approbation des Statuts du Port autonome d'Abidjan (P.A.A.) et reclassification des immobilisations concédées;

7) Décret du 29 septembre 1928 portant réglementation du domaine d'utilité publique et des servitudes publiques (modifié par décrets du 7 septembre 1935 et du 3 juin 1952);

8) Arrêté GG n`2895 A. E. du 24 novembre 1928 réglementant les conditions d'application du décret du 29 septembre 1928 sur le domaine public et les servitudes d'utilité publique;

9) Circulaires aux opérateurs économiques du Port autonome d'Abidjan ;

10) Annexes des tableaux, graphiques et images. 


\section{B. - Attributions.}

$6^{\circ}$ La conférence est chargée de prendre toutes mesures pour faciliter la mise à exécution par les membres des dispositions de la convention.

$7^{\circ}$ En particulier la conférence :

a) Examine le rapport du président relatant son activité et celle de l'Union depuis la dernière session ;

b) Prend les dispositions nécessaires pour la convocation des réunions d'études administratives et techniques conformément à l'article 5 et fixe les programmes de travail de celle-ci.

c) Approuve les différents fascicules de l'instruction générale ;

d) Prend les dispositions opportunes pour donner suite aux demandes ou rećommandations soumises par les Gouvernements des Eitats de l'Union ;

e) Remplit les autres fonctions prévues dans la présente convention et, dans le cadre de celle-ci, toutes les fonctions jugées nécessaires à la bonne administration de l'Union ;

f) Prépare les rẻvisions à apporter à la convention si elle le juge nécessaire, elle les soumet à la ratification des Gouvernements des Etats.

\section{ARTICLE 5}

\section{Réunions d'études administratives et techniques}

\section{A. - Organisation et fonctionnement.}

10 Les réunions d'études administratives et techniques groupent les directeurs des organisations postales et de télécommunications de chacun des Etats de l'Union ou leurs délégués.

20 Les réunions se tiennent aux lieux et dates déterminés par la conférence des ministres.

$3^{\circ}$. Des personnalités qualifiées peuvent être appelées en séance.

$4^{\circ}$ Les frais de déplacement et de séjour des membres des réunions sont à la charge de chaque Etat membre intéressé.

B. - Attributions.

$5^{\circ}$ Les réunions d'études administratives et techniques sont convoquées pour examiner les questions inscrites à leur ordre du jour fixé par la conférence des ministres ou éventuellement par le président.

\section{ARTICLE 6}

\section{Dénonciation}

La présente convention peut être dénoncẻe par l'un quelconque des Etats signataires dans les formes suivies par son adoption. La dénonciation n'entre en vigueur qu'à compter du $1^{\text {er }}$ janvier suivant sa notification au président de la conférence des ministres et au plutôt six mois après cette notification.

\section{ARTICLE 7}

Mise en vigueur de la convention

La présente convention entrera en vigueur à titre provisoire à compter du 6 octobre 1959 et ne sera définitive qu'après sa ratification dans les formes constitutionnelles par les Etats signataires.
LoI $n^{\circ}$ 60-84 du 10 février 1960, portant organisation et fonctionnement du chemin de fer Abidjan-Niger.

L'ASSEMBLÉE LÉGISLATIVE A ADOPTÉ,

LE Premier Ministre, Ministre DE L'INT'ÉRIEUR, PROMULGUE LA LOI DONT LA TENEUR SUIT :

Article premier. - A compter du $1^{\mathrm{er}}$ janvier 1960, l'exploitation des ivoies ferrées de la république de Côte a' Ivoire est confiè à un organisme à caractère industriel et commercial investi de la personnalité civile et de l'autonomie financière.

Les opérations financières de cet organisme sont effectuées et constatées conformément aux règles en usage dans les établissements commerciaux et industriels.

Art. 2. - L'organisation et le fonctionnement de cet organisme seront fixés par décret pris en conseil des ministres après convention à passer avec la république de la Haute-Volta.

Le décret précisera notamment :

1. La composition et les pouvoirs du conseil d'adminis- . tration et du comité de direction ;

$2^{\circ}$ Les ressources et le mode d'approbation du budget et des divers fonds dont sera doté cet organisme;

$3^{\circ}$ Le cahier des charges techniques et financières auquel cet organisme sera soumis ;

$4^{\circ}$ Les modalités d'exercice d'un contrôle financier des opérations de cet organisme.

Art. 3. - La présente loi sera publiée au Journal officiel de la république de Côte d'Ivoire et exécutée comme loi de l'Etat.

Fait à Abidjan, le 10 février 1960.

$$
\begin{gathered}
\text { A. DENISE, } \\
\text { Ministre d'Etat chargé de l'intérim } \\
\text { du Premier Ministre } \\
\text { et du Ministre des Travaux publics, } \\
\text { des Transports, } \\
\text { des Postes et Télécommunications. }
\end{gathered}
$$

LoI $n^{\circ}$ 60-85 du 10 février 1960, portant création d'un établissement public qui prendra le nom de « Port d'Abidjan».

\section{L'ASSEMBLÉE LÉGISLATIVE A ADOPTÉ,}

Le Premier Ministre, Ministre de L'INTÉRIeUR' PROMULGUE LA LOI DONT LA TENEUR SUIT :

Article premier. - Il est créé un établissement public investi de la personnalité civile et soumis aux règles générales qui régissent la gestion des deniers publics, notamment à celles de la loi organique du 31 décembre 1959, relative aux lois de finances pour assurer l'administration et l'exploitation du port d'Abidjan et de ses accès et dépendances, y compris la station de pilotage, les feux et balises et le phare de Port-Bouet, ainsi que la gestion de son domaine et les études et les travaux de construction, de répelration et d'entretien des ouvrages.

Cet établissement public prend le nom de « Port d'Abidjan ».

Art. 2. - Un décret pris en conseil des ministres, sur la proposition du ministre des Travaux publics, des Transports, des Postes et Télécommunications et du ministre des Finances, des Affaires économiques et du Plan, déterminera l'organisation administrative du port et notamment la composition et les pouvoirs du conseil d'adminis- 
tration, définira ses ressources, le mode d'approbation de son budget, ainsi que le contrôle de la gestion financière, définira la circonscription du port et réglera les dispositions que nécessite la substitution du nouveau régime au régíme antérieur.

Le port et ses dépendances continue à faire partie du domaine public et du domaine privé de l'Etat.

En matière de domanialité et de travaux publics, le port a les mêmes droits et les mêmes obligations que l'Etat.

Art. 3. - Des droits de quai et des taxes de péages peuvent être institués par décret et recouvrés dans le port et à son profit.

Art. 4. - La présent loi sera publiée au Journal of ficiel de la république de Côte d'Ivoire et exécutée comme loi de l'Etat.

Fait à Abidjan, le 10 février 1960.

\section{A. DENISE,}

Ministre d'Etat chargé de l'intérim du Premier. Ministre,

du Ministre des Travaux publics, des Transports,

des Postes et Télécommunications

LoI $n^{\circ}$ 60-86 du 10 février 1960, portant création d'un établissement public qui prendra le nom « d'Office des Postes et Télécommunications de Côte d'Ivoire».

\section{L'ASSEMBLÉE LÉGISLATIVE A ADOPTÉ,}

Le Premier Ministre, Ministre DE L'INTÉRIEUR; PROMUTGGUE LA LOI DONT LA TENEUR SUIT :

Article premier. - A compter du $1^{\text {er }}$ janvier 1960, le service public dès Postes et Télécommunications est confié à un établissement public à caractère industriel et commercial, doté de la personnalité civile et de l'autonomie financière, dénommé Office des Postes et Télécommunications de la république de Côte d'Tvoire.

Art. 2. - Les biens nécessaires au fonctionnement de l'Office seront mis à la disposition par décret pris en conseil des ministres.

L'Office est subrogé dans tous les droits et obligations résultant des contrats, conventions et accords de toute nature passés pour le fonctionnement du sërvice auquel ill succède.

Art. 3. - L'Óffice des Postes et Télécommunications est chargé notamment de l'exploitation du service public des Postes et Télécommunications ; il exerce à cet effet les monopoles postal, télégraphique et téléphonique; il effectue le règlement des valeurs, effets et virements postaux échangés hors de son ressort ; il applique la législation et la réglementation relative aux postes et télécommunications ainsi que les conventions, règlements et arrangements de l'Union postale universelle et de l'Union internationale des télécommunications ; il est également chargé de l'étude et de l'exécution des plans d'équipement des Postes et Télécommunications.

Art 4. - L'Office pourra contracter des emprunts pour le développements ou la construction de liaisons ou d'installations postales, télégraphiques ou téléphoniques nouvelles, y compris bâtiments et logements, suivant"les modalités qui seront déterminées par décret pris en conseil des ministres.

Art. 5. - L'office est administré par un conseil d'administration dont le siège est à Abidjan.
Art. 6. - Le personnel reste soumis aux dispositions du statut général et des statuts particuliers de la Fonction publique ou des régimes d'emploi qui lui sont applicables.

Art. 7. - L'organisation et le fonctionnement de cet Office seront fixés par décret pris en conseil des ministres qui prescrira notamment la composition et les pouvoirs du conseil d'administration, les ressources et le mode d'approbation du budget et des tarifs, compte tenu des dispositions des conventions, règlements et arrangements en vigueur ainsi que les modalités d'exercice du contrôle financier de l'Etat.

Art. 8. - La présente loi sera publiée au Journal officiel de la république de Côte d'Ivoire et exécutée comme loi de l'Etat.

Fait à Abìdjan, le 10 février 1960.

A. DENISE,

Ministre d'Etat chargé de l'intérim du Premier Ministre et du Ministre des Travaux publics, des Transports, des Postes et Télécommunications. "

\section{PREMIER MINISTRF}

ARRÊTÉ $n^{\circ} 4$ PM. SEI. du 10 février 1960, créant un comité interministériel d'information.

\section{LE PREMIER MINISTRE,}

Sur le rapport du secrétaire d'Etat auprès du premier ministre, chargé de l'Information;

Vu les décrets $n^{23} 59-36$ et 59-46 des 30 avril 1959 et 20 mai 1959 , portant nomination des membres du Gouvernement;

$\mathrm{Vu}$ le décret $\mathrm{n}^{\circ}$ 59-61 du $1^{\mathrm{er}}$ juin 1959, déterminant les attributions du secrétaire d'Etat à l'Information,

\section{ARRÊTE :}

Article premier. - Il est créé, auprès du secrétaire d'Etat à l'Information, un comité interministériel chargé :

- D'assurer une liaison plus étroite et plus efficace entre les différents départements ministériels quant aux problèmes de l'information;

- De regrouper régulièrement toute documentation susceptible de faire connaître aux populations de Côte d'Ivoire et à l'extérieur les activités gouvernementales et parlementaires ;

- De faciliter ainsi la préparation régulière d'un bulletin d'information qui tienne compte, en grande partie; d'abord des réalités de la Côte. d'Ivoire, les nouvelles extérieures n'intervenant qu'en complément d'information.

Art. 2. - Ce comité comprend, outre le secrétaire d'Etat à l'Information ou son délégué, président, un représentant de chaque cabinet ministériel.

Il siège deux fois par semaine sur convocation de son président.

Entre deux séances, les informations rédigées sont centralisées au niveau du cabinet du secrétaire d'Etat à l'Information.

Art. 3. - Le présent arrêté sera publié au Journal officiel de la république de Côte d'Ivoire et communiqué partout où besoin sera.

Abidjan, le 10 février 1960.

Félix HOUPHOUET-BOIGNY. 


\section{JOURNAL OFFIGIE \\ de la \\ REPUBLIQUE DE COTE D'IVOIRE} paraissant le jeudi de chaque semaine

\begin{tabular}{|c|c|c|c|c|}
\hline AHONNEMENTS & a mois & UNAN & ABONNLMENTS IT INSERTIONS & ANNONCES EX AYIS \\
\hline 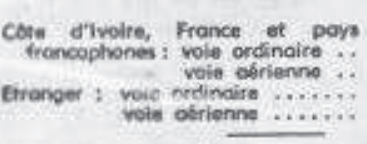 & $\begin{array}{l}1.900 \\
3.200 \\
2.300 \\
3.300\end{array}$ & $\begin{array}{r}3.500 \\
6.000 \\
10.000 \\
10.300\end{array}$ & 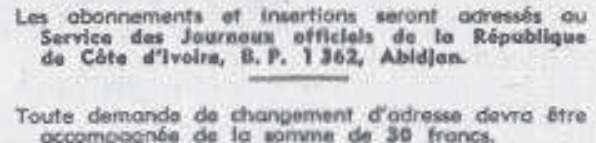 & 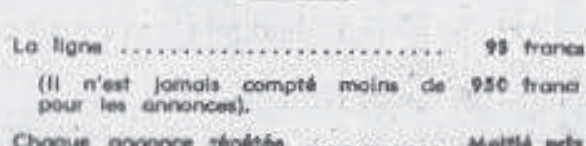 \\
\hline 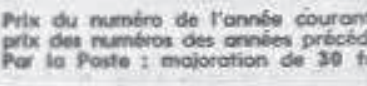 & te $\operatorname{lentes} 1$ & $\begin{array}{l}73 \text { francs } \\
106 \text { fronck } \\
\text { os numbiro. }\end{array}$ & 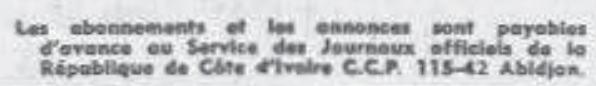 & 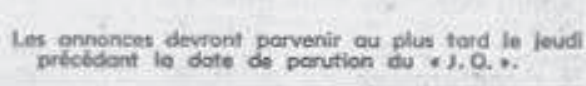 \\
\hline
\end{tabular}

\section{SOMMAIRE \\ PARTIE OFFICIELLE}

\section{ACTES DU GOUVERNEMENT}

81 déc..... Lot $\mathrm{n}^{\circ} \quad 70-726$ portant lot de Finances pour la gestion 1971 .

\section{PARTIE OFFICIELLE}

\section{ACTES DU GOUVERNEMENT}

Lor $n \cdot 70-726$ du 31 décembre 1970 , portant wi de Finances pour la gestion 1971.

L'A SSEMGLÉ NATIONALE A ADOPTB,

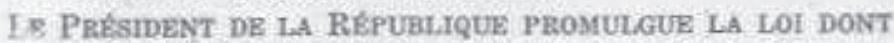
LA TENEUR SUIT:

PREMIERE PARTIE

\section{CONDITIONS GENERALES DE L'EQUILIBRE FINANCIER} TITRE PREMIER

MESURES DYEQUILIBRE

A. - Mesures d̀ coroctére économique

Article premier. - En vue d'agir sur les prix, le Gouvernement pourra décider des exonérations fiscales sur les produits utilitaires destinés à la consommntion courante.

\section{TITRE II}

\section{EQUILIERE FINANCIER}

A. - Dispositions relatives aux ressources, impôts et revenus autorisés Art. 2. - La perception des impôts directs ou indirects th des produits et revenus publics continuera d'être opérée, pour lannée 1971 , conformément rux textes en vigueur. De même, les taxes parafiscales non modifiées continueront à être perçues et effectuées suivant les modalités prévues antérieurement.

Art. 3, - Les produits et revenus applicables au Budget général de Fonctionnement pour ig7i sélevent ấ la somme de 62,7 milliards de francs.

\section{B. - Dispositions roletives aux charges budgótoires.}

Art. 4. - Les plafonds des crédite applicables au Budget général de Fonctionnement pour 197 i s'élèvent à la somme de 62,7 milliards de francs.

\section{DEUXIEME PARTIE \\ MOYENS ET DISPOSITIONS SPECIALES \\ TITRE PREMIER}

Dispositions relatives au Budgot gónéral de Fonctionnement

Art. 5. - Dans la limite du plafond prévu à Particle 4 de la présente loi, il est ouvert, pour 1971, au titre des dépenses de fonctionnement des services publies, des crédits s'appliquant :

Au titre I :

Dettes contractuelles; ì coneurrence de

1.000 .000 .000

Au titre II :

Pouvoirs publics et

Au titre III :

39.835.300.000

Moyens des services, it concurrence de

Au titre IV :

Dépenses communes de personnel et d'entretien, a concurrence de .......

Au titre V :

Transferts et interventions, à concurrence de .....................

Total

12.229 .000 .000

$62.700,000.000$ 
Art. 6. - Le plafond àes avais consenis par 1T tat êt. prévu à Yarticle 53 de la loi dut $8 \hat{i}$ décembre 1959 , organisant les Finances publiques, est fixé pour l'année 1971 à quinze milliards de francs.

Art. 7. - Wen-cours total à recouvrer sur les prêts et avances de l'Etat ne pourra en 1971, être supérieur à cinq cents millions.

\section{TITRE ॥}

\section{DISPOSITIONS RELATIVES AUX BUDGETS ANNEXES}

Art. 8. - A compter du $1^{\text {er }}$ janvier 1971, le Port d'Abidjan est érigé en établissement public à caractère industriel et commercial, doté de la personnalité morale et de l'autonomie financière, placé sous la tutelle technique et administrative du ministre des Travaux publics et des Transports et sous la tutelle financière du ministre de P'Economie et des Finances.

Art. 9. - Les budgets annexes au Budget général de Fonctionnement sont arrêtés en recettes et en dépenses pour 1971 aux chiffres suivants :

Budget annexe de la direction du Maté-

riel des Travaux publies ...........

Budget annexe du Wharf de Sassandra

Budget annexe de la Radio Télévision

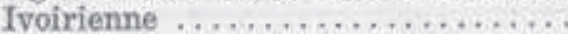

Budget annexe de I'Agence Ivoirienne

de Presse ....................

1.000 .000 .000

90.000 .000

678.500 .000

155.000 .000

Budget annexe des Postes et Télécom-

munications :

- Fonetionnement ...............

- Equipement ..................

3.045 .900 .000

1.064 .300 .000

Budget annexe du Centre Hospitalier

Universitaire ...................

$416,900,000$

Art. 10. - La présente loi sera exécutée comme loi de rEtat et publiée au Journal officiel de la République de Cóte d'Ivoire.

Fait a Abidjan, le 31 décembre 1970.

\section{Félix HOUPHOUET-BOIGNY.}

\section{ANNEXE}

\section{A LA LOI DE FINANCES POUR LA GESTION 1971}

\section{Dispositions d'ordre Exonomique}

Artiele premier, - Le premier paragraphe de trarticle 2 de la loi $\mathrm{n}^{*} 64-293$ du $1^{\text {* }}$ soût 1964 est modifí conme sult :

- La fabrication des boissons alcooliques des $3^{\circ}$, 4t. et $5^{\circ}$ groupes est interdite en Cote d'Twoire en dehors des distillexies industrielles spécialement sgréées par décret et soumises à un contrôle permanent de l'Administration, ct. 2. - Tarticle 3 do la loi $\mathrm{n}^{*} 64-293$ du 10 achit 1964 est 9. sivilich in fine comme suit.

c La même obligation est faite a toute entreprise industriclie egrécé eo livrant à la fabrication d'une boisson alcoolique du 8 , $4^{4}$ et $5^{\circ}$ groupe.

Axt. 3. - Les alinéas 2 at 3 de l'article 82 du déeret foncier du eis fuillet 1932 sont modifiés comme suit

c Toutefois un immeuble immutrieulé ahandonné pendant dix années consécutives par ses occupants légitimes sera considéré comme vacant et incorporé au Domuine de l'tiat.

c Lindue occupation par un tiers ne jastifiant d'aneun títre $n$ interrompt pas cette preseription décennale, 2

Art. 4. - Le decxième alinéa de Particle 2 de la loi n" 62.54 du 12 fósxier 1962, créant un Fonds national d'Investizsement est abroge et remplacé par les dispositions suivantes :

c Les cotisations arrondies au millier de francs inféxieur ne sont 19an mines an recouvrement lorgcue leur montant est égal ou infe. rieur a 61.000 frsnes en ce qui concerne le prélèvement additionnel aux impôts sur les bénéfices et \& 81.000 franes en ce qui concerne le prélevement adaitionnel à la contribution fonciére des propriétén battes: :

\section{Dispositions fiscoles}

Art. 5. - Les dispositions de larticle 12 de l'annexe fiscale at la lof de Finances pour lexercice 1970 sont rapportées.

Art, 6, - Warticle 10 de la loi $n^{*} 69.240$ du 9 jain 1969, portant création d'un Conseil ivolirien des Chargeurs, est abrogé et remplacé par Tarticle suivant :

-Article 10, - Le budget du Conseil est alimenté par les cotiastions des membres et par un prelevvement de $0,15 \%$ applicable a la valeur en Douane à l'importation et à l'exportation par voie maritime.

Art. 7. - 1' Le budget du Centre ivoirien du Commerce extérieur ent alimente :

- Par les sources de financement prévues à Particle 9 du dócrut a" 70-616 du 14 octobre 1970, portant organisation du Centre ivoirien du Commerce extérieur ;

- Par un prélèvement de 0,15 \% appliesble a la ralear en Dounne a 1importation et a P'exportation par voie maritime;

2* Lea biens et matériels exonérés de tons droits et taxes percin en Doune en vertu du Code des Douanes, du tarif douanier ou de toute antre disposition en vigueur, sont ́́galement exonérés du predèvement préva au derniex alinéa ci-deasus ;

3* L'Administration des Donanes est chargée d'assurer la percaption du prelèvement de $0,15 \%$ en faveur du Centre fvoirien ou Commerce extérieur dans les conditions fixćes par larticle 196 du Code des Dousnes.

Art. 8. - L'Administration des Douanes percevra en une perception unique le prelèvement de $0,15 \%$ au bénéfice du Conseil veririen des Chargeurs et le prelevement de $0,15 \%$ an bénéfice du Centre ivoirien du Cornmerce extorieur: elle rêpartirs ensuite, par des veraements a deux comptes ouverts au Trésor a cet effet, le produit
de cette perception unique selon les proportions sulvantea :

- 1/2 au compte du Conseil ivoirien des Changeurs;

- 1/2 au compte du Centre ivoirien du Commerce extérieur.

\section{RECETTES}

Titre 1. - Recettes fiscoles of domaniales.

Section L. - Impóts directs.

Chap, 00-01. - Impóts proportionnels et progressifs sur le nevense.

Art. 01. - Impots sur les bénéfloes . ........................

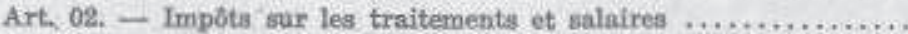

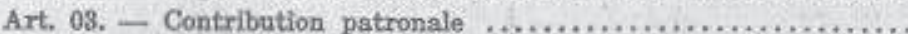

Art. 04. - Impot sénéral sur le revenu ........................ 2.300

Axt. 05, - Exercices 1966 \& 1970

P.M. 


\section{JOURNAL OFFICIEL}

\section{DE LA \\ REPUBLIQUE DE COTE D'IVOIRE}

\section{paraissant les lundi et jeudi de chaque semaine}

\begin{tabular}{|c|c|c|c|c|}
\hline ABONNEMENT & UN AN & ABONNEMENT ET INSERTIONS & \multicolumn{2}{|l|}{ ANNONCES ET AVIS } \\
\hline \multirow{2}{*}{\multicolumn{5}{|c|}{$\begin{array}{l}\text { Cóte d'lvoire et pays de ia } \\
\text { CAPTEAO: voie ordinaire : }\end{array}$}} \\
\hline & 42.000 & Adresser les demandes d'abonnement au chef du & & \\
\hline voie aérienne : .................28.000 & 39.000 & Service des Journaux officiels de la République & 62 lettres ou signes, interlignes et & \\
\hline $\begin{array}{l}\text { communs : voic ordinairc. } \\
\text { voie aérienne }\end{array}$ & 35.000 & de Côte d'Ivoire, B.P. V 70 Abidjan, & 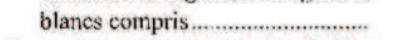 & 2.500 francs \\
\hline Etranger : France et pays cxtérieurs & 90.000 & BCEAO A 00050002 . & Pour chaque annonce répctée, la ligne & 1.500 francs. \\
\hline 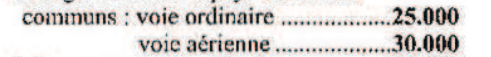 & 35.000 & & & \\
\hline $\begin{aligned} \text { voic aćrienne .........................060 } & \mathbf{2 5 . 0 0 0}\end{aligned}$ & 50.000 & Les abonnés désireux de recevoir un reçu sont priés & II n'est jamais compté moins de & 5000 franco \\
\hline $\begin{array}{l}\text { Autres pays: voie aérienne .........................40.000 } \\
\text { voing }\end{array}$ & 50.000 & d'ajouter à leur envoi le montant de l'affranchissement. & pour les annonecs. & 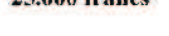 \\
\hline Prix du numéro de l'annéc courante ..................... & .....1.000 & & & \\
\hline Au-delà du cinquième exemplaire ......................... & $1 . . .800$ & Les insertions au I.O.R.C.I, devront parvenir au Scrvice & Pour les exemplaires à certifier et à léga & iser, il sera perçu \\
\hline 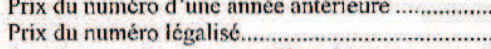 & 1.1 .500 & des Journaux officiels au plus tard le jeudi précédant & en plus du prix du numéro les frais & do timbre et de \\
\hline Pour les cnvois par poste, affranchissement en plt & & la date de parution du \& J.O. & légalisation en vigue & \\
\hline
\end{tabular}

\section{SOMMAIRE}

PARTIE OFFICIELLE

\section{ACTES PRESIDENTIELS}

\section{PRESIDENCE DE LA REPUBLIQUE}

3 août....... Ordonnance $n^{\circ} 2016-588$ pportant titres d'occupation du domaine public.

TEXTES PUBLIES A TITRE D'INFORMATION COOPEC

Bilan

Compte de résultat

\section{PARTIE NON OFFICIELLE}

Avis et annonces.

\section{PARTIE OFFICIELLE}

\section{ACTES PRESIDENTIELS}

\section{PRESIDENCE DE LA REPUBLIQUE}

ORDONNANCE $n^{\circ} 2016-588$ du 3 août 2016 portant titres d'occupation du domaine public.

LE PRESIDENT DE LA REPUBLIQUE,

Sur rapport du ministre des Infrastructures économiques,

Vu la Constitution;
Vu la loi $n^{\circ} 2 \mathrm{C} 15-840$ du 18 décembre 2015 portant budget de l'Etat pour l'année 2016, en son article 12 :

Le Conseil des ministres entendu,

ORDONNE :

\section{CHAPITRE PREMIER}

Dispositions générales

Article 1. - La présente ordonnance s'applique aux biens du domaine public appartenant :

- à l'Etat ;

— aux collectivités territoriales ;

— aux établissements publics ;

Que ces biens soient gérés par la personne publique propriétaire ou par toute personne morale de droit public ou privé ayant reçu mandat de la personne publique propriétaire à cet $\mathrm{cffet}$.

Art. 2. - Au sens de la présente ordonnance on entend par :

- bail emphytéotique administratif, le contrat administratif de location de biens immeubles appartenant au domaine public. Le bail emphytéotique administratif (BEA) de biens immeubles confère au preneur un droit d'occupation du domaine public et un droit réel non seulement sur le titre d'occupation, mais également sur les constructions qu'il va édifier sur le domaine public pendant la durée du bail. Toutefois, les droits réels conférés par le bail emphytéotique administratif ne sont pas librement cessibles et hypothécables. Ce bail doit être consenti pour plus de dix-huit années et ne peut dépasser quatre-vingt-dix-neuf ans ; il ne peut se prolonger par tacite reconduction; 
- contrat de partenariat public-privé, le contrat écrit conclu à titre onéreux par une des personnes morales de droit public ou de droit privé visées à l'article 1 de la présente ordonnance, pour répondre à ses besoins en matière de travaux, de fourniture ou de services, confiant à un preneur une mission globale ayant pour objet, tout à la fois la construction, l'acquisition, la transformation, la rénovation d'ouvrages ou d'équipements nécessaires à un service public, à l'exércice d'une mission d'intérêt général, au développement et à l'exploitation des domaines publics ou privés et tout ou partie de leur financement;

- contravention de voirie, la sanction spéciale destinée à réprimer les infractions à la police de la conservation du domaine public, c'est-à-dire les agissements susceptibles de compromettre l'intégrité matérielle des biens du domaine public ou de ne nuire à l'usage auquel il est légalement destiné ;

- domaine public, les biens des personnes publiques qui ne sont pas classés dans le domaine privé et qui sont soumis à un régime de droit public ;

- droits réels, l'ensemble des prérogatives et obligations de propriétaire reconnu à l'occupant ou au preneur sur les ouvrages réalisés sur le domaine public pendant la durée du titre d'occupation. Certains titres d'occupation du domaine public sont constitutifs de droit réel, notamment un droit de superficie. Les droits réels en cause sont des droits réels administratifs ;

- titres exécutoires, les arrêtés, états, rôles, avis de mise en recouvrement, titres de perception ou de recettes que l'Etat, les collectivités territoriales ou les établissements publics dotés d'un comptable public ou assimilé délivrent pour le recouvrement des recettes de toute nature qu'ils sont habilités à recevoir.

Art. 3. - Les biens du domaine public sont utilisés, conformément à leur affectation, à l'utilité publique. Aucun droit d'aucune nature ne peut être consenti s'il fait obstacle au respect de cette affectation.

Art. 4. - Les biens du domaine public sont insaisissables, inaliénables et imprescriptibles.

L'occupation ou ['utilisation par des personnes privées des dépendances immobilières de ce domaine ne confère pas à ces dernières de droit réel, sous réserve des dispositions des chapitres 3 et 4 de la présente ordonnance.

Art. 5. - Nul ne peut, sans disposer d'un titre l'y habilitant, occuper une dépendance du domaine public de l'une des personnes morales de droit public mentionnées à l'article 1 de la présente ordonnance ou l'utiliser dans des limites dépassant le droit d'usage qui appartient à tous.

Art. 6. - Tout occupant du domaine public a, sauf prescription contraire de son titre, un droit réel sur les constructions et installations de caractère immobilier qu'il réalise pour l'exercice d'une activité autorisée par son titre d'occupation.

Art. 7. - L'occupation ou l'utilisation du domaine public ne peut être que temporaire.

Art. 8. - L'autorisation d'occupation ou d'utilisation du domaine public présente un caractère précaire et révocable.

Art. 9. - Toute occupation ou utilisation du domaine public de l'une des personnes morales de droit public mentionnées à l'article 1 de la présente ordonnance donne lieu au paiement d'une redevance.

Par dérogation aux dispositions de l'alinéa précédent, l'autorisation d'occupation ou d'utilisation du domaine public peut être délivrée gratuitement : $1^{\circ}$ soit lorsque l'occupation ou l'utilisation est la condition naturelle et forcée de l'exécution de travaux ou de la présence d'un ouvrage intéressant un service public qui bénéficie gratuitement à tous ;

$2^{\circ}$ soit lorsque l'occupation ou l'utilisation contribue directement à assurer la conservation du domaine public lui-même.

Art. 10. - La redevance due pour l'occupation ou l'utilisation du domaine public tient compte des avantages de toute nature procurés au titulaire de l'autorisation.

La redevance due pour l'occupation ou l'utilisation du domaine public peut comporter plusieurs composantes, notamment fixes et variables.

Art. 11. - La redevance due pour l'occupation ou l'utilisation du domaine public, par le bénéficiaire d'une autorisation, est payable d'avance et annuellement, sauf disposition contraire du titre d'occupation.

Toutefois, le bénéficiaire peut, à raison du montant et du mode de détermination de la redevance :

- être admis à se libérer par le versement d'acomptes ;

- être tenu de se libérer par le versement de la redevance due soit pour toute la durée de l'autorisation si cette durée n'excède pas cinq ans, soit pour une période quinquennale, dans le cas contraire.

Art. 12. - En cas de retard dans le paiement des redevances dues pour l'occupation ou l'utilisation du domine public de l'une des personnes morales de droit public mentionnées à l'article 1 de la présente ordonnance, les sommes restant dues sont majorées d'intérêts moratoires au taux légal.

Art. 13. - En cas de retrait de l'autorisation avant le terme prévu, pour un motif autre que l'inexécution de ses clauses et conditions, la partie de la redevance versée d'avance et correspondant à la période restant à courir est restituée au titulaire.

Art. 14. - Le recouvrement des produits et redevances du domaine de l'Etat et des collectivités territoriales et en général de toute somme, dont la perception incombe aux comptables publics et assimilés chargés des recettes domaniales, s'opère par la transmission au redevable des titres exécutoires mentionnés à l'article 2 de la présente ordonnance et dans les conditions fixées aux articles 101, 102, 103 et 107 du livre de procédures fiscales.

Art. 15. - Le recouvrement des produits et redevances du domaine que sont habilités à recevoir les établissements publics de l'Etat et les personnes morales de droit public ou privé ayant reçu mandat de la personne publique de gérer une partie de son domaine public, s'opère dans les conditions fixées par les textes qui les créent et les régissent.

L'article 14 ci-dessus s'applique au recouvrement de ces produits et redevances, lorsque ces établissements publics sont dotés d'un comptable public.

Art. 16. - Les produits et redevances du domaine public de l'une des personnes morales de droit public mentionnées à l'article 1 de la présente ordonnance se prescrivent par cinq ans, quel que soit leur mode de fixation.

Cette prescription commence à courir à compter de la date à laquelle les produits et redevances sont devenus exigibles.

Art. 17. - L'action en restitution des produits et redevances de toute nature de l'une des personnes morales de droit public ou de droit privé mentionnées à l'article 1 de la présente ordonnance est soumise à la prescription quadriennale. 
Art. 18. - Le redevable qui conteste l'existence de sa dette, son montant ou son exigibilité peut s'opposer à l'exécution du titre.

Le redevable qui conteste la validité en la forme d'un acte de poursuite émis à son encontre pour recouvrer les produits, redevances et sommes de toute nature, peut s'opposer à son exécution.

Art. 19. - L'introduction devant une juridiction de l'instance ayant pour objet de contester le bien-fondé d'une créance assise et liquidée par une des personnes morales de droit public ou de droit privé mentionnées à l'article 1 de la présente ordonnance suspend la force exécutoire du titre.

L'introduction de l'instance ayant pour objet de contester la régularité formelle d'un acte de poursuite suspend l'effet de cet acte.

L'action dont dispose le débiteur d'une créance assise et liquidée par une personne publique pour contester directement devant la juridiction compétente le bien-fondé de ladite créance se prescrit dans le délai de deux mois suivant la réception du titre exécutoire ou, à défaut, du premier acte procédant de ce titre ou de la notification d'un acte de poursuite.

L'action dont dispose le débiteur de la créance prévue à l'alinéa précédent pour contester directement devant le juge de l'exécution la régularité formelle de l'acte de poursuite diligenté à son encontre se prescrit dans le délai de deux mois suivant la notification de l'acte contesté.

Art. 20. - Les conditions de recouvrement des redevances, les mesures préalables aux poursuites ct l'exercice des poursuites sont prévus par décret.

Art. 21. - Les dépendances du domaine public peuvent être occupées à la suite de l'obtention :

- soit d'une Autorisation d'Occupation temporaire, en abrégé AOT, classique ;

- soit d'une Autorisation d'Occupation temporaire, en abrégé AOT constitutive de droit réel ;

- soit d'un Bail emphytéotique administratif, en abrégé BEA.

CHAPITRE 2

Les autorisations d'occupation temporaire classiques

Art. 22, - Des autorisations d'occupation précaires et révocables peuvent être délivrées par l'Etat, les collectivités territoriales, les établissements publics et les personnes morales de droit public ou privé ayant reçu mandat de la personne publique de gérer une partie de son domaine public :

- soit sous forme d'actes unilatéraux appelés permission de voirie ;

- soit sous forme contractuelle appelée concession de voirie.

Art. 23. - Les autorisations prévues à l'article précédent ne sont pas constitutives de droits réels. Elles sont accordées à titre personnel et ne sont pas transmissibles à des tiers, sauf accord préalable et cxpress de la personne morale de droit public ou de droit privé, propriétaire ou gestionnaire.

Art. 24. - Les droits d'usage du titulaire d'une autorisation d'occupation temporaire classique sont opposables aux tiers.

Le titulaire d'une autorisation d'occupation temporaire classique dispose des actions possessoires et en responsabilité contre les tiers qui troublent sa détention devant les tribunaux ordinaires.

Art. 25. - La permission de voirie est délivrée sous la forme d'un titre d'occupation signé par la personne morale de droit public ou de droit privé, propriétaire ou gestionnaire du domaine public.
Le titre fixe le point de départ et la durée de l'occupation ainsi que les conditions techniques et financières imposées par l'occupation.

Art. 26. - La permission de voirie peut être retirée pour tout motif d'intérêt général.

Le retrait d'une permission de voirie ne vaut pas droit à indemnité au profit du permissionnaire évincé.

Art. 27. - Le bénéficiaire d'une autorisation d'occupation temporaire n'a pas droit à indemnité en cas de dommage de travaux publics.

Ne sont pas susceptibles d'ouvrir droit à indemnité des travaux exécutés par la personne propriétaire, le gestionnaire ou pour leur compte, en vue de la conservation, de l'aménagement, ou de l'utilisation du domaine public conformément à sa destination.

Art. 28. - La concession de voirie est consentie pour une durée déterminée. Elle ne peut être inféricurc à deux ans.

Art. 29. - La conccssion de voirie peut être résiliée pour tout motif d'intérêt général.

Art. 30. - En dehors des cas de sanction pour violation des clauses contractuelles, la résiliation avant terme d'une concession de voirie ouvre droit à indemnité, notarıment lorsque les ouvrages et les investissements réalisés su: le domaine public n'ont pas été amortis.

Art. 31. - Le bénéficiaire d'une : torisation d'occupation temporaire est propriétairc des con: ructions et installations qu'il implante sur le domaine public pendant toute la durée de l'occupation, sauf dans les cas d'outillages publics ou lorsque les ouvrages sont grevés d'une clausc de retour obligatoire.

Art. 32. - A l'expiration du titre d'occupation, les lieux doivent être remis dans leur état primitif par l'occupant, sous peine de se rendre coupable d'une contravention de voirie.

La personne morale de droit public ou de droit privé mentionnée à l'article 1 de la présente ordonnance peut procéder d'office, aux frais de l'occupant, à l'enlèvement des installations et à la remise des lieux dans leur état primitif.

Toutefois, la personne morale de droit public ou de droit privé peut dispenser l'occupant de cette obligation de remise en l'état, et s'approprier, sans indemnité, les installations édifiées.

\section{CHAPITRE 3}

\section{Les autorisations d'occupation temporaire constitutives de droit réel}

Art. 33. - Les personnes morales de droit public ou de droit privé mentionnées à l'article 1 de la présente ordonnance peuvent délivrer des autorisations d'occupation temporaire constitutives de droit réel, dans les conditions déterminées au présent chapitre.

Art. 34. - Les personnes morales de droit public ou de droit privé mentionnées à l'article 1 de la présente ordonnance peuvent délivrer sur leur domaine publie ou le domaine public dont la gestion leur a été confiée, des autorisations d'occupation temporaire constitutives de droit réel, pour l'exercice de toute activité privée ou publique autorisée par ce titre.

Les AOT ainsi délivrées prennent la forme soit :

- d'un acte administratif unilatéral ;

- d'une convention. 
Art. 35. - Outre le droit réel sur le titre, le titulaire d'une autorisation temporaire constitutive de droit réel possède un droit réel sur les ouvrages, constructions et installations de caractère immobilier qu'il réalise pour l'exercice de cette activité. Ce droit réel confère à son titulaire, pour la durée de l'autorisation et dans les conditions et les limites précisées dans le présent chapitre, les prérogatives et obligations du propriétaire.

Le titre fixe la durée de l'autorisation, en fonction de la nature de l'activité et de celle des ouvrages autorisés, et compte tenu de l'importance de ces derniers, sans pouvoir excéder cinquante ans.

Les constructions mentionnées au présent article peuvent donner lieu à la conclusion de contrats de crédit-bail. Dans ce cas, le contrat comporte des clauses permettant de préserver les exigences du service public.

Art. 36. - Le droit réel conféré par le titre sur les ouvrages, constructions et installations de caractère immobilier ne peuvent être cédés, ou transmis dans le cadre de mutations entre vifs ou de fusion, absorption ou scission de sociétés, pour la durée de validité du titre restant à courir, y compris dans le cas de réalisation de la sûreté portant sur lesdits droits et biens et dans les cas prévus aux premier et deuxième alinéas de l'article 35 précédent, qu'à une personne agréée par les personnes publiques mentionnées à l'article 1 de la présente ordonnance, en vue d'une utilisation compatible avec l'affectation du domaine public occupé.

Lors du décès d'une personne physique titulaire d'un titre d'occupation constitutif de droit réel, celui-ci peut être transmis, dans les conditions prévues à l'alinéa précédent, au conjoint survivant ou aux héritiers sous réserve que le bénéficiaire, désigné par accord entre eux, soit présenté à l'agrément de l'autorité compétente dans un délai de six mois à compter du décès.

Art. 37. - Les droits réels sur le titre, les ouvrages, constructions et installations ne peuvent être hypothéqués que pour garantir les emprunts contractés par le titulaire de l'autorisation en vue de financer la réalisation, la modification ou l'extension des ouvrages, constructions et installations de caractère immobilier situés sur la dépendance domaniale occupée.

Les créanciers chirographaires autres que ceux dont la créance est née de l'exécution des travaux mentionnés à l'alinéa précédent ne peuvent pratiquer des mesures conservatoires ou des mesures d'exécution forcée sur les droits et biens mentionnés au présent article. Les hypothèques sur ces droits et biens s'éteignent au plus tard à l'expiration des titres d'occupation délivrés, quels qu'en soient les circonstances et le motif.

Art. 38. - A l'expiration du titre d'occupation, les ouvrages, constructions et installations de caractère immobilier existant sur la dépendance domaniale occupée doivent être démolis, soit par le titulaire de l'autorisation, soit à ses frais, à moins que leur maintien en l'état n'ait été prévu expressément par le titre d'occupation ou que l'autorité compétente ne renonce en tout ou partie à leur démolition.

Les ouvrages, constructions et installations de caractère immobilier dont le maintien à l'expiration du titre d'occupation a été accepté deviennent de plein droit la propriété des personnes morales de droit public ou de droit privé mentionnées à l'article 1 de la présente ordonnance, francs et quittes de tous privilèges et hypothèques.

Art. 39. - Lorsque le retrait de l'autorisation intervient avant le terme prévu, pour un motif autre que l'inexécution de ses clauses et conditions, le titulaire est indemnisé du préjudice direct, matériel et certain né de l'éviction anticipée.
Les règles de détermination de l'indemnité doivent être précisées dans le titre d'occupation.

Les droits des créanciers régulièrement inscrits à la date du retrait anticipé sont reportés sur cette indemnité.

Trois mois au moins avant la notification d'un retrait pour inexécution des clauses et conditions de l'autorisation, les créanciers régulièrement inscrits sont informés des intentions de l'autorité compétente à toutes fins utiles, et notamment pour être mis en mesure de proposer la substitution d'un tiers au permissionnaire défaillant ou de s'y substituer eux-mêmes.

Art. 40. - Les procédures de passation, de contrôle et de modification des autorisations d'occupation temporaire constitutives de droit réel sont prévues par décret.

\section{CHAPITRE 4}

\section{Le bail emphytéotique administratif}

Art. 41. - Un bien immeuble appartenant au domaine public de l'une des personnes morales de droit public ou droit privé mentionnées à l'article 1 de la présente ordonnance peut faire l'objet d'un Bail emphytéotique administratif ou BEA en vue de :

- l'accomplissement, pour le compte de la personne publique, d'une mission de service public dans le cadre d'un contrat de partenariat public-privé ;

- la réalisation d'une opération d'intérêt général relevant de sa compétence, dans le cadre d'un contrat de partenariat public-privé ;

- de sa restauration, de sa réparation ou de sa mise en valeur, dans le cadre ou non d'un contrat de partenariat public-privé.

Le BEA peut prévoir l'obligation pour le preneur de se libérer du paiement de la redevance d'avance, pour tout ou partie de la durée du bail.

Art. 42. - Les BEA doivent remplir les conditions particulières suivantes :

- les droits résultant du bail ne peuvent être cédés, avec l'agrément de la personne publique, qu'à une personne subrogée au preneur dans les droits et obligations découlant de ce bail et, le cas échéant, des conventions non détachables conclues pour l'exécution du service public ou la réalisation de l'opération d'intérêt général ;

- le droit réel conféré au titulaire du bail de même que les ouvrages dont il est propriétaire sont susceptibles d'hypothèque uniquement pour la garantie des emprunts contractés par le preneur en vue de financer la réalisation ou l'amélioration des ouvrages situés sur le bien loué.

Ces emprunts sont pris en compte pour la détermination du montant maximum des garanties et cautionnements qu'une personne publique est autorisée à accorder à une personne privée. Le contrat constituant l'hypothèque doit, à peine de nullité, être approuvé par la personne publique ;

- seuls les créanciers hypothécaires peuvent exercer des mesures conservatoires ou des mesures d'exécution sur les droits immobiliers résultant du BEA. La personne publique a la faculté de se substituer au preneur dans la charge des emprunts en résiliant ou en modifiant le bail et, le cas échéant, les conventions non détachables. Elle peut également autoriser la cession conformément aux dispositions du premier tiret du présent article ;

- les modalités de contrôle de l'activité du preneur par la personne publique propriétaire ou la personne privée gestionnaire du domaine sont prévues dans le BEA; 
- les constructions réalisées dans le cadre de ces BEA peuvent donner lieu à la conclusion de contrats de crédit-bail. Dans ce cas, le contrat comporte des clauses permettant de préserver les exigences du service public.

Art. 43. - A l'issue du BEA, les ouvrages, constructions et installations de caractère immobilier existant sur la dépendance deviennent de plein droit et gratuitement la propriété des personnes morales de droit public mentionnées à l'article 1 de la présente ordonnance, francs et quittes de tous privilèges et hypothèques.

Toutefois, en cas de retrait du titre d'occupation avant le terme prévu, pour un motif autre que l'inexécution de ses clauses et conditions, le titulaire est indemnisé du préjudice direct, matériel et certain né de l'éviction anticipée.

Les règles de détermination de l'indemnité doivent être précisées dans le titre d'occupation.

Les droits des créanciers régulièrement inscrits à la date du retrait anticipé sont reportés sur cette indemnité.

Trois mois au moins avant la notification d'un retrait pour inexécution des clauses et conditions de l'autorisation, les créanciers régulièrement inscrits sont informés des intentions de l'autorité compétente à toutes fins utiles, et notamment pour être mis en mesure de proposer la substitution d'un tiers à l'emphytéote défaillant ou de s'y substituer eux-mêmes.

\section{CHAPITRE 5}

Règlement des litiges

Art. 44. - Les différends ou litiges nés à l'occasion de la passation, de l'exécution, du règlement et du contrôle des $\mathrm{AO} T$ classiques, des AOT constitutives de droit réel et des BEA ne peuvent en aucun cas être portés devant la juridiction compétente avant l'épuisement des voies de recours amiables prévues aux articles 45 à 54 ci-après.

Art. 45. - L'occupant, l'emphytéote et le soumissionnaire peuvent introduire un recours formel préalable à l'encontre des décisions rendues, leur causant préjudice, devant la personne morale de droit public ou de droit privé mentionnée à l'article 1 de la présente ordonnance qui est à l'origine de la décision contestée. La décision de cette dernière, rendue suite à ce recours préalable, peut être, le cas échéant, contestée devant son supérieur hiérarchique ou le cas échéant, devant l'autorité exerçant la tutelle technique.

Art. 46. - Ce recours doit être exercé dans les quinze jours ouvrables de la publication ou de la notification de la décision ou du fait contesté.

Art. 47. - En l'absence de décision rendue par l'autorité à l'origine de la décision contestée, par le supérieur hiérarchique ou le cas échéant par l'autorité exerçant la tutelle technique, dans les quinze jours ouvrables à compter de sa saisine, la requête est considérée comme rejetée.

Dans ce cas, le requérant peut saisir la juridiction compétente dans un délai de deux mois à compter de la décision implicite de rejet.

Art. 48. - La procédure décrite aux articles 49 à 54 est un recours administratif préalable obligatoire avant toute saisine de la juridiction compétente.
Art. 49. - Tout différend que les parties ne peuvent résoudre par elles-mêmes, peut être soumis, à l'initiative de la partie la plus diligente, et selon le cas, à un conciliateur unique ou à une commission de conciliation.

Art. 50. - Avant que le litige ne soit né, les stipulations contractuelles peuvent prévoir une phase de conciliation préalable à la saisine de la juridiction compétente. Dans ce cas, les parties au litige désignent un conciliateur unique parmi une liste de cinq propositions établie par elles au préalable et annexée au contrat.

Art. 51. - La commission de conciliation peut être désignée une fois le litige né. Dans ce cas, la commission de conciliation est composée de trois membres dont un sera désigné par l'une des personnes morales de droit public ou de droit privé mentionnées à l'article 1 de la présente ordonnance, un autre par l'occupant ou l'emphytéote et le troisième par les deux premiers d'un commun accord.

Art. 52. - Les conditions de désignation, de saisine et d : fonctionnement de la commission de conciliation et du conciliateur unique sont précisées par décret.

Art. 53. - La saisine de la commission re conciliation ou du conciliateur unique a un effet suspensif sur le litige.

Art. 54. - La proposition d'avis de règlement de la commission ou du conciliateur unique n'a pas de valeur obligatoire.

Art. 55. - Sous réserve de l'épui sement des voies de recours non juridictionnelles, sont portés devant la Chambre administrative de la Cour suprême les litiges relatifs :

- à l'appartenance d'un bien au domaine public ;

- aux autorisations ou contrats comportant occupation du domaine public, quelle que soit leur forme ou leur dénomination, accordées ou conclus par les personnes morales de droit public ou privé mentionnées à l'article 1 ;

- au principe ou au montant des redevances d'occupation ou d'utilisation du domaine public, quelles que soient les modalités de leur fixation ;

- aux contraventions de voirie ;

— aux baux emphytéotiques administratifs ;

- aux autorisations d'occupation temporaire constitutives de droit réel.

Art. 56. - Les litiges relatifs aux AOT constitutives de droit réel et aux BEA peuvent également être soumis à un tribunal arbitral dans les conditions prévues par l'Acte uniforme de l'OHADA relatif à l'arbitrage.

\section{CHAPITRE 6}

\section{Disposition finale}

Art. 57. - La présente ordonnance abroge toutes les dispositions antérieures qui lui sont contraires.

Art. 58. - La présente ordonnance sera publiée au Journal officiel de la République de Côte d'Ivoire et exécutée comme loi de l'Etat.

Fait à Abidjan, le 3 août 2016. 
Art. 8. - La Commission nationale produit des rapports trimestriels, faisant le point de l'exécution du Programme national de Lutte contre le phénomène des Enfants de la Rue.

Les rapports de la Commission nationale sont présentés au Gouvernement par l'intermédiaire de son Président.

Art. 9. - Le ministre de la Famille et de la Promotion de la Femme, le ministre d'Etat chargé des Relations avec les Institutions, le ministre d'Etat chargé de la Solidarité nationale, le ministre des Affaires étrangères, le ministre de l'Intérieur et de l'Intégration nationale, le ministre de la 'Défense, le ministre de la Justice et des Libertés publiques, le ministre de l'Agriculture et des Ressources animales, le ministre de l'Economie et des Finances, le ministre de l'Enseignement supérieur, de la Recherche et de l'Innovation technologique, le ministre de l'Education nationale et de la Formation de Base, le ministre de l'Enseignement technique et de la Formation professionnelle, le ministre de la Sécurité, le ministre de la Santé publique, le ministre de l'Emploi, de la Fonction publique et de la Prévoyance sociale, le ministre du Commerce, le ministre du Logement, du Cadre de Vie et de l'Environnement, le ministre de la Communication, le ministre de la Culture, le ministre de la Promotion des Jeunes et de la Culture civique, le ministre des Sports, le ministre du Développement de l'Artisanat, sont chargés, chacun en ce qui le conceme, de l'exécution du présent décret qui sera publié au Journal officiel de la République de Côte d'Ivoire.

Fait à Abidjan, le 16 octobre 1997.

Henri Konan BEDIE.

\section{$\longrightarrow$ \\ MINISTERE DELEGUE AUPRES DU MINISTRE DES INFRASTRUCTURES ECONOMIQUES, CHARGE DE L'ENERGIE ET DES TRANSPORTS}

\section{DECRET $n^{\circ}$ 97-614 du 16 octobre 1997 relatif à l'exercice des professions de manutentionnaire portuaire et de consignataire maritime dans les Ports ivoiriens.}

\section{LE PRESIDENT DE LA REPUBLIQUE,}

Sur rapport du ministre délégué auprès du ministre des Infrastructures économiques, chargé de l'Energie et des Transports ;

$\mathrm{Vu}$ la Consitution;

Vu la loi $n^{\circ}$ 61-349 du 9 novembre 1961 portant Code de la Marine marchande ;

Vu la loi $n^{\circ}$ 64-292 du $1^{\text {er }}$ août 1964 relative aux obligations des commerçants;

Vu la loi $n^{\circ} 78-633$ du 28 juillet 1978 relative aux prix, à la poursuite et à la répression des infractions à la législation économique ;

Vu le décret $n^{\circ} 96$ PR. 02 du 26 janvier 1996 portant nomination des membres du Gouvernement, tel que modifié par le décret n 96 PR. 10 du 10 août 1996 ;

Vu le décret $n^{\circ}$ 96-179 du $1^{\text {er }}$ mars 1996 portant attributions des membres du Gouvemement ;

Vu le décret $n^{\circ} 244$ du 13 mars 1996 portant organisation du ministère délégué auprès du ministre des Infrastructures économiques, chargé de l'Energie et des Transports ;

Le Conseil des ministres entendu,
DECRETE :

\section{ARTICLE PREMIER}

Définitions

Est réputé :

$1^{\circ}$ Manutentionnaire portuaire, toute personne morale, auxiliaire du transport maritime, chargée d'accomplir toutes les opérations d'arrimage, de désarrimage, de chargement et de déchargement des marchandises, les opérations de mise et de reprise des marchandises sous hangar et sur terre-plein ou dans les magasins, de même que la garde et la conservation des marchandises destinées à être chargées ou qui ont été déchargées dans les ports de la Côte d'Ivoire ;

$2^{\circ}$ Consignataire maritime, toute personne morale, auxiliaire du transport maritime, chargée, pour le compte de l'armateur ou du transporteur maritime, de recevoir et de délivrer les marchandises ainsi que de pourvoir, le cas échéant, aux besoins du navire et/ou de l'équipage.

\section{ARTICLE 2 \\ Agrément}

L'agrément de manutentionnaire portuaire et/ou de consignataire maritime est délivré pour une période probatoire d'un an, par lettre du ministre chargé de la Marine marchande, après avis de la commission d'agrément visé par les articles 13 , 14 et 15 du présent décret.

Cette disposition ne concerne pas les sociétés déjà agréées avant l'entrée en vigueur du présent décret.

\section{ARTICLE 3}

\section{Titulaire de l'agrément}

$1^{\circ}$ L'agrément de manutentionnaire portuaire et/ou de consignataire maritime ne peut être délivré qu'à une personne morale auxiliaire du transport maritime. Il n'est pas cessible, sauf en cas de fusion-absorption;

$2^{\circ}$ L'agrément n'est valable que pour le port qu'il désigne.

\section{ARTICLE 4}

\section{Conditions de délivrance de l'agrément}

L'agrément de manutentionnaire portuaire et/ou de consignataire maritime n'est accordé qu'aux personnes morales régulièrement constituées et justifiant d'un capital social minimum fixé comme suit :

Pour le port de Commerce

- 150.000.000 de francs pour la manutention portuaire ;

- 50.000.000 de francs pour la consignation maritime ;

- 200.000.000 de francs en cas de cumul des deux activités. Pour le port de Pêche

-70.000 .000 de francs pour la manutention portuaire ;

- 30.000.000 de francs pour la consignation maritime ;

- 100.000.000 de francs en cas de cumul des deux activités.

\section{ARTICLE 5}

\section{Composition du dossier}

Un dossier de demande d'agrément, adressé au ministre chargé de la Marine marchande est à retirer et à retourner, sous pli recommandé, avec accusé de réception, à la direction des Transports maritimes, Fluvio-lagunaires et de Plaisance. Ce dossier retoumé doit comprendre les pièces suivantes : 
$1^{\circ}$ Quelle que soit la forme juridique de la société :

- Une copie de l'avis publié au journal d'annonces légales relatif à la constitution de la société ;

- Une copie des statuts de la société et une copie du récépissé attestant du dépôt de ces statuts au greffe du tribunal ;

— Un extrait du registre du commerce ;

- Une déclaration fiscale ;

- Un compte d'exploitation prévisionnel, une prévision d'investissement en équipements et matériels ;

- Une lettre d'intention de collaboration de la part d'un armateur.

$2^{\circ}$ Sont également exigés :

a) Pour les sociétés anonymes:

- Un certificat de souscription au capital social délivré par un notaire ;

- Une copie du procès-verbal de l'assemblée générale des a innaires au cours de laquelle a été désigné le Président directeur général et, éventuellement, le directeur général ou l'administrateur ayant reçu délégation, conformément aux dispositions prévues dans les statuts de la société et dans la législation relative aux sociétés anonymes.

b) Pour les autres types de sociétés :

- Une photocopie de la carte nationale d'identité ou de toute autre pièce en tenant lieu, du représentant légal ;

- Un extrait du casier judiciaire, datant de moins de trois mois, du représentant légal ;

- Une copie du procès-verbal de l'assemblée des associés au cours de laquelle ont été désignés le ou les gérants, s'il n'est pas ou s'ils ne sont pas gérants statutaires.

\section{ARTICLE 6}

\section{Procédure d'octroi de l'agrément}

La direction des Transports maritimes, Fluvio-lagunaires et de Plaisance reçoit le dossier de demande d'agrément $\epsilon \quad$ uit exemplaires et le transmet dans un délai de sept jours aux membres de la Commission pour instruction.

La Commission d'agrément se réunit dans les quinze jours de la transmission du dossier. Les membres de la Commission peuvent procéder à des enquêtes éventuelles. Elle délibère conformément aux articles 14 et 15 du présent décret. Il en est dressé procès-verbal signé par tous les membres de la Commission.

En cas d'avis défavorable, le président de la Commission d'agrément adresse aux requérants, une note motivée relative à la décision de refus, dans les quinze jours qui suivent la date de la délibération. Ampliation de cette note est faite au ministre chargé de la Marine marchande.

En cas d'avis favorable, le président de la Commission d'agrément prépare un projet de lettre ou d'arêté qui sera soumis à la signature du ministre chargé de la Marine marchande dans les huit jours qui suivent la réunion de la Commission. Ce projet de lettre ou d'arrêté est accompagné du dossier complet de demande d'agrément ainsi que du procès-verbal de délibération de la Commission d'agrément.

Le ministre chargé de la Marine marchande statue dans les quinze jours de la transmission du dossier.
En cas de non respect de ce délai maximum de quarante cinq jours ou en cas de silence de l'Administration à l'issue de celui-ci, la demande d'agrément est réputée acceptée et le bénéficiaire habilité à exercer un recours en régularisation auprès des services compétents du Premier Ministre.

\section{ARTICLE 7}

\section{Renouvellement de l'agrément}

A l'issue de la période probatoire, l'agrément est accordé pour une période de cinq ans renouvelable par arrêté du ministre chargé de la Marine marchande, aux conditions suivantes :

- Respect du programme d'investissement en équipements et en matériels de travail ;

- Présentation d'une attestation d'assurance multirisque pour l'activité de manutention ;

- Présentation d'une attestation d'assurance de responsabilité civile ;

- Respect des règles et usages de la profession ;

- Respect de la réglementation portuaire (règlement de Police, règlement d'exploitation et autres dispositions en vigueur) ;

- Respect des règles d'embauche de la main-d'œuvre docker et kroomen, des tarifs des prestations et autres dispositions.

Cet agrément est soumis au visa annuel du directeur des Transports maritimes conformément à l'annexe fiscale de la loi de Finances.

La demande de renouvellement est adressée au ministre chargé de la Marine marchande sur papier préimprimé à retirer et à retourner à la direction des Transports maritimes, sous pli recommandé, avec accusé de réception.

Cette demande est examinée dans les conditions et délais prévus aux articles 5 et 6 du présent décret conformément auquel, tout refus devra être motivé et notifié au demandeur.

\section{ARTICLE 8}

\section{Extension de l'agrément}

L'extension de l'agrément est accordée dans les mêmes conditions que l'agrément lui-même. Dans ce cas, le formulaire de demande est accompagné uniquement d'une déclaration par laquelle, le requérant atteste qu'il possède dans le port pour lequel il sollicite l'extension de son agrément, une représentation et des installations appropriées pour l'exercice de son activité.

\section{ARTICLE 9}

\section{Enregistrement de l'agrément}

$1^{\circ}$ Il est tenu, à la direction des Transports maritimes, un registre sur lequel sont inscrits tous les manutentionnaires portuaires et consignataires maritimes agréés ainsi que les personnes habilitées à les représenter.

$2^{\circ}$ Aux fins de la tenue à jour du registre susvisé, toute modification dans les statuts de la société, dans la composition du Conseil d'administration et tout changement de personne habilitée à la représenter, doivent être notifiés dans un délai de trente jours à compter de leur date, au ministre chargé de la Marine marchande. 


\section{ARTICLE 10}

Cas de retrait de l'agrément

$1^{\circ}$ En cas de dissolution d'une société titulaire d'un agrément, ou en cas de changement de l'objet social, le ministre chargé de la Marine marchande constate la caducité de l'agrément accordé.

$2^{\circ}$ Le ministre peut faire engager la procédure de retrait de l'agrément :

- Lorsque les modifications prévues à l'article 9 ci-dessus n'ont pas été notifiées dans les conditions visées audit article ;

- Lorsque la Commission d'agrément constate que ces modifications sont contraires aux dispositions du présent decret ;

- Lorsque dans le port où il exerce ses activités, le titulaire de l'agrément n'a pas pendant une période d'un an, satisfait aux obligations énumérées à l'article 7 ci-dessus ;

— En cas de cession de l'agtément à un tiers.

\section{ARTICLE 11}

\section{Procédure de retrait}

Avant le retrait de l'agrément, le ministre chargé de la Marine marchande fait procéder à une enquête par ses services. Pendant cette période, la société fautive est suspendue d'activité.

Le dossier ainsi constitué est transmis à la Commission d'agrément qui émet alors un avis. Le ministre chargé de la Marine marchande statue dans les deux mois qui suivent la date de cet avis. Il rend une décision dâment motivée. En cas de silence à l'issue de ce délai, la procédure de retrait de l'agrément sera réputée nulle et non avenue.

\section{ARTICLE 12}

\section{Notification de décisions}

$1^{\circ}$ Les décisions d'octroi ou de retrait de l'agrément sont publiées au Journal officiel et sont en outre, notifiées individuellement aux requérants par le ministre chargé de la Marine marchande ;

$2^{\circ}$ Les décisions rejetant la demande d'agrément ou la - demande d'extension ou de renouvellement d'agrément sont notifiées individuellement aux requérants par le directeur des Transports maritimes ;

$3^{\circ} \mathrm{La}$ demande d'agrément ou d'extension d'agrément peut être renouvelée après l'expiration d'un délai de six mois suivant la notification de la décision de rejet.

\section{ARTICLE 13}

\section{Composition de la Commission d'agrément}

La Commission d'agrément est composée de six membres répartis comme suit :

$$
\text { président : }
$$

- Le directeur des Transports maritimes.

\section{Membres :}

- Le directeur général des Douanes ou son représentant ;

- Le directeur général du Port autonome d'Abidjan ou son représentant ;
- Le directeur général du Port autonome de San-Pédro ou son représentant ;

- Trois représentants des manutentionnaires et des consignataires désignés par leurs pairs.

\section{ARTICLE 14}

\section{Conpétence de la Commission d'agrément}

La Commission d'agrément :

— Emet des avis sur l'attribution ou le retrait de tout agrément de manutentionnaire portuaire et/ou de consignataire maritime ;

- Peut faire au ministre toute proposition relative à l'organisation de la profession.

\section{ARTICLE 15}

\section{Fonctionnement de la Commission d'agrément}

La Commission d'agrément se réunit sur convocation de son président.

Ses avis sont formulés à la majorité des voix. En cas d'égalité, celle du président est prépondérante. Il est dressé un procès-verbal de chaque séance.

\section{ARTICLE 16}

\section{Mesures conservatoires}

Toute circonstance de nature à empêcher un manutentionnaire portuaire et/ou de consignataire maritime de continuer l'exercice de sa profession peut conduire le ministre chargé de la Marine marchande, compte tenu des intérêts en cause, à prendre toutes mesures conservatoires destinées à assurer le fonctionnement normal de l'entreprise jusqu'à ce que la situation ait pu être régularisée dans le cadre de la réglementation de la profession.

\section{ARTICLE 17}

\section{Infractions et sanctions}

$1^{\circ}$ Les infractions au présent décret sont constatées par les personnes ci-après désignées, qui en informent le directeur des Transports maritimes. Ce sont :

- Administrateurs, officiers et contrôleurs des Affaires maritimes et portuaires ;

- Agents de Police maritime ;

- Tout autre personnel des Affaires maritimes dûment mandaté par le directeur des Transports maritimes ;

- L'autorité portuaire ;

— Les services de la direction générale des Douanes.

$2^{\circ} \mathrm{Ces}$ infractions, sans préjudice de celles prévues par les textes en vigueur, peuvent entraîner de la part du ministre chargé de la Marine marchande, sur proposition du directeur des Transports maritimes, les mesures administratives suivantes :

- Rappel à l'ordre ;

- Mise en demeure ;

- Amende disciplinaire ;

- Suspension de six mois ;

— Retrait de l'agrément. 
Le montant ainsi que l'affectation du produit des amendes sont fixés par les dispositions pertinentes de l'annexe fiscale à la loi de Finances en vigueur.

\section{ARTICLE 18}

\section{Dispositions transitoires}

Un délai de douze mois est accordé aux sociétés de manutention portuaire et de consignation maritime précédemment agréés pour se mettre en conformité avec le présent décret à compter de sa date de signature.

\section{ARTICLE 19}

\section{Dispositions finales}

Le ministre délégué auprès du ministre des Infrastructures économiques, chargé de l'Energie et des Transports est chargé de l'exécution du présent décret qui sera publié au Journal officiel de la République de Côte d'Ivoire.

Fait à Abidjan, le 16 octobre 1997.

Henri Konan BEDIE.

\section{DECRET $n^{\circ} 97-615$ du 16 octobre 1997 portant réglemen- tation de l'exercice de la profession d'avitailleur maritime dans les Ports ivoiriens.}

\section{LE PRESIDENT DE LA REPUBLIQUE}

Vu la Consitution;

Vu la loi $n^{\circ}$ 61-349 du 9 novembre 1961 portant Code de la Marine marchande ;

Vu la loi $n^{\circ}$ 64-292 du $1^{\text {er }}$ août 1964 relative aux obligations des commerçants ;

Vu la loi $n^{\circ} 78-633$ du 28 juillet 1978 relative aux prix, à la poursuite et à la répression des infractions à la Législation économique ;

Vu la loi $n^{\circ} 95-15$ du 12 janvier 1995 portant Code du Travail ;

/u le décret $\mathrm{n}^{\circ} 96$ PR. 02 du 26 janvier 1996 portant nomination des membres du Gouvernement, tel que modifié par le décret $n^{\circ} 96$ PR. 10 du 10 août 1996 ;

Vu le décret $n^{\circ}$ 96-179 du $1^{\text {er }}$ mars 1996 portant attributions des membres du Gouvernement ;

Vu le décret $n^{\circ}$ 96-244 du 13 mars 1996 portant organisation du ministère délégué auprès du ministre des Infrastructures économiques, chargé de l'Energie et des Transpoits ;

Le Conseil des ministres entendu,

DECRETE :

\section{ARTICLE PREMIER}

\section{Champ d'application}

Le présent décret fixe les règles particulières à l'exercice de la profession d'avitailleur maritime.

\section{ARTICLE 2}

\section{Définitions}

Est avitailleur maritime, toute personne morale auxiliaire du transport maritime chargée de fournir à un navire son approvisionnement.

\section{ARTCLE 3}

L'avitaillement maritime s'exécute à quại et au mouillage ainsi que sur les plates-formes pétrolières, en présence des agents des Douanes.

L'accès à bord du navire est soumis à la présentation par l'avitailleur, des propositions du consignataire.

\section{ARTICLE 4}

\section{Agrément}

L'agrément d'avitailleur maritime est délivré, pour une période probatoire d'un an, par lettre du ministre chargé de la Marine marchande, après avis de la Commission d'agrément visé par les articles 16,17 et 18 du présent décret.

\section{ARTICLE 5}

\section{Titulaire de l'agrément}

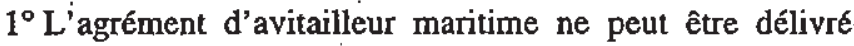
qu'à une personne morale auxiliaire du transport maritime. Il n'est pas cessible, sauf en cas de fusion-absorption ;

$2^{\circ}$ L'agrément n'est valable que pour le port qu'il désigne.

\section{ARTICLE 6}

\section{Conditions de délivrance de l'agrément}

L'agrément d'avitailleur maritime n'est accordé qu'aux personnes morales régulièrement constituées et justifiant d'un capital social minimum de deux millions cinq cents francs.

ARTICLE 7

\section{Composition du dossier}

Un dossier de demande d'agrément, adressé au ministre chargé de la Marine marchande est à retirer et à retourner, sous pli recommandé, avec accusé de réception, à la direction des Transports maritimes, Fluvio-lagunaires et de Plaisance. $\mathrm{Ce}$ dossier retoumé doit comprendre les pièces suivantes :

$1^{\circ}$ Quelle que soit la forme juridique de la société :

- Une copie de l'avis publié au journal d'annonces légales relatif à la constitution de la société ;

- Une copie des statuts de la société et une copie du récépissé attestant du dépôt de ces statuts au greffe du tribunal ;

— Un extrait du registre du commerce ;

—Une déclaration fiscale ;

- Un compte d'exploitation prévisionnel et une prévision d'investissement en équipements et matériels.

$2^{\circ}$ Sont également exigés :

a) Pour les sociétés anonymes :

- Un certificat de souscription au capital social délivré par un notaire ;

- Une copie du procès-verbal de l'assemblée générale des actionnaires au cours de laquelle a été désigné le Président directeur général et, éventuellement, le directeur général ou l'administrateur ayant reçu délégation, conformément aux dispositions prévues dans les statuts de la société et dans la législation relative aux sociétés anonymes. 
Le montant ainsi que l'affectation du produit des amendes sont fixés par les dispositions pertinentes de l'annexe fiscale à la loi de Finances en vigueur.

\section{ARTICLE 18}

\section{Dispositions transitoires}

Un délai de douze mois est accordé aux sociétés de manutention portuaire et de consignation maritime précédemment agréés pour se mettre en conformité avec le présent décret à compter de sa date de signature.

\section{ARTICLE 19}

\section{Dispositions finales}

Le ministre délégué auprès du ministre des Infrastructures économiques, chargé de l'Energie et des Transports est chargé de l'exécution du présent décret qui sera publié au Journal officiel de la République de Côte d'Ivoire.

Fait à Abidjan, le 16 octobre 1997.

Henri Konan BEDIE.

\section{DECRET $n^{\circ} 97-615$ du 16 octobre 1997 portant réglemen- tation de l'exercice de la profession d'avitailleur maritime dans les Ports ivoiriens.}

\section{LE PRESIDENT DE LA REPUBLIQUE}

Vu la Consitution;

Vu la loi $n^{\circ}$ 61-349 du 9 novembre 1961 portant Code de la Marine marchande ;

Vu la loi $n^{\circ}$ 64-292 du $1^{\text {er }}$ août 1964 relative aux obligations des commerçants ;

Vu la loi $n^{\circ} 78-633$ du 28 juillet 1978 relative aux prix, à la poursuite et à la répression des infractions à la Législation économique ;

Vu la loi $n^{\circ} 95-15$ du 12 janvier 1995 portant Code du Travail ;

/u le décret $\mathrm{n}^{\circ} 96$ PR. 02 du 26 janvier 1996 portant nomination des membres du Gouvernement, tel que modifié par le décret $n^{\circ} 96$ PR. 10 du 10 août 1996 ;

Vu le décret $n^{\circ}$ 96-179 du $1^{\text {er }}$ mars 1996 portant attributions des membres du Gouvernement ;

Vu le décret $n^{\circ}$ 96-244 du 13 mars 1996 portant organisation du ministère délégué auprès du ministre des Infrastructures économiques, chargé de l'Energie et des Transpoits ;

Le Conseil des ministres entendu,

DECRETE :

\section{ARTICLE PREMIER}

\section{Champ d'application}

Le présent décret fixe les règles particulières à l'exercice de la profession d'avitailleur maritime.

\section{ARTICLE 2}

\section{Définitions}

Est avitailleur maritime, toute personne morale auxiliaire du transport maritime chargée de fournir à un navire son approvisionnement.

\section{ARTCLE 3}

L'avitaillement maritime s'exécute à quại et au mouillage ainsi que sur les plates-formes pétrolières, en présence des agents des Douanes.

L'accès à bord du navire est soumis à la présentation par l'avitailleur, des propositions du consignataire.

\section{ARTICLE 4}

\section{Agrément}

L'agrément d'avitailleur maritime est délivré, pour une période probatoire d'un an, par lettre du ministre chargé de la Marine marchande, après avis de la Commission d'agrément visé par les articles 16,17 et 18 du présent décret.

\section{ARTICLE 5}

\section{Titulaire de l'agrément}

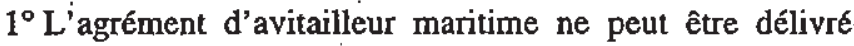
qu'à une personne morale auxiliaire du transport maritime. Il n'est pas cessible, sauf en cas de fusion-absorption ;

$2^{\circ}$ L'agrément n'est valable que pour le port qu'il désigne.

\section{ARTICLE 6}

\section{Conditions de délivrance de l'agrément}

L'agrément d'avitailleur maritime n'est accordé qu'aux personnes morales régulièrement constituées et justifiant d'un capital social minimum de deux millions cinq cents francs.

ARTICLE 7

\section{Composition du dossier}

Un dossier de demande d'agrément, adressé au ministre chargé de la Marine marchande est à retirer et à retourner, sous pli recommandé, avec accusé de réception, à la direction des Transports maritimes, Fluvio-lagunaires et de Plaisance. $\mathrm{Ce}$ dossier retoumé doit comprendre les pièces suivantes :

$1^{\circ}$ Quelle que soit la forme juridique de la société :

- Une copie de l'avis publié au journal d'annonces légales relatif à la constitution de la société ;

- Une copie des statuts de la société et une copie du récépissé attestant du dépôt de ces statuts au greffe du tribunal ;

— Un extrait du registre du commerce ;

—Une déclaration fiscale ;

- Un compte d'exploitation prévisionnel et une prévision d'investissement en équipements et matériels.

$2^{\circ}$ Sont également exigés :

a) Pour les sociétés anonymes :

- Un certificat de souscription au capital social délivré par un notaire ;

- Une copie du procès-verbal de l'assemblée générale des actionnaires au cours de laquelle a été désigné le Président directeur général et, éventuellement, le directeur général ou l'administrateur ayant reçu délégation, conformément aux dispositions prévues dans les statuts de la société et dans la législation relative aux sociétés anonymes. 
b) Pour les autres types de sociétés :

- Une photocopie de la carte nationale d'identité ou de toute autre pièce en tenant lieu du représentant légal ;

- Un extrait du casier judiciaire, datant de moins de trois mois, du représentant légal ;

- Une copie du procès-verbal de l'assemblée des associés au cours de laquelle ont été désignés le ou les gérants, s'il n'est pas ou s'ils ne sont pas gérants statutaires.

\section{ARTICLE 8}

\section{Procédure d'octroi de l'agrément}

La direction des Transports maritimes, fluvio-lagunaires et de Plaisance reçoit le dossier de demande d'agrément en huit exemplaires et le transmet dans un délai de sept jours aux membres de la Commission pour instruction.

La Commission d'agrément se réunit dans les quinze jours de la transmission du dossier. Les membres de la Commission euvent procéder à des enquêtes éventuelles. Elle délibère conformément aux articles 14 et 15 du présent décret. Il en est dressé procès-verbal signé par tous les membres de la Commission.

En cas d'avis défavorable, le président de la Commission d'agrément adresse aux requérants, une note motivée relative à la décission de refus, dans les quinze jours qui suivent la date de la délibération. Ampliation de cette note est faite au ministre chargé de la Marine marchande.

En cas d'avis favorable, le président de la Commission d'agrément prépare un projet de lettre ou d'arrêté qui sera soumis à la signature du ministre chargé de la Marine marchande dans les huit jours qui suivent la réunion de la Commission. Ce projet de lettre ou d'arrêté est accompagné du dossier complet de demande d'agrément ainsi que du procès-verbal de délibération de la Commission d'agrément.

Le ministre chargé de la Marine marchande statue dans 'es quinze jours de la transmission du dossier.

En cas de non respect de ce délai maximum de quarante cinq jours ou en cas de silence de l'Administration à l'issue de celui-ci, la demande d'agrément est réputée acceptée et le bénéficiaire habilité à exercer un recours en régularisation auprès des services compétents du Premier Ministre.

\section{ARTICLE 9}

\section{Octroi et renouvellement de l'agrément}

A l'issue de la période probatoire, l'agrément est accordé pour une période de cinq ans renouvelable par arêté du ministre chargé de la Marine marchande, aux conditions suivantes :

- Respect du programme d'investissement en équipements et en matériels de travail ;

- Respect des règles et usages de la profession ;

- Respect de la réglementation portuaire (règlement de Police, règlement d'exploitation et autres dispositions en vigueur) ;

- Respect des tarifs des prestations et autres dispositions.

Cet agrément est soumis au visa annuel du directeur des Transports maritimes conformément à l'annexe fiscale de la loi de Finances.
La demande de renouvellement est adressée au ministre chargé de la Marine marchande sur papier préimprimé à retirer et à retoumer à ja direction des Transports maritimes, sous pli recommandé, avec accusé de réception.

La demande de renouvellement est examinée dans les conditions et délais prévus aux articles 7 et 8 du présent décret conformément auquel, tout refus devra être motivé et notifié au demandeur.

\section{ARTICLE 10}

\section{Enregistrement de l'agrément}

$1^{\circ}$ Il est tenu à la direction des Transports maritimes, un registre sur lequel sont inscrits tous les avitailleurs maritimes agréés ainsi que les personnes habilitées à les représenter ;

$2^{\circ}$ Aux fins de la tenue à jour du registre susvivé, toute modification dans les statuts de la société, dans la composition du conseil d'administration et tout changement de personne habilitée à la représenter, doivent être notifiés dans un délai de trente jours à compter de leur date, au ministre chargé de la Marine marchande.

\section{ARTICLE II}

\section{Extension de l'agrément}

L'extension de l'agrément est accordée dans les mêmes conditions que l'agrément lui-même. Dans ce cas, le formulaire de demande est accompagné uniquement d'une déclaration par laquelle, le requérant atteste qu'il possède dans le port pour lequel il sollicite l'extension de son agrément, une représentation et des installations appropriées pour l'exercice de son activité.

\section{ARTICLE 12}

\section{Obligations du titulaire de l'agrément}

Tout titulaire de l'agrément doit tenir un cahier de soumissions annuellement visé par la direction générale des Douanes.

\section{ARTICLE 13}

\section{Cas de retrait de l'agrément}

$1^{\circ}$ En cas de dissolution d'une société titulaire d'un agrément, ou en cas de changement de l'objet social, le ministre chargé de la Marine marchande constate la caducité de l'agrément accordé ;

$2^{\circ}$ Le ministre peut faire engager la procédure de retrait de l'agrément :

— Lorsque les modifications prévues à l'article 10 ci-dessus n'ont pas été notifiées dans les conditions visées audit article ;

- Lorsque la Commission d'agrément constate que ces modifications sont contraires aux dispositions du présent décret ;

- Lorsque dans le port où il exerce ses activités, le titulaire de l'agrément n'a pas pendant une période d'un an, satisfait aux obligations énumérées aux articles 9 et 12 ci-dessus ;

- En cas de cession de l'agrément à un tiers. 


\section{ARTICLE 14 \\ Procédure de retrait}

Avant le retrait de l'agrément, le ministre chargé de la Marine marchande fait procéder à une enquête par ses services. Pendant cette période, la société fautive est suspendue d'activité.

Le dossier ainsi constitué est transmis à la Commission d'agrément qui émet alors un avis. Le ministre chargé de la Marine marchande statue dans les deux mois qui suivent la date de cet avis. Il rend une décision doment motivée. En cas de silence à l'issue de ce délai, la procédure de retrait de l'agrément sera réputée nulle et non avenue.

\section{ARTICLR 15}

\section{Notification de décisions}

$1^{\circ}$ Les décisions d'octroi ou de retrait de l'agrément sont publiées au Journal officiel et sont en outre, notifiées individuellement aux requérants par le ministre chargé de ! tarine marchande ;

$2^{\circ}$ Les décisions rejetant la demande d'agrément ou la demande d'extension ou de renouvellement d'agrément sont notifiées individuellement aux requérants par le directeur des Transports maritimes ;

$3^{\circ} \mathrm{La}$ demande d'agrément ou d'extension d'agrément peut être renouvelée après l'expiration d'un délai de six mois suivant la notification de la décision de rejet.

\section{ARTICLE 16}

\section{Composition de la Commission d'agrément}

La Commission d'agrément est composée de six membres répartis comme suit :

\section{Président :}

— Le directeur des Transports maritimes.

\section{Membres :}

- Le directeur général des Douanes ou son représentant ;

- Le directeur général du Port autonome d'Abidjan ou son représentant ;

- Le directeur général du Port autonome de San-Pédro ou son représentant ;

- Deux représentants des avitailleurs.

\section{ARTICLE 17}

\section{Conpétence de la Commission d'agrément}

La Commission d'agrément :

- Emet des avis sur l'attribution ou le retrait de tout agrément d'avitailleur maritime ;

- Peut faire au ministre chargé de la Marine marchande, toute proposition relative à l'organisation de la profession.

\section{ARTICLE 15}

\section{Fonctionnement de la Commission d'agrément}

La Commission d'agrément se réunit sur convocation de son président.

Ses avis sont formulés à la majorité des voix. En cas d'égalité, celle du Président est prépondérante. Il est dressé un procès-verbal de chaque séance.
ARTICLE 19

\section{Mesures conservatoires}

Toute circonstance de nature à empêcher un avitailleur maritime de continuer l'exercice de sa profession peut conduire le ministre chargé de la Marine marchande, compte tenu des intérêts en cause, à prendre toutes mesures conservatoires destinées à assurer le fonctionnement normal de l'entreprise jusqu'à ce que la situation ait pu être régularisée dans le cadre de la réglementation de la profession.

\section{ARTICLE 20}

\section{Infractions et sanctions}

$1^{\circ}$ Les infractions au présent décret sont constatées par les personnes ci-après désignées, qui en informent le directeur des Transports maritimes. Ce sont :

- Administrateurs, officiers et contrôleurs des affaires maritimes et portuaires ;

- Agents de Police maritime ;

- Tout autre personnel des Affaires maritimes dûment mandaté par le directeur des Transports maritimes ;

- L'autorité portuaire ;

— Les services de la direction générale des Douanes.

$2^{\circ} \mathrm{Ces}$ infractions, sans préjudice de celles prévues par les textes en vigueur, peuvent entraîner de la part du ministre chargé de la Marine marchande, sur proposition du directeur des Transports maritimes, les mesures administratives suivantes :

- Rappel à l'ordre ;

- Mise en demeure ;

- Amende disciplinaire ;

- Suspension de six mois ;

- Retrait de l'agrément.

Le montant ainsi que l'affectation du produit des amendes sont fixés par les dispositions de l'annexe fiscale à la loi de Finances en vigueur.

\section{ARTICLE 21}

\section{Dispositions transitoires}

Un délai de douze mois est accordé aux sociétés et aux personnes physiques précédemment agréées en qualité d'avitailleur maritime pour se mettre en conformité avec le présent décret à compter de sa date de signature.

\section{ARTICLE 22}

\section{Dispositions finales}

Le ministre délégué auprès du ministre des Infrastructures économiques, chargé de l'Energie et des Transports est chargé de l'exécution du présent décret qui sera publié au Journal officiel de la République de Côte d'Ivoire.

Fait à Abidjan, le 16 octobre 1997, 


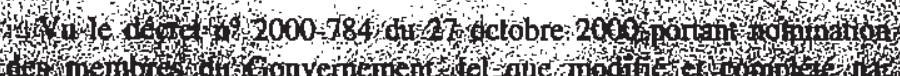

S.

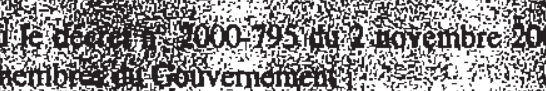

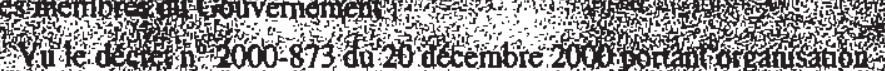

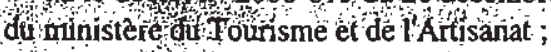

Le Conseil des ministres entendu,

\section{DECRETE :}

DECRET $n^{\circ}$ 2001-26 du 10 janvier 2001. - M. KONE Salifou, mle 065 127-J, administrateur civil, est nommé en qualité d'inspecteur général du Tourisme et de l'Artisanat.

L'intéressé aura droit aux indemnités et avantages prévus par les textes en vigueur.

DECRET $n^{\circ}$ 2001-27 du 10 janvier 2001. - Sont nommës directeurs d'Administration centrale au ministère du Tourisme et de l'Artisanat :

Mme ATSIN Etti Dia, mle 203 758-V, administrateur civil, directeur du Tourisme ;

M. KOUEYYOU Otokoré Christophe, mle 203 862-E, ingenieur industriel, directeur de l'Artisanat.

Les intéressés auront droit aux indemnités et ayantages prévus par les textes en vigueür.

La ministre du Tourisme et de l'Artisanat et le ministre de l'Économie èt des Finances sont chargés, chacun en ce qui le concerne, de l'exécution du présent décret qui sera publié au Journal officiel de la République de Côte d'Ivoire.

Laurent GBAGBO.

DECRET $n^{\circ}$ 2001-89 du 8 février 2001 portant nomination du directeur des. Affaires administratives et financières du ministère du Tourisme et de l'Artisanat.

\section{LE PRESIDENT DE LA REPUBLIQUE,}

Sur rapport conjoint du ministre du Tourisme et de l'Artisanat et du ministre de l'Economie et des Finances,

Vu la Constitution ;

$\mathrm{Vu}$ le décret $n^{\circ}$ 63-163 du 11 avril 1963 portant institution d'une indemnité représentative de frais en faveur des fonctionnaires et agents occupant certains emplois, tel que modifié par le décret $n^{\circ} 81-642$ dù 5 août 1981 ;

Vu le décret $n^{\circ} 2000-795$ du 2 novembre 2000 portant attributions des membres du Gouvemement ;

$\mathrm{Vu}$ le décret $\mathrm{n}^{\circ} 2000-873$ du 20 décembre 2000 portant organisation du ministère du Tourisme et de l'Artisanat ;

$\mathrm{Vu}$ le décret $\mathrm{n}^{\circ} \cdot 2001-42$ du 24 janvier 2001 portant nomination des membres du Gouvernement ;

Le Conseil des ministres entendu,

\section{DECRETE :}

Article premier. - Mlle KASSI Amah Yolande, administrateur des Services financiers, grade A4, mle 256 164-E, est nommée en qualité de directeur des Affaires administratives et financières du ministère du Tourisme et de l'Artisanat.

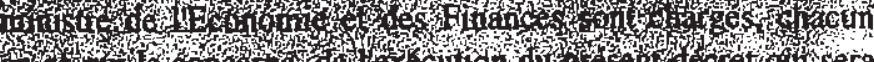

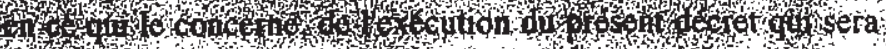

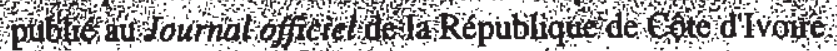

Fait à Abidjar, le 8 févinè 2001.

Laurent GBAGBO.

\section{MINISTERE DES INFRASTRUCTURES ECONOMIQUES}

DECRET $n^{\circ}$ 2001-143 du 14 mars 2001 portant approbation des Statuts du Port autonome d'Abidjan (P.A.A.) et reclassification des immobilisations concédées.

LE PRESIDENT DE LA REPUBLIQUE,

Sur rapport conjoint du ministre des Infrastructures économiques et du ministre de I'Economie et des Finances,

Vu la Constitution ;

Vu la loi $n^{\circ}$ 60-85 de févirier 1960 portant création de l'Etablissement public « Port autonome d'Abidjan »;

Vu la loí $\mathrm{n}^{\circ}$ 94-440 du 16 aøût 1994 déterminant la compósition. l'organisation, les attributions et le fonctionnement de la Cour suprême et abrogeant la loi n ${ }^{\circ} 78-663$ da 5 août 1978 relative à la Cour suprême. telle que modifiée et complétée par la loi $n^{\circ} 97-243$ du 25 avril 1997 ;

Vu la loi $n^{\circ}$ 97-519. du 4. septembre 1997 portant définition et organisation des sociétés d'Etat ;

Vu le décret $n^{\circ} 72-07$ du 11 janvier 1972 fixant les modalités de fonctionnement du "Fonds emploi des bénéfices réalisés". par les sociétés d'Etat ;

Vu le décret $n^{\circ}$ 92-940 du 23 décembre 1992 portant transformation du Port autonome d'Abidjan en société d'Etat ;

$\mathrm{Vu}$ le décret $\mathrm{n}^{\circ} 2001-42$ du 24 janvier 2001 portant nomination des membres du Gouvernement ;

Vu le décret $n^{\circ} 2001-91$ du 11 février 2001 portant attributions des membres du Gouvemement ;

Vu le décret $n^{\circ} 2000-488$ du 12 juillet 2000 portant orgánisation du ministère des Infrastructures,

Le Conseil des ministres entendu, DECRETE :

Article premier. - Sont approuvés les statuts de la société d'Etat Port autonome d'Abidjan, ci-après annexés, harmonisés conformément aux dispositions de la loi $n^{\circ}$ 97-519 du 4 septembre 1997 portant définition et organisation des Sociétés d'Etat et de l'Acte uniforme relatif aux Sociétés commerciales et au Groupement d'Intérêt économique.

Art. 2. - Sont placés sous le régime de la concession, les terrains du domaine public de l'Etat et le canal de Vridi.

Tous les biens et autres éléments d'actif initialement concédés sont désormais classés comme éléments du patrimoine de la Société d'Etat Port autonome d'Abidjan.

Art. 3. - Le capital social du Port autonome d'Abidjan, société d'Etat, est de 16.000.000.000 de francs C.F.A., entièrement libérés et détenus par l'Etat, par incorporation des réserves subsistantes eu égard à la valeur du patrimoine de ladite Société, suite à la cession de certains biens. 
Art. 4. - Toutes dispositions antérieures contraires à celles du présent décret sont abrogées.

Art. 5. - Le ministre des Infrastructures économiques et le ministre de l'Economie et des Finances sont chargés, chacun en ce qui le concerne, de l'exécution du présent décret qui sera publié au Journal officiel de la République de Côte d'Ivoire.

Fait à Abidjan, le 14 mars 2001.

GBAGBO Laurent.

\section{STATUTS DU PORT AUTONOME D'ABIDJAN}

\section{SOCIETE D'ETAT \\ au capital de 16.000 .000 .000 de francs C.F.A.}

\section{TITRE PREMIER}

\section{GENERALITES, DENOMINATION, SIEGE SOCIAL, OBJET SOCIAL, LIMITES TERRITORIALES, DUREE, CAPITAL SOCIAL}

Article premier. - Le Port autonome d'Abidjan est une société d'Etat placée sous la tutelle technique et administrative du ministre chargé des Infrastructures portuaires et sous la tutelle économique et financière du ministre de l'Economie et des Finances, régie par la loi $\pi^{\circ} 97-519$ du 4 septembre 1997 portant définition et organisation des sociétés d'Etat et ses décrets d'application, par les dispositions de l'Acte uniforme relatif au Droit des Sociétés commerciales et du Groupement d'Intérêt économique, ainsi que par les présents statuts.

Art. 2. - La dénomination de la société est « Port autonome d'Abidjan » en abrégé « P.A.A. ». Dans tous les actes, factures, annonces, publication et autres documents émanant de la société, la dénomination sociale doit toujours être précédée ou suivie immédiatement des mots écrits lisiblement et en toute lettre «Société d'Etat régie par la loi $n^{\circ}$ 97-519 du 4 septembre 1997 portant définition et organisation des sociétés d'Etat, et par le décret $n^{\circ}$ 92-940 du 23 décembre 1992 portant transformation du Port autonome d'Abidjan (P.A.A.) en société d'Etat » ainsi que de l'énonciation du montant du capital social, et de la mention de l'immatriculation au registre du Commerce.

Art. 3. - Le siège social de la société est fixé à : rue A22 des Piroguiers, boulevard du Port, B.P. V 85 Abidjan.

Toutefois, il peut être transféré en tout autre lieu de la même ville sur décision du conseil d'administration et en tout autre lieu par décret en conseil des ministres, sur rapport conjoint des ministres de tutelle, après avis, le cas échéant, du conseil d'administration.

Art. 4. - Le Port autonome d'Abidjan, directement et indirectement, dans les limites de ses circonscriptions et dépendances, a pour objet :

- La gestion administrative et comptable de l'ensemble des éléments formant le domaine public portuaire et du matériel ferroviaire ; l'acquisition du matériel portuaire; le suivi de la gestion de l'exploitation du service concédé ;

- L'exploitation et l'entretien des installations portuaires ;

- La réalisation de toutes les opérations d'exploitation rattachées aux activités portuaires notamment remorquage, acconage, entreposage, manutention, avec la possibilité de les concéder à des sociétés nationales privées ou d'économie mixte, toutes les sociétés appelées à exercer ces opérations y compris celles de transit, d'avitaillement et de consignation devant préalablement recevoir l'avis favorable du Port autonome d'Abidjan avant tout agrément par les services compétents ;

— La gestion du domaine mobilier et immobilier ;

- La réalisation des travaux de construction, d'extension, d'amélioration, de renouvellement, de reconstruction et de dragage ;

— La coordination des activités de tous les services publics et privés concernant l'exploitation du Port ;
- et généralement l'accomplissement, de toutes opérations industrielles, commerciales, mobilières, immobilières et financières se rattachant à son objet ou de nature à favoriser le dévelöppement de ses activités ;

- Pour la réalisation de ses objectifs, le Port autonome d'Ábidjan peut créer et aménager des zones industrielles portuaires nouvelles ou participer à une telle création ou un tel aménagement.

Pour les grands travaux d'entretien des infrastructures de base. de création, d'extension ou de renouvellement d'ouvrages importants, les ministres de tutelle peuvent proposer la prise en charge par l'Etat d'une partie ou de la totalité de leur financement.

Le Port autonome d'Abidjan reçoit à titre de concession et gratuite'ment, uniquement les terrains aménagés du domaine public et le Canal de Vridi.

Le reste des biens et autres éléments d'actif sont classés comme éléments du patrimoine de la société.

Ces remises de biens sont exonérées des impositions de toute nature.

La société est mandataire de l'Etat pour toutes les questions concernant le service public portuaire.

Art. 5. - Les limites territoriales du Port autonome d'Abidjan sont définies par le plan de délimitation conformément au décret $n^{\circ} 98-151$ du 25 mars 1998.

Le Port et ses dépendances font partie du domaine public et privế de l'Etat.

Art. 6. - La durée de la société est fixée à quatre-vingi-dix-neuf années à compter du jour de sa constitution définitive, par immatriculation au registre du commerce d'Abidjan, sauf les cas de dissolution anticipée ou de prorogation prévus aux présents stạtuts.

Art. 7. - Le capital social de la société est fixé à 16.000.000.000 de francs C.F.A.

Il est reparti en 1600000 actions d'une valeur nominale de 10.000 francs C.F.A. chacune, entièrement libérées et appartenant toutes à l'Etat de Côte d'Ivoire.

Il peut être ouvert à d'autres personnes morales de Droit public ivoiriennes.

Art. 8. - Le capital social peut faire l'objet d'une augmentation. en une ou plusieurs fois, par la création d'actions nouvelles, ou par incorporation de réserves ou de bénéfices. Les décisions d'augmentation du capital, de fusion, scission, transformation, dissolution et en général toutes décisions de modification statutaire sont prises par décret.

Art. 9. - Les conditions et modalités de réduction du capital sor sont fixées par décret après avis du conseil d'administration.

Art. 10. - Les cessions d'actions doivent être autorisées par décret. sans préjudice, le cas échéant, de l'application des dispositions législatives et réglementaires régissant la privatisation des entreprises et actif de l'Etat.

Dans le cas où, par fusion, scission, cession d'actions ou augmentation de. capital, la societé viendrait à ne plus satisfaire aux conditions de l'article 2 de la loi $n^{\circ}$ 97-519 du 4 septembre 1997 portant définition et organisation des sociétés d'Etat, elle deviendrait de plein droit soumis aux règles régissant les sociétés anonymes ou, le cas échéant, les sociétés à participation financière publique. Il serait alors satisfait aux règles de publicité relatives aux sociétés anonymes.

\section{TITRE II}

\section{ADMINISTRATION DE LA SOCIETE CONSEIL D'ADMINISTRATION}

Art. 11. - L'Administation du Port autonome d'Abidjan est assurée par un conseil d'administration.

Les membres du conseil d'administration, représentants permanents de l'Etat ou des autres personnes morales de Droit public actionnaires. sont nommés et révoqués par décret en Conseil des ministres. sur rapport conjoint des ministres de tutelle, après avis, le cas échéant, des personnes morales de Droit public actionnaires dont ils sont les représentants permanents. 
Le conseil d'administration est composé de neuf membres au moins -et de douze membres au plus dont le président, désignés par les ministères et les structures spécifiques, selon la configuration du Gouvernement.

Ce'sont :

- Premier Ministre : un représentant ;

- Ministère chargé des Infrastructures économiques : deux représentanis dont le président ;

— Ministère chargé de l'Economie et des Finances : un représentant ;

- Ministère chargé du Commerce : un représentant ;

—Ministère chargé des Transpờts : un représentant ;

— Ministère chargé de la Défense : un représentant ;

- - Le directeur général de l'Administration des Douanes ;

— Le président de la Chambre de Commerce et d'Industrie ou son représentant.

Art. 12. - Les administrateurs sont nommés et révoqués par décret en Conseil des ministres, sur rapport conjoint des ministres de tutelle, après avis, le cas échéant, des personnes morales de Droit public actionnaires dont ils sont les représentants permánents.

La durée du mandat d'administrateur 'est de trois ans, renouvelable au maximum deux fois. Ils sont révocables à tout moment par décret.

En cas de vacance d'un ou de plusieurs sièges d'administrateurs, il est pourvu à leur remplacement par décret dans un délai de trois mois à compter du jour où se produit la vacance, et pour la durée restant à courir du mandat.

Art. 13. - Le conseil d'administration élit parmi ses membres un président. Le conseil d'administration peut le révoquer à tout moment.

L'élection ou la révocation du président par le conseil est entérinée par"décret en Conseil de ministres.

En cas d'empêchement temporaire de ce dernier, le conseil d'administration peut déléguer un autre administrateur dans. les fonctions de président. Cette délégation est donnée pour une durée qui ne peut excéder six mois. Elle n'est pas renouvelable.

Art. 14. - Les administrateurs perçoivent dans les conditions qui sont fixées par décret, en rémunération de leur activité au sein du conseil d'administration, une somme fixe annuelle à titre de jetons de présence.

Des rémunérations exceptionnelles peuvent être alloués par le conseil d'administration à certains de ses administrateurs pour des missions ou mandats spéciaux. Ces rémunérations sont soumises à la procédure de contrôle et d'approbation prévue à l'article 18, ci-dessous, relative aux Conventions réglementées.

Art. 15. - Le conseil d'administration met en cuvre la politique portuaire définie par le Gouvemement et prend à cet effet toutes décisions appropriées dns les domaines de la gestion de l'exploitation, des travaux, des outillages.

Art. '16. - Le conseil d'administration est investi des pouvoirs les plus étendus pour agir en toute circonstance au-nom de la société dans la limite de l'objet social et des pouvoirs expressément réservés par la loi ou les statuts.

Il exerce les attributions ci-après :

- Il détermine la.politique générale de la société et donne au directel̆r général les instructións nécessaires à l'exécution de cette politique ;

- Il. approuve les programmes pluriannuels d'activités et d'investissement ;

- Il approuve les projets de budget et les comptes prévisionnels ;

- Il autorise les acquisitions et les aliénations de patrimoine immobilier ainsi que les prises de participation financière ;

- Il établit et arrête les comptes de fin d'exercice ;

- Il approuve le régime particulier applicable au personnel ;
- Il approuve le projet de règlement ou d'accord collectif d'établissement ;

- Il définit la politique tarifaire de la société ;

- Il fixe le cadre organique de la société ;

- Il autorise les emprunts.

Art. 17. - Le conseil d'administration se réunit sur la convocation de son président, dans un délai de quinze jours au moins avant la date de l'assemblée à son initiative, ou à la demande du directeur général. chaque fois que l'intérêt de la société l'exige et au moins une fois par trimestre.

Il peut inviter à ses réunions à titre consultatif toute personne dont il juge utile d'entendre les avis.

Le conseil d'administration ne délibère que si la moitié au moins de ses membres est présente ou représentée.

Un administrateur ne peut être représenté que par un autre administrateur. De même un administrateur ne peut recevoir qu'une seule procuration.

Les décisions sont prises à la majorité des voix des membres présents ou'représentés, la voix du président étant prépondérante en cas de partage.

Les délibérations du conseil d'administration sont constatées par des procès-verbaux inscrits sur un registre spécial tenu au siège de la - société, signés du président et d'un administrateur désigné en qualité de secrétaire de séance.

Ces procès-verbaux mentionnent en outre le nom des administrateurs présents, excusés ou absents.

Les copies ou extraits de ces procès-verbaux à produire en Justice ou ailleurs sont certifiées conformes à l'original par le président.

Art. 18. - Toute Convention entre la société et ses administrateurs, son directeur général et ses directeurs généraux adjoints soit directement, soit indirectement, soit par personne interposée, doit être soumise a l'autorisation préalable du conseil d'administration.

Cette autorisation n'est pas requise pour les Conventions portant sur des opérations courantes conclues à des conditions normales.

L'administrateur, le directeur général ou le directeur général adjoint intéressé informe le conseil d'administration préalablement à toute Convention réglementée.

L'administrateur intêressé ne prend pas part au vote sur l'autorisation sollicitée.

Le président du conseil d'administration transmet la Convention autorisée aux ministres de tutelle pour approbation.

Le président du conseil d'administration avise les commissaires aux Comptes dès l'approbation donnée.

Les Conventions qui n'ont êté ni approuvées, ni autorisées sont nulles de plein droit.

Il est interdit aux administrateurs, au directeur général, aux directeurs généraux adjoints ou à leurs adjoints, ascendants ou descendants, à peine de nullité du contrat et sans préjudice de leur responsabilité, de contracter des emprunts auprès de la société d'Etat, de se faire consentir par elle un decouvert ou compte courant. ou de faire garantir par elle leurs engagements envers les tiers.

Il en est de même des Conventions de prêts ou de garantie auxquelles un administrateur, le directeur général ou un directeur général adjoint est indirectement intéressé ou dans lesquelles il traite avec la société par personne interposée.

Art. 19. - Les administrateurs sont responsables, individuellement ou solidairement selon le cas, envers la société ou les tiers, soit des fautes commises dans leur gestion soit des actes qu'ils auraient accomplis en infraction des dispositions légales ou réglementaires en vigueur.

L'action en responsabilité se prescrit par cinq ans à compter du fait dommageable, ou de sa révélation s'il a été dissimulé.

Toutefois, lorsque le fait est qualifié crime, l'action se prescrit par dix ans. 


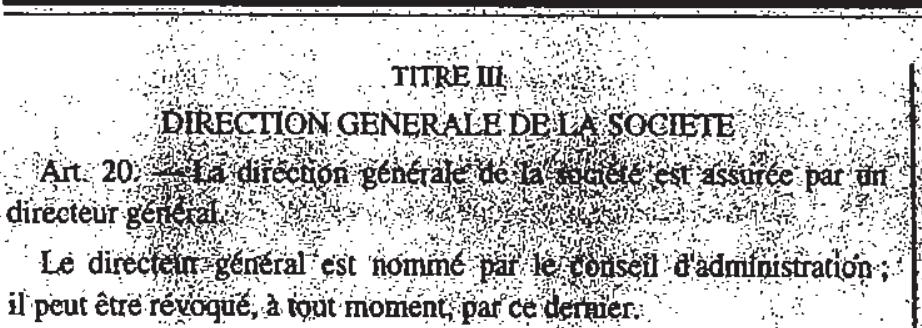

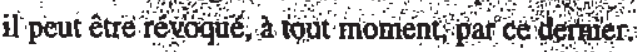

Les rémuinerations des fonctions du dúfecteưr gennéral sont fixées par le conseil d'administration.

Le directeur général est assisté de un ou deux directeurs généraux adjoints nommés eux aussi par le conseil d'administration sur proposition du đirecteur générai.

Art. 21. - En cas de nomination d'un seul directeur général adjoint, ce dernier assiste le directeur général pour la coordination et le suivi de toutes les activités de l'ensemble des directions et services de la société.

Les conditions de cette assistance sont proposées par le directeur général et approuvées par le conseil d'administration.

En cas de nomination de deux directeurs generaux adjoints, ces demiers assistent le directeur général pour la coordination et le suivi de toutes les activités de l'ensemble des directions et services de la société, en fonction des domaines de compétence de chacun.

Les conditions de cette assistance sont proposées par le directeur général et approuvées par le conseil d'administration suivant les attributions ci-dessous :

- L'un sera chargé de la conduite des affaires administratives, financières, commerciales et de l'exploitation;

- L'autre sera chargé de la conduite des dossiers techniques, du développement du Port en général, de la conduite des projets d'infrastructures et d'equipements en particulier.

Art. 22. - En cas d'absence du directear général, l'intérim de la direction générale, pour ce qui est de la représentation de la société, est assuré obligatoirement de façon altemative par un directeur général adjoint désigné à cet effet par le directeur général.

En ce qui conceme la gestion des affaires courantes, l'intérim de la direction générale sera assuré à la fois par l'un ef l'autre des directeurs généraux adjoints conformément à leurs attributions et domaines de compétences.

Art. 23. - En cas d'empêchement du directeur général, les fonctions de directeur général peuvent être confiées au président du conseil d'administration.

Le conseil d'administration peut alors, en cas d'urgence ou pour cause de vacance, donner mandat d'assumer provisoirement la direction générale de la société soit à son président si celui-ci n'est pas déjà investi de cette fonction, soit à toute autre personne physique. Ce mandat n'est donné que pour une durée limitée à la vacance et prend fin à compter de la nomination d'un nouveau directeur général.

Art. 24. - Le directeur général exerce tous pouvoirs de gestion sous résrve des attributions du conseil d'administration et dans la limite de l'objet social.

Notamment :

- Il est chargé de l'exécution d'une part des textes réglementaires intéressant le Port et, d'autre part, des décisions du conseil d'administration;

- Il procède aux achats, passe et signe les marchés, contrats et Conventions, en assure l'exécution et le contrôle dans le cadre du budget ;

- Il est chargé de la gestion du domaine public et privé de l'Etat affecté au Port ;

- Il accorde les autorisations d'occupation du domaine portuaire ;

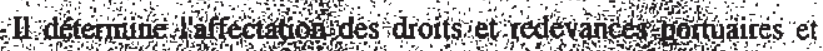

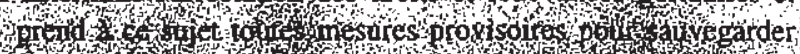

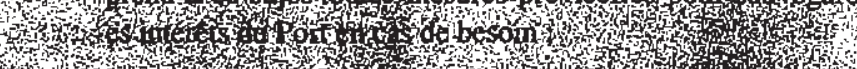
H.

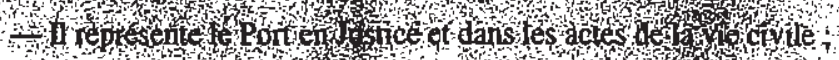

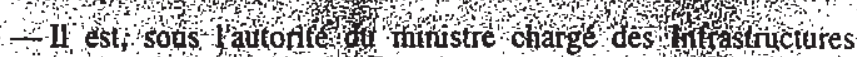
portuaires et confomęment a la réglementâtón en viguéur, chef de l'Information nautique en Côtéd'Ivoire.

Art. 25. - Le directeur général peut également recevoir délégation de pouvoirs da conseil d'administration pour l'exécution dé certaines de ses attributions dans le respect des pouvoirs qui lui sont expressément réservés par les dispositions législatives et reglementaires en vigueur et par les présents statuts. Les conditions de cette délégation sont fixées par ledit conseil.

Art. 26. - Le directeur général présente annuellement les états financiers au conseil et lui soumet un rapport de gestion faisant notamment le point sur l'exécution des budgets et des programmes pluriannuels d'activités.

Art. 27. - Conformément à la réglementation en vigueur, le directeur général est, dans les limites de la circonscription du Port et de $\mathrm{s} r$ dépendances, l'agent du pouvoir central.

A ce titre, il est chargé de la coordination de tous les services publics en ce qui concerne les affairés qui intéressent directement l'exploitation du Port.

Il exerce également une action générale de contrôle suri tous les services publics et privés en ce qui concerne les affaires qui intéressent directement l'exploitation du Port. Les conditions dans, lesquelles s'exerce celte action sont précișées par arrêté interministériel pour lés services dépendant d'un département ministériel autre que celui de tutelle du Port autonome d'Abidjan.

Il exerce enfin un contrôle sur les entreprises publiques et privées utilisant le domaine portuaire tant sur le plan des opérations que sur celui des tarifs qu'elles pratiquent et dont l'homologation est décidée après son avis.

Il exerce, dans ce cadre, un contrôle global sur les conditions d'emploi et de gestion de la main-d'ouvre dockers.

Art. 28. - La société, représentée par son directeur général, a la qualité d'employeur à l'égard du personnel qu'elle emploie. Ce personnel est régi par les dispositions du Code du Travail.

A ce titre, il recrute dans le cadre du Code du Travail, des Convention. collectives et de tout régime particulier approuvé par le conseil d'administration, tous les agents et employés de la société, fixe leur rémunération, décide de leur avancement et met fin à leur engagement.

Il nomme aux différents postes de responsabilité.

Il procède notamment à la nomination des directeurs de service après consultation du président du conseil d'administration.

\section{TITRE IV}

\section{GESTION FINANCIERE BUDGET GESTION COMPTABLE}

Art. 29. - L'exercice social a une durée de douze mois qui commence le $1^{\text {er }}$ janvier de chaque année et finit le $3 i$ décembre de la mêmè année.

Art. 30. - Le Port autonome d'Abidjan dispose des ressources ordinaires et des ressources extraordinaires suivantes :

Ressources ordinaires:

- Le produit des droits et redevances sur les navires ;

- Le produit des droits et redevances d'embarquement et de débarquement des marchandises, des produits et des passagers ;

- Le produit des droits et redevances dues à l'occasion de l'utilisation de l'outillage du Port ; 
— Le produit des droits et redevances de toute nature dont la perception aura été régulièrement autorisée.

Ressources extraordinaires :

— Les intérêts de ses fonds ;

- Les produits des emprunts et des participations ;

- Les subsides de l'Etat, des Collectivite territoriales, des Chambres consulaires ainsi que des particuliers donnés sous forme de subvention en capital ou d'annuité ;

- Les subventions exceptionnelles d'exploitation ;

- Les dons et legs ;

- Toutes autres ressources.

Art. 31. - A peine de nullité de toute délibération contraire, il est pratiqué sur le bénéfice de l'exercice, une dotation égale à un dixième au moins à la formation d'un fonds de réserve dit « réserve légale *. Cette dotation cesse d'être obligatoire lorsque la réserve atteint le cinquième du montant du capital social.

Art. 32. - Les disponibilités du Port autonome d'Abidjan sont déposées auprès de la Caisse autonome d'Amortissement ou de toute autre Institution financière publique ou privée.

Art. 33. - Chaque année, avant la fin de l'exercice, le directeur général du Port autonome d'Abidjan prếsente pour approbation par conseil d'administration, le budget et le compte d'exploitation de l'exercice suivant.

Ces documents sont transmis, dans le mois suivant leur adoption, au ministre chargé de l'Economie et des Finances, par la direction générale.

Le ministre chargé de l'Economie et des Finances peut, dans un délai d'un mois à compter de la date de réception desdits documents, demander au conseil d'administratin d'y introduire toute modification tendant au respect de l'équilibre financier de la sociẹté et à celui de ses engagements contractuels éventuès à l'égard de l'Etat.

L'absence d'observation du ministre charge de l'Economie et des Finances vaut approbation.

\section{Gestion complable}

Art. 34: - Le bilan et les documents comptables de fin d'exercice sont arrêtés et établis dans les délais et conformément aux dispositions législatives et réglementaires applicables aux sociétés anonymes.

La sociêté est tenue de publier son bilan dans un joumal d'annonces 'égales dans le mois suivant son approbation par le ministre chargé de Economie et des Finances.

Art. 35. - A la clôture de chaque exercice, le conseil d'administration dresse l'inventaire des éléments d'actif et de passif de la société, établit les documents comptables et documents annexes de l'exercice et rédige un rapport sur l'activité đe la société pendant cet exercice.

Le bilan et les documents comptables de fin d'exercice sont approuvés par le ministre chargé de l'Economie et des Finances dans un délai de six mois à compter de la clôture de l'exercice.

A défaut d'approbation expresse ou de demande de révision, le bilan et les documents comptables de fin d'exercice sont réputés approuvés.

En cas de demande de révision, le ministre chargé de l'Economie et des Finances peut désigner des professionnels qualifiés et indépendants pour un audit de la société dans les conditions et selon une fréquence qu'il fixe.

Art. 36. - Après approbation des comptes, les ministres de tutelle décident de l'affectation des résultats de l'exercice sur proposition; du conseil d'administration.

\section{TITRE V}

\section{CONTROLE ET VERIFICATION DES COMPTES}

Art. 37. - Les comptes du Port autonome d'Abidjan sont vérifiés annuellement par deux commissaires aux Comptes choisis sur la liste des commissaires agréés par la Cour d'Appel d'Abidjan.
Ils sont nommés pour trois exercices sociaux par le ministre chargé del'Economieet des Finances: Leurs fonctions expirent après approbation par le ministre chargé de l'Economie e... des Finances, des comptes du troisième exercice de leur mandat.

En cas d'empêchement ou de défaillance de l'un d'entre eux, il est pourvu à son remplacement.

Le commissaire ainsi nommé ne demeure en fonction que jusqu'à l'expiration du mandat de son prédécesseur.

Art. 38. - Les commissaires aux Comptes ont pour mission permanente de vérifier, eńsemble ou séparément les documents, livres et valeurs de la société et de contrôler la régularité et la sincérité des comptes sociaux, des informations données dans les rapports du conseil d'administration et dans les documents adressés aux ministres de tutelle.

Ils certifient la régularitế et la sincérité de l'inventaire des documents comptables et des documents annexes établis en fin d'exercice.

Ils transmettent leurs rapports au ministre chargé de l'Economie et des Finances:

Art. 39. - Les commissaires aux Comptes sont obligatoirement convoqués à la réunion du conseil d'administration qui artête les comptes de l'exercice écoulé, ainsi que le cas échéant, à toute autre réunion du conseil d'administration.

La convocation est faite par lettre recommandée avec accusé de réception au plus tard quinze jours au moins avant la délibération du conseil.

Dans tous les cas les commissaires aux Comptes n'ont que voix consultative.

Art. 40. - Les commissaires aux Comptes sont responsables, tant à l'égard de la société que des tiers, des conséquiences dommageables des fautes et négligences par eux commises dans l'exercice de leurs fonctions.

Ait. 41. - Le Port autonome d'Abidjan est soumis au contrôle de la Chambre des Comptes de là Cour suprême dans les conditions fixées par la législation en vigueur:

\section{TITRE VI}

\section{MODIFICATION, TRANSFORMATION ET DISSOLUTION}

Art. 42. - A toute époque et dans toutes circonstances, la dissolution de la société peut être décidée par décret en Conseil des ministres sur proposition des ministres de tutelle.

Si du fait des pertes constatées dans le bilan et les documents comptables de fin d'exercice, approuvés par le ministre chargé de l'Economie et des Finances, l'actif net de la société devient inférieur à la moitié du capital, un décret pris dans les quatre mois qui suivent l'approbation desdits comptes, décide de la dissolution de la société ou de la continuation de ses activités.

A la dissolution de la société un ou plusieurs liquidateurs sont nommés par le décret de dissolution.

En cas de dissolution, le décret la prononçant fixe les conditions et modalités de la liquidation.

\section{TITRE VII}

\section{DISPOSITIONS DIVERSES}

Art. 43. - Le Port autonome d'Abidjan est soumis à un régime fiscal et douanier particulier défini par arrêté du minitre chargé de l'Economie et des Finances.

Art. 44. - Les présents statuts entrent en vigueur à compter de la date de signature du décret dont ils constituent l'annexe.

Art. 45. - Tous différends, litiges ou contestations avec les tiers qui peuvent s'élever pendant la durée de la société ou de sa liquidation. soit entre les actionnaires et sociétés, soit entre les actionnaires eux-mêmes, au sujet des affaires sociales, sont jugés conformément à la jurisprudence des tribunux du siège social. 
A cet effet, en cas de contestation, tout actionnaire doit faire élection de domicile dans le ressort du tribunal du siège social et toutes issignations ou significations sont régulièrement donnêes à ce - lomicile.

Art. 46. - Les présents statuts secont enregistrés et publiés conformément à la loj.

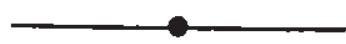

\section{MINISTERE DE LA CONSTRUCTION ET DE L'URBANISME}

\section{Concessions accordées à titre provisoire}

LE MINISTRE DE LA CONSTRUCTION ET DE LURBANISME,

$\mathrm{Vu}$ la Constitution ;

Vu le décret $n^{\circ} 71-74$ du 16 février 1971 relatif aux procédures domaniale et foncière :

Vu le décret $n^{\circ} 2000-783$ du 27 octobre 2000 portant nomination du Premier Ministre ;

Vu le décret $n^{\circ} 2000-784$ du 27 octobre 2000 portant nomination des membres du Gouvernement, tel que modifié et complété par le décret $n^{\circ} 2000-792$ du 2 novembre 2000 ;

Vu le décret $n^{\circ} 2000-795 \cdot d u 2$ novembre 2000 portant attributions des membres du Gouvemement ;

Vu l'arrêté n 2164 du 9 juillet 1936 modifié par l'arrêté $n^{\circ} 83$ du 31 janvier 1938 réglementant l'aliénation des terrains domaniaux ;

Sur proposition du chef de Service,

ARREIE :

ARRETE n 3946 MLU. SDU. ACP. TA. DC. du 21 décembre 1999. - Il est concédé à titre provisoire à M. et Mme AMON Téhoua, le lot $n^{\circ} 4621$, îlot 458 de Yopougon-Attié, neuvième tranche, d'une superficie de 525 mètres carrés, immatriculé au nom de I'Etat sous le numéro 66084 de la circonscription foncière de Bingerville.

ARRETE n 3947 MLU. SDU. ACP. TA. DC. du 21 décembre 1999. - Il est concédé à titre provisoire à M. AKENOU Guedéhi Benjamin, le lot $n^{\circ} 4916$, îlot 125 de YopougonNiangon-Nord, deuxième tranche, d'une superficie de 224 mètres carrés, immatricule au nom de l'Etat sous le numéro 62470 de la circonscription foncière de Bingerville.

ARRETE $n^{\circ} 3948$ MLU. SDU. ACP. TA. DC. du 21 décembre 1999. - Il est concédé à tiţre provisoire à $\mathrm{M}$. et Mme KADJO Koffí Séraphin, le lot $n^{\circ} 5402$, îlot 490 de Yopougon-Banco-Nord, deuxième tranche, d'une superficie de 1099 mètres carrés, immatriculé au nom de l'Etat sous le numéro $3 \dot{5} 122$ dé la circonscription foncière de Bingerville.

ARRETE $n^{\circ} 3953$ MLU. SDU. ACP. TA. NYJ. du 21 décembre 1999. - Il est concédé à titre provisoire à M. KONE Saibou, le lot $n^{\circ} 39$, îlot 6 de Yopougon-Gare, d'une superficie de 500 mètres carrés, immatriculé au nom de l'Etat sous le numéro 94331 de.la circonscription foncière de Bingerville.
ARRETE nº 3954 MLU. SDU. ACP. AA. AA. du 21 décembre 1999. - Il est concédé à titre provisoire à Mlle DOUMBIA Namaraman, le lot $n^{\circ} 4012$ bis, îlot 1 de Cocody-Les-DeuxPlateaux, septième tranche, d'une superficie de 860 mètres carrés, immatriculé au nom de l'Etat sous le numéro 95812 de la circonscription foncière de Bingerville.

ARRETE $n^{\circ} 3978$ MLU. SDU. ACP. TA. NYJ. du 22 décem-bre 1999. - Il est concédé à titre provisoire à M. AKOSSI Noël, le lot $n^{\circ} 1825$, îlot 184 d'Abobo-Anyama PK 18, d'une superficie de 600 mètres carrés, immatriculé au nom de l'Etat sous le numéro 96295 de la circonscription foncière de Bingerville.

ARRETE $n^{\circ} 3980$ MLU. SDU. ACP. TA. NYJ. du 22 décem-bre 1999. - Il est concédé à titre provisoire à M. DIAR-RASSOUBA Siriki, le lot $n^{\circ} \mathrm{D}$, îlot 238 bis de Yopougon-Andokoi, d'unè superficie de 776 mètres carrés, immatriculé au nom de l'Etat sous le numéro 96320 de la circonscription foncière de Bingerville.

ARRETE $n^{\circ} 3981$ MLU. SDU. ACP. TA. NYJ. du 22 décem-bre 1999. - Il est concédé à titre provisoire à M. ABODOU N'rho Grégoire, le lot $n^{\circ} 1830$, îlot 184 d'Abobo-Anyam. PK 18, d'une superficie de 600 mètres carrés, immatriculi au nom de l'Etat sous le numéro 96296 de la circonscriptic $n$ foncière de Bingerville.

Le chef de servic :Domaine urbain est chargé de l'exécution des présents arrêtés qui seront publiés au Journal officiel de la République de Côte d'Ivoire.

TIAPANI Kakou.

ARRETE $n^{\circ} 151$ MCE. SDU. ST. du 3 mai 2000. Il est prononcé au profit de M. AKO Amaffé Roger, le transfert de la concession provisoire du $\operatorname{lot} n^{\circ} 3826$, îlot 310 des Deux-Plateaux, septième tranche (Partie Djibi), d'une superficie de 484 mètres carrés, immatriculé au nom de l'Etat sous le numéro 58144 de la circonscription foncière de Bingerville (section cadastrale OW).

Vincent Essoh LOHOUES.

ARRETE $n^{\circ} 263$ MCU. SDU. du 29 décembre 2000. Il est accordé à la société GANDOUR, 01 B.P. 3838 Abidjan 01, la concession provisoire avec promesse de bail emphytéotique, du lot $\mathrm{n}^{\circ} \cdot 308$, îlot 38 d'une superfiçie de 12844 mètres carrés sis en zone industrielle de Yopougon, immatriculé aù nom de l'Etat sous le numéro 77535 de la circonscription foncière de Bingerville. 


\section{DÉCRET DU 29 SEPTEMBRE 1928, PORTANT RÉGLEMENTATION DU DOMAINE D'UTILITÉ PUBLIQUE ET DES SERVITUDES PUBLIQUES (MODIFIÉ PAR DÉCRETS DU 7 SEPTEMBRE 1935 ET DU 3 JUIN 1952)}

Article 1. Font partie du domaine public dans les Colonies et Territoires de l'AfriqueOccidentale française :

a. Le rivage de la mer jusqu'à la limite des plus hautes marées ainsi qu'une zone de 100 mètres mesurée à partir de cette limite ;

b. Les cours d'eau navigables ou flottables dans les limites déterminées par la hauteur des eaux coulant à pleins bords avant de déborder, ainsi qu'une zone de passage de 25 mètres de large à partir de ces limites sur chaque rive et sur chacun des bords des îles ;

c. Les sources et cours d'eau non navigables ni flottables dans les limites déterminées par la hauteur des eaux coulant à pleins bords avant de déborder :

d. Les lacs, étangs et lagunes dans les limites déterminées par le niveau des plus hautes eaux avant débordement, avec une zone de passage de 25 mètres de large à partir de ces limites sur chaque rive extérieure et sur chacun des bords des îles ;

e. Les canaux de navigation et leurs chemins de halage, les canaux d'irrigation et de dessèchement et les aqueducs exécutés dans un but d'utilité publique, ainsi que les dépendances de ces ouvrages ;

f. Les chemins de fer, les routes, les voies de communication de toute nature et les dispositifs de protection de ces voies, les conduites d'eau, les conduites d'égouts, les ports et rades, les digues maritimes et fluviales, les sémaphores, les ouvrages d'éclairage et de balisage, ainsi que leurs dépendances ;

g. (D. 3 juin 1952)1. Les lignes télégraphiques et téléphoniques, ainsi que leurs dépendances ; h. Les ouvrages déclarés d'utilité publique en vue de l'utilisation des forces hydrauliques et du transport de l'énergie électrique ;

i. Les ouvrages de fortification des places de guerre ou des postes militaires, ainsi qu'une zone large de 250 mètres autour de ces ouvrages ;

j. Et généralement les biens de toute nature que le code civil et les lois françaises déclarent non susceptibles de propriété privée.

Article 2. Les riverains des cours d'eau non navigables ni flottables sont soumis à une servitude de passage sur une zone large de 10 mètres sur chaque rive.

Article 3. (D. 3 juin 1952)2. Les terrains et bâtiments des propriétés privées sont soumis à toutes les servitudes de passage, d'implantation, d'appui et de circulation nécessitées par l'aménagement des conduites d'eau, des conduites d'égouts et des dispositifs de protection des voies de communication ou, par l'établissement, l'entretien, l'exploitation des lignes télégraphiques et téléphoniques et des conducteurs d'énergie électrique ou de forces hydrauliques classés dans le domaine public. 
En cas de doute ou de contestation sur les limites du domaine public ou l'étendue des servitudes établies en vertu de l'article 2 et du présent article, il est statué par décision du Lieutenantgouverneur de chaque colonie, sauf recours au Conseil du contentieux administratif.

Article 4. Toutes proprietés privées urbaines sont en outre susceptibles d'être assujetties aux servitudes d'hygiène, d'esthétique, d'alignement et de sécurité publique, qui peuvent être imposées par le plan d'aménagement et l'extension dont les conditions d'établissement et d'exécution sont fixées par le Gouverneur général après avis du Conseil privé ou du conseil d'administration de la Colonie et, le cas échéant, des assemblées municipales intéressées.

Des associations syndicales de propriétaires peuvent être, ainsi que l'office des habitations économiques de l'Afrique-Occidentale française, chargées de l'exécution des plans d'aménagement, suivant des modalités approuvées comme il est dit ci-dessus.

Le Gouverneur général statue dans les mêmes formes et sauf recours au Conseil d'État, sur les contestations relatives à l'étendue des servitudes résultant des plans d'aménagement et d'extension.

Article 5. Aucune indemnité n'est donc due aux propriétaires en raison des servitudes établies en vertu des articles 2, 3 et 4 ci-dessus

Article 6. Le Lieutenant-gouverneur accorde, par arrêté rendu en Conseil privé ou en Conseil d'administration, les autorisations d'occuper le domaine public elles dérogations aux servitudes de passage, sous la réserve que ces autorisations et dérogations sont à tous moments révocables sans indemnité, pour un motif d'intérêt public, et sous réserve également des règles qui pourraient être posées, à cet effet, par les arrêtés généraux prévus à l'article 8 ci-après.

Article 7. Les portions du domaine public, autres que celles qui sont affectées par décret et que les ouvrages de fortification, qui seraient reconnues sans utilité pour les services publics ou l'intérêt général, pourront être déclassées et affectées par arrêté du Lieutenant-gouverneur, rendu en Conseil et approuvé par le Gouverneur général en Commission permanente du Conseil du Gouvernement.

Pour les postes militaires, la zone de 250 mètres peut être réduite ou supprimée, sur proposition du Lieutenant-gouverneur et du commandant militaire, par arrêté du Gouverneur général, après avis du Général commandant supérieur.

Article 8. Des règlements généraux arrêtés par le Gouverneur général en Conseil de Gouvernement peuvent édicter les règles relatives à la police, à la conservation et à l'utilisation du domaine public, à la police du roulage ainsi qu'à l'exercice des servitudes d'utilité publique et des servitudes militaires.

Le Gouverneur général pourra déléguer aux Lieutenant-gouverneurs le soin de déterminer par arrêtés les mesures d'exécution et les conditions d'application desdits règlements.

Les infractions à ces règlements et arrêtés sont déférées aux Tribunaux de simple police et passibles de peines de 1 à 500 francs d'amende; en cas de récidive dans les douze mois ou de non-exécution des travaux prescrits dans un laps de temps déterminé par le Tribunal, l'amende peut être triplée et il peut, en outre, être prononcé une peine d'emprisonnement de cinq jours au plus, le tout sans préjudice de la réparation des dommages causés ou de la démolition, aux frais du contrevenant, des ouvrages indûment établis sur le domaine public et dans les zones de servitude, ou de l'exécution, également à ses frais, des travaux prescrits.

Article 9. Les détenteurs de terrains compris dans le domaine public qui possèdent ces terrains en vertu de titres réguliers et définitifs antérieurs à la promulgation des décrets du 20 juillet 
1900 pour le Sénégal et dépendances du 20 juillet 1900 pour la Côte d'Ivoire, du 5 août 1900 pour le Dahomey, du 24 mars 1901 pour la Guinée française, ne pourront être dépossédés, si l'intérêt public venait à l'exiger, que moyennant le payement ou la consignation d'une juste et préalable indemnité.

Il en serait de même dans le cas où l'intérêt public exigerait pour l'exercice des servitudes prévues aux articles 2,3 et 4 la démolition des constructions ou l'enlèvement des clôtures ou plantations établies par lesdits détenteurs antérieurement à la promulgation des décrets cidessus visés.

L'indemnité sera fixée, sauf recours au Conseil du Contentieux administratif, par une Commission arbitrale de trois membres, dont un sera désigné par le Lieutenant-gouverneur, un autre par le propriétaire et le troisième par les deux premiers d'un commun accord.

Dans le cas où le propriétaire n'aurait pas désigné son arbitre dans un délai de trois mois et dans le cas où l'accord ne se produirait pas pour le choix du troisième arbitre, ces désignations seront faites par le président du Tribunal siégeant au chef-lieu de la Colonie

Article 10. (D. 7 septembre 1935)3. Sont abrogées toutes dispositions antérieures relatives au domaine public en Afrique-Occidentale Française contraires au présent décret.

Article 11. Le Ministre des Colonies et le Garde des Sceaux, Ministre de la Justice, sont chargés, chacun en ce qui le concerne, de l'exécution du présent décret.

Fait à Paris, le 29 septembre 1928

Gaston Doumergue

Par le Président de la République

Le Ministre des Colonies. Léon Perrier

Le Garde des Sceaux, Ministre de la Justice, Louis Barthou

1. Les lignes télégraphiques et téléphoniques et leurs dépendances, ainsi que les aériens des stations radioélectriques, y compris leurs supports, ouvrages, lignes d'alimentation, appareils de couplage ou d'adoption et leurs dépendances.

2. Les terrains et bâtiments des propriétés privées sont soumis à toutes les servitudes de passages, d'implantation, d'appui et de circulation nécessitées par l'aménagement des conduites d'égouts et des dispositifs de protection des voies de communication ou par l'établissement, l'entretien, l'exploitation des lignes télégraphiques et téléphoniques, des aériens des stations radio électriques, y compris leurs supports, ouvrages, lignes et leurs dépendances et des conducteurs d'énergie électrique ou de force hydraulique classés dans le domaine public

3 Dans le cas où les détenteurs de terrains visés au premier alinéa du présent article ne seraient pas connus, l'administration après avoir publié par tous les moyens appropriés son intention de prendre possession des dits terrains en fera fixer la valeur au moment de l'occupation, par la commission arbitrale prévue à l'alinéa 4 du présent article, le montant du prix ainsi déterminé restera à la disposition du propriétaire éventuel pendant toute la durée des délais primaires de prescription. 


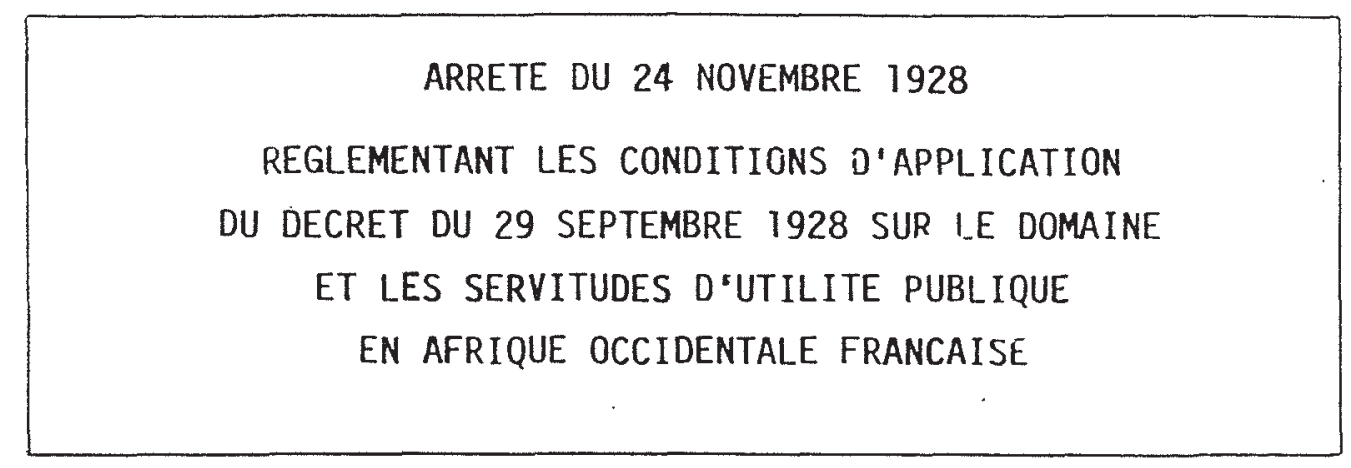

LE GOUVERNEUR GENERAL DE L'AFRIQUE OCCIDENTALE FRANCAISE, COMMANDEUR DE LA LEGION D'HONNEUR,

VU le décret du 18 OCTOBRE 1904, réorganisant le Gouvernement général de 1 'Afrique occidentale française, modifié par les décrets du 4 DECEMBRE 1920 et du 30 MARS 1925;

VU le décret du 29 SEPTEMBRE 1928, modifiant le dēcret du 23 OCTOBRE 1904 sur le Domaine;

Le Conseil de Gouvernement entendu,

A R R TE:

\section{TITRE PREMIER}

De la gestion, de la jouissance et de la réglementation du Domaine public

\section{ART. ler}

Le Domaine public est géré par les Lieutenants-Gouverveurs, à l'exception du Domaine militaire et des ouvrages dont l'aménagement ou l'entretien est mis à la charge des budgets communaux. 
Les Lieutenants-Gouverneurs peuvent toutefois déléguer leurs pouvoirs de gestion à des concessionnaires dûment agréês.

ART. 2

Les particuliers ont le droit de jouir du Domaine public suivant les conditions spéciales à chaque nature de biens, suivant l'usage auquel ils sont destinés et dans les limites déterminées par les règlements administratifs.

ART. 3

Indépendamment des règlements en vigueur ou à intervenir en ce qui concerne les chemins de fer, les voies routières, fluviales ou aériennes de communication, les lignes têlégraphiques ou tẻléphoniques, l'usage et la police des ports et rades, le régime des eaux, les distributiorıs d'énergie électrique, etc., les Lieutenants-Gouverneurs sont habilitês à prendre, dans le cadre desdits règlements et du présent arrêté, toutes mesures d'exécution et d'application non réglées et toutes autres dispositions n!e comportent la situation des lieux, les usages et les conditions clima éricues ou géographiques spéciales à chacune des voies de communication, l'usage et la police des ponts, bacs, quais et appontements, et l'installation des pêcheries.

TITRE II

Des servitudes établies au profit du Domaine public

ART. 4

L'exercice des servitudes non prévues par des règlements particuliers est soumis aux dispositions ci-après. 
ART. 5

L'exercice d'une servitude se rapportant à l'amēnagement ou l'exploitation des forces hydrauliques est subordonné à la déclaration préalable d'utilité publique des ouvrages correspondants, suivant arrêté du Lieutenant-Gouverneur.

ART. 6

L'éxercice d'une servitude d'utilité publique se rapportant aux autres catégories du Domaine public, indiquées à l'article 3 du décret du 29 SEPTEMBRE 1928 , découle du fait même de leur existence ou du commencement d'execution des travaux, ouvrages ou aménagements exécutés en vue de leur établissement, de leur entretien ou de leur exploitation.

ART. 7

Lorsqu'il s'agit d'exercer ou d'établir une des servitudes visées aux deux articles précédents sur une propriété non close et qui ne fait pas partie des dépendances immédiates d'une habitation, et lorsque cette servitude n'est susceptible d'occasionner aucun dommage ni aucun trouble de jouissance, elle pourra ètre exercée ou établie-d'office par les agents dūment qualifiés de l'Administration ou par ses délégataires.

Dans les autres cas, et sauf force majeure, nécessité immédiate ou consentement des intẻressés, il doit être donné à ceux-ci un avertissement préalable, soit suivant avis individuel de la part des autorités administratives, soit suivant insertion au Journal officiel, soit par placards, criées ou palabres sur les lieux.

Les réclamations sont reçues par l'autorité administrative dans la quinzaine qui suit. Il est statué sur leur suite par arrêté du Lieutenant-Gouverneur en Conseil privé ou d'administration. 
Passē le délai de quinzaine susvisé, si aucune réclamation n'a été élevée, les agents de l'Administration ou les personnes à qui l'Administration a délégué ses droits peuvent exercer ou établir les servitudes envisagées.

ART. 8

Les servitudes ci-dessus prévues sont permanentes et sont considérées comme des dépendances de l'ouvrage au profit ou en vue duquel elles sont ètablies.

ART. 9

Il peut ètre aussi créé, dans les mêmes formes que pour les servitudes permanentes, des servitudes temporaires nécessitées pour l'exécution des travaux, ouvrages ou aménagements du Domaine public. Avis est donné, le cas échēant, de la date de leur commencement et de leur durée probable.

Dans :ous les cas, la remise des lieux en état doit être faite dans le plus court dēlai possible.

\section{ART. 10}

L'exercice-ou l'établissement-des servitudes comporte le droit de passer sur les propriētés privées, d'y stationner et d'y faire toute autre opération nécessitée pour'l'aménagement, l'exploitation, l'usage ou l'entretien du Domaine public.

I1 ne comporte, en aucun cas le droit d'introduction dans les maisons'd'habitation, non plus que l'occupation permanente, par les agents de l'Administration ou autres personnes, des propriétēs attenantes aux habitations et closes par des murs ou clôtures équivalentes et élevés d'au moins un mètre. 


\section{TITRE III}

Des plans d'aménagement et d'extension des villes

ART. 11

(Abrogé par arrêté du 13 DECEMBRE 1939 -article 30-. Voir textes sur 1'urbanisme publiés ci-après.)

TITRE IV

Des occupations temporaires et du déclassement

du Domaine public

ART. 14

Les occupations du Domàine public peuvent correspondre, soit à un besoin individuel, soit à un intérêt éçonomique d'ordre collectif ou général.

Dans le premier cas (cales de halage privées, chemins d'accès à la mer ou à des cours d'eau, appontements, extraction de pierre ou de sable, petites installations commerciales provisoires, telles qu'échoppes, kiosques, abris, etc.), le droit d'occupation est strictement personnel, limité aux besoins indiqués et essentiellement révocable à première réquisition pour tout motif d'intérêt public.

Aucune condition de durée ne peut, en conséquence, être stipulée.

Dans le deuxième cas (cales de halage publiques, bassins de radoub; appontements en vue d'un service public, magasins généraux, entrepôts de consignataires, transitaires, commissionnaires ou armateurs, permis d'occuper délivrés à une commune ou à un établissement public, etc.), la forme du bail renouvelable peut être adoptée sous la réserve d'une résiliation toujours possible de la part de 1'Administration après préavis de six mois au plus. 
Dans tous les cas, l'Administration a la faculté de racheter les installations existantes à un prix fixé par la Commission arbitrale prévue par l'article 9 dU DECRET du 29 SEPTEMBRE 1928.

Après révocation du permis d'occuper, s'il n'est fait usage de la faculté ci-dessus spëcifiée, les lieux doivent être remis en état dans les conditions et dans un délai qui sont fixés par la réquisition ou le préavis susvisés.

\section{ART. 15}

Lorsque la partie du Domaine public dont l'occupation est demandée se trouve dans un centre loti, le permis n'est délivré qu'après enquête de commodo et incommodo.

ART. 16

Les permis d'occuper peuvent être soumis au paiement d'une redevance fixée, soit de $\cdots$ à gré, soit suivant arrêtē du Lieutenant-Gouverneur pris dans les formes régiementaires.

\section{ART. 17}

Les déc-lassements du Domaine public sont prononcés, dans les centres lotis, après enquête de commodo et incommodo $e_{i}$, s: cu cure, dans les communes, après avis des conseils municipaux ou des commissions municipales.

Les portions du Domaine public déclassées rentrent dans le Domaine de l'Etat et leur aliénation est soumise aux conditions ordinaires d'aliénation des terrains domaniaux.

L'arrêté de déclassement peut toutefois, quand il y a lieu, affecter le terrain en cause à un servic public ou à un établissement public. 
TITRE $V$

Dispositions gēnērales

\author{
ART. 18
}

Toute indue occupation malgré défense faite, toute dégradation du Domaine public ou de ses dépendances, toute entrave opposée à l'exercice ou à l'établissement des servitudes ci-dessus dëfinies et, en général, toute infraction aux dispositions du présent arrēté sont sanctionnées conformément à l'article 18 du décret du 29 SEPTEMBRE 1928.

\title{
ART. T9
}

Les pouvoirs des Lieutenants-Gouverneurs sont exercés, dans la Circonscription de DAKAR et Dépendances, par l'Administrateur de la Circonscription de DAKAR, dans les conditions du décret du 27 NOVEMBRE 1924.

DAKAR, le 24 novembre 1928.

CARDE 


\section{PORT AUTONOME D'ABIDJAN}

Une Référence Intèrnationále

LE DIRECTEUR GENERAL

N/Réf.: :

ABIDJAN, LE 16 MARS 2016

/DOMS/DS/SS/TFC

\section{CIRCULAIRE AUX OPERATEURS ECONOMIQUES DU PORT D'ABIDJAN}

Objet: Interdiction d'accès en zone

soüs douane des engins à deux roues

Il est porté à la connaissance des usagers du port d'Abidjan que pour des raisons de sécurité et de sûreté, les engins à deux roues sont désormais interdits d'accès en zone sous douane, à compter de la date de signature de la présente, jusqu'à nouvel ordre.

\section{AMPLIATIONS:}

CT M. N'GBALA

CT M. DJE

SG Communauté Portuaire d'Abidjan (pour large diffusion)

UCACI (pour large diffusion)

FEDERMAR

GSP-GN

CPSPAA

PortSécurité

Archives
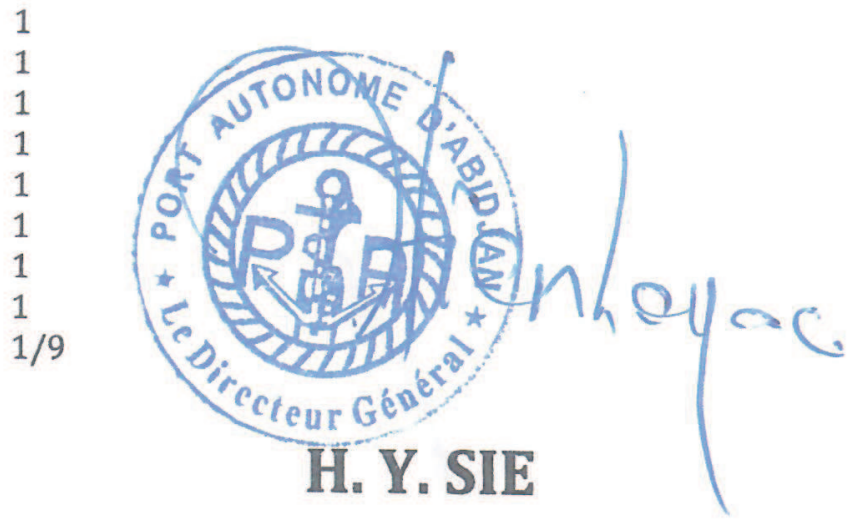


\section{ANNEXES DES TABLEAUX, GRAPHIQUES, CARTES ET IMAGES}

\section{I.1. TABLEAUX}

Tableau 1 : Escale de navires, par région et type, 2015

\begin{tabular}{|c|c|c|c|c|c|c|c|c|}
\hline Navires & Afrique & Asie & Caraïbes & Europe & $\begin{array}{l}\text { Amérique } \\
\text { du Nord }\end{array}$ & Océanie & $\begin{array}{r}\text { Amérique } \\
\text { du Sud }\end{array}$ & Total \\
\hline \multicolumn{9}{|l|}{$\begin{array}{l}\text { Navires de charges } \\
\text { classiques }\end{array}$} \\
\hline Vraquiers & 9486 & 69150 & 3684 & 17048 & 10553 & 14051 & 13403 & 137375 \\
\hline Porte-conteneurs & 20418 & 180705 & 16729 & 64900 & 14620 & 7188 & 17669 & 322229 \\
\hline $\begin{array}{l}\text { Cargos mixtes } \\
\text { (marchandises/passagers) }\end{array}$ & 36915 & 375134 & 13035 & 431849 & 48834 & 40651 & 19780 & 966198 \\
\hline Pétroliers & 9160 & 127312 & 6599 & 62721 & 10387 & 3306 & 10312 & 229797 \\
\hline Total & 75979 & 752301 & 40047 & 576518 & 84394 & 65196 & 61164 & 1655599 \\
\hline
\end{tabular}

Source : Tableau établi par le secrétariat de la CNUCED, à partir de données d'observation brutes fournies par Marine Traffic.

Note : Les régions listées ont été définies par la CNUCED ; aux fins de la présente étude, la région des Caraïbes inclut les pays d'Amérique centrale.

Tableau 2 : Dysfonctionnements des corridors ouest-africains

\begin{tabular}{|l|c|c|c|c|c|}
\hline \multicolumn{1}{|c|}{ Corridor } & $\begin{array}{c}\text { Distance } \\
\mathbf{( k m )}\end{array}$ & $\begin{array}{c}\text { Points de } \\
\text { contrôle } \\
\text { (nombre) }\end{array}$ & $\begin{array}{c}\text { Temps } \\
\text { passé aux } \\
\text { contrôles } \\
\text { (min) }\end{array}$ & $\begin{array}{c}\text { Coûts des } \\
\text { prélèvements } \\
\text { (f cfa) }\end{array}$ & $\begin{array}{c}\text { Moyenne } \\
\text { annuelle des } \\
\text { taux de } \\
\text { change de } \\
\text { 2011 (CA \$) }\end{array}$ \\
\hline Dakar-Bamako & 1476 & 43 & 409 & 67.200 & 140,99 \\
\hline Abidjan-Bamako & 1174 & 16 & 109 & 55.500 & 116,44 \\
\hline Abidjan-Ouagadougou & 1263 & 9 & 90 & 61.600 & 129,24 \\
\hline Accra-Ouagadougou & 1057 & 21 & 326 & 15.780 & 33,11 \\
\hline Lomé-Ouagadougou & 1020 & 19 & 130 & 15.195 & 31,88 \\
\hline Bamako-Ouagadougou & 1035 & 19 & 129 & 48.000 & 100,70 \\
\hline
\end{tabular}

Source: Observatoire des pratiques anormales, UEMOA, 2011 et Banque centrale du Canada, Moyennes mensuelles des taux de change, 10 dernières années, CFA, 2011.

Cité par STECK Benjamin, "Introduction à l'Afrique des ports et des corridors : comment formuler l'interaction entre logistique et développement ", Cahiers de géographie du Québec, Volume 59, $\mathrm{n}^{\circ} 168$, décembre 2015, p.456. 
Tableau 3 : Trafic portuaire mondial de conteneurs par région, 2014 et 2015 (En EVP et variation annuelle en pourcentage)

\begin{tabular}{lrrr}
\hline & $\mathbf{2 0 1 4}$ & $\mathbf{2 0 1 5}$ & $\mathbf{2 0 1 6}$ \\
\hline Afrique & 28027967 & 28122893 & 27909132 \\
Asie & 429641660 & 439573985 & 446813796 \\
Pays en développement d'Amérique & 45615876 & 45804387 & 45915853 \\
Europe & 109018957 & 108359396 & 113831821 \\
Amérique du Nord & 51659185 & 53689663 & 54120207 \\
Océanie & 11017084 & 11139239 & 11112739 \\
Total & $\mathbf{6 7 4 9 8 0 7 2 9}$ & $\mathbf{6 8 6 6 8 9 5 6 3}$ & $\mathbf{6 9 9 7 0 3 5 4 6}$ \\
Variation annuelle en pourcentage & $\mathbf{5 , 7}$ & $\mathbf{1 , 7}$ & $\mathbf{1 , 9}$
\end{tabular}

Source : Tableau établi par le secrétariat de la CNUCED, à partir de données tirées de diverses sources, dont Lloyd's List Intelligence, Hofstra University, Dynamar B.V., Drewry Maritime Research, Containerization International (jusqu'en 2014) et d'informations affichées sur les sites Web d'autorités portuaires et de terminaux portuaires de conteneurs. Cité par HOFFMANN Jan (dir.), Étude sur les transports maritimes 2016, CNUCED, New York et Genève, Côte UNCTAD/RMT/2016, 2016, p.65.

Tableau 4 : Évolution du trafic de transit au Port autonome d'Abidjan de 2001 à 2003 (en t) ${ }^{3}$.

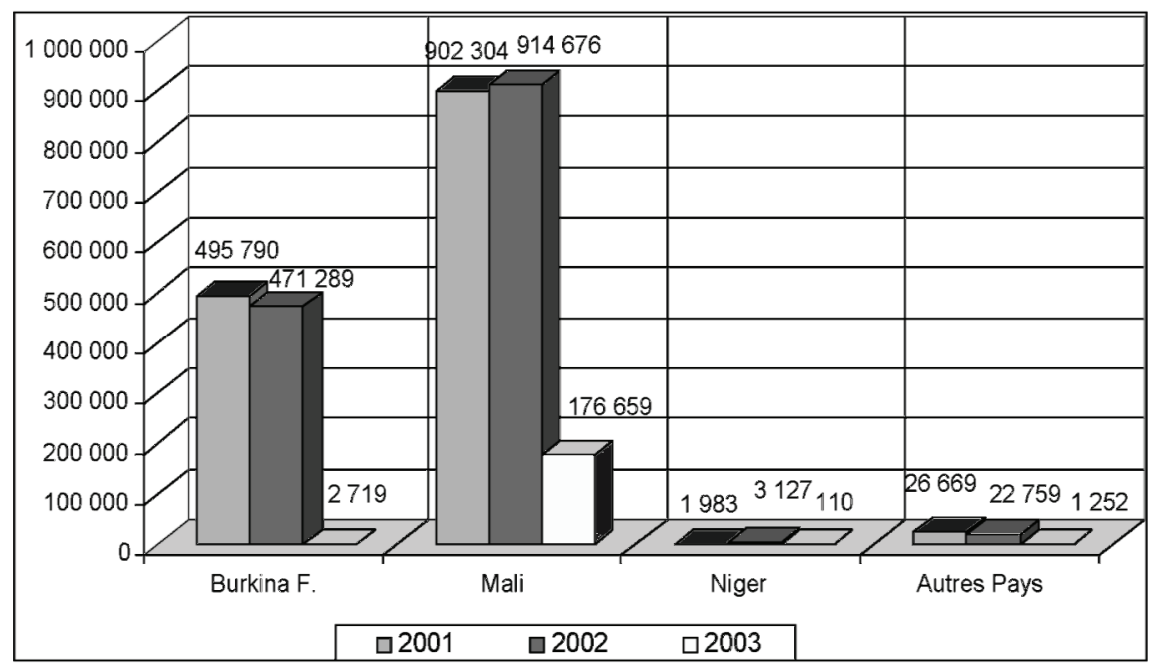

Source : BIDI Tapé Jean, "Impact de la crise ivoirienne sur les ports ouest-africains, OutreTerre, $2005 / 2 \mathrm{n}^{\circ} 11$, p.311. 
Tableau 5 : Trafics totaux comparés des ports de 2004 à 2010 (en milliers de tonnes)

\begin{tabular}{lllllllll}
\hline \multicolumn{1}{c}{ Années } & 2004 & 2005 & 2006 & 2007 & \multicolumn{1}{c}{2008} & 2009 & 2010 & Rang \\
\hline Dakar & 9.375 & 9.905 & 8.552 & 10.036 & 10.000 & 8.743 & 10.271 & $3^{\text {ème }}$ \\
\hline Conakry & 5676 & 6087 & 6243 & 5804 & 6912 & 5948 & 6876 & $7^{\text {ème }}$ \\
\hline Abidjan & 17.770 & 18.662 & 18.856 & 21.378 & 22.080 & 22.633 & 22.484 & $2^{\text {ème }}$ \\
\hline Téma & 11.288 & 12.637 & 11.371 & 8.868 & 9.182 & 7.710 & 9.432 & $4^{\text {ème }}$ \\
\hline Lomé & 3299 & 3452 & 3531 & 4429 & 4937 & $6121^{\mathrm{b}}$ & $6895^{\mathrm{b}}$ & $6^{\text {ème }}$ \\
\hline Cotonou & 3969 & 5153 & 5369 & 6152 & 6998 & 6698 & 6959 & $5^{\text {ème }}$ \\
\hline Lagos & 15.152 & 16.930 & 19.837 & $22.217^{\mathrm{a}}$ & $24.884^{\mathrm{a}}$ & $27.870^{\mathrm{a}}$ & $31.214^{\mathrm{a}}$ & $1^{\text {er }}$ \\
\hline
\end{tabular}

$\mathrm{a}=$ Volume estimé sur la base d'une augmentation moyenne annuelle de $12 \%$.

$\mathrm{B}=$ Volume obtenu après déduction du double emploi des trafics transbordement et conteneurisé.

Source: M. Lihoussou, d'après les statistiques des autorités portuaires 2004-2010.

\section{I.2. GRAPHIQUE}

\section{Graphique 1 : Volumes portuaires mondiaux de conteneurs par région, 2016 (Part en pourcentage)}

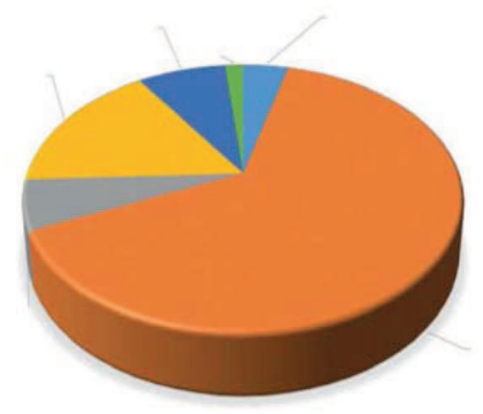

\section{Légende :}

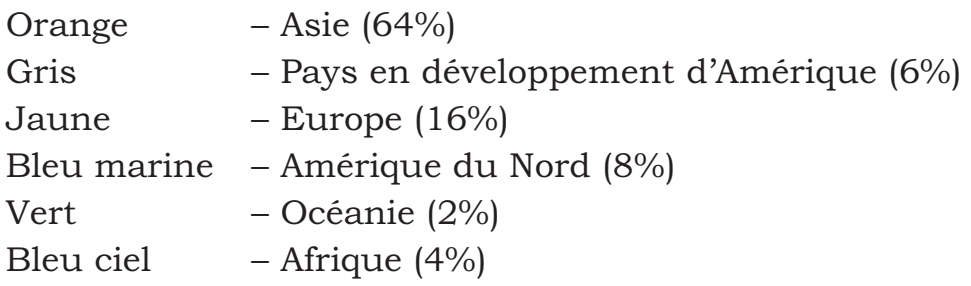

Source : Graphique établi par le secrétariat de la CNUCED, à partir de données figurant dans le tableau 3 ci-dessus.

Note: Les données par pays à jour sont disponibles sur le site : http://unctadstat.unctad.org à la rubrique "Transport maritime". 


\section{I.3. CARTES}

Carte1: Trafic portuaire : Afrique de 1'ouest (2002)

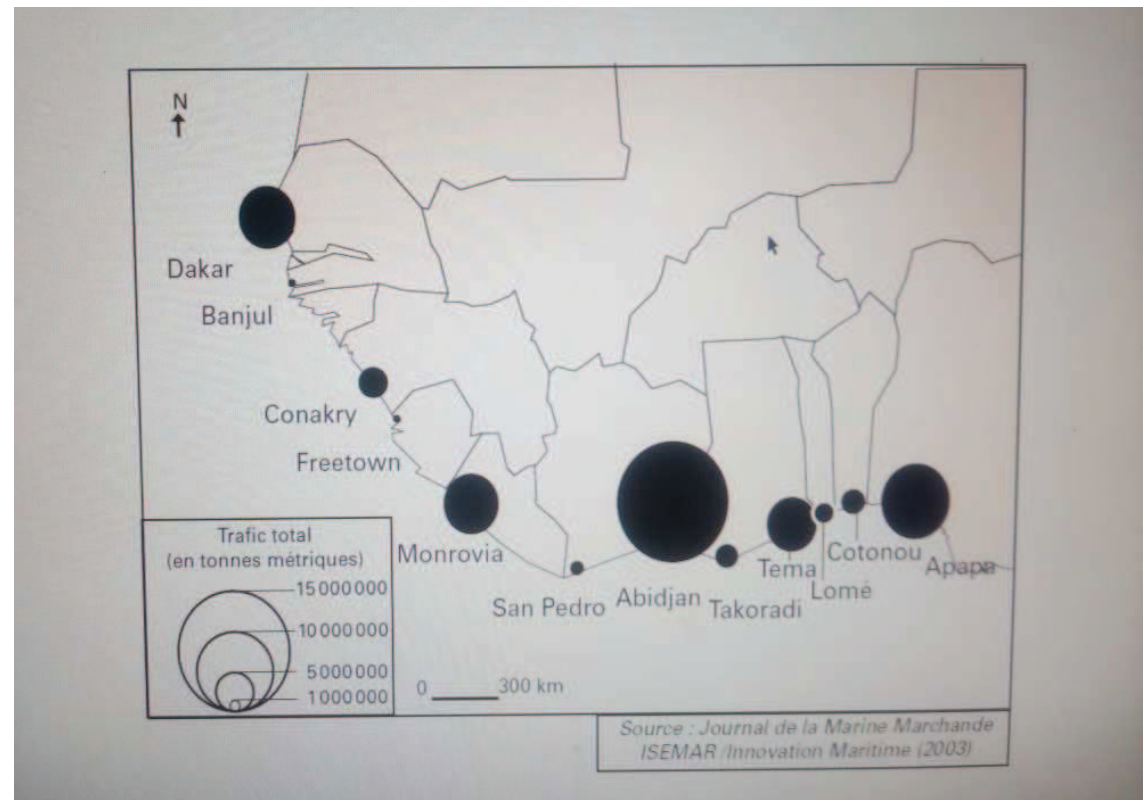

Source : Journal de la Marine Marchande ISEMAR (Innovation Maritime 2003). Cité par DEBRIEJean et De GUIOSandrine, "Interfaces portuaires et compositions spatiales: instabilités africaines ", Autrepart, n³2, 2004, p.29.

\section{Carte 2 : Ports de 1'Afrique de l'Ouest étudiés suivant leur trafic total (2010)}

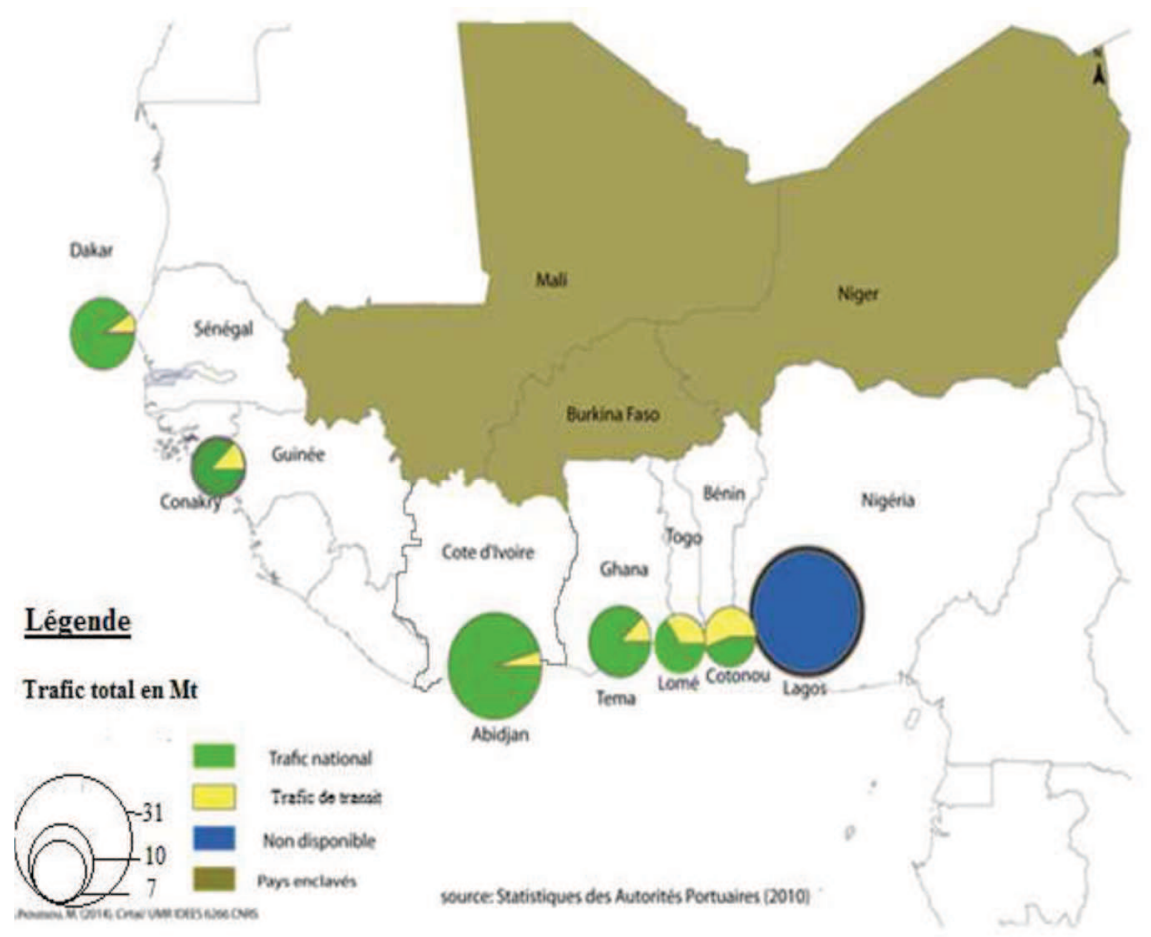

Source: M. Lihoussou, d'après les statistiques des autorités portuaires 2010. 
Carte 3 : Carte retraçant la forte proximité géographique des ports et la vive concurrence interportuaire dans le Golfe de Guinée

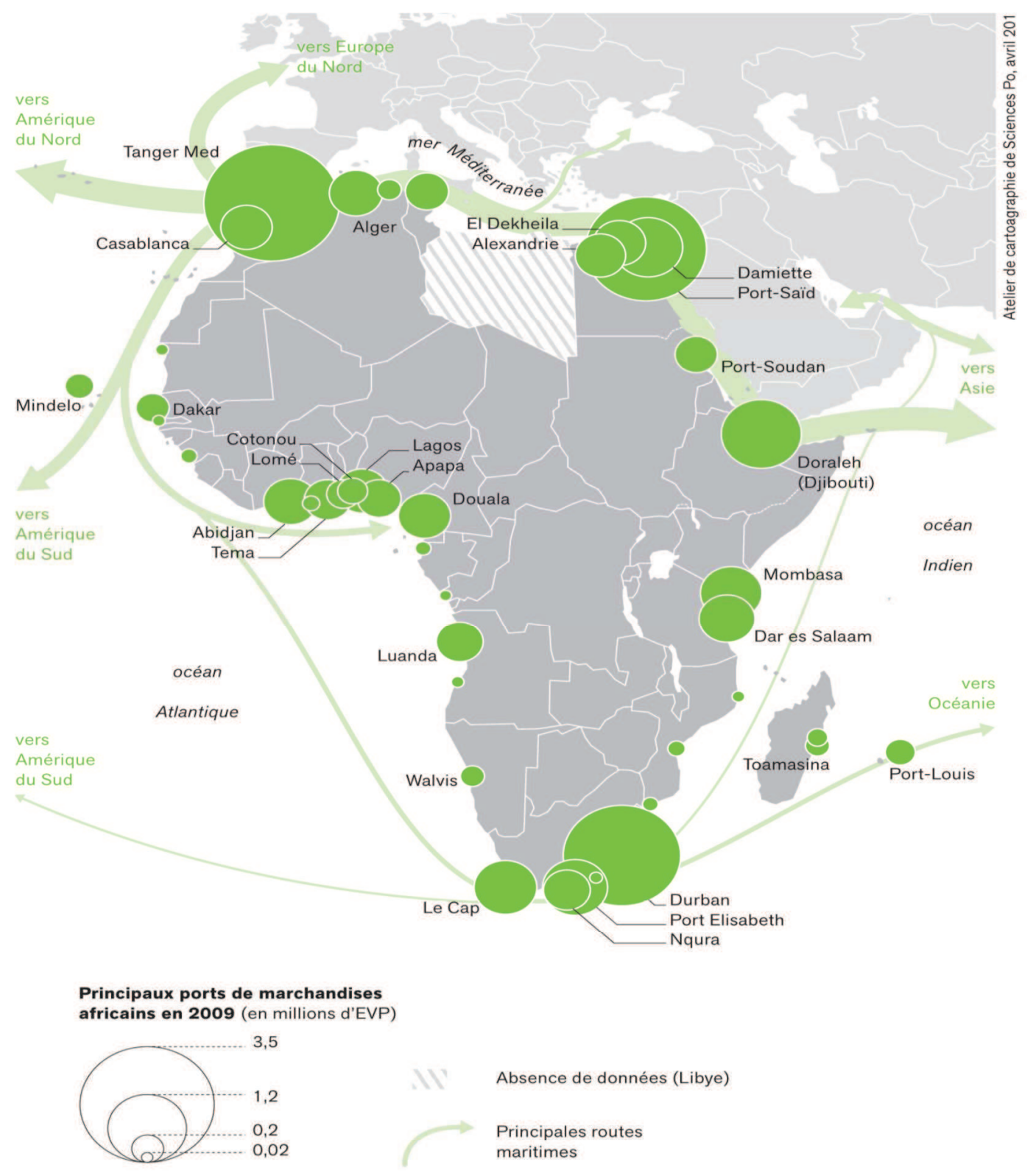

Source: compilation de Jean-Raphaël Chaponnière et Institute of Shipping Economics and Logistics, Containerisation International Yearbook 2010.

Source: Carte reproduite par Arthur Foch. $C f$. FOCH Artur, "Djibouti, une nouvelle porte de l'Afrique ? L'essor du secteur portuaire djiboutien ", Afrique contemporaine, n²34, 2010/2, p.90. 


\section{I.4. IMAGES}

Figure 1 : Vue aérienne montrant le canal de Vridi, avant l'exécution des travaux d'élargissement et d'approfondissement

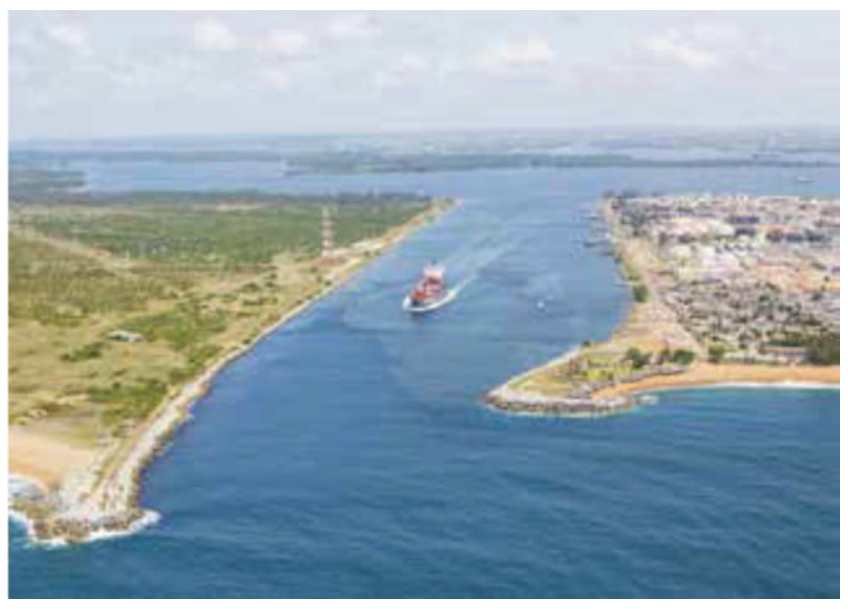

Source : Rapport d'activités du PAA 2017, p.35.

Figure 2 : Vue aérienne montrant les travaux d'élargissement du canal de Vridi, porte d'entrée au Port autonome d'Abidjan

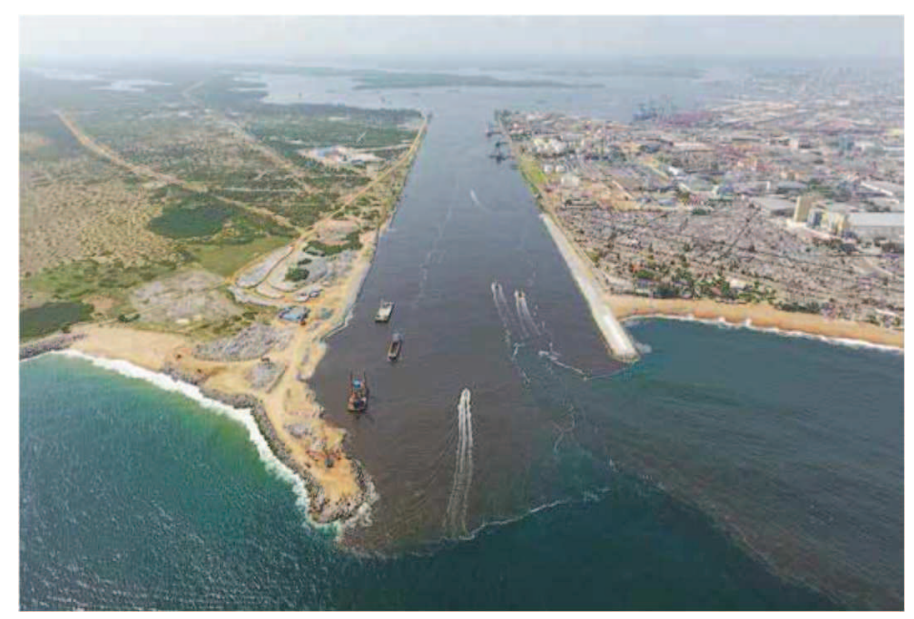

Source : Rapport d'activités du PAA 2017, p.31. 